\title{
Automotive Security Functions
}

The Use of New Technologies to Tackle

Vehicle-Related Crime

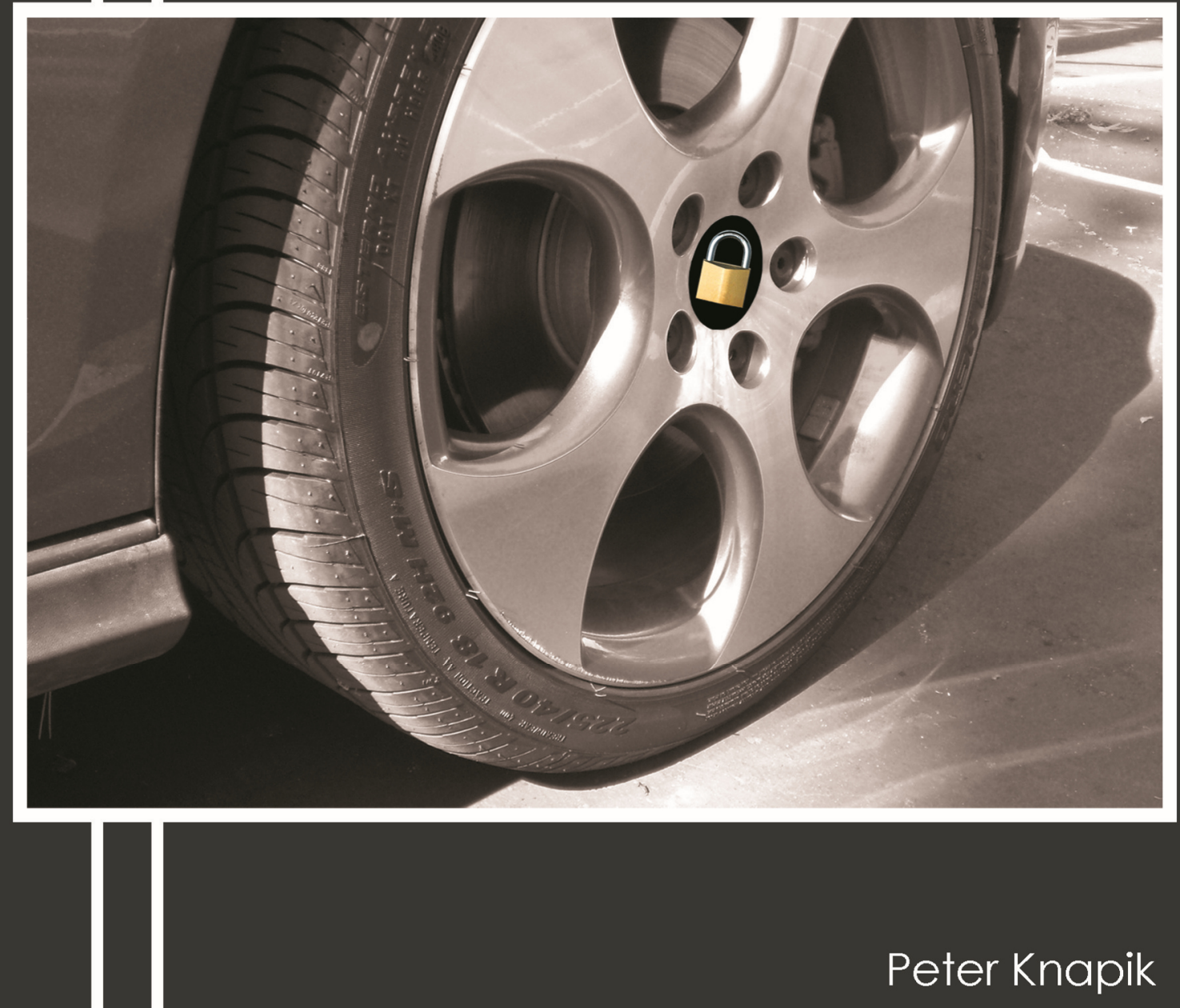




\section{Automotive Security Functions The Use of New Technologies to Tackle Vehicle-Related Crime}




\section{Composition of the Graduation Committee:}

$\begin{array}{lll}\text { prof. dr. } & \text { F.E. Kargl } & \text { Universiteit Twente, Universität Ulm } \\ \text { prof. dr. } & \text { M. Junger } & \text { Universiteit Twente } \\ \text { prof. dr. } & \text { P.H. Hartel } & \text { Universiteit Twente } \\ \text { prof. dr. } & \text { G. Laycock } & \text { University College London } \\ \text { prof. em. dr. iur. } & \text { H.-J. Kerner } & \text { Universität Tübingen } \\ \text { dr. } & \text { E. Schoch } & \text { Audi AG }\end{array}$

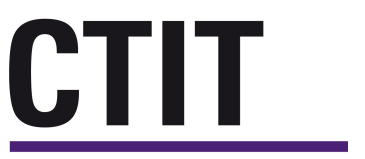

CTIT Ph.D. Thesis Series No. 15-379

Centre for Telematics and Information Technology

P.O. Box 217, 7500 AE

Enschede, The Netherlands

ISBN: 978-90-365-4010-0

ISSN: $1381-3617$

DOI number: 10.3990/1.9789036540100

Official URL: http: / /dx.doi.org/10.3990/1.9789036540100

Typeset with $\mathrm{AT}_{\mathrm{E}} \mathrm{X}$. Cover photo and design: Peter Knapik

Copyright @ 2016, Peter Knapik

All rights reserved. No part of this dissertation may be reproduced, stored in a database or retrieval system, or published in any form or in any way, electronically, mechanically, by print, photo print, microfilm, or any other means without prior written permission by the author and Volkswagen AG. Publications concerning the content of this work require the written consent of Volkswagen AG. The results, opinions and conclusions expressed in this thesis are not necessarily those of Volkswagen AG. 


\section{AUTOMOTIVE SECURITY FUNCTIONS THE USE OF NEW TECHNOLOGIES TO TACKLE \\ VEHICLE-RELATED CRIME}

\section{DISSERTATION}

to obtain

the degree of doctor at the University of Twente, on the authority of the rector magnificus, prof. dr. H. Brinksma, on account of the decision of the graduation committee, to be publicly defended

on Friday, 29th of January 2016 at 12:45

by

\section{Peter Knapik}

born on 13th of July 1981

in Königshütte, Poland 
The dissertation is approved by:

prof. dr. F.E. Kargl (promotor) 


\section{Abstract}

Daily life is increasingly penetrated by new technologies. Advanced driver assistance systems with sophisticated sensors are increasingly available in all classes of vehicles. Moreover, mobile devices, such as smartphones, have become our daily companions. With the help of wireless communication technologies, our society and mobility have become increasingly connected. Based on these technologies, industry and academia have developed applications within the automotive field to provide customers with improved traffic efficiency, infotainment features and driver assistance.

Vehicle-related crime as well as fear of vehicle-related crime are omnipresent in our society. They result in personal injury, economic losses and reduced quality of life. Vehicle-related crime is a worldwide problem beyond national borders. Since criminals usually adjust their skills to overcome countermeasures, continuous development towards more innovative security measures is necessary to counteract them. Until now, existing countermeasures dealing with vehicle-related crime are mostly concentrated on the vehicle itself and focus on physical target hardening. Neither occupants, infrastructure nor other vehicles are involved to counteract vehicle-related crime collaboratively.

To close this gap, we focus on automotive security functions. These functions make use of new technical capabilities of modern vehicles and consumer electronics to tackle vehicle-related crime, decrease fear of crime and provide tangibility of security to customers.

In this thesis, we focus on the identification of potential security functions in a structured way and the pre-emptive evaluation of security functions, i.e., estimating the (expected) effectiveness before a security function is entirely developed and deployed. Our contributions can be summarized as follows:

- We propose a definition of automotive security functions and vehicle-related crime to establish a fourth class of applications besides infotainment, traffic efficiency and assistance applications.

- We analyze statistical crime data from several countries as well as data from existing victimization surveys to gain a deeper understanding of vehicle-related crime. Additionally, we conduct a victimization survey in Germany, the USA and Mexico to gain further insights into (fear of) vehicle-related crime. Making use of the same methodology in all three countries, we are able to compare findings across these countries.

- We propose a methodology which uses both the crime script concept and the 25 techniques of situational crime prevention to identify security functions in a structured way. To support the structured identification, we provide a hierarchical classification of vehicle- 
related crime as well as a categorization of existing countermeasures and new technologies.

- We develop four vehicle-related crime scripts and subsequently apply our methodology. We identify and propose six potential security functions, thus showing the suitability of our methodology.

- We design two security functions, namely the cooperative home light (CHL) and the electronic decal (ED). We identify and analyze the underlying technologies and show the feasibility of implementing both security functions. The CHL aims to provide improved lighting to the driver when going to or from their vehicle by involving neighboring vehicles to provide lighting. The ED continuously broadcasts a request that the vehicle be stopped and checked by police when it is illegally moved.

- We evaluate the CHL and ED with respect to the (expected) effectiveness with the help of several approaches. First, we transfer the existing results from similar countermeasures to our security functions. Second, we conduct a customer study to rate the effectiveness of reducing the fear of crime, the expected effectiveness of fighting crime and attitudes towards the CHL and ED. Third, interviewed experts assess the potential of our security functions to fight crime. Last, we propose defining measurable criteria which represent the effectiveness of both security functions. As a proof of concept, we implement a simulation environment in order to simulate the CHL to estimate its effectiveness.

Using these contributions, interest groups such as car manufacturers can develop supplemental security measures and provide customers with tangible security functions. With this work, we pursue the goal of contributing to combat vehicle-related crime and make our mobility more secure. 


\section{Samenvatting}

Het dagelijks leven wordt steeds meer door nieuwe technologieën gestuurd. Geavanceerde rijhulpsystemen en sensoren zijn in toenemende mate beschikbaar in alle klassen van voertuigen. Bovendien zijn mobiele apparaten, zoals smartphones, uitgegroeid tot onze dagelijkse metgezellen. Door draadloze communicatietechnologieën is onze samenleving en mobiliteit steeds sterker verbonden. Op basis van deze technologieën hebben de industrie en de academische wereld binnen het automotive bereik toepassingen ontwikkeld om klanten te voorzien met verbeterde verkeer efficiëntie, infotainment functies en rijhulpsystemen.

Voertuigcriminaliteit en de angst daarvoor zijn alomtegenwoordig in onze samenleving. Ze leiden tot persoonlijk letsel, economische verliezen en een verminderde kwaliteit van leven. voertuigcriminaliteit is een wereldwijd probleem dat landsgrenzen overschrijdt. Aangezien criminelen meestal hun vaardigheden aanpassen om beschermende maatregelen te overwinnen, is continue ontwikkeling van meer innovatieve veiligheidsmaatregelen nodig. Tot nu toe concentreren veiligheidsmaatregelen om voertuigcriminaliteit tegen te gaan vooral op het voertuig zelf en de focus ligt op fysieke maatregelingen. Bewoners, infrastructuur en andere voertuigen worden niet betrokken bij het tegengaan van deze criminaliteit.

Om deze kloof te dichten, richten wij ons op automotive beveiligingsfuncties. Deze functies maken gebruik van nieuwe technische mogelijkheden van moderne voertuigen en consumentenelektronica om de voertuigcriminaliteit en de angst daarvoor te verminderen, om zo de klanten een gevoel van veiligheid te geven.

In dit proefschrift richten wij ons op een gestructureerde identificatie van mogelijke beveiligingsfuncties en de preventieve evaluatie daarvan, dat wil zeggen, het schatten van de (verwachte) effectiviteit voordat een beveiligingsfunctie geheel wordt ontwikkeld en geïmplementeerd. Onze bijdragen kunnen als volgt worden samengevat:

- Wij stellen een definitie van automobiele veiligheid functies en voertuigcriminaliteit op, om een vierde klasse van toepassingen te vestigen naast infotainment, verkeer efficiëntie en rijhulpsystemen.

- Wij analyseren de statistisch criminaliteitsgegevens van verschillende landen, alsmede gegevens uit bestaande slachtofferenquêtes om een dieper begrip van voertuigcriminaliteit te krijgen. Daarnaast hebben wij een slachtofferenquête in Duitsland, de VS en Mexico gevoerd, om verder inzicht te krijgen in (angst voor) voertuigcriminaliteit. Door gebruik te maken van dezelfde methode in deze drie landen, zijn wij in staat om de bevindingen tussen deze landen te vergelijken. 
- Wij stellen een methodologie voor die het concept van misdaadscripts en de 25 technieken van situationele criminaliteitspreventie gebruikt om beveiligingsfuncties op een gestructureerde manier te identificeren. Om de gestructureerde identificatie ondersteunen, bieden wij een hiërarchische indeling van het voertuigcriminaliteit, alsmede een indeling van de bestaande beschermende maatregelen en nieuwe technologieën.

- Wij ontwikkelen vier voertuig-gerelateerde misdaadscripts en passen vervolgens onze methodologie toe. Wij identificeren zes mogelijke beveiligingsfuncties en stellen deze voor, waarmee de geschiktheid van onze methodologie duidelijk wordt.

- Wij ontwerpen twee beveiligingsfuncties, namelijk het coöperatieve huislicht (CHL) en de elektronische sticker (ED). Wij identificeren en analyseren de onderliggende technologieën en tonen de haalbaarheid van de implemnetatie van beide beveiligingsfuncties. Het CHL streeft naar een betere verlichting van de bestuurder wanneer hij of zij zich in de buurt van zijn voertuig beweegt, door het gebruik van verlichting door naburige voertuigen. De ED zendt continue een verzoek om een politiecontrole als het voertuig het illegaal wordt verplaatst.

- Wij evalueren de (verwachte) effectiviteit van het CHL en de ED met behulp van verschillende benaderingen. Ten eerste gebruiken wij bestaande resultaten van vergelijkbare beveiligingsmaatregelen voor onze veiligheid functies. Ten tweede hebben wij een klantenonderzoek uitgevoerd, om de effectiviteit ten opzichte van het verminderen van de angst voor criminaliteit, de bestrijding van de criminaliteit en de houding van de klant ten opzichte van de CHL en ED te bestuderen. Ten derde hebben wij met geinterviewde experts de haalbaarheid van onze beveiligingsfuncties om de criminaliteit te bestrijden beoordeeld. Ten slotte definiëren wij meetbare criteria, die de doeltreffendheid van beide beveiligingsfuncties vertegenwoordigen. Als proof of concept simulieren wij het CHL, om het op zijn effectiviteit te schatten.

Met behulp van deze bijdragen kunnen belangenorganisaties, zoals autofabrikanten, aanvullende veiligheidsmaatregelen ontwikkelen en klanten voorzien van concrete beveiligingsfuncties. Met dit werk streven wij het doel aan bij te dragen aan de bestrijding van voertuigcriminaliteit en daarmee een veiligere mobiliteit. 


\section{Acknowledgments}

Time goes by quickly...

After having spent the last five years working towards a PhD degree, this work has only been possible thanks to the support I have received from various people throughout that time.

First of all I would like to thank my promoter Frank Kargl, who guided me from my first day of research up to the last day when discussing the abstract. Frank, you were always patient with me and never gave up on me. I particularly enjoyed our discussions, which ranged from computer science to crime science and social science. Frank, it was a great pleasure working with you.

Elmar, you were my supervisor at Volkswagen Group Research. Unfortunately, you left earlier than planned to advance development at Audi AG. Although we were long way away from each other you made yourself always available for discussions.

I remember when I got to know that my supervising university would be the University of Twente. I had not been expecting a university outside of Germany. I can say now that I am very glad about this choice. Although I was an external PhD candidate, everyone at the UT were always very helpful and friendly. I have always felt welcome and have enjoyed my visits. Thanks to all the current and former members from the DIES and SCS group.

I also wish to thank the members of my graduation committee that I have not addressed so far Marianne Junger, Gloria Laycock, Pieter Hartel and Hans-Jürgen Kerner. Thank you Marianne and Pieter for our fruitful interdisciplinary discussions and your insightful comments.

I am also very grateful to you, Bertine and Stefan. Thank you for helping me through the labyrinth of university procedures and for helping me in preparing this thesis.

I would like to express my gratitude towards all my former colleagues at Volkswagen Group Research who provided an enjoyable working environment. I have learned countless new things during my projects beyond this thesis, during our discussions, meetings, events and of course during our lunch times.

Thank you Laura, Sebastian, Christian, Waldemar and Torsten for our great collaborations as well as for your great project work, bachelor theses and master theses that I had the pleasure to supervise. 
The deepest gratitude goes to my family. I want to thank my wife Agnieszka for being by my side every day and giving unconditional support. Thank you for your loving care of our children Julia and Sebastian throughout these intense years.

Schließlich danke ich meinen Eltern, die mir alle Möglichkeiten eröffnet haben meinen gewünschten Weg einzuschlagen. Ihr habt mich und vor allem uns als Familie in allem unterstützt. Danke für eure Geduld und dass ihr super Eltern und Großeltern seid!

Thank you all,

Peter

Berlin, January 2016 


\section{Contents}

1. Introduction 1

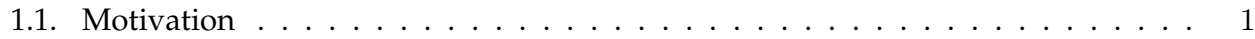

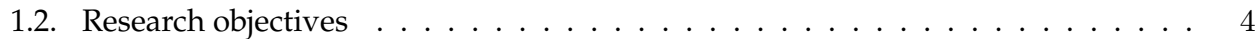

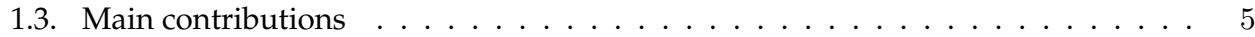

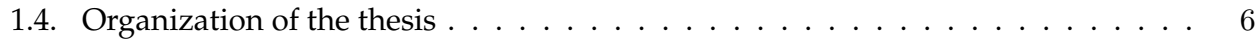

2. Understanding vehicle-related crime 9

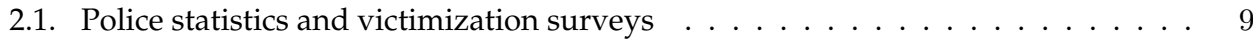

2.2. Statistical crime analysis . . . . . . . . . . . . . . . . . . . . . 10

2.2.1. Method . . . . . . . . . . . . . . . . . 11

2.2.2. Results: crime by country . . . . . . . . . . . . . . . . . . . 14

2.2.3. Results and discussion: vehicle-related crimes . . . . . . . . . . . . . . 20

2.2.4. Conclusion . . . . . . . . . . . . . . . . . . . . 30

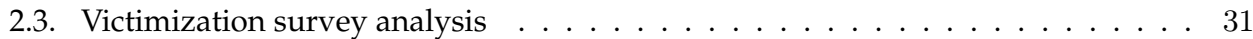

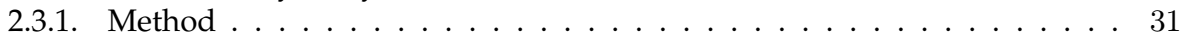

2.3.2. Results . . . . . . . . . . . . . . . . . . . 33

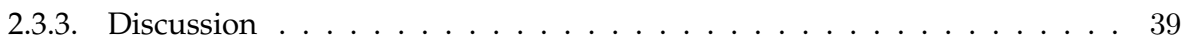

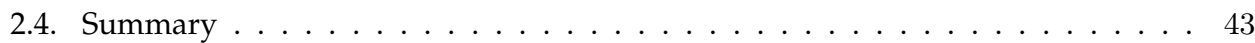

3. Cross-country survey to research aspects of car-related crime 45

3.1. Method . . . . . . . . . . . . . . . . . . . 48

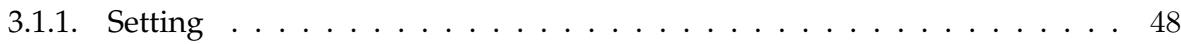

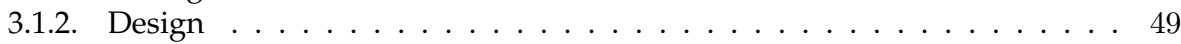

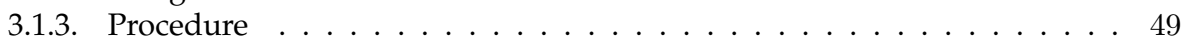

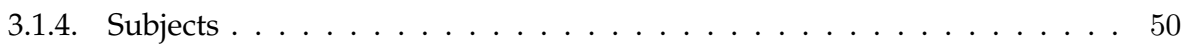

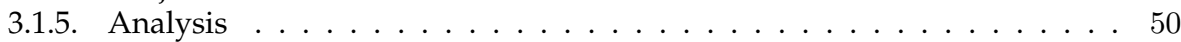

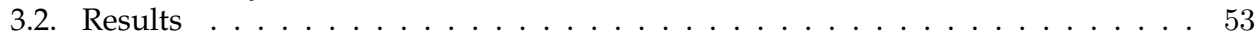

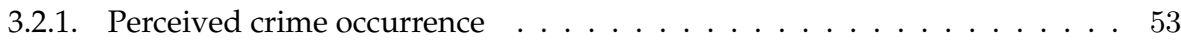

3.2.2. Fear of car-related crime . . . . . . . . . . . . . . . . . . . . . . . . . . . . . . . . . . . 54

3.2.3. Fear of specific car-related crimes . . . . . . . . . . . . . 56

3.2.4. Quality of police work . . . . . . . . . . . . . . . 62

3.2.5. Willingness to have car recovered . . . . . . . . . . . . . . 64

3.2.6. Demand for security systems . . . . . . . . . . . . . . . 66

3.2.7. Importance of security systems $\ldots \ldots \ldots \ldots$. . . . . . . . . 68

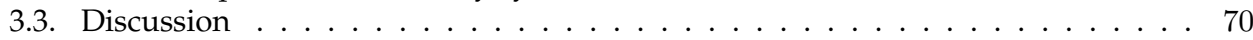

3.3.1. Perceived crime occurrence . . . . . . . . . . . . . . . 70

3.3.2. Fear of car-related crime . . . . . . . . . . . . . . . . . 72

3.3.3. Fear of specific car-related crimes . . . . . . . . . . . . . . . . . . 72

3.3.4. Quality of police work . . . . . . . . . . . . . . 73 
3.3.5. Willingness to have car recovered . . . . . . . . . . . . . . . . 74

3.3.6. Demand for security systems . . . . . . . . . . . . . . . . . . 74

3.3.7. Importance of security systems . . . . . . . . . . . . . . . . . . . . . . . . . . . . . . . . . . . . .

3.3.8. Limitations . . . . . . . . . . . . . . . . . . . . . . . 75

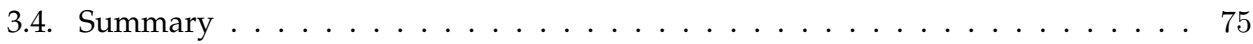

$\begin{array}{ll}\text { 4. Design of structured approach } & \mathbf{7 7}\end{array}$

4.1. Introduction to crime science . . . . . . . . . . . . . . . . . 77

4.1.1. Rational Choice Perspective . . . . . . . . . . . . . . . . . . . 77

4.1.2. Situational Crime Prevention . . . . . . . . . . . . . . . . 80

4.2. Security measures in the automotive field . . . . . . . . . . . . . . . . . . . . . . . . . . . . . . . . . .

4.2.1. Preventive measures . . . . . . . . . . . . . . . . . . . 82

4.2.2. Protective measures . . . . . . . . . . . . . . . . . . . 84

4.2.3. Detection measures . . . . . . . . . . . . . . . . . . . 85

4.2.4. Reactive measures . . . . . . . . . . . . . . . . . . . 87

4.3. SAIAS - Structured Approach to Identify Automotive Security functions . . . . . 88

4.3.1. Categorization of vehicle-related crime . . . . . . . . . . . . 88

4.3.2. Categorization of countermeasures . . . . . . . . . . . . . . . . . . 91

4.3.3. Categorization of enabling technologies . . . . . . . . . . . . . 92

4.3.4. Procedure of SAIAS . . . . . . . . . . . . . . . . . . . 94

4.4. Summary . . . . . . . . . . . . . . . . . . . . . . 99

5. Application of SAIAS to vehicle-related crime 101

5.1. Vehicle-related crime scripts . . . . . . . . . . . . . . . . . . . . . . 101

5.1.1. Car theft from public street . . . . . . . . . . . . . . . . . . . 102

5.1.2. Theft of valuables from inside of a car . . . . . . . . . . . . . 105

5.1.3. Robbery while going to car . . . . . . . . . . . . . . . . . 107

5.1.4. Car vandalism . . . . . . . . . . . . . . . . . . . . . . . 109

5.2. Identified security functions $\ldots \ldots \ldots \ldots \ldots \ldots$

5.2.1. Cooperative home light . . . . . . . . . . . . . . . . . 111

5.2.2. Electronic decal . . . . . . . . . . . . . . . . . . . . . . 112

5.2.3. Visual vehicle tracking . . . . . . . . . . . . . . . . . . . . 113

5.2.4. Open door / window reminder . . . . . . . . . . . . . . . . . 114

5.2.5. Voice-enabled crime detection . . . . . . . . . . . . . . . . . . 115

5.2.6. Cooperative alarm system . . . . . . . . . . . . . . . . 116

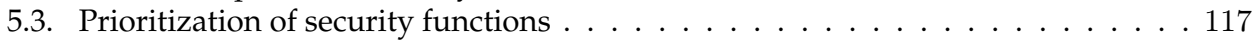

5.4. Summary . . . . . . . . . . . . . . . . . . 118

6. Technical feasibility of the electronic decal and cooperative home light 121

6.1. Electronic decal . . . . . . . . . . . . . . . . . . . . . . 121

6.1.1. (De)activation methods . . . . . . . . . . . . . . . . . . . . . . . . . . . . . . . . . . . . . .

6.1.2. V2V communication . . . . . . . . . . . . . . . . . . . . . . . . . . . . . . . . . . . . . . . . . . . .

6.2. Cooperative home light . . . . . . . . . . . . . . . . . . . 129

6.2.1. Positioning . . . . . . . . . . . . . . . . 130

6.2.2. Smart grids . . . . . . . . . . . . . . . . . . . . . . . . . . . . . . . . . . . . . .

6.2.3. V2X Communication . . . . . . . . . . . . . . . . . 133

6.2.4. Lighting . . . . . . . . . . . . . . . . . . 135 


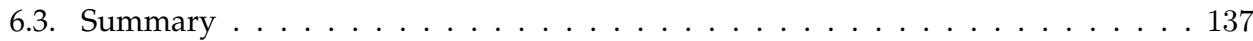

7. Evaluation of security functions 139

7.1. Transfer of related research results . . . . . . . . . . . . . . . . . . 140

7.1.1. Cooperative home light . . . . . . . . . . . . . . . . . 140

7.1.2. Electronic decal . . . . . . . . . . . . . . . . . . . . . . . . 141

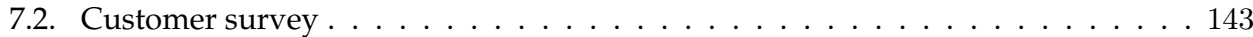

7.2.1. Method . . . . . . . . . . . . . . . . . . . 147

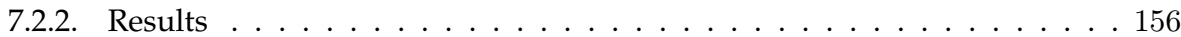

7.2.3. Discussion . . . . . . . . . . . . . . . . . 178

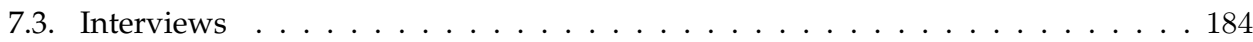

7.3.1. Electronic decal . . . . . . . . . . . . . . . . . . . . 184

7.3.2. Cooperative home light . . . . . . . . . . . . . . . 187

7.4. Summary . . . . . . . . . . . . . . . . . . . 189

8. Simulation to evaluate the cooperative home light 193

8.1. Simulation environment . . . . . . . . . . . . . . . . . . . 193

8.1.1. Requirements . . . . . . . . . . . . . . . . . . . 194

8.1.2. Implementation . . . . . . . . . . . . . . . . . . . . . 196

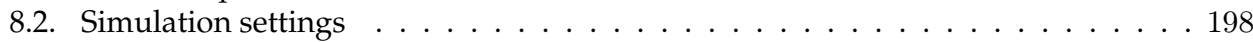

8.3. Simulation results . . . . . . . . . . . . . . . . . . . 199

8.3.1. Consecutive parking arrangement . . . . . . . . . . . . . . 199

8.3.2. Consecutive and skewed parking arrangement . . . . . . . . . . . . . . 200

8.3.3. Side-by-side parking arrangement . . . . . . . . . . . . . . . . . . . . . . . . . 201

8.3.4. Side-by-side and skewed parking arrangement . . . . . . . . . . . . . 203

8.3.5. Consecutive, side-by-side and skewed parking arrangement . . . . . . . . 205

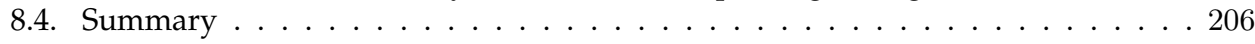

9. Summary 209

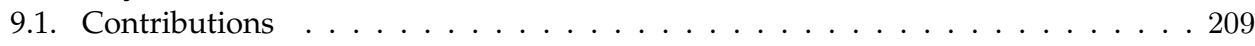

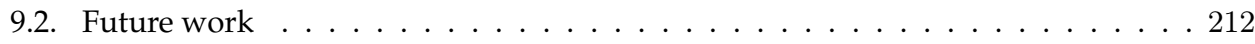

9.3. Conclusion . . . . . . . . . . . . . . . . . . . . 214

$\begin{array}{ll}\text { A. Abbreviations } & 217\end{array}$

B. Questionnaires 219

B.1. Questionnaire for online survey in Germany, USA and Mexico (English version) 219

B.2. Questionnaire for face-to-face survey in Germany . . . . . . . . . . . . . . . . . 224

C. Bibliography 241

C.1. Author's publications . . . . . . . . . . . . . . . . . . . . . 241

C.2. Bibliography . . . . . . . . . . . . . . . . . . . . 241

C.3. Web references . . . . . . . . . . . . . . . . . . . . . . . . . 249 



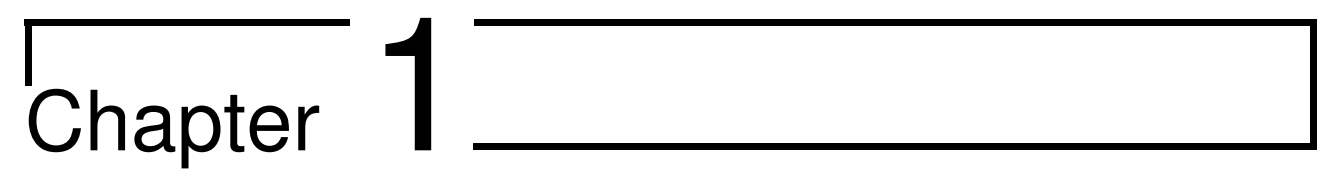

\section{Introduction}

\subsection{Motivation}

Our daily life is increasingly dominated by new technologies. The vision of accident-free driving and the guarantee of our future mobility leads to an increasing number of advanced driver assistance systems (ADAS). In the past, ADAS were mainly available only in high-class vehicles. Since then, these systems have become available in mid- and even low-class vehicles. Consequently, the number of vehicles equipped with ADAS is continuously increasing, leading to a growing availability of sophisticated sensors and actuators in a wide range of vehicles. New technologies are also increasingly available in the consumer market, and here even faster than in the automotive field. The frame of electronic devices to satisfy daily entertainment and communication demands is almost infinite. Mobile devices, such as smartphones, play a growing role in our daily life and have become a constant companion. They provide increasing processing power and are increasingly employed in daily use. Furthermore, our society and means of mobility are becoming increasingly connected. Different wireless communication approaches as well as technologies are already available or in development to realize Vehicle-to-X (V2X) communication. Besides Vehicle-to-Vehicle (V2V) and Vehicle-to-Infrastructure (V2I), V2X communication also includes Vehicle-to-Device (V2D) communication. Academia and industry invest a lot of resources and effort to make new technologies safe and reliably usable. These technologies form the basis for applications which are experienced by customers. Considering the automotive field, academia as well as industry design and develop applications based on these technologies in three main fields:

- Traffic efficiency: increasing traffic efficiency by reducing traffic jams and enabling fluent traffic seeks to improve customers' traveling convenience as well as ecological friendliness.

- Infotainment: reliable internet connection opens the door for social networks, online radio or even movies in the vehicle. Driver and passengers are increasingly provided with infotainment features.

- Assistance functions: besides assisting the driver while driving, assistance functions mainly aim to reduce the number of accidents as well as their impact. The work moves towards fully-automated driving with zero accidents, and consequently no fatalities. 
Crime and fear of crime are pervasive in our society, experienced in discussions with friends and family, in newspapers, on television or in the worst case even from first-hand experience. It leads to personal injury, economic losses and reduced quality of life. Criminal offenses are usually defined by the criminal laws of each country of which vehicle-related crime forms a part. According to statistics provided by the Federal Criminal Police Office in Germany [139], vehicle-related crime has constantly made up over $10 \%$ of overall crime in Germany during the last 10 years. However, vehicle-related crime is not only a German phenomenon but an ongoing worldwide problem which does not respect national borders and affects everyone. Vehicle-related crime is not limited to vehicle theft. Instead, the term vehicle-related crime encapsulates all crimes in relation to a vehicle, focusing on motor operated road vehicles, such as cars, buses, motorbikes and trucks. From the perspective of a car manufacturer, cars play an essential role but the other vehicles mentioned here cannot be neglected since they constitute a non-negligible part, e.g., in Germany one-fourth of all registered motorised road vehicles [140]. Furthermore, considering V2V communication, the involvement of a broad number of vehicles is of great importance, especially to achieve high penetration rates. Thus, vehicle-related crime relates to any malicious attacks defined as criminal offenses by legislation in a given country which are directed against occupants as well as the vehicle itself, and cause some degree of property damage, property loss or bodily injury and which, in a broad sense, relate to a vehicle.

To fight vehicle-related crime and reduce fear of vehicle-related crime national governments, the automotive industry, insurance companies and other parties have taken several countermeasures. However, until now, existing countermeasures dealing with vehicle-related crime are mostly concentrated on the vehicle itself and focus on physical target hardening. That means existing countermeasures ignore the involvement of other vehicles, occupants and infrastructure in tackling vehicle-related crime by making use of sophisticated technologies. Research and industry mainly uses these sophisticated technologies to develop infotainment features, to improve traffic efficiency and in particular to develop assistance functions. Since criminals typically adjust their skills steadily to keep up with countermeasures, it is important to continuously keep pace with criminals and to even be a step ahead. Hence, the use of sophisticated technologies to involve other vehicles, occupants and infrastructure provides the potential to increase the effort required by criminals to commit vehicle-related crimes. Thus, as shown in Figure 1.1, we claim that new technologies have the potential to be enablers for a fourth class of applications, namely security functions, which must not be mixed up with IT-security mechanisms, such as securing V2X communication or an ECU (electronic control unit) against tampering. Applications falling into the class of automotive security functions pursue the following three goals:

1. Fighting vehicle-related crime: Security functions make use of sophisticated technologies to (cooperatively) fight vehicle-related crime. They aim to reach this goal by

- predicting an occurring offense

- preventing the offense

- warning occupants of the offense

- reducing the impact of the offense

- helping to investigate the offense 
2. Reducing fear of vehicle-related crime: Fear of crime negatively affects our behavior, economics, politics and our daily life. Hence, in addition to fighting crime, security functions aim to reduce fear of vehicle-related crime. Fear of crime does not necessarily correlate with crime; anomalies exist, e.g., crime is low but fear of crime is high and vice versa [7]. Thus, fear of crime needs to be considered independent of crime. Furthermore, vehicle manufacturers want their customers to feel comfortable while driving their vehicles. Reducing the fear of crime, i.e., increasing the feeling of security, contributes to improving the driving experience in addition to improving assistance systems, infotainment features and traffic flow. From an economic point of view, tackling fear of crime provides a unique selling point to the vehicle manufacturer. This can be used to stand out from competitors and increase the number of sales and improve the firm's brand image.

3. Providing tangibility of security: Security, not only in the automotive field, is essential and forms the basis for reliable applications. The main drawback of security is that it is not tangible, especially not for customers. Therefore, the importance of security is mostly not appreciated and sometimes even neglected until security measures are compromised. Moreover, since security is not tangible for customers, it is difficult to sell it as a product and there is a lack of understanding on the customer side. Therefore, security functions aim to make security tangible, providing vehicle manufacturers with the opportunity to extend their set of applications. This way, a vehicle manufacturer can stand out from competitors, increase sales and in particular bring security closer to customers in order to improve its understanding and importance.

In a nutshell, automotive security functions, which are on the whole white spots in academia and especially in industry, make use of sophisticated technologies to tackle vehicle-related crime, decrease fear of crime and make security more tangible.

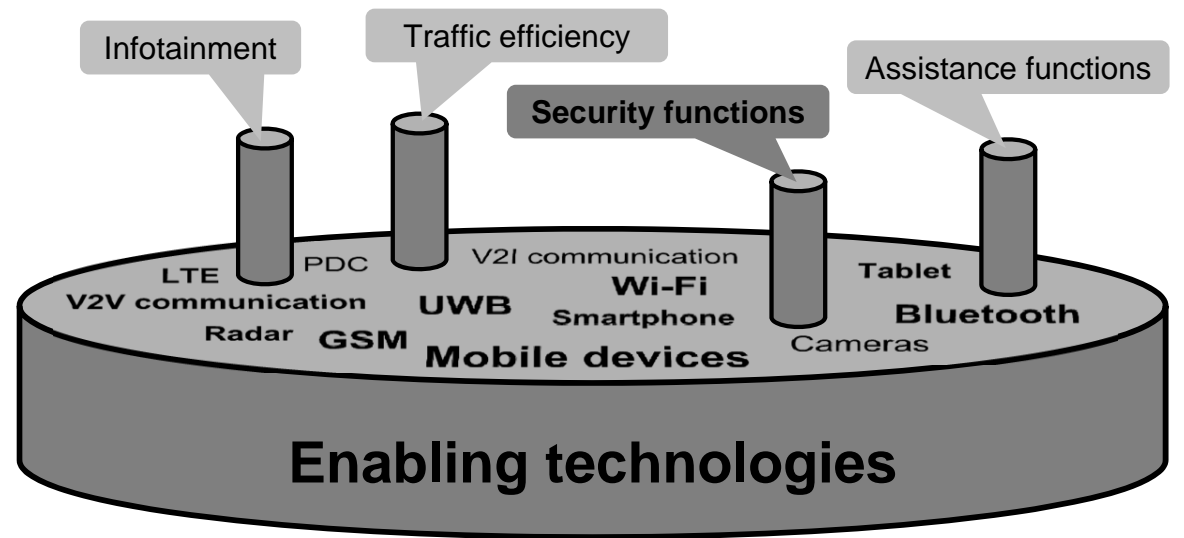

Figure 1.1.: New technologies as enablers for automotive security functions 


\subsection{Research objectives}

The main focus of this thesis is to study the opportunity to use new technologies to develop security functions following our definition from the introductory Section 1.1. Additionally, the effectiveness estimation of potential candidate functions will be focused on in this thesis. In our opinion, working on security functions from the application perspective is still a white spot in research. Thus a security function has to be seen as an extension to the three classes of applications from Figure 1.1. Security functions must not be mixed up either with safety functions, which form a subset of assistance functions, or with IT-security mechanisms, which protect from malicious cyber attacks seeking to gain control over a system or to gain access to (critical) private information.

In the course of the introduction of infotainment, traffic efficiency and driving assistance applications, the technological basis for the development of security functions including IT-security mechanisms and privacy issues is being widely researched and is even partially available in series products. These topics are being widely discussed in both the community and in standardization committees. Therefore, we leave these topics to one side, though they are important research topics in relation to the issue of security functions.

Until now, existing countermeasures dealing with vehicle-related crime are mostly concentrated on the vehicle itself and focus on physical target hardening. That means they neither involve other vehicles, occupants and infrastructure, nor do they make use of other sophisticated technologies. Hence, considering the aforementioned scope, the main research hypothesis of the thesis is:

Main research hypothesis: New technologies can be enablers for a novel class of advanced and cooperative security functions in the automotive field.

To research our main hypothesis, we have to deal with two central issues. First, combining the opportunities and richness of new technologies with the high diversity of vehicle-related crime leads to a nearly infinite frame of possible security functions. To handle this complexity, a structured approach to develop proposals for security functions is necessary. Second, the effectiveness of a security function is crucial. To estimate how effective a security function fights crime, decreases fear of crime and provides tangibility to customers, the straightforward approach is to evaluate statistical data considering other influencing factors from the past. However, this approach implies the implementation of a security function and continuous usage under realistic conditions along with high and even unnecessary costs as well as requiring observation over a prolonged period. From the perspective of a car manufacturer, it is unsatisfactory to spend resources to develop security functions with unpredictable effectiveness. Therefore, it is of great interest for a car manufacturer to identify beforehand security functions which have the potential to be effective.

Hence, in order to research our main hypothesis, we seek to answer two main research questions: 
Main research question 1: How can we identify automotive security functions?

To identify automotive security functions, we firstly need a deeper understanding and knowledge of the occurrence of crime and fear of crime. The focus therefore is on vehicle-related crime. To be able to combine this knowledge about aspects of vehicle-related crime with new technologies in order to identify security functions that account for the diversity of vehiclerelated crime, a structured approach is necessary. Therefore, we tackle our first main research question by answering the following two sub research questions:

$R Q$ 1.1: How can we gain deeper understanding of the factors leading to (fear of) vehiclerelated crime?

$R Q$ 1.2: How can we identify tailored automotive security functions in a structured way?

Main research question 2: How can we evaluate the effectiveness of automotive security functions?

To avoid unnecessary implementation costs and to shorten the time frame in which effectiveness results of security functions become available, it is of great importance to know as early as possible whether a security function has the potential to effectively fight crime, to decrease fear of crime and to find customer acceptance by providing tangibility of security. Consequently, we refine the second main research question in the following three sub research questions:

$R Q$ 2.1: How can we evaluate the effectiveness of fighting crime?

$R Q$ 2.2: How can we evaluate the effectiveness of reducing fear of crime?

$R Q$ 2.3: How can we evaluate customer acceptance of security functions?

\subsection{Main contributions}

This thesis provides methodological and empirical approach to identify, design and evaluate automotive security functions. The results can be used as an orientation on the development of security functions. Our work is of an interdisciplinary nature and involves the following three domains: computer engineering, crime science and social science. The contributions of this thesis can be summarized as follows:

- Introducing the concept of automotive security functions in the community to form a fourth class of applications besides infotainment, traffic efficiency and assistance applications makes up a significant part of this work. We propose a definition of security functions and a distinction with the other classes of applications appearing in [1,2]. 
- Understanding vehicle-related crime forms the basis of successful identification of security functions. We use a combination of analysis of statistical (vehicle) crime data and data from victimization surveys to gain a deeper understanding of vehicle-related crime. Additionally, we conduct an online survey in Germany, the USA and Mexico in order to gain further insights into (fear of) vehicle-related crime as well as to compare the results on an international level. The results have been published in $[2,3]$.

- A methodology is proposed to identify security functions in a structured way. We make use of two approaches from crime science, namely crime scripts and 25 techniques of situational crime prevention. Both approaches are used in collaboration to identify possible security functions in a structured way. The methodology appears in [1].

- Security functions are identified by developing vehicle-related crime scripts and consequently applying our methodology, and thus, showing the suitability of our methodology.

- By designing two security functions, namely the cooperative home light (CHL) and the electronic decal (ED), we show the feasibility of their realization in consideration of the underlying technologies. Both security functions appear in $[4,5]$.

- An evaluation of the CHL and ED is conducted in this thesis. We seek to estimate the (expected) effectiveness with the help of several approaches. First, we consider results of already existing and similar countermeasures. These results are transferred on our security functions. Second, we conduct a customer study to rate their effectiveness in reducing fear of crime and identify their expected effectiveness in fighting crime. Customers' attitudes towards the CHL and ED and thus the tangibility of security are also evaluated. Third, we interview experts to consider the potential of our security functions to fight crime. Lastly, we suggest measurable criteria representing the effectiveness of both security functions. We implement a simulation environment in order to simulate the $\mathrm{CHL}$ to estimate the effectiveness derived from simulation results. Evaluation results partly appear in [6].

\subsection{Organization of the thesis}

The contributions of this thesis are discussed as shown in Figure 1.2. In Chapter 2, we conduct a statistical (vehicle-related) crime analysis for several countries to gain a deeper understanding of the objective facts on (vehicle-related) crime. Additionally, we analyze the results of existing victimization surveys to cover the subjective view of vehicle-related crime. Chapter 3 presents our cross-country survey from Germany, the USA and Mexico including research results considering the aspects of vehicle-related crime. In Chapter 4, we introduce and develop the necessary basics for our methodology SAIAS (Structured Approach to Identify Automotive Security Functions) before designing SAIAS. Considering our understanding of vehicle-related crime from the previous chapters, we apply SAIAS in Chapter 5 to propose six possible security functions. Two selected security functions, namely the electronic decal (ED) and the cooper- 
ative home light (CHL), are refined subsequently in Chapter 6. An evaluation of the ED and $\mathrm{CHL}$ as well as security functions in general is conducted in Chapter 7. Here, we transfer results from related work and conduct a supervised one-to-one survey as well as expert interviews. In Chapter 8, we additionally suggest evaluating security functions with the help of simulations. Hence, we implement a simulation environment and evaluate the CHL as an example. Finally, Chapter 9 summarizes this thesis with a revisit of our research questions and directions for future work, before concluding the thesis. 


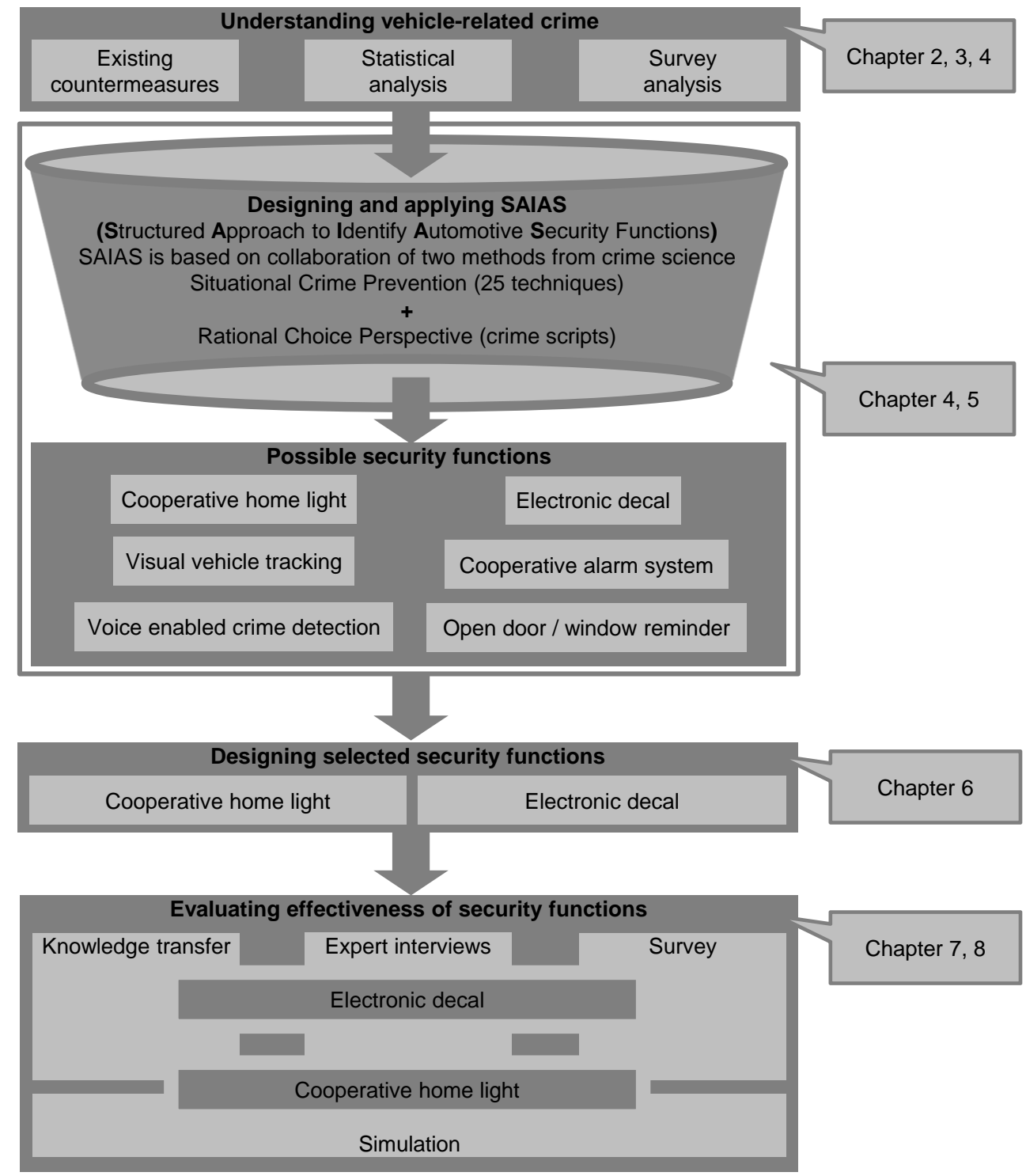

Figure 1.2.: Contributions and organization of this thesis 


\section{Chapter}

2

\section{Understanding vehicle-related crime}

To elaborate on security functions, a deeper understanding of vehicle-related crime and the fear of it is necessary. Therefore, we conduct a statistical crime analysis based on police statistics. Additionally, we analyze and provide core findings from existing victimization surveys regarding vehicle-related crime.

In the beginning of this chapter, we first discuss the benefits as well as drawbacks of police statistics and victimization surveys. In the following, we conduct a statistical crime analysis and an analysis of victimization surveys before summarizing the chapter.

\subsection{Police statistics and victimization surveys}

The two most important data sources for gaining understanding about the development of crime are police statistics and victimization surveys. Basically, to gain statistical data the police record crimes detected or reported by victims or witnesses. Since not all crimes committed are detected or reported to the police, statistics are supplemented by victimization surveys. In these surveys, a randomly-selected sample of the population is asked whether they have fallen victim of specific crimes. Beyond that, surveys can also cover aspects of fear of crime as well as more details about the circumstances of a crime. In using police statistics and victimization surveys to gain better understanding of crime development, we need to consider the limitations of both.

Police statistics aim to provide an objective view of crime development over time. However, police statistics may be inaccurate due to unreported cases since they depend on the willingness of victims or witnesses to report the crime to the police. For example, with theft of vehicle parts, it is possible that the victim does not report the loss to the police or their insurance company as the victim does not expect the police to solve the crime and has no insurance to cover the loss. Consequently, offenses not reported to the police lead to inaccurate data, i.e., a dark figure of crime. Furthermore, not all crimes which come to the attention of police through reporting or investigation are recorded in the end. Whether a crime is recorded or not depends on the investigation policies of the police. For example, the setting of different priorities in the investigation influences crime recording. Generally, more serious crimes are better recorded than less serious crimes. Crime is not always reported and not all reported crimes actually enter the official records. Furthermore, offenses can be wrongly recorded or may be misin- 
terpreted by the victim or police since the offender's intention is ultimately hard to ascertain. For example, a vehicle theft may be interpreted as vehicle vandalism when the offender was disturbed during the offense and left a smashed window. There is always considerable leeway for interpretation of the crime. Due to the ambiguous character of crime, it might not always be precisely clear what happened. Furthermore, the introduction of computer systems and continuous improvement can also influence statistics. The penetration of computerization can lead to a simplified recording process which in turn might influence the statistics due to a general increase of productivity and automation. In contrast, a policy of financial cuts, and thus, a reduction in police officers might negatively influence productivity and lead to inferior recording.

Victimization surveys provide a supplement to police statistics, since statistics do not reveal information about people's fear of crime. The main advantage of surveys is the consideration of emotional influences and personal experiences. Furthermore, surveys might help to reveal eventual dark figures in crime resulting from unreported incidents. Since surveys aim to measure victimization against individuals and households, crimes which are directly victimless, such as dealing with stolen cars, are not covered by victimization surveys. Furthermore, surveys do not cover the entire range of demographics since interviews are conducted with people from a specific age, e.g., 16. and the way questions are structured and asked may have an impact on the respondent, and thus, influence the results. Applied descriptions generally allow a broader interpretation than the legal description of a crime.

In a nutshell, we have to treat police statistics as well as victimization surveys with care. First of all, Wittebrood and Junger [8] showed that both police statistics and victimization surveys might reflect a different trend in the development of crime within a country. Second, people's fear of crime does not necessarily go hand in hand with the real development of crime [9]. Third, police statistics as well as victimization surveys from different countries might diverge due to different measuring methods and criminal law descriptions of crime applied by police and authorities. Nevertheless, police statistics and victimization surveys are the leading measures of crime development as well as fear of crime.

\subsection{Statistical crime analysis}

Few countries provide annual crime statistics over a relatively long period. As discussed in the previous section, police statistics come with several drawbacks which need to be kept in mind while conducting a statistical (vehicle-related) crime analysis to show trends in development.

We first describe the methodology of our statistical crime analysis. The main goal is to show the trends of vehicle-related crime over a longer period and provide explanations for these trends. We will therefore look at selected countries on their own to provide an overview of crime development in general. In the second step, we then focus on vehicle-related crimes, namely vehicle theft, theft from vehicle, vehicle vandalism and carjacking, since these crimes are statistically covered in the main. The knowledge from our first step supports the under- 
standing as well as the explanation of the effects of the development of vehicle-related crime. Afterwards, we draw conclusions for the development of security functions.

\subsubsection{Method}

To be able to assess crime in different parts of the world, we considered conducting a statistical analysis in the countries shown in Figure 2.1. These countries range from emerging countries to industrialised countries with high living standards and stable legal and political systems. These selected countries are spread across the globe and provide different economic competitiveness. Among others, we considered China to be part of our crime analysis. However, to the best of our effort, we were not able to get any statistical data considering crime or even vehiclerelated crime. Furthermore, we considered Brazil to be one of our selected countries. Again, the available data is highly incomplete and crime categories have changed several times during the last few years. We also identified inconsistencies in data comparing crime reports from former years. Consequently, China and Brazil were discarded from our statistical analysis.
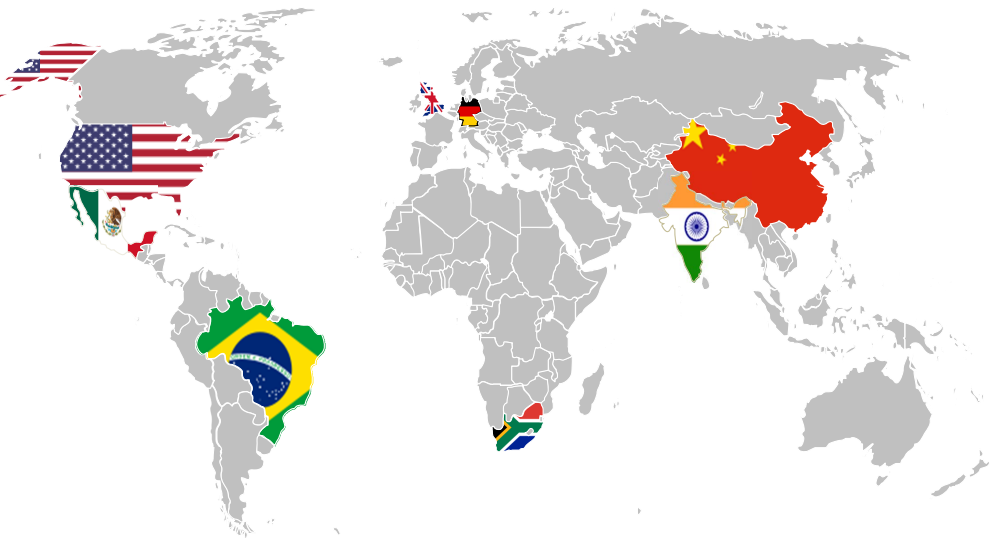

- Germany

- USA

- England and Wales

- Ehina

- India

- Mexico

- Brazil

- South Africa

Figure 2.1.: Countries considered for statistical crime analysis

Conducting our statistical (vehicle-related) crime analysis, we draw on freely-accessible crime data provided by the according state authorities within each country. We use the number of reported offenses to the police in each country. Table 2.1 provides an overview of the data sources we used to estimate the number of reported offenses within our selected countries.

We further need the number of population as well as the number of registered vehicles in our selected countries. We do not present absolute data, i.e., the absolute number of offenses, since the number is influenced by the number of inhabitants as well as registered vehicles in the country concerned. Therefore, we give the number of offenses per 100,000 inhabitants and per 100,000 registered vehicles. Table 2.1 shows the sources of data used to estimate the population size as well as the number of registered vehicles in our selected countries. 
Table 2.1.: Overview of sources used for statistical crime analysis

\begin{tabular}{|c|c|c|c|}
\hline & $\begin{array}{l}\text { Number of } \\
\text { reported crimes }\end{array}$ & $\begin{array}{l}\text { Population } \\
\text { size }\end{array}$ & $\begin{array}{l}\text { Number of } \\
\text { registered vehicles }\end{array}$ \\
\hline Germany & $\begin{array}{l}\text { Bundeskriminalamt, } \\
\text { Polizeiliche Kriminal- } \\
\text { statistik [139] }\end{array}$ & $\begin{array}{l}\text { Statistisches } \\
\text { desamt, Bun- } \\
\text { rungsentwicklung in } \\
\text { Deutschland [141] }\end{array}$ & $\begin{array}{l}\text { Kraftfahrt Bundesamt, } \\
\text { Fahrzeugbestand [140] }\end{array}$ \\
\hline USA & $\begin{array}{l}\text { Federal Bureau of In- } \\
\text { vestigation, Uniform } \\
\text { Crime Reports [142] }\end{array}$ & $\begin{array}{l}\text { United States Census } \\
\text { Bureau, Population } \\
\text { Overview [143] }\end{array}$ & $\begin{array}{l}\text { Department of Trans- } \\
\text { portation, Number of } \\
\text { Vehicles [144] }\end{array}$ \\
\hline $\begin{array}{l}\text { England } \\
\text { and } \\
\text { Wales }\end{array}$ & $\begin{array}{ll}\text { Home Office, } & \text { Crime } \\
\text { Statistics at } & \text { Home } \\
\text { Office [145] } & \end{array}$ & $\begin{array}{l}\text { Office for National } \\
\text { Statistics, Population } \\
\text { Estimates for England } \\
\text { and Wales [146] }\end{array}$ & $\begin{array}{l}\text { Department for Trans- } \\
\text { port, Vehicles statistics } \\
{[147]}\end{array}$ \\
\hline Mexico & $\begin{array}{lr}\text { Secretariado } & \text { Ejecutivo } \\
\text { del Sistema } & \text { Nacional } \\
\text { de Seguridad } & \text { Publica, } \\
\text { Incidencia } & \text { Delictiva } \\
{[148]} & \\
\end{array}$ & $\begin{array}{l}\text { Instituto Nacional de } \\
\text { Estadistica y Geografia, } \\
\text { Poblacion total [149] }\end{array}$ & $\begin{array}{l}\text { Instituto Nacional de } \\
\text { Estadistica y Geografia, } \\
\text { Vehiculos de motor reg- } \\
\text { istrados en circulacion } \\
\text { [150] }\end{array}$ \\
\hline India & $\begin{array}{l}\text { National Crime Records } \\
\text { Bureau, Crime in India } \\
\text { [151] }\end{array}$ & $\begin{array}{l}\text { Ministry of Home Af- } \\
\text { fairs, Census Data Sum- } \\
\text { mary [152] }\end{array}$ & $\begin{array}{l}\text { Ministry of Road Trans- } \\
\text { port and Highways, } \\
\text { Road Transport Year } \\
\text { Book [153] }\end{array}$ \\
\hline $\begin{array}{l}\text { South } \\
\text { Africa }\end{array}$ & $\begin{array}{l}\text { South African Police } \\
\text { Service, Crime Report } \\
{[154]}\end{array}$ & 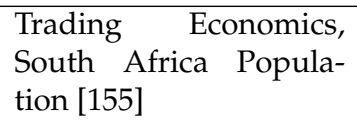 & $\begin{array}{l}\text { National Traffic Infor- } \\
\text { mation System, Live Ve- } \\
\text { hicle Population [156] }\end{array}$ \\
\hline
\end{tabular}

Since offenses are presented as a per population and/or per number of vehicle rate, we show in Figure 2.2 the number of vehicles per population for the according countries, respectively. Additionally, Table 2.2 summarizes our calculation of the average growing rates of population as well as the number of registered vehicles for specified time periods dependent on data availability. The vehicle possession rate is noticeably higher in industrialized countries. However, growth rates of both population and especially numbers of registered vehicles are noticeably higher in emerging countries. Overall, there are clearly fewer vehicles per person in emerging countries than in industrialized countries. This circumstance of course influences statistical figures and needs to be kept in mind.

Each country has proprietary crime variables so crime variables differ across countries. Therefore, we define crime categories with definitions shown in Table 2.3. These crime categories and definitions are guided by common law [10], which is the legal system in most English-speaking countries. In the further course of our analysis, we assign statistical data from proprietary crime variables to the according crime categories, respectively. This way, we aim to make data comparable across countries. It is important that data remains independent, for example, theft from vehicle can be sometimes a subcategory of theft. In this case, theft from vehicle has to 


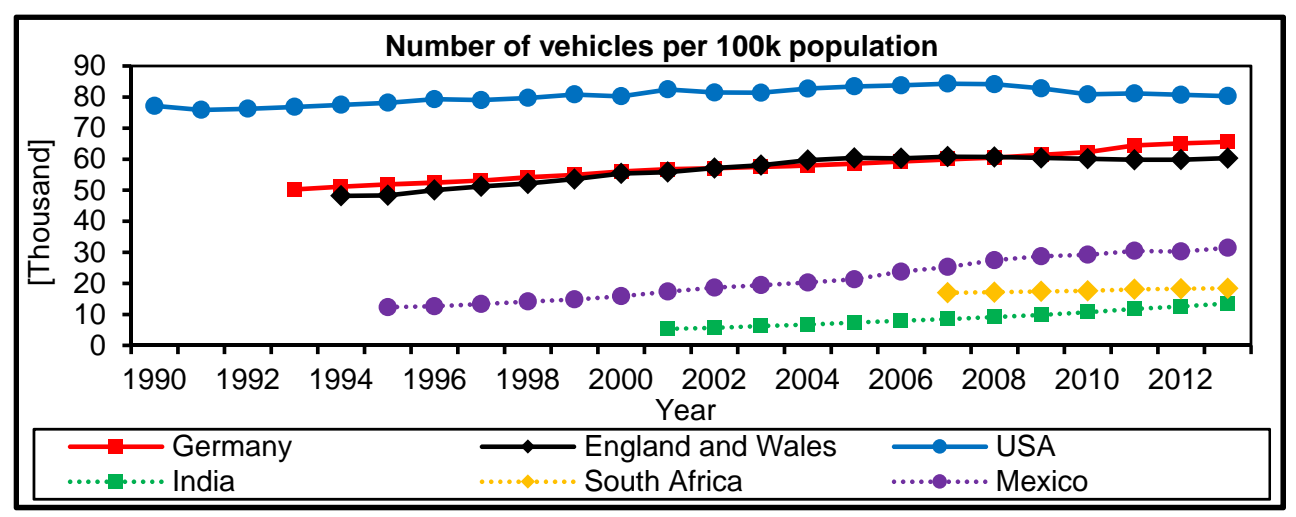

Figure 2.2.: Number of vehicles per 100,000 population

Table 2.2.: Average vehicle and population growth rates for selected countries

\begin{tabular}{lllllll}
\hline & Germany & USA & $\begin{array}{l}\text { England } \\
\text { and } \\
\text { Wales }\end{array}$ & India & $\begin{array}{l}\text { South } \\
\text { Africa }\end{array}$ & Mexico \\
\hline Years & $1993-$ & $1994-$ & $\begin{array}{l}1990- \\
2013\end{array}$ & $\begin{array}{l}2001- \\
2013\end{array}$ & $\begin{array}{l}2007- \\
2013\end{array}$ & $\begin{array}{l}1995- \\
2013\end{array}$ \\
\hline $\begin{array}{l}\text { Average } \\
\text { vehicle } \\
\text { growth rate }\end{array}$ & $1.3 \%$ & $1.3 \%$ & $1.8 \%$ & $9.8 \%$ & $3.1 \%$ & $6.5 \%$ \\
\hline $\begin{array}{l}\text { Average } \\
\text { population } \\
\text { growth rate }\end{array}$ & $0.0 \%$ & $1.0 \%$ & $0.6 \%$ & $1.6 \%$ & $1.7 \%$ & $1.1 \%$ \\
\hline
\end{tabular}

be excluded from this category otherwise results are falsified due to dependency. Nevertheless, we have to keep in mind that statistical data underlies different measuring methods and different criminal law descriptions of crime in each country. 
Table 2.3.: Crime categories with according definitions

\begin{tabular}{|c|c|}
\hline Crime category & Definition \\
\hline $\begin{array}{l}\text { Vandalism: } \\
\text { (VAN) }\end{array}$ & $\begin{array}{l}\text { Vandalism covers any damage to a person's personal goods or } \\
\text { property as well as to public property. }\end{array}$ \\
\hline $\begin{array}{l}\text { Vehicle vandalism: } \\
\text { (VTV) }\end{array}$ & This offense covers any damage to a vehicle. \\
\hline $\begin{array}{l}\text { (Aggravated) Assault: } \\
\text { (AAS) }\end{array}$ & $\begin{array}{l}\text { Assault consists of intentionally afflicting violence on a person. } \\
\text { As soon as the attacker makes use of a weapon assault is con- } \\
\text { sidered to be aggravated. The attempt to commit a murder falls } \\
\text { also in this group. }\end{array}$ \\
\hline $\begin{array}{l}\text { Murder: } \\
\text { (MUR) }\end{array}$ & $\begin{array}{l}\text { Murder covers offenses of intentionally or negligently killing } \\
\text { another person. }\end{array}$ \\
\hline $\begin{array}{l}\text { Sexual offense: } \\
\text { (SEX) }\end{array}$ & $\begin{array}{l}\text { Any sexual attack directed against another person without this } \\
\text { person's consent is seen as sexual offense. }\end{array}$ \\
\hline $\begin{array}{l}\text { Robbery: } \\
\text { (ROB) }\end{array}$ & $\begin{array}{l}\text { Robbery represents the unauthorized taking or attempting to } \\
\text { take personal goods or property from another person. The of- } \\
\text { fender makes use of violence or threat of force. }\end{array}$ \\
\hline $\begin{array}{l}\text { Burglary: } \\
\text { (BUR) }\end{array}$ & $\begin{array}{l}\text { Burglary covers unauthorized entries into buildings or other } \\
\text { structures with the intention to steal. }\end{array}$ \\
\hline $\begin{array}{l}\text { Larceny/theft: } \\
\text { (THE) }\end{array}$ & $\begin{array}{l}\text { Larceny summarizes unauthorized taking from personal goods } \\
\text { or property from within a building to which the offender has } \\
\text { free or legal access, e.g. shoplifting. Pickpocketing also falls in } \\
\text { the category of larceny/theft. }\end{array}$ \\
\hline $\begin{array}{l}\text { Vehicle Theft: } \\
\text { (VTH) }\end{array}$ & $\begin{array}{l}\text { Vehicle theft describes the unauthorized taking of another per- } \\
\text { son's vehicle. }\end{array}$ \\
\hline $\begin{array}{l}\text { Theft from vehicle: } \\
\text { (TFV) }\end{array}$ & $\begin{array}{l}\text { Theft from vehicle summarizes theft of valuables and other } \\
\text { things from the inside of the vehicle. Furthermore, theft of vehi- } \\
\text { cle parts and accessories is also represented by theft from vehi- } \\
\text { cle. }\end{array}$ \\
\hline
\end{tabular}

\subsubsection{Results: crime by country}

In this section, we provide the results of the development of our crime categories defined in Table 2.3 for each selected country separately. We provide a graphical analysis which aims to show the development and trends of crime categories. This way, we estimate relationships across crime categories. For example, when violent crimes as well as property crimes have decreased to the same extent it might be an indication that the economical, social and/or political situation has improved in the country, which might have had a positive overall effect on crime development. But for example when vehicle theft has decreased significantly and other property crimes, such as burglary, robbery and larceny, have remained stable or even increased, this might be an indication that the introduction of measures against vehicle theft encouraged this development. Furthermore, contrasting developments might be an indication of crime displacement to other crime categories. 


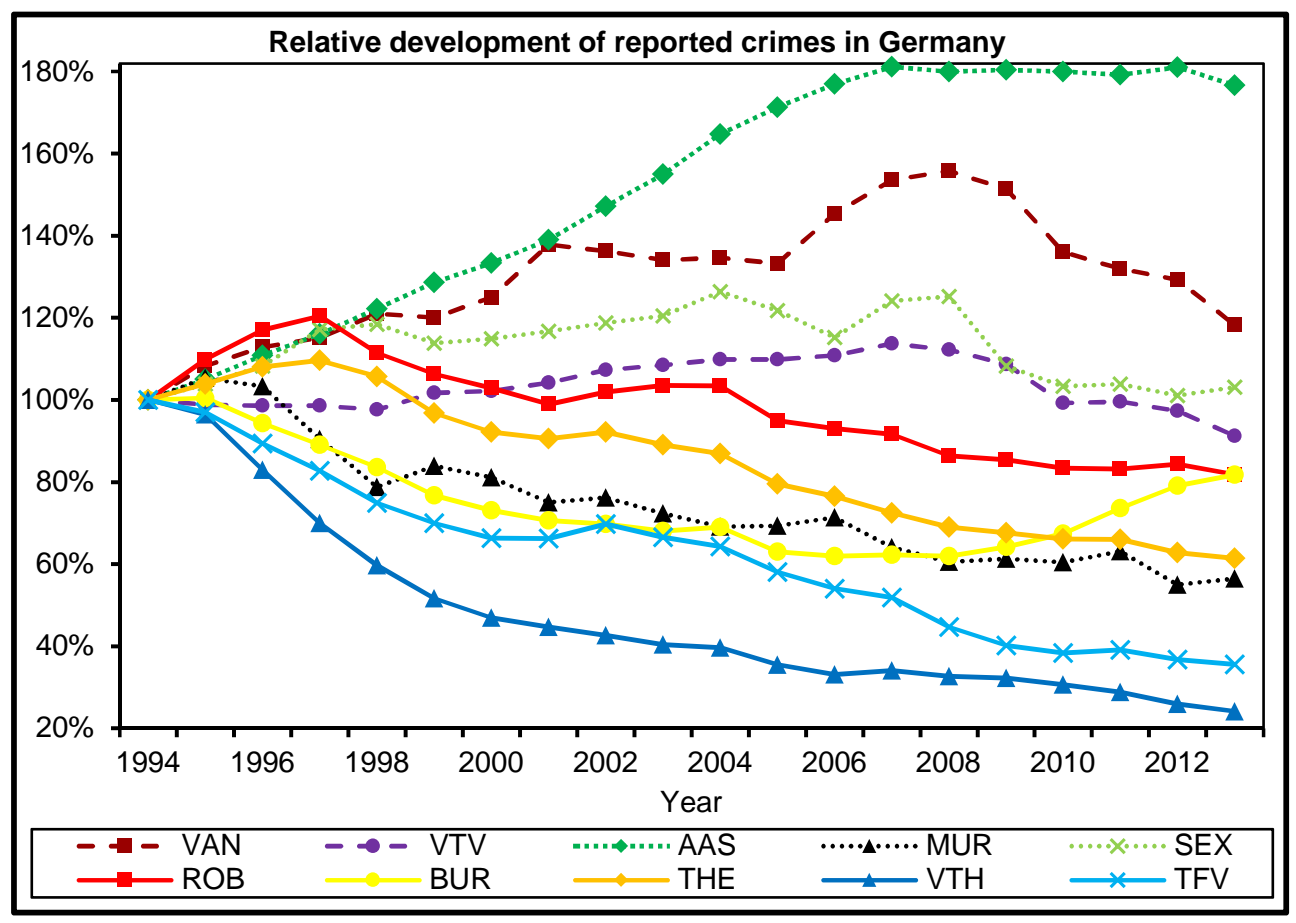

Figure 2.3.: Relative development of reported crimes in Germany since 1994

\section{Germany}

As can be seen from Figure 2.3, there has been neither an overall increase nor a decrease of crime in Germany since 1994. Nevertheless, trends are evident. Violent crime, namely (aggravated) assault, sexual assault, vandalism and vehicle vandalism increased since 1994 with (aggravated) assault standing out. Murder is the only violent crime which decreased. In contrast, property crime, namely robbery, burglary, theft, vehicle theft and theft from vehicle, have decreased since 1994. Only burglary started to increase against the trend a few years ago whilst the other property crime categories continued decreasing. It seems that property theft has displaced vehicle-related theft, i.e. from vehicle theft and theft from vehicle to burglar, meaning property crime has remained stable in the last few years. Violent crime also showed in the last few years a sideways trend though without displacement across crime categories. 


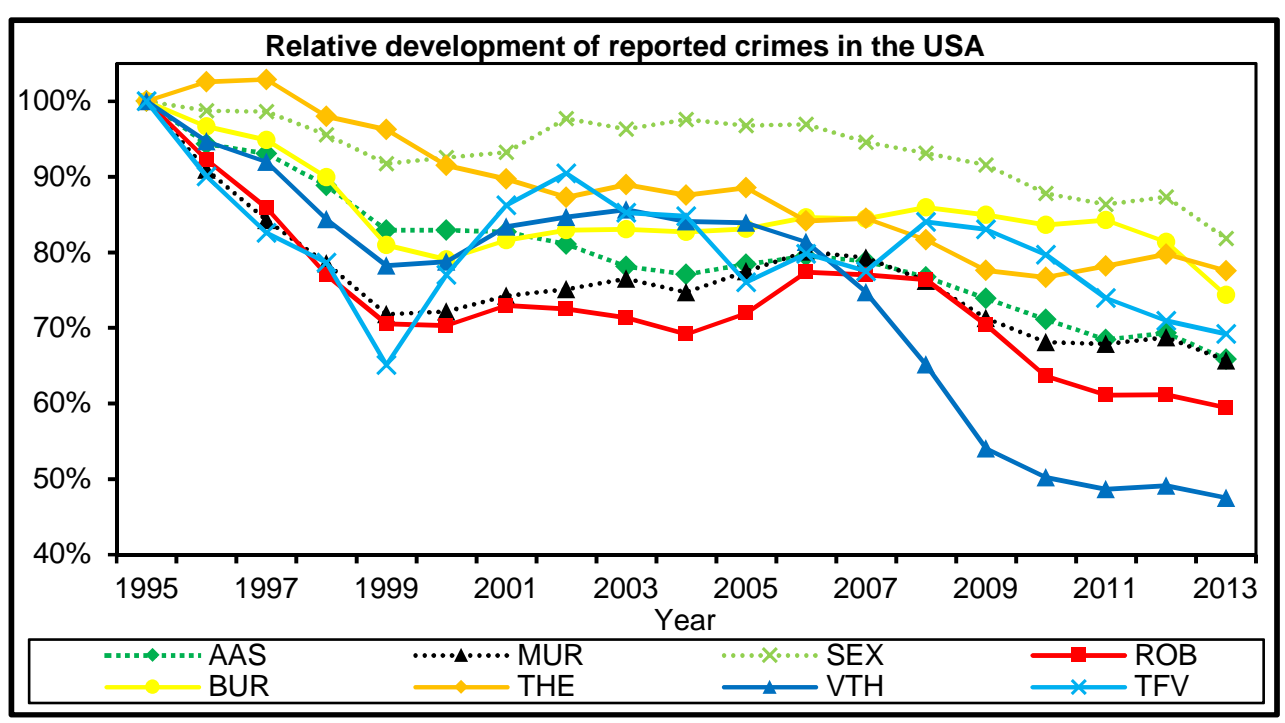

Figure 2.4.: Relative development of reported crimes in the USA since 1995

\section{USA}

Figure 2.4 shows crime development in the USA since 1995 where it can be seen that crime generally decreased within the period from 1995 to 2013. However, crime development has proceeded in a volatile manner so we cannot observe clear trends. Noticeable is the fact that vehicle theft underwent the largest decrease of all crimes, similarly to Germany. Furthermore, the crime development can be split up in three phases. In the first phase from 1995 to 1999 , all crimes decreased. During the second phase from 2000 to 2007, all crime rates remained approximately unchanged (that is, they moved sideways) except theft from vehicle which largely increased in the beginning before moving sideways as well. In the third phase from 2008 to 2013, all crimes decreased again and generally reached a bottom line again which indicates a fourth phase where crime rates follow a sideways trend again. 


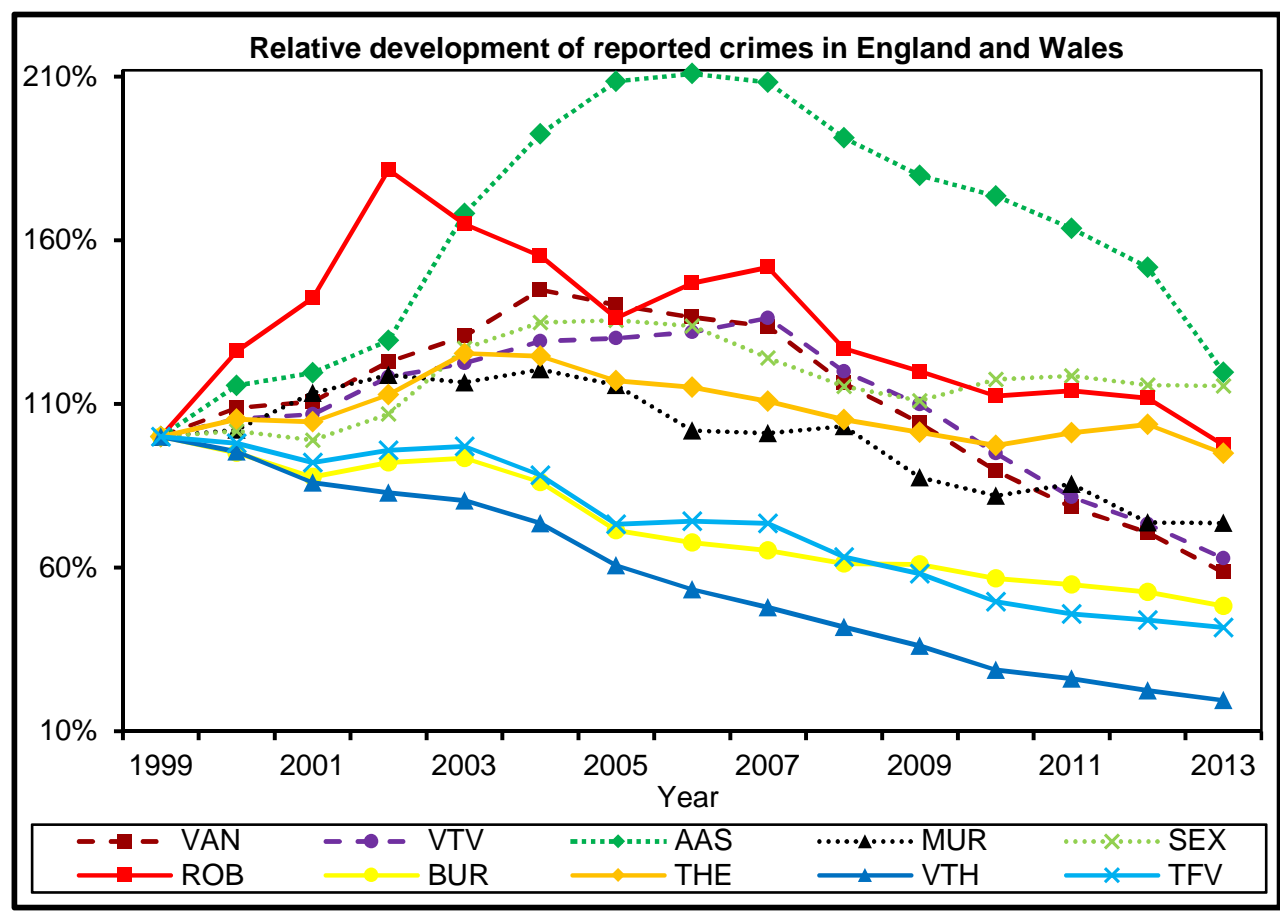

Figure 2.5.: Relative development of reported crimes in England and Wales since 1999

\section{England and Wales}

As can be seen from Figure 2.5, property crimes, namely burglary, vehicle theft and theft from vehicle mostly decreased during the last decade. Theft remained nearly constant. Robbery started to decrease in the second half of the last decade after having increased by $80 \%$ in the beginning of the last decade. Similar to Germany, property crimes mostly decreased. The remarkable decrease of vehicle theft is noteworthy, similar to Germany and the USA. 


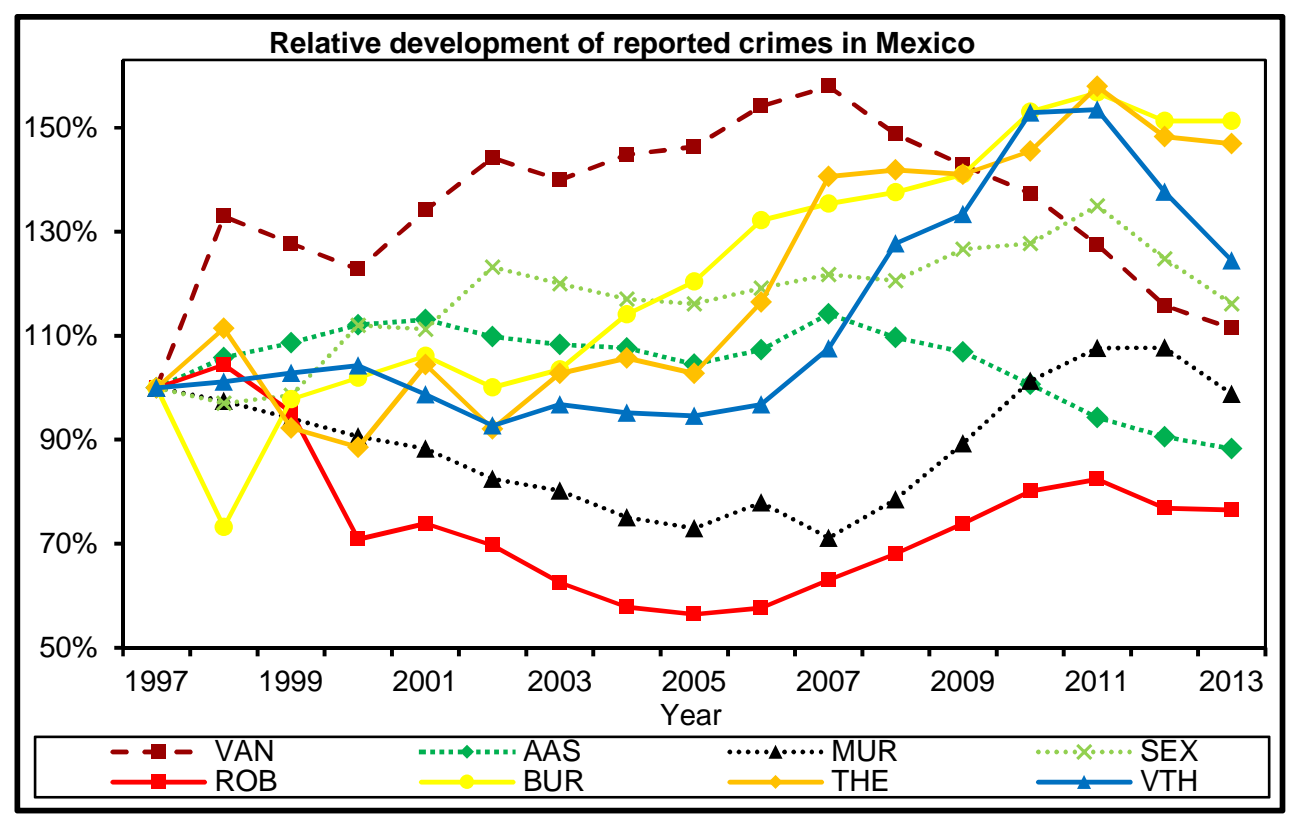

Figure 2.6.: Relative development of reported crimes in Mexico since 1997

\section{Mexico}

Figure 2.6 shows the relative development of crime categories for Mexico since 1997. All crimes, except assault and vandalism, increased since 2007 noticeably. Possible reasons for the increase are the consequences of the world economic crisis, which started approximately in the beginning of 2008. The decrease in assaults was displaced by increased murder rates, in our opinion. This indicates an increase of brutality, which is also noticeable for vehicle theft. The number of vehicle thefts without violence decreased slightly within our studied period. In contrast, vehicle theft using violence increased, and thus is mainly responsible for the large increase in vehicle theft since 2007. In particular property crimes, namely burglary, vehicle theft, robbery and theft increased noticeably since 2007. These property crimes started to decrease slightly again with an improvement of the economic situation after the economic crisis. 


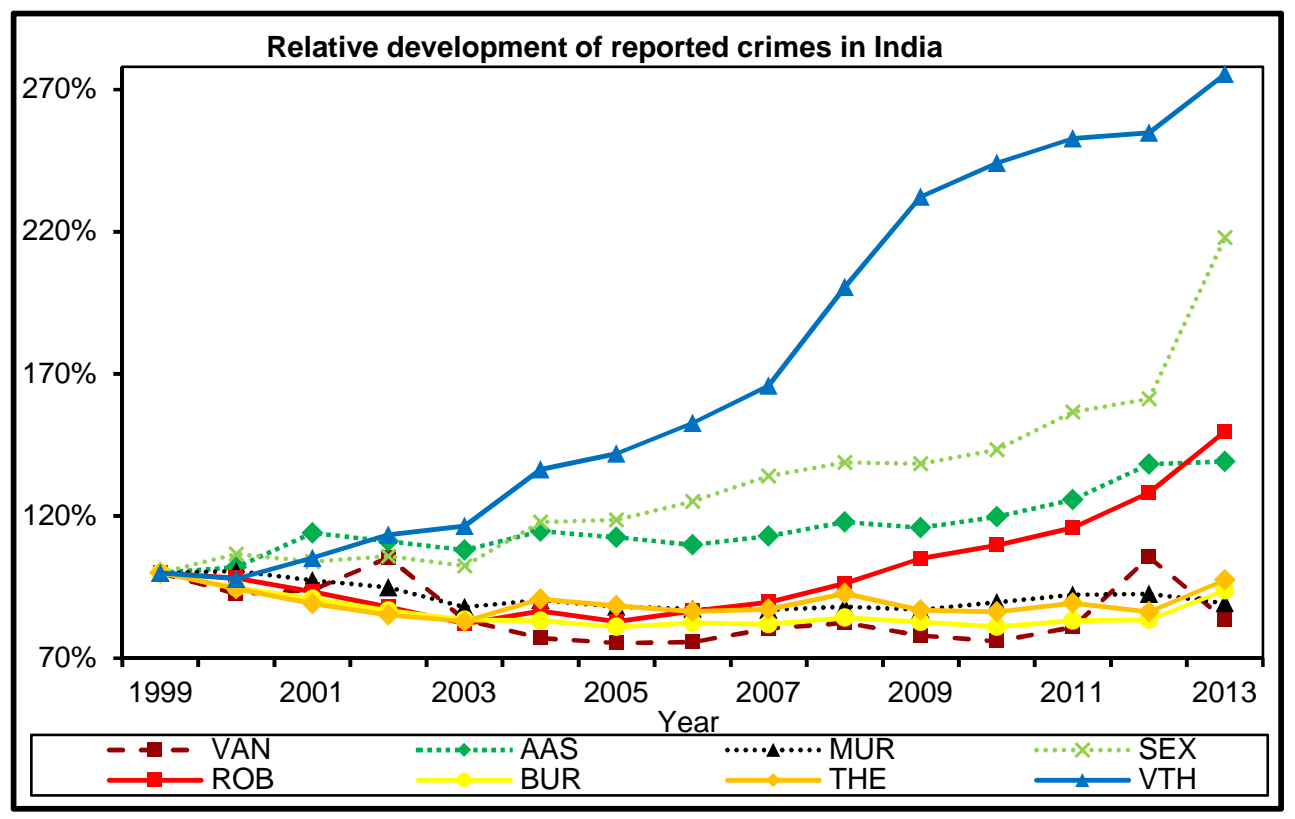

Figure 2.7.: Relative development of reported crimes in India since 1999

\section{India}

Relative crime development in India is shown in Figure 2.7. Vehicle theft stands out in particular, with a significant increase of approximately $150 \%$ since 1999 . Other property crimes moved sideways. Only robbery started to increase by $40 \%$ since 2008 , during which the world economic crisis began. We have no definitive explanation for this significant increase of vehicle theft, but a possible explanation is the growing demand for personal mobility which is growing faster than the offer of affordable opportunities for personal mobility. Hence, vehicle theft is one opportunity to satisfy the demand for personal mobility. Additionally, across our selected countries, India has the highest average vehicle growth rate at nearly $10 \%$ (Table 2.2 ) so the number of potential targets has greatly increased as well. It is important to consider that the ratio of cars to motorbikes remained constant since 1999, namely one to five, indicating there has not been a shift away from motorbikes to cars. Cars, it seems, are still not affordable for the majority in India. Furthermore, there is a distinct increase in sexual offenses in 2013 which can be mainly explained by a higher number of reported cases following to the "Delhi gang rape" [157] in December 2012. A young foreign female was raped by several men and died from her injuries. The "Delhi gang rape" has led to a world wide attention and demonstrations especially by women in India. Both facts have made it easier for women to report rapes and led state authorities to consider sexual offenses with increased seriousness. 


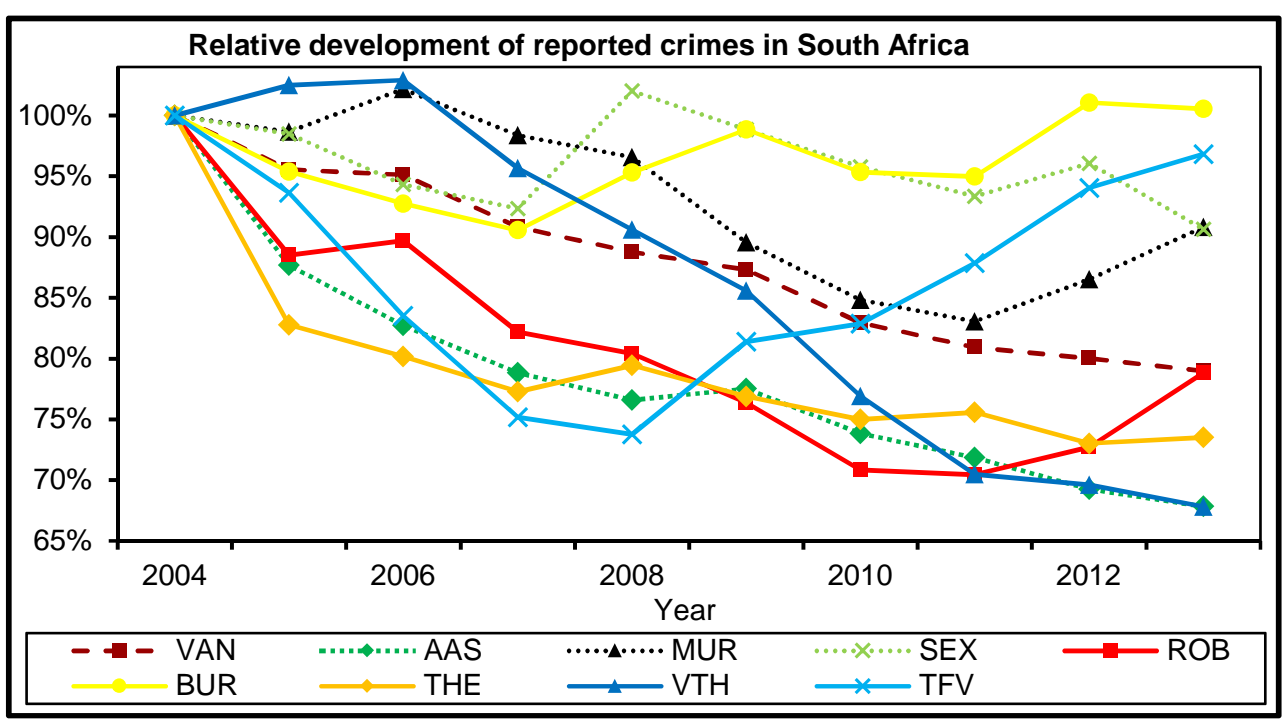

Figure 2.8.: Relative development of reported crimes in South Africa since 2004

\section{South Africa}

As can be seen in Figure 2.8, crime generally decreased or remained at least at the same level since 2004. We think that the overall decrease results in part from the declaration of "war" on crime by the South African government in preparation for the football world cup in 2010. Crime categories did not decrease at the same rate and in our opinion, there is no clear trend visible. An interesting fact is however that vehicle theft started to decrease later than other crimes. In contrast, theft from vehicle is one of the crimes which quickly decreased. However, theft from vehicle is also the only crime which increased again.

\subsubsection{Results and discussion: vehicle-related crimes}

In this section, we focus on vehicle-related crime within our selected countries. We compare the development of vehicle theft, theft from vehicle, vehicle vandalism and carjacking across our selected countries since these crimes are statistically covered in the main. The knowledge from the previous section supports the understanding as well as the explanation of effects. 


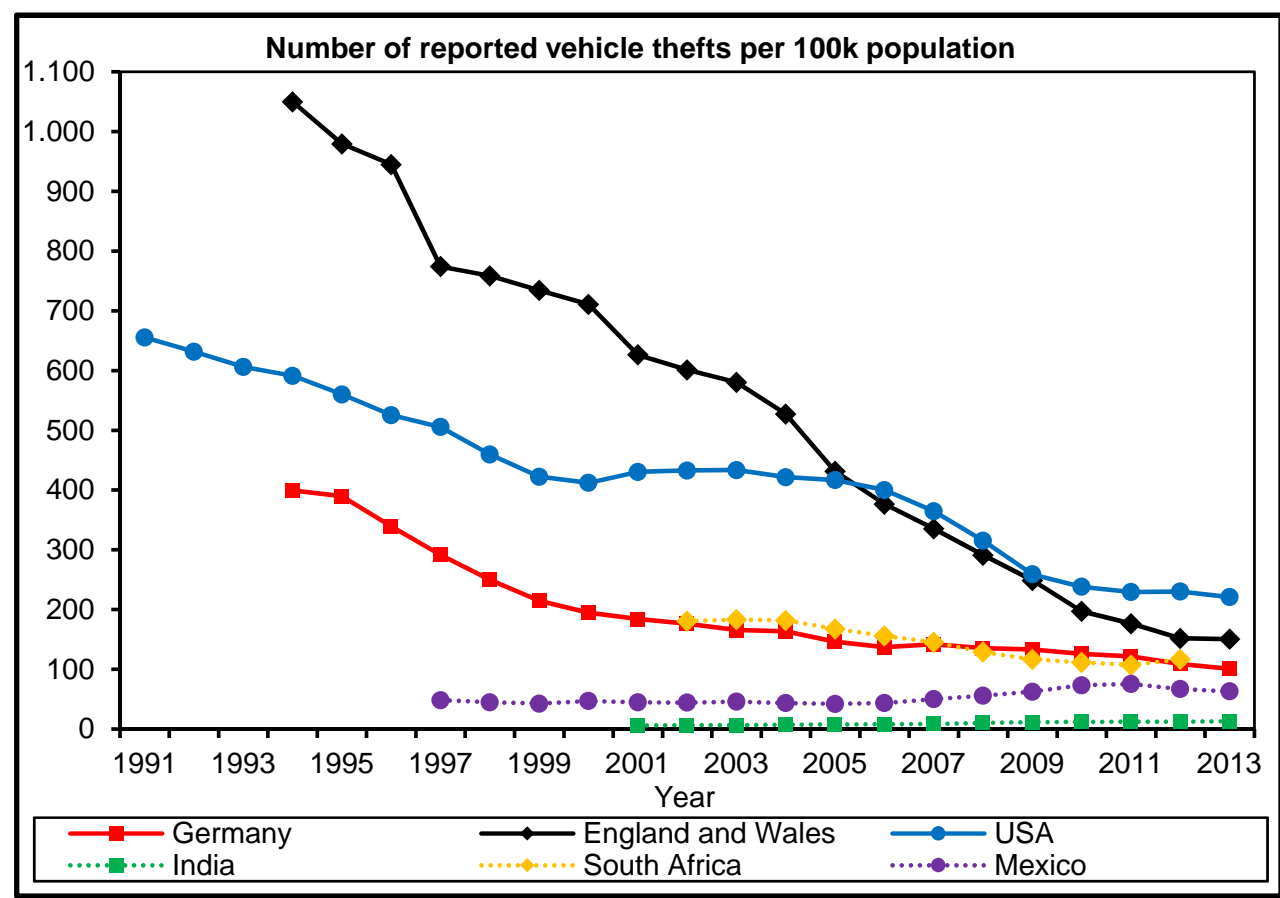

Figure 2.9.: Number of reported vehicle thefts per 100,000 population

\subsubsection{Vehicle theft}

Figure 2.9 and Figure 2.10 show the development of vehicle theft. The former figure shows the number of thefts per 100,000 inhabitants and the latter shows the number of thefts per 100,000 registered vehicles. As can be seen by comparing both figures, the number of registered vehicles per inhabitants influences the results, especially when considering emerging countries with small vehicle per population rates. The theft rate per registered vehicles in India is nearly constant although the absolute number of vehicle thefts steadily increases. However, this increase is neutralized by the steady increase of registered vehicles. We have a similar figure for Mexico, although the vehicle growth rate is not as high as in India. Nevertheless, the vehicle growth rate even led to a small decrease in the vehicle theft rate per registered vehicle. The vehicle theft rate per population increased however. With the beginning of the world economic crisis in 2008 the Mexican theft rate per vehicle increased again. South Africa comes along with much higher theft rates compared to the aforementioned emerging countries despite a continuous decrease in recent years.

Although comparing data across countries has to be treated with care due to different data gathering methodologies, industrialized countries, namely Germany, the USA and especially 


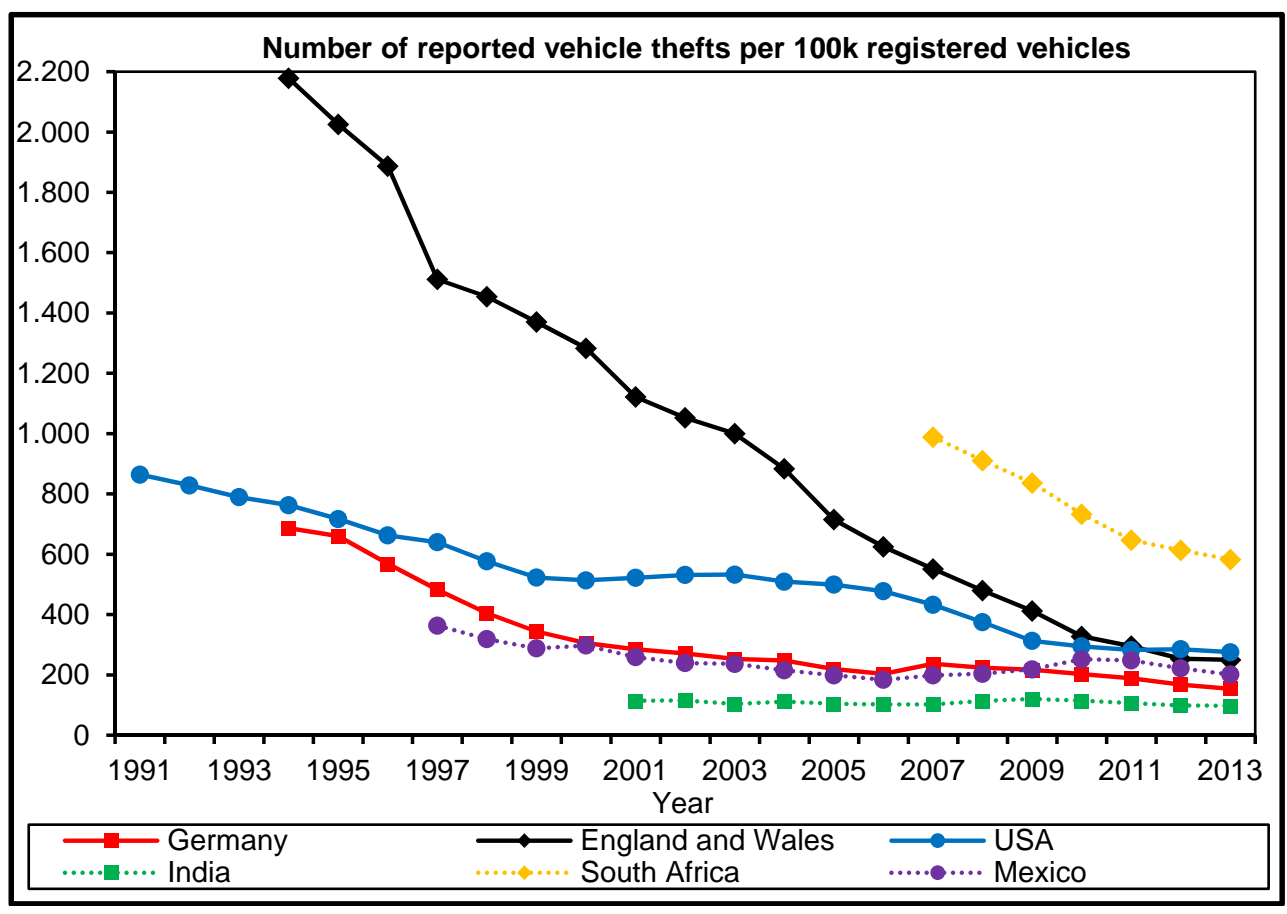

Figure 2.10.: Number of reported vehicle thefts per 100,000 registered vehicles

England and Wales, show noticeably higher theft rates. However, vehicle theft rates decrease steadily from high rates since the early 1990s. These high decreases are achieved neither by a growing population nor a growing number of vehicles. Both factors increased to a very slight degree within the last decades, as was shown in Table 2.2.

According to [11, 12], in the 1990s vehicle theft achieved an all-time high in England and Wales as well as in the USA. But Germany also suffered from high vehicle theft rates in the beginning of the 1990s, as shown in Figure 2.10. Furthermore, Figure 2.11 shows the development of vehicle theft rates from 1960 to 1990 based on data from [11, 12]. Both figures provide a good overview about the long-term development of vehicle theft in our considered industrialized countries where England and Wales stands out especially with its high theft rates.

One possible reason for the rise of vehicle theft during the 1980s and early 1990s in the USA is the loosening of international borders [13]. In England and Wales, the high increase of vehicle theft is related to the late mandatory introduction of steering column locks for new cars [11]. Germany introduced legislation for mandatory steering column locks in 1961, almost 10 years earlier than England and Wales [14]. Furthermore, in Germany steering column locks were also mandatory for motorcycles in addition to cars whereas in England and Wales only passenger cars were targeted. Since the effect on vehicle theft needs some time until enough vehicles are 


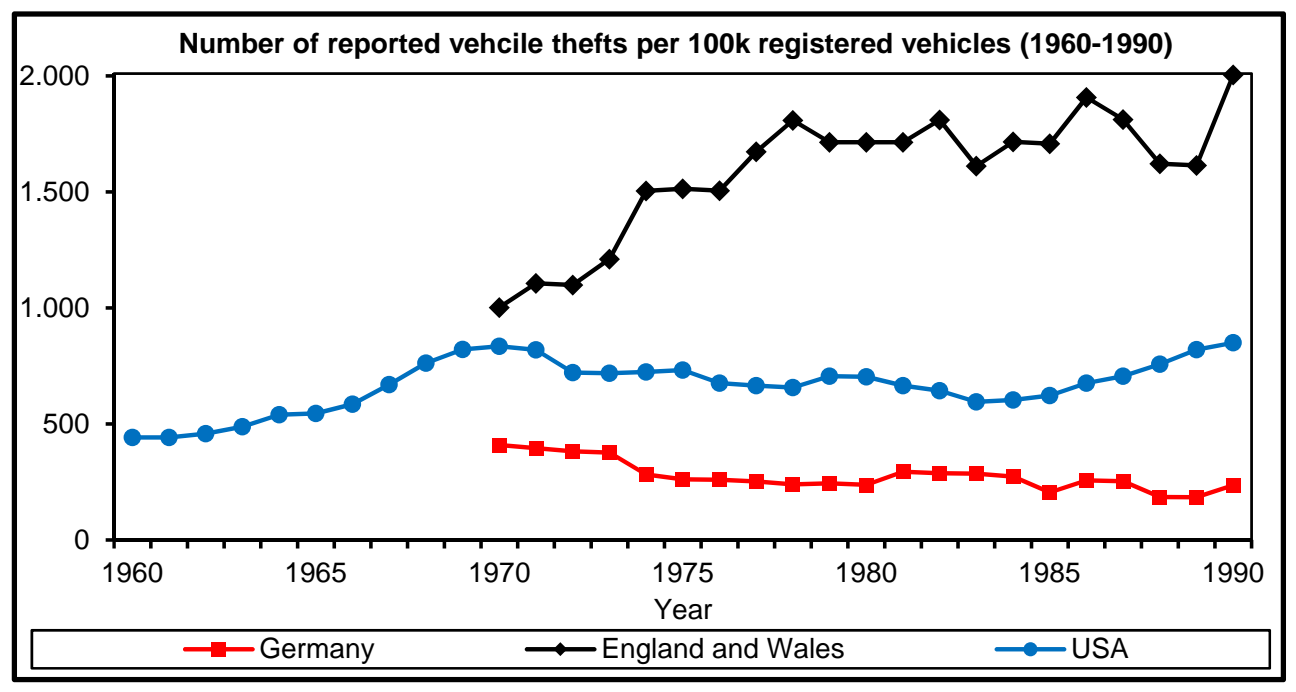

Figure 2.11.: Number of reported vehicle thefts per 100,000 registered vehicles (1960-1990)

equipped with such locks, the earlier introduction and wider scope of such locks partly helped to keep vehicle theft under control in Germany, in contrast to England and Wales. In the USA, all car makers started to equip their cars with steering column locks in 1969 [15].

So, the introduction of steering column locks had different beneficial effects in Germany, the USA as well as England and Wales. In Germany, there was evidence of significant displacement of car thefts by motorcycle thefts. That means, opportunistic thieves switched from cars to motorcycles since steering column locks on motorcycles were easier to break [17]. In 1980, the proportion of motorcycle thefts accounted for $70 \%$ of all vehicle thefts in Germany whereas in the USA and England and Wales the proportions were below 11\% [11]. In England and Wales, thefts for temporary use and joyriding were mainly responsible for the high increase of vehicle theft. Joyriding was mainly committed by young males in hot spot areas, i.e., areas with high crime rates. In the USA, Clarke and Harris [18] suggested a similar development as in England and Wales though the evidence was not as strong in the USA. The vehicle ownership rates has been higher in the USA than in England and Wales, with young people especially having more legal access to vehicles and thus less need or motivation to commit theft for temporary use and joyriding.

High vehicle theft rates in the 1980s and early 1990s prompted governments and car manufacturers to counteract. In the USA for example, the Congress adopted the Motor Vehicle Theft Law Enforcement Act of 1984 [19] which aimed to improve the identification of passenger cars and introduced penalties for removing or altering the identification number. Furthermore, the import and export of stolen vehicles has been more severely punished. This act was extended by the Anti Car Theft Act of 1992 [20] where penalties were further strengthened, potentially resulting even in life imprisonment or death. In 1992, the Thatcham Research Centre [158] es- 

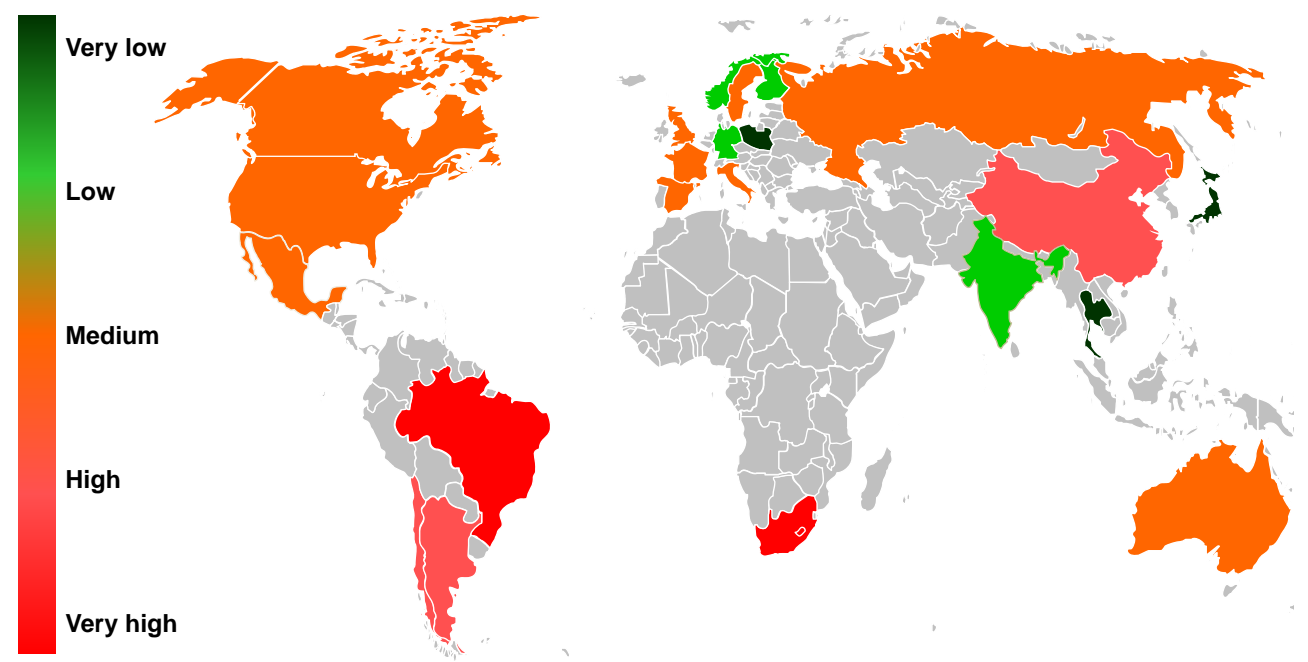

Figure 2.12.: Map of available vehicle theft rates (thefts per registered vehicle) [16]

tablished a working group whose main goal was to tackle vehicle security. The group assesses almost all new vehicles destined for the UK market and security equipment from the perspective of vehicle theft. Based on these results a ranking is established. Additionally, the British government introduced a car-theft index to rank car models by their vulnerability to theft [21]. Both Thatcham and the government's ranking aimed to show vehicles' risk for theft in order to elevate vehicle theft security to a marketing tool, and thus put pressure on car manufacturers to improve vehicle theft security. In October 1998, European Union legislation making the installation of electronic immobilizers mandatory for new vehicles became effective [22]. However, most vehicle manufacturers started to equip their vehicles with immobilizers as standard equipment since 1995 .

Although manufacturers have introduced further countermeasure besides electronic immobilization, such as improved door locks, more sophisticated locking systems that are more difficult to circumvent and visible VINs, the steady decrease in vehicle thefts from the 1990s in Germany, the USA as well as England and Wales is mainly ascribed to the introduction and continuous improvement of electronic immobilizers [12, 23, 24]. Occasional thefts in particular have been made difficult. Nevertheless, vehicle theft is not completely eliminated. The remaining thefts are mainly committed by highly professional and organized gangs using sophisticated techniques or even violence to circumvent security measures. Thus, the steady decrease of vehicle theft in industrialized countries since the early 1990s has been mainly achieved by the reduction of occasional thefts for temporary use and joyriding. The rate of permanent loss did not change over the period [25]. The theft to gain financial benefits has steadily become professional and organized. Figure 2.12 shows the latest qualitative theft rates for several countries over the globe based on the data from [16]. 


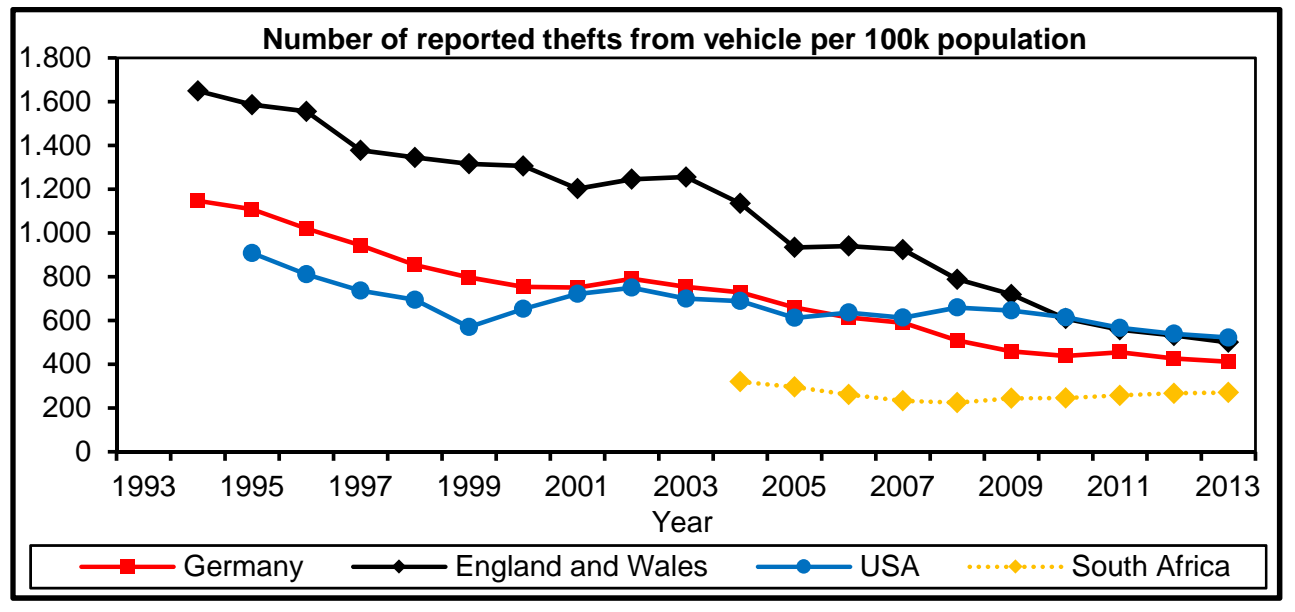

Figure 2.13.: Number of reported thefts from vehicle per 100,000 population

\subsubsection{Theft from vehicle}

Theft from vehicle rates are shown in Figure 2.13 and Figure 2.14. As can be seen from both figures, no data is presented for Mexico and India since officially published data does not cover theft from vehicle in these countries.

Considering South Africa, data does not reach as far into the past as for Germany, the USA and England and Wales. Nevertheless, we can see that theft from vehicle has started to move sideways since 2009 after a decline in the previous years. We think that similar to vehicle theft, the introduction of increased measures to fight crime in general in preparation for the football world cup in 2010 contributed to this decline.

As can be seen from Figure 2.14 and Figure 2.15, England and Wales stand out with a high theft rate, reaching its highest values around 1990. Germany followed this trend especially in the 1970s and in the early 1980s though the rate did not reach that of England and Wales. In the USA the theft rate has moved mostly sideways except during two peaks in 1976 and 1995.

According to Mayhew et al. [26], the increasing rate at which victims reported crime contributed partly to the increasing theft rate. The reporting rate increased by nearly $10 \%$ from 1981 to 1987. Furthermore, Webb and Laycock [11] state that the attractiveness of in-car entertainment systems increased in the beginning of the 1980s since most manufacturers started to equip their cars with radios with cassette player as a standard feature. Hence, in-car entertainment spread to lower-end cars and led to increased availability. Theft of vehicle accessories and parts increased in England and Wales by 143\% whereas other theft increased by "only" $43 \%$ in the time frame, 1980 to 1990 . The data may also suggest a displacement from vehicle theft to theft from vehicle, not only in England and Wales, but in Germany too. 


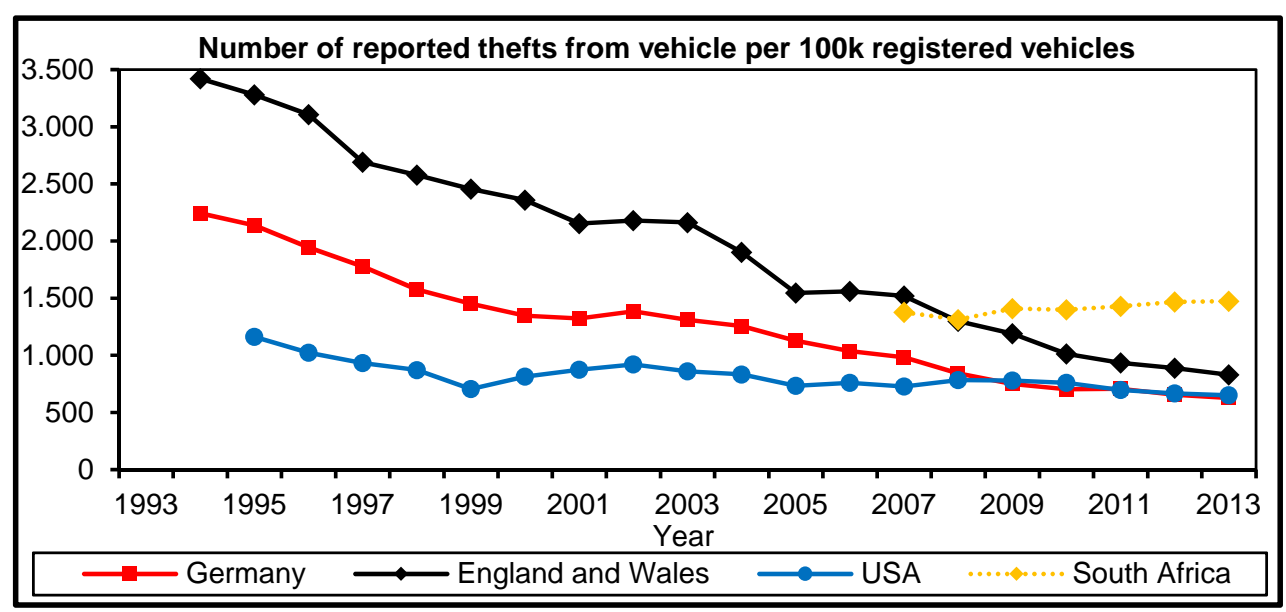

Figure 2.14.: Number of reported thefts from vehicle per 100,000 registered vehicles

Around 1990 both vehicle theft and theft from vehicle reached record high rates. Governments and car manufacturers thus considered theft from vehicle within their remit as well. Both the Motor Vehicle Theft Law Enforcement Act of 1984 [19] and the Anti Car Theft Act of 1992 [20] considered enhanced penalties. Additionally, awareness of theft from vehicles was increased so that people locked their vehicles, closed windows and kept valuables out of sight in vehicles. Furthermore, manufacturers steadily introduced security measures and thus contributed to the decline. Examples include improved locks with sophisticated locking systems as well as shatter-proof windows, complicating entry into vehicles. Moreover, the introduction of removable audio devices as well as etching the VIN in vehicle parts played an important role. Nowadays, software protection of in-car entertainment systems and more sophisticated component protection fights theft from vehicles.

\subsubsection{Vehicle vandalism}

As can be seen from Figure 2.16 and Figure 2.17, we are only able to provide data representing vehicle vandalism for Germany and England and Wales. In Germany, the increasing absolute incidences of vehicle vandalism have gone hand in hand with the steady increase of vehicles and so the rate has stayed nearly constant since 1994. In contrast, in England and Wales vehicle vandalism mostly correlates with overall vandalism. Both steadily increased in the beginning of this century but then noticeably started to decrease in 2007. We think that similar reasons are responsible for the decrease in both cases. However, according to Wheeler [159], criminologists have no clear reason for the decline in England and Wales. Nevertheless, he suggests the following possible reasons for the reduction in overall vandalism, and thus, vehicle vandalism. 


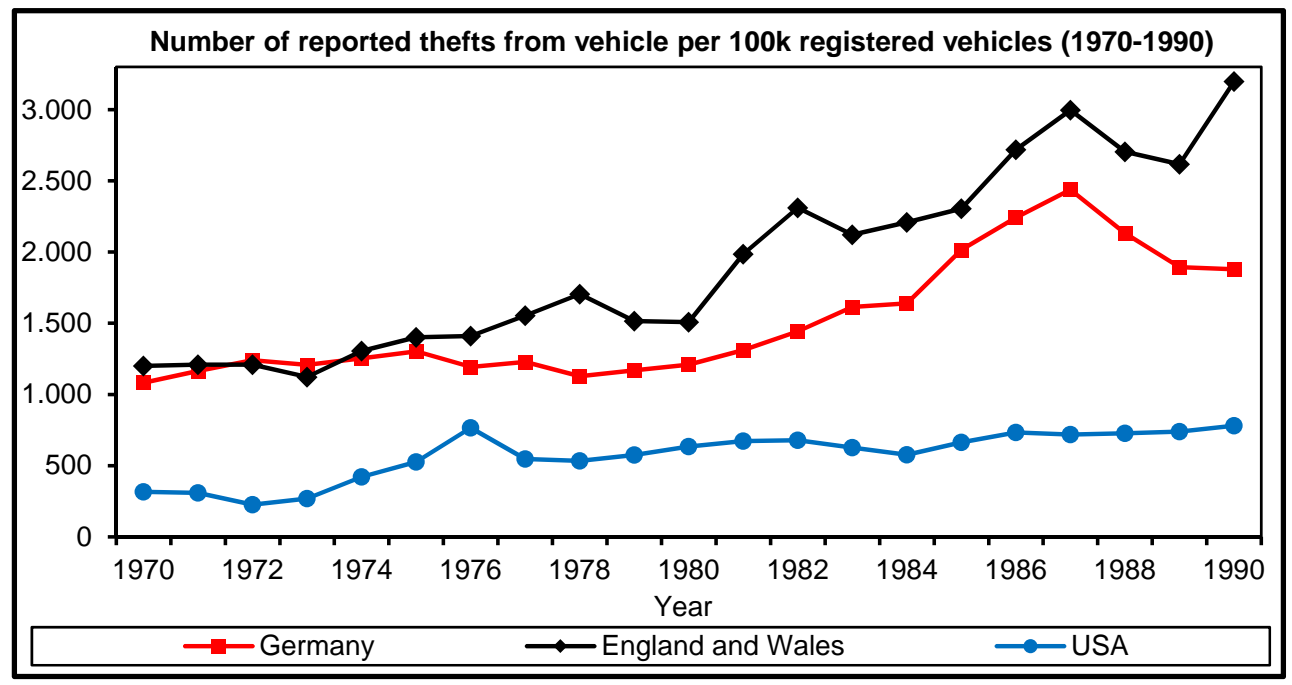

Figure 2.15.: Number of reported thefts from vehicle per 100,000 registered vehicles (1970-1990)

- People gave up hope that vandalism ever gets under control and decreases. Consequently, they have continuously stopped reporting incidents.

- Potentially endangered property has been reconstructed to reduce provocation and better materials have been used to deter vandals.

- Considering the broken-windows theory [27], damages have been steadily removed quicker to reduce provocation as well as imitation.

- Social workers state that violence and drug taking has increased so there has been a displacement towards these incidents.

- Greater awareness of CCTV surveillance has partly contributed to increased fear of being detected.

- Around the same time as when vandalism started to decrease smartphone sales increased greatly. Hence, there is evidence to suggest that spending time on the internet and socializing via smartphone provides an activity to youths. Furthermore, youths have the opportunity to express themselves in social networks rather than by damaging property.

- The consumption of alcohol among young people has noticeably diminished.

It is difficult to provide an exact figure of vehicle vandalism since, as stated by Mayhew et al. [28], reporting has underlined significant variances in England and Wales. Additionally, 


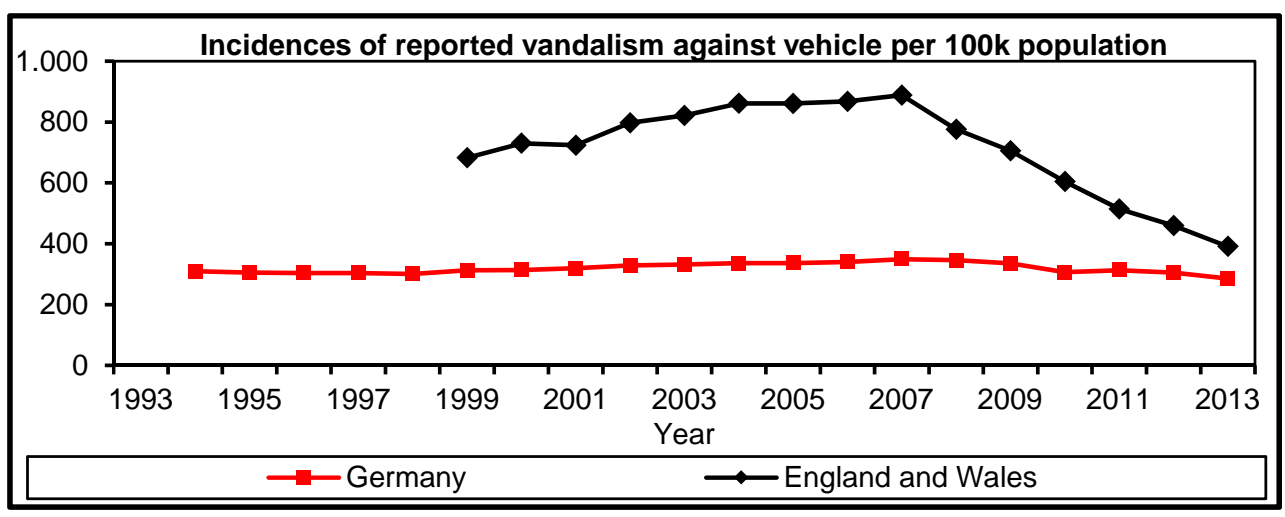

Figure 2.16.: Incidences of reported vandalism against vehicle per 100,000 population

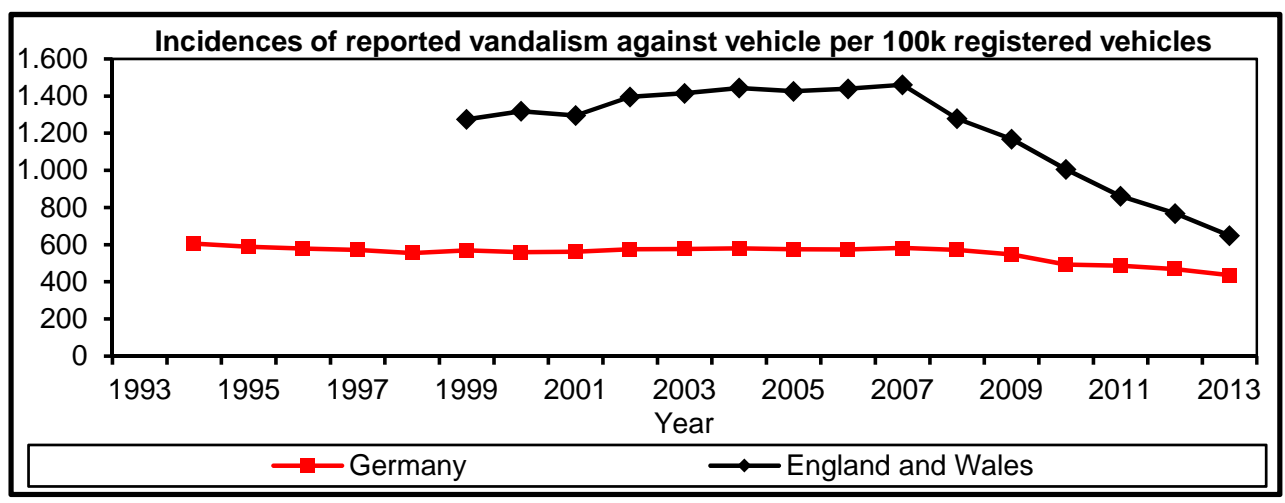

Figure 2.17.: Incidences of reported vandalism against vehicle per 100,000 registered vehicles

reporting rates were lower compared to other vehicle-related crimes, such as theft from vehicle or even vehicle theft. This leads to falsified statistics and a high dark figure of vehicle vandalism.

\subsubsection{Carjacking}

Figure 2.18 and Figure 2.19 show the number of carjackings per 100,000 population and registered vehicles, respectively. We are not able to provide statistical data for India. Furthemore, data for carjackings in the USA were to the best of our effort not available either. The US state of New Jersey however provides detailed data for carjackings [160]. Hence, we made use of this data to represent carjacking in the USA. 


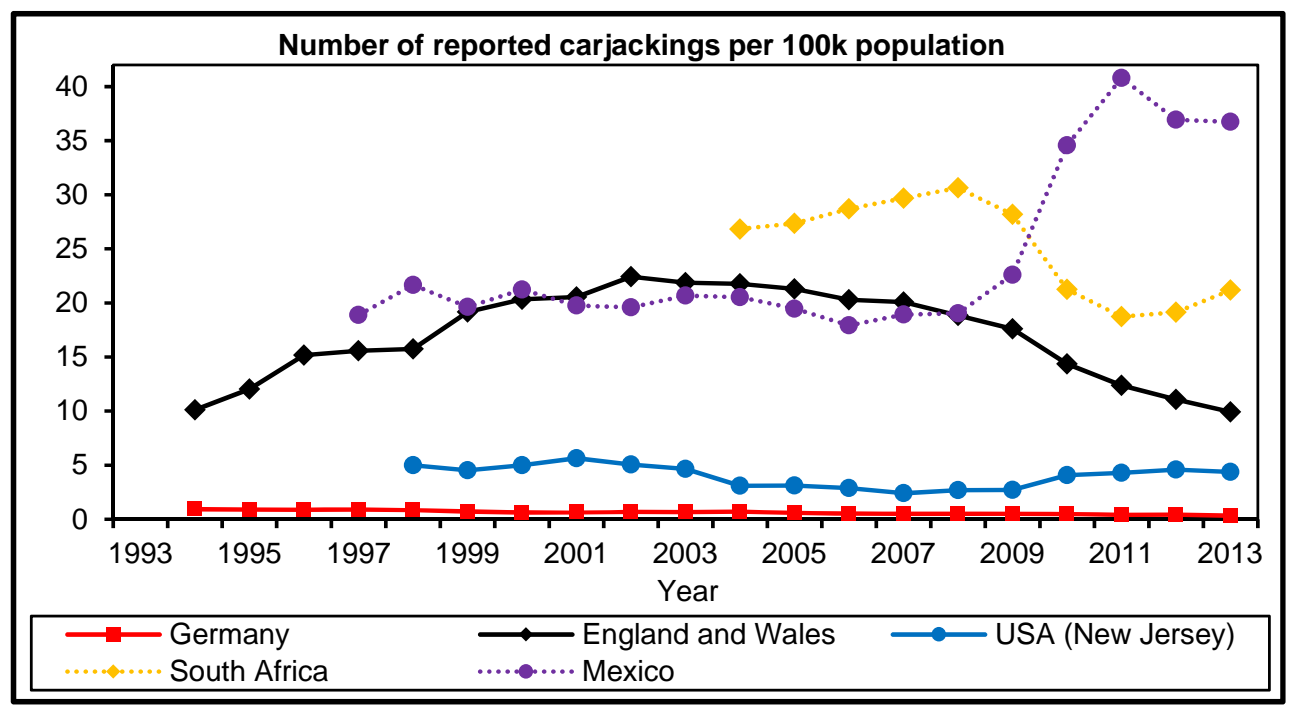

Figure 2.18.: Number of reported carjackings per 100,000 population

As can be seen from both figures, carjacking is extremely rare in Germany and remained constant within the regarded time period. It plays an insignificant role in Germany. In New Jersey (USA), carjacking is not really relevant either. Therefore, we assume that carjacking generally plays a minor role in the wider USA. In England and Wales, the number of carjackings has significantly decreased again after a peak in 2002. Professional gangs, which are meanwhile responsible for a large proportion of vehicle thefts in industrialized countries, seek to avoid meeting the vehicle owner and act under the cover of darkness [29].

In contrast to both aforementioned industrialized countries, carjacking is a daily occurrence in Mexico and South Africa. However, both emerging countries show different developments. In South Africa, carjacking has decreased in the last five years whereas in Mexico carjacking has increased noticeably in the last five years. We think that the decrease in carjackings in South Africa correlates with the overall decrease in vehicle thefts. Due to the introduction of new countermeasures, occasional vehicle theft, which is more likely to end up in carjacking than professional theft, has decreased. Professionals are less dependent on the use of violence since they posses sophisticated methods. Considering Mexico, we found evidence in Section 2.2.2 that the overall use of violence has increased in the last years. We think that this increase comes along with the increasing number of carjackings, which increased despite a steady decrease in vehicle thefts in recent years. 


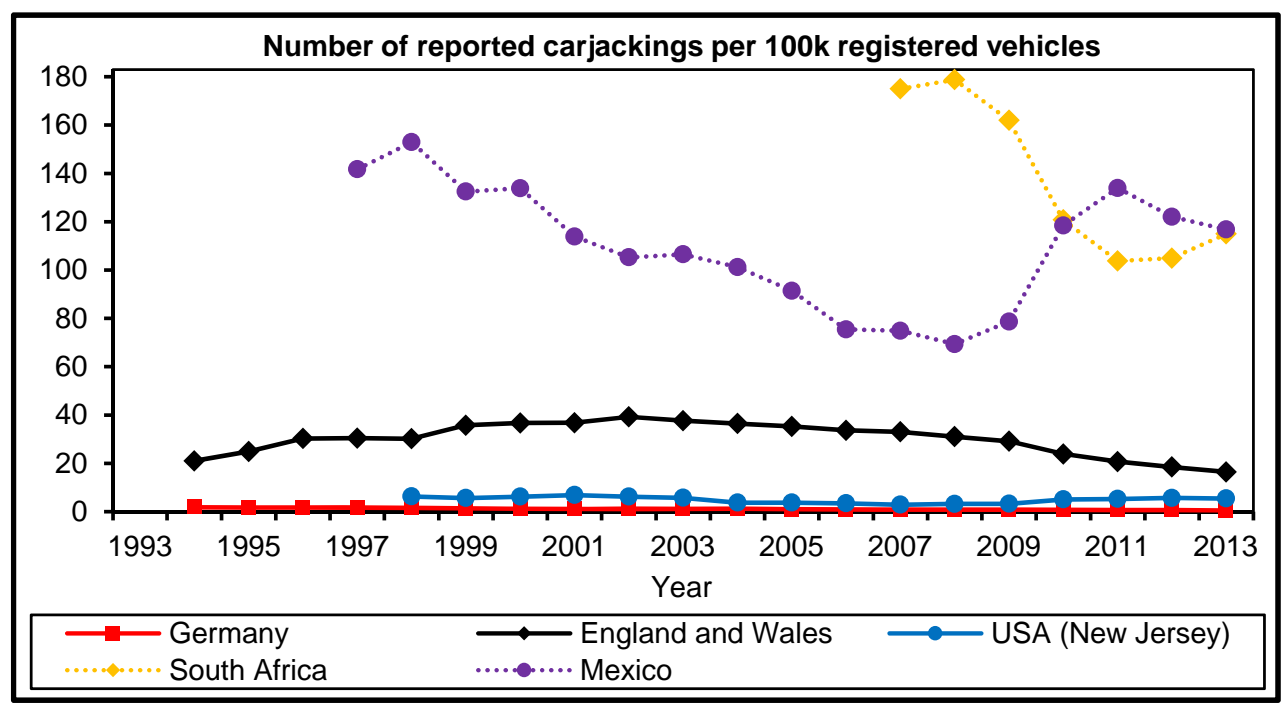

Figure 2.19.: Number of reported carjackings per 100,000 registered vehicles

\subsubsection{Conclusion}

Due to different gathering methodologies in countries, directly comparing data across countries has to be treated with caution. Nonetheless, we identified interesting crime developments and trends. Vehicle theft has steadily decreased since the 1990s in industrialized countries due to several countermeasures. However, a bottom line seems to have been reached. Occasional vehicle theft has largely decreased but professional vehicle theft committed by organized gangs is still present. Theft from vehicle has seen a similar trend. Theft has noticeably declined but the nature of theft has changed as well. Theft from vehicle and especially vehicle theft have become professional and organized whereas improvements in security measures have deterred less-skilled and occasional thieves. Security functions should therefore mainly aim to deter organized theft.

In emerging countries, vehicle theft rates developed in different ways, partly due to different growth rates of population and registered vehicles. However, theft rates are not significantly higher in emerging countries than in industrialized countries. Only South Africa shows slightly higher theft rates. Furthermore, the use of violence seems to be at a higher level than in industrialized countries. This increased propensity to violence is partly evident in the high rates of carjackings in emerging countries compared to industrialized countries. Security functions should therefore seek to protect driver and occupants from violence, especially when targeted at emerging countries.

Although vehicle-related crime has developed similarly across industrialized countries and also in part across emerging countries, each country provides specific demands for security 
functions due to different social, economical, political and cultural influences. Researching the effect of security functions on crime thus demands separate analysis for each country.

\subsection{Victimization survey analysis}

In this section, we provide core findings from existing victimization surveys, focusing on findings covering (fear of) vehicle-related crime. Hence, this section forms a counterpart to the previous section where we conducted our statistical analysis. We first introduce the victimization surveys before showing core findings and discussing conclusions.

\subsubsection{Method}

To estimate core findings considering (fear of) vehicle-related crime, we draw on the results of three victimization surveys shown in Table 2.4. In the following, we briefly introduce theses victimization surveys.

\section{Crime Survey for England and Wales}

The Crime Survey for England and Wales (CSEW) [30], known as the British Crime Survey (BCS) until 2012, is a victimization survey conducted for the UK's national statistical institute, the Office for National Statistics [161]. The CSEW primarily focuses on victimization for respondents resident in England and Wales. Respondents answer questions in a face-to-face interview about their experiences of crime in the last 12 months. Questions cover a wide range of crime, from property to personal crime. The CSEW aims to gather a middle five-digit number of interviews per year with persons aged over 16.

Amongst a wide range of different crimes, the CSEW also considers vehicle theft, theft from vehicle and vehicle vandalism. To gain deeper understanding of offenses, detailed data is gathered covering the following properties.

- Timing, place and method of offense

- Returning/clearance rate

- Costs of incident

- Emotional impact

- Perceived seriousness

- Offender characteristics

We will present selected results regarding vehicle-related crime based on the CSEW data from $2003 / 04$ to $2012 / 13$. In some cases, percentages do not add to 100 percent since respondents 
Table 2.4.: Overview of victimization surveys

\begin{tabular}{|c|c|c|c|}
\hline & $\begin{array}{l}\text { Crime Survey for } \\
\text { England and Wales } \\
\text { (CSEW) }\end{array}$ & $\begin{array}{lr}\text { International } & \text { Crime } \\
\text { Victims } & \text { Survey } \\
\text { (ICVS) } & \\
\end{array}$ & $\begin{array}{l}\text { National Crime Vic- } \\
\text { timization Survey } \\
\text { (NCVS) }\end{array}$ \\
\hline $\begin{array}{l}\text { Considered } \\
\text { VRCs }\end{array}$ & $\begin{array}{l}\text { Vehicle theft, theft } \\
\text { from vehicle, vehicle } \\
\text { vandalism }\end{array}$ & $\begin{array}{l}\text { Vehicle theft, theft } \\
\text { from vehicle }\end{array}$ & Vehicle theft \\
\hline $\begin{array}{l}\text { Considers } \\
\text { fear of crime }\end{array}$ & $\begin{array}{l}\text { Perceived seriousness, } \\
\text { emotional impact }\end{array}$ & None & None \\
\hline Pros & $\begin{array}{l}\text { Detailed data for tim- } \\
\text { ing, place, method, } \\
\text { returning/clearance } \\
\text { rate, costs, offender } \\
\text { characteristics, etc. }\end{array}$ & $\begin{array}{l}\text { Aims to compare dif- } \\
\text { ferent countries }\end{array}$ & $\begin{array}{l}\text { Detailed data for time, } \\
\text { gender, age, income, } \\
\text { marital status, persons } \\
\text { in household, locality } \\
\text { of residence, educa- } \\
\text { tional status, ethnicity, } \\
\text { race, annoyance, rea- } \\
\text { sons for (not) report- } \\
\text { ing, etc. }\end{array}$ \\
\hline Cons & $\begin{array}{l}\text { Limited to England } \\
\text { and Wales }\end{array}$ & $\begin{array}{l}\text { Not yearly, last sub- } \\
\text { stantial survey for } \\
2004 \text {, limited to ve- } \\
\text { hicle theft and theft } \\
\text { rate }\end{array}$ & $\begin{array}{l}\text { Limited to USA and to } \\
\text { vehicle theft }\end{array}$ \\
\hline
\end{tabular}

had the opportunity to provide more than one response. The interested reader can find further information and data in [161].

\section{International Crime Victims Survey}

In 1989, the International Crime Victims Survey (ICVS) [162] was firstly conducted in the then 15 member states of the European Union as well as Poland, Hungary and Estonia. In later publications of the ICVS, further developed and developing countries were included. The ICVS aims to monitor and study crime, perception of crime and opinions on the criminal justice system. The main goal of the ICVS is to provide comparable data across different countries. Until now, the ICVS was conducted five times in the past, in 1989, 1992, 1996, 2000, and 2005 where the number of participating countries increased and partly changed.

The ICVS covers a wide spectrum of crimes including data for vehicle (cars, vans and trucks) theft and theft from vehicles. Vehicle vandalism was dropped from the ICVS in 2004. Additionally, the ICVS considers fear of crime, though unfortunately only fear of burglary and feelings of security on the streets are tackled. We summarize the results and findings in the ICVS 2004, 
covering vehicle theft and theft from vehicle and considering the results from earlier findings as well.

\section{National Crime Victimization Survey}

The US Census Bureau [163] conducts the National Crime Victimization Survey (NCVS) on behalf of the Bureau of Justice Statistics (BJS) [164]. The NCVS collects data from a five-digit number of households to measure the frequency of victimization and characteristics of victimization. Violent crimes, i.e., sexual assault, robbery, aggravated assault and simple assault, as well as property crimes, i.e., household burglary, motor vehicle theft and theft are considered. Theft from vehicle is considered only within theft, with vehicle vandalism not considered at all. Furthermore, the NCVS mainly focuses on the analysis of victimization rates by demographics and so victimization rates are dependent not only on typical demographics such as gender and age but also income, marital status, persons in household, locality of residence, educational status, ethnicity and race. Unfortunately, fear of crime is not considered in the NCVS.

We show selected findings regarding vehicle theft based on NCVS data since 2000. Due to methodological changes in 2006, comparing data from 2006 with data from previous and subsequent years has to be done with caution.

\subsubsection{Results}

\subsubsection{Crime Survey for England and Wales}

\section{Vehicle theft}

During the last ten years, approximately two-thirds of vehicles are stolen during the week, i.e., from Monday $6 a \mathrm{~m}$ to Friday $6 \mathrm{pm}$, and one-third during the weekend. This trend has been nearly constant for the last ten years.

Three out of four vehicles are stolen during the evening (6pm to midnight) or night (midnight to $6 \mathrm{am}$ ). Half of these vehicles are stolen during the night and the rest during evening or at an uncertain time. Only one in four vehicles is stolen during the day.

The location of vehicle theft is also gathered, with respondents distinguishing between home, work or elsewhere. Home is further divided into private, semi-private and street where semiprivate includes parking areas on the premises and garages or car parks around but not connected to the home. Work is separated into on-street parking and car park parking. Public places are also put into categories, such as the street, car parks, shopping centers, universities etc. Figure 2.20 shows the development and distribution of the locations where vehicles are stolen. As can be seen, vehicles are mostly stolen when parked at home. However, there is an increasing trend away from public places towards semi-private and even private places. 


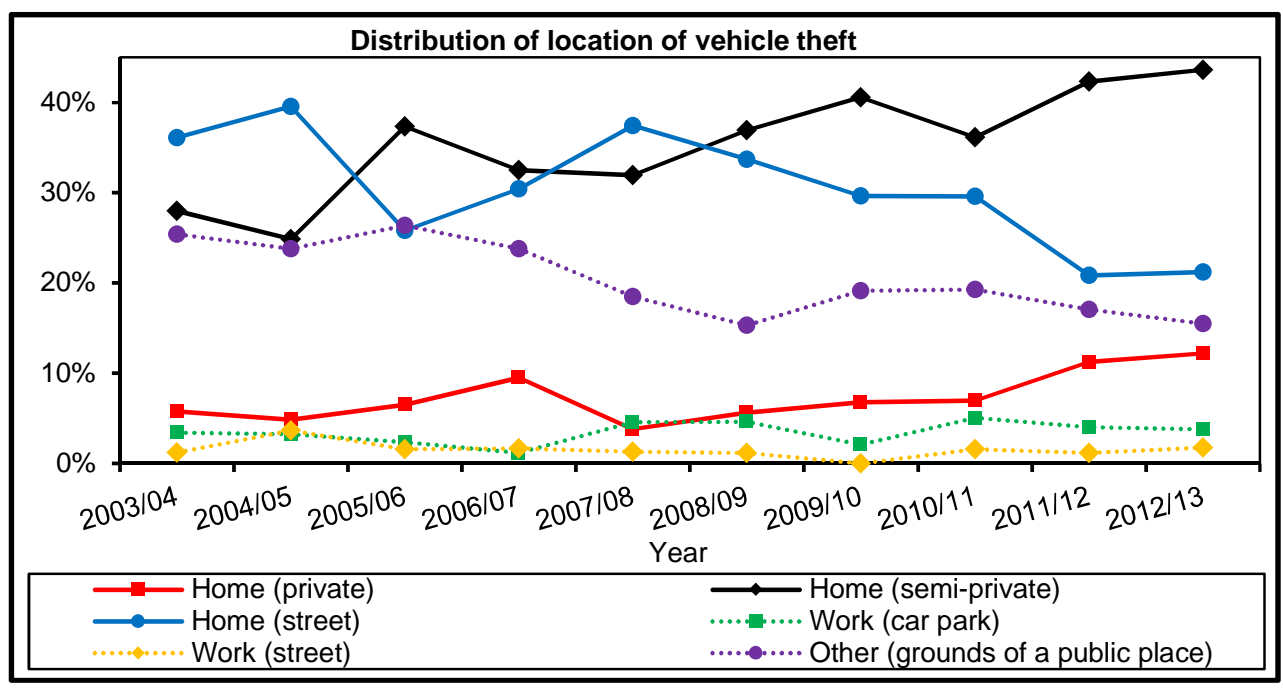

Figure 2.20.: Development and distribution of locations of vehicle theft

Considering the method offenders entered into vehicles, forcing the lock or breaking the window constantly decreased from $78 \%$ in $2002 / 03$ to $35 \%$ in $2012 / 13$. In contrast, the use of a key increased from $10 \%$ in $2002 / 03$ to $41 \%$ in $2012 / 13$. In $10 \%$ of vehicle thefts, the door was not locked.

Considering the age of stolen vehicles, the distribution has trended towards newer vehicles. In 2002/03 two-thirds of stolen vehicles were more than five-years old. In 2012/13, only half of stolen vehicles were older than five years.

The emotional impact of vehicle theft on respondents is also studied. Several emotional factors are considered. Annoyance about the theft has varied over the last decade at around $70 \%$. The anger about the theft has varied as well and increased from $50 \%$ to $60 \%$. One-third of respondents were shocked. Other impacts such as difficulty of sleeping, fear, depression, anxiety or panic attacks are reported over recent years as less than $10 \%$, and thus, play a minor role. However, fear of vehicle theft continuously increased over the last decade from $3 \%$ to $10 \%$.

\section{Theft from vehicle}

Considering the timing of occurrence, theft from vehicle behaves similarly to vehicle theft. Theft from vehicle is equally distributed during the week (Monday 6am to Friday 6pm) and weekends (Friday $6 \mathrm{pm}$ to Monday 6am). The distribution has remained nearly constant in the last ten years. Approximately two-thirds of thefts from vehicle occurred during the week. Three out of four offenses occur between $6 \mathrm{pm}$ and $6 \mathrm{am}$, with half of these offenses occuring during the night (midnight to 6am), one-quarter during the evening (6pm to midnight) and 


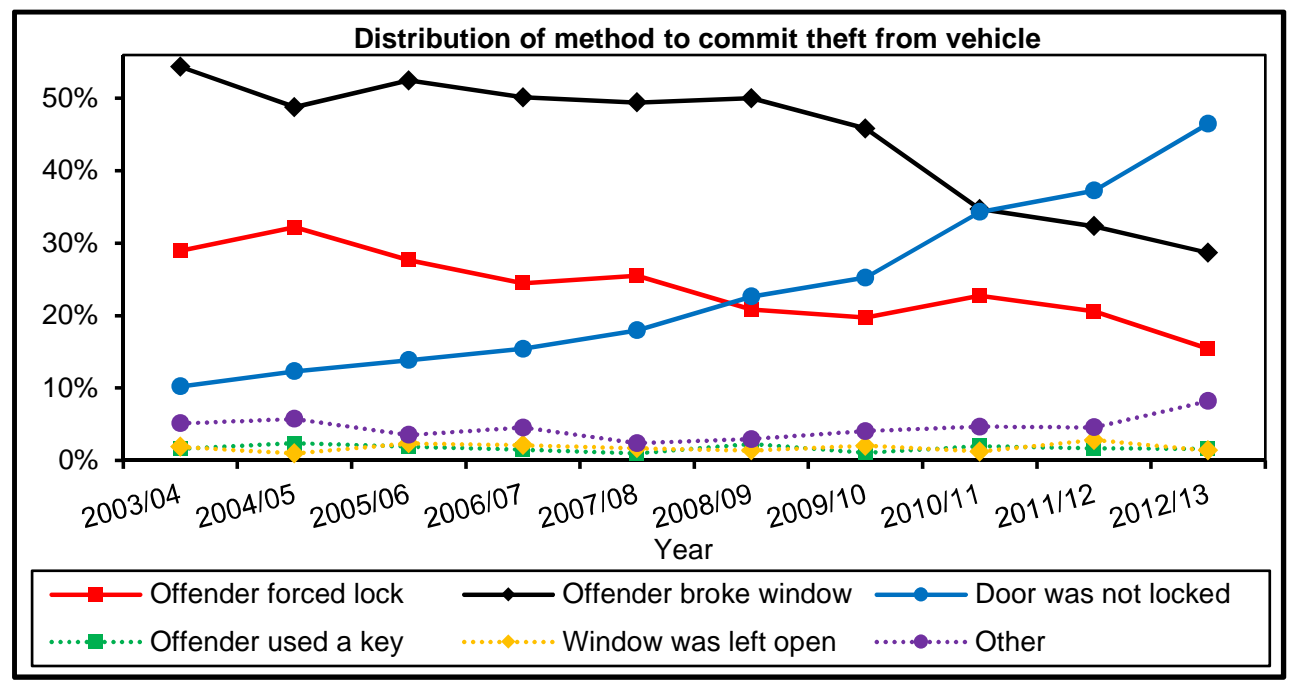

Figure 2.21.: Development and distribution of methods of theft from vehicle

one-quarter either during the night or the evening. Hence, only one-quarter of thefts from vehicle is committed during the day.

The majority of thefts occur when the vehicle is parked at home. Approximately $40 \%$ of thefts occurred on the street during the last decade. Theft from semi-private parking has increased from $22 \%$ to $32 \%$. In contrast, for vehicles parked in public places, thefts decreased from $32 \%$ to $23 \%$.

Considering how offenders gain access into vehicles to steal from the inside, forcing the lock or breaking the window were the main methods in 2002/03, as shown in Figure 2.21. However, both methods have continuously decreased until 2012/13. Conversely, making use of an unlocked door noticeably increased from $10 \%$ up to nearly $50 \%$. An open window or the use of keys have played a minor role over this period

Over the last decade, approximately one-third of all items stolen from vehicles were exterior fittings. Car radios decreased from $20 \%$ by three-quarters to $5 \%$. Conversely, the theft of electrical equipment, such as portable navigation systems, televisions, DVD players and MP3 players, increased from $3 \%$ to $16 \%$. Theft of valuables, such as jewelry, handbags, wallets, money, credit cards, clothes and documents, remained at the same level of approximately $20 \%$. Other items, for example glasses, wheels, fuel, house keys and food, played a minor role.

The emotional impact of theft from vehicle is equally dominated by annoyance and anger over the entire decade, whereas anger decreased slightly to $43 \%$ and annoyance increased slightly to $59 \%$. Approximately $15 \%$ were shocked about the theft from their vehicle. Other emotional 
impacts, such as fear, depression, panic attacks or difficulty of sleeping play a minor role and were reported by less than $3 \%$ of respondents.

\section{Vehicle vandalism}

The occurrence of vehicle vandalism behaves similarly to vehicle theft and theft from vehicle when considering the timing. Two-thirds of offenses occurred during the week and the rest during the weekend. Three-quarters of offenses were committed during the evening or night, whereas only one-quarter were committed during the day.

Vehicle vandalism remained nearly constant for all places over the last decade. More than $50 \%$ of offenses involved vehicles parked at home on a public street. Vehicles parked on semiprivate parking even slightly decreased by $3 \%$ to $18 \%$. Vehicles parked at work are largely unaffected by vandalism regardless of whether they are parked on the street or in a car park. Parking in public places contributes with at least 10\% from 2002/01 to 2012/13.

The distribution behaves largely equally across all types of damage for the entire period. Scratches to the bodywork are with approximately $40 \%$ the most commonly occurring damage to vehicles. Damage to side mirrors and bodywork follow in second place, each with approximately $20 \%$. Broken windows and damaged tires contribute alltogether to approximately $15 \%$. Other damage to vehicles, such as damaging door locks or arson, are negligible.

As with vehicle theft and theft from vehicle, the emotional impact is dominated by annoyance and anger, with both at $60 \%$ during the entire period. The next most common emotional impact is shock, with a constant rate of $15 \%$. Fear, difficulty sleeping, depression and panic attacks do not occur in more than $5 \%$ of cases.

Only $40 \%$ of all vehicle vandalism is committed by strangers. People the victim recognizes or knows well are responsible for the rest of vehicle vandalism.

\subsubsection{International Crime Victims Survey}

\section{Vehicle theft}

Van Dijk et al. [25] provide in their report the key findings from the ICVS 2005 involving results from earlier ICVS waves. Figure 2.22 shows the victimization rate of vehicle theft based on population. The results are shown for all waves of the ICVS when data was available. Overall, the victimization rate generally decreased compared to the first ICVS. Only in the Netherlands there was an increase in the victimization rate of vehicle theft.

\section{Theft from vehicle}

The key findings for theft from vehicle show a decrease in theft from vehicles in almost all countries. The according population-based victimization rates are shown in Figure 2.23. Only Portugal and Denmark show increased victimization rates. In contrast, the decrease is notice- 
able especially in France, Italy and the United Kingdom. Nevertheless, the UK still has a high victimization rate; only Estonia's is higher.

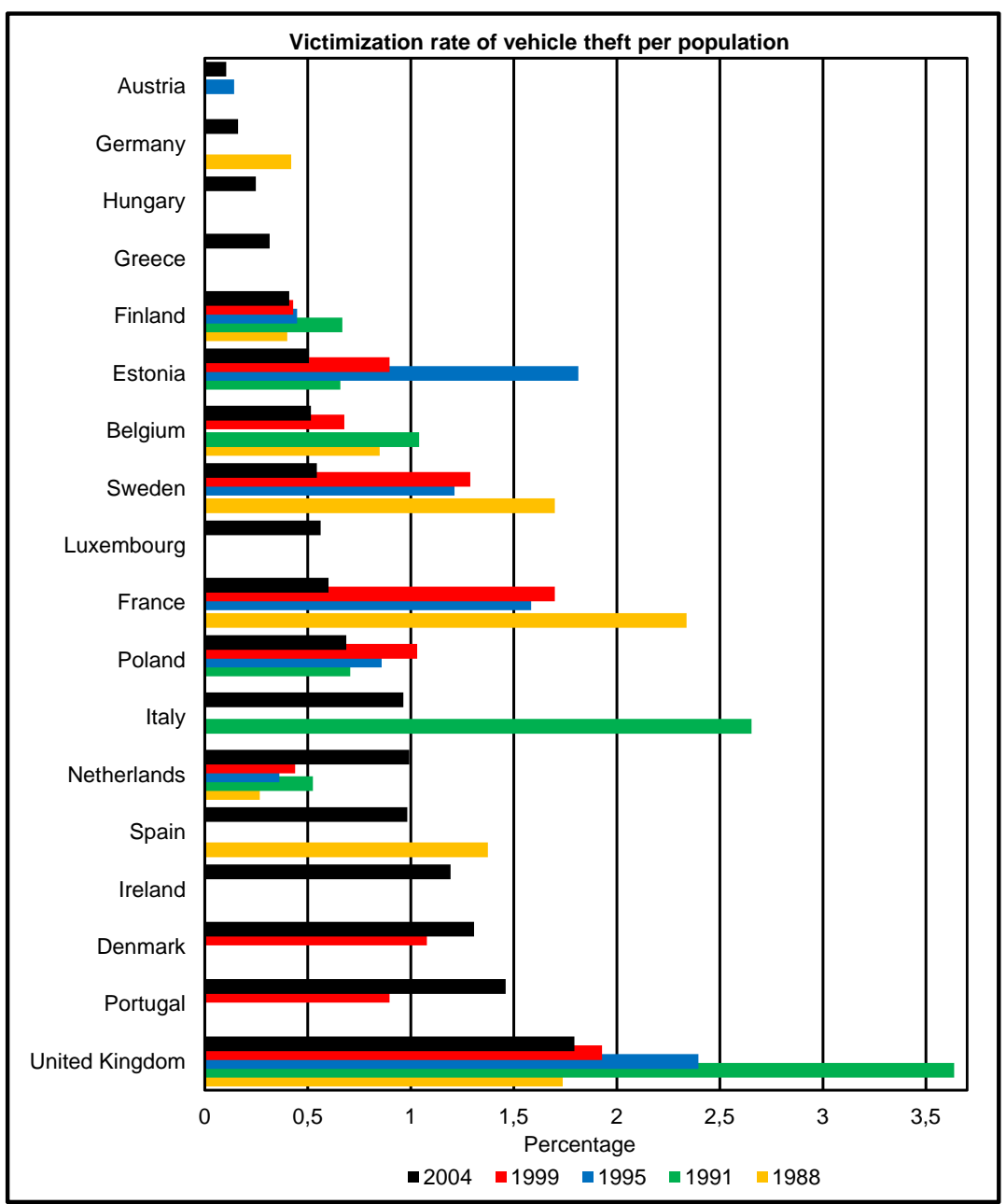

Figure 2.22.: Population-based victimization rate for vehicle theft in 2004 and earlier [25] 


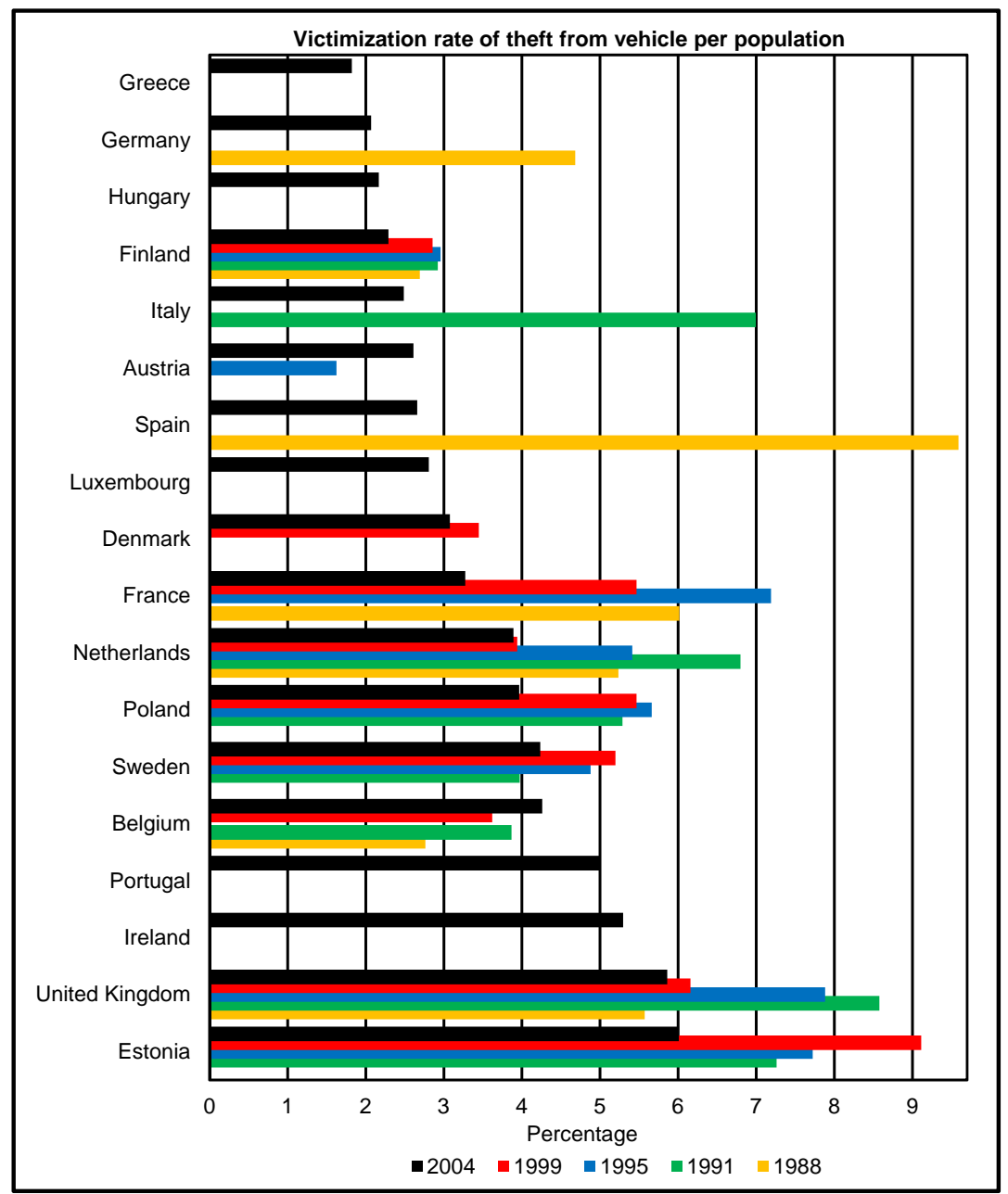

Figure 2.23.: Population-based victimization rate for theft from vehicle in 2004 and earlier [25] 


\subsubsection{National Crime Victimization Survey}

On vehicle-related crime, the NCVS is limited to motor vehicle theft. Figure 2.24 shows the development of the victimization rate of motor vehicle theft per 1000 households. As can be seen, the victimization rate continuously decreased over the last decade down to five offenses per 1000 households. The rate remained constant over the last three years however.

Participants were also asked to rate the time of occurrence. Similar to the BCS, two-thirds of vehicle thefts occurred during the night, with the time frame between midnight and 6am most commonly used to steal a vehicle.

Furthermore, participants rated their loss of time at work due to vehicle theft. Overall, approximately $25 \%$ of participants lost only one day at work. However, the majority of participants, approximately $60 \%$, lost one to five days from work. The rest of the participants lost more than six working days.

The NCVS contains data about the reporting rate of vehicle theft which has oscillated continuously around $80 \%$ in recent years.

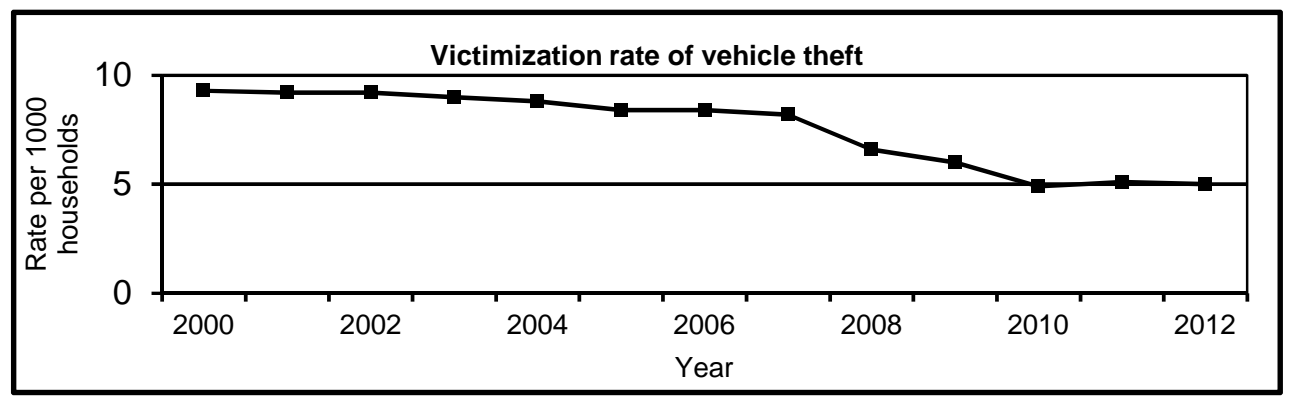

Figure 2.24.: Vehicle theft victimization rate per 1000 households

\subsubsection{Discussion}

Due to different methodologies across our regarded surveys, comparison of data is not possible. Furthermore, the ICVS and NCVS in particular consider vehicle-related crimes and aspects of fear of crime in a limited way. Nonetheless, all three surveys provide interesting findings about vehicle-related crime, which are discussed in the following. 


\subsubsection{Crime Survey for England and Wales}

\section{Vehicle theft}

Vehicles are mostly stolen during the evening and night. Thefts during the day occur less often. This indicates that thieves use the cover of darkness and reduced surveillance to commit their offense. Accordingly, vehicles are equally stolen during the week and weekends.

Vehicles are mostly stolen when parked at home. This seems to be reasonable since most people work during the day and are at home during the evening and at night. However, there is an increasing trend away from public places towards semi-private and even private places. A possible reason is increased CCTV surveillance in public places in England and Wales. (Semi)private parking often lacks CCTV surveillance. Additionally, (semi-)private parking is mainly available in suburban areas where natural surveillance is lower than in urban areas. This limited surveillance allows thieves to stay undetected.

Turning to the methods offenders use to enter vehicles, forcing locks or breaking windows constantly decreased. In contrast, the use of a key constantly increased. We think that electronic immobilizers especially are responsible for this development. In earlier years, after having gained access into the vehicle, hot-wiring was enough to start the vehicle. Nowadays, starting the vehicle is not as easy as before since the offender has to circumvent the electronic immobilizer which demands sophisticated skills. Additionally, electronic immobilizers have become sophisticated with time and so getting in possession of vehicle keys greatly facilitates vehicle theft.

Considering the age of stolen vehicles, the trend is for distribution to shift towards newer vehicles. Thanks to improved measures, occasional vehicle theft has reduced whereas professional theft remained almost at the same level. This explains the shift towards more recent vehicles. Stealing modern vehicles requires more sophisticated knowledge due to better anti-theft measures. Generally, only professional and organized gangs possess sophisticated knowledge. Furthermore, occasional thieves mainly use stolen vehicles temporarily and abandon the vehicle shortly after the theft. In contrast, professional gangs either resell the entire vehicle or strip down the vehicle to resell the parts. In both cases, modern vehicles bring higher profit margins.

The emotional impact associated with vehicle theft has largely reduced, both for annoyance as well as anger about the theft. Fear of vehicle theft slightly increased over the last years which can be explained by the increasingly professional structures linked to vehicle theft. Nevertheless, fear of vehicle theft as well as other impacts such as difficulty in sleeping, depression, anxiety or panic attacks play a minor role. In our opinion, they play a minor role so long as victims do not get directly in contact with the thief.

\section{Theft from vehicle}

Like vehicle theft, theft from vehicle also mainly occurs at night (midnight to 6am) followed by evening ( $6 \mathrm{pm}$ to midnight). Considering the timing of occurrence, thieves obviously make use of the protection of darkness. 
The location where theft from vehicle occurs shifted from public streets towards semi-private parking. We think that the spread of CCTV surveillance in public is partly responsible for the displacement towards vehicles parked at home.

Offenders mainly gain access to vehicles to steal from the inside by forcing the lock or breaking the window. However, both methods have decreased continuously. Conversely, the use of an unlocked door noticeably increased. In our opinion, breaking the window or forcing the lock still remain relevant approaches to get access into the inside of a vehicle. However, due to innovative locking systems, the likelihood of drivers failing to lock their car has increased. For example, in making use of a remote key, vehicle owners often press the locking button on their remote key while walking away from their vehicle without checking whether their vehicle has confirmed the locking procedure. Furthermore, thieves can use signal jammers to disturb the communication between key and vehicle. Consequently, innovative locking opportunities demand further awareness of vehicle owners to avoid unlocked doors.

The theft of car radios decreased significantly. One reason for this decrease is the introduction of electronic component protection and the replacement of standardized car radios by make and model-specific radio (navigation) systems. Conversely, the theft of portable electrical equipment has increased. Theses devices can be sold on by occasional thieves and their theft does not require sophisticated skills. Therefore, the theft of valuables still plays an important role.

The emotional impact of theft from vehicle is equally dominated by annoyance and anger. Fear of theft from vehicle and other emotional impacts, such as depression, panic attacks or difficulty of sleeping play a minor role. We think that these emotional impacts play a similarly minor role as in vehicle theft since victims are rarely in contact with the offender.

\section{Vehicle vandalism}

Temporally, the occurrence of vehicle vandalism behaves similarly to vehicle theft and theft from vehicle, i.e., equally distributed from Monday to Sunday. The majority of offenses are committed during evening and night. Offenders clearly make use of the protection effect of darkness.

In contrast to vehicle theft and theft from vehicle, vehicle vandalism remained nearly constant across all places over the last decade. More than $50 \%$ of offenses are commited to vehicles parked at home on the public street. In our opinion, there has not been a shift towards (semi)private parking since only one-third of vandalism is committed by strangers. That means two-thirds of vehicle vandalism seems to be committed to specific predestined vehicles, e.g., as a revenge or due to envy. Hence, offenders cannot simply move to an area without CCTV surveillance or with less public surveillance since their goal is to damage a specific vehicle. 


\subsubsection{International Crime Victims Survey}

\section{Vehicle theft}

Vehicle theft mostly decreased in the considered countries. According to [31], the decreasing trend in vehicle theft across Europe has been mainly achieved by improved and increasingly widespread measures, such as steering column locks, vehicle alarms and electronic immobilizers. These measures have mainly reduced occasional theft and other non-professional theft. Decreasing recovery rates however indicate that measures introduced are still circumvented by professional gangs making use of sophisticated technologies or even violence.

\section{Theft from vehicle}

Theft from vehicle has decreased in almost all countries. The main reasons for this decrease are improved security measures as well as the use of more precautionary measures, e.g. removable car radios [31]. Van Dijk et al. [25] consider an additional interesting reason. Theft from vehicle is often committed by drug addicts in order to finance their addiction demands. Increased drug control and fighting of drug crime may have led to a diffusion of benefits.

\subsubsection{National Crime Victimization Survey}

\section{Vehicle theft}

The victimization rate decreased continuously over the last decade. However, the rate has remained constant for the last three years. It seems that a bottom line has been reached. Meanwhile, occasional thieves are generally unable to circumvent actual measures, and thus are not able to easily steal a vehicle. However, organized gangs and professional vehicle thieves are still present, and so existing security measures need to be improved and further developed. Moreover, an extension of existing countermeasures with innovative security measures, such as security functions, can be a promising step to support further decreases in vehicle theft.

The results also support the findings that vehicle thieves act mainly during the night since two-thirds of vehicle thefts occurred at night.

Similar to the BCS, the annoyance and anger about, for instance, losing days from work due to the vehicle theft, are the main emotional indications. Vehicle theft involves annoyance for the majority of victims.

Approximately $20 \%$ of vehicle thefts are not reported. One-quarter did not report the theft since the vehicle had already been recovered. Another quarter of participants either reported private / personal matters or had lack of proof. The remaining half of participants had other reasons for not reporting their vehicle stolen, such as no insurance to cover the loss, finding reporting too inconvenient or time consuming or police inefficiency. Hence, there is clearly a dark figure considering statistical data, which is based on the number of reports. However, the reporting rate has remained nearly constant so that the overall trend of vehicle theft can be interpreted as valid. 


\subsection{Summary}

In the beginning of this chapter, we briefly discussed the benefits as well as drawbacks of police statistics and victimization surveys. Then, we conducted a statistical analysis of (vehiclerelated) crime for several industrialized and emerging countries. It became obvious that there are differences in the quality but also quantity of data availability. Generally speaking, data quality and quantity decreases from industrialized to emerging countries. For example, in Germany data is available without gaps far into the past, not only for vehicle theft but also theft from vehicle, vehicle vandalism and carjacking. German authorities even subdivide theft from vehicle into theft of vehicle parts and theft of valuables from the inside of a vehicle. In contrast, emerging countries such as India or South Africa provide data only for vehicle theft reaching back a few years. We then used core findings from existing victimization surveys to gain further understanding of aspects of vehicle-related crime. Due to different methodologies across these surveys, the comparability of data is limited. Additionally, the ICVS and NCVS consider vehicle-related crimes to only a limited extent, i.e., only vehicle theft and partial theft from vehicle. Fear of vehicle-related crime is not covered at all. Therefore, we will conduct our own victimization survey in Germany, USA and Mexico to extend our understanding and compare results. This victimization survey is presented in the next chapter. 



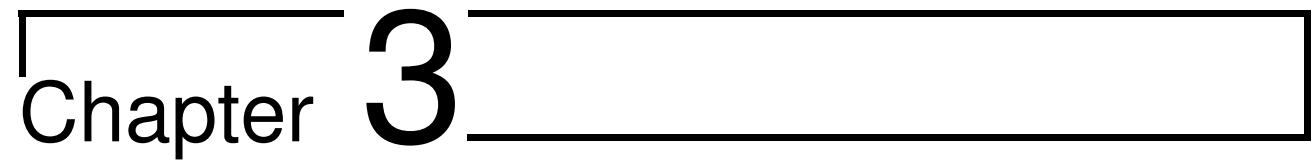

\section{Cross-country survey to research aspects of car-related crime}

In this chapter, we conduct our own victimization survey, focusing on (fear of) vehicle-related crime in Germany, the USA as well as Mexico and investigate deeper aspects of both existing and potential security measures. This is necessary for two reasons. As shown in the previous chapter, existing victimization surveys lack a focus on aspects of vehicle-related crime. These surveys cover a wide spectrum of crimes where vehicle-related crime is one crime among others, and thus does not receive the main focus. Second, due to different survey methodologies comparing data across countries is not possible. We aim to test several hypotheses which can be broken down into two groups. The first group covers aspects of (car-related) crime and fear of (car-related) crime. The second group covers security measures tackling car-related crime with regard to the development of security functions. Each group is further subdivided into topics which are presented including our detailed hypothesis as follows:

- Perceived crime occurrence: Due to the different economical, political and legal conditions in each country, we assume that there are differences across countries in how subjects perceive the occurrence of crime. We additionally aim to find out the relationship of car crime to other property and violent crimes.

H: There are differences across countries in how subjects perceive the occurrence of crime.

- Fear of becoming a victim of car-related crime: We hypothesize that there are differences across countries in the fear of becoming a victim of car-related crime. Furthermore, we assume that gender and age influence fear of car-related crime. Surveying the literature, we found indications that there is a relationship between gender and fear of crime. In Cops' and Pleysier's opinion [32], gender is the most influential demographic factor on fear of crime, with women more fearful than men. This opinion is supported by MirrleesBlack and Allen [33] who also state that women are generally more worried than men about most types of crime. Kury and Obergfell-Fuchs [9] as well as Naplava [34] go even further. They also assume a relationship between gender and fear of crime. But fear is dependent on the type of crime. For example, women are in particular more afraid of robberies and sexual offenses whereas other offenses play a less important role. Women are typically seen as the more fearful gender [35]. Following literature [33], age also plays a role considering the level of fear of crime. Ferraro [36] reviewed several pieces 
of research and summarized that the majority of research assumes older people to be more fearful than the young. According to [34], the association between age and fear of crime is crime specific. The elderly are more afraid of robbery and burglary, with other offenses seeming to be less considerable. In [37], Chivite-Matthews and Maggs state that older persons are less likely to fall victim of a crime. Nevertheless, they have a similar level of fear of crime as younger persons.

H: There are differences across countries in the fear of becoming a victim of car-related crime.

H: Female participants are more worried about becoming a victim of car-related crime than male participants.

H: Older participants are more worried about becoming a victim of car-related crime than young participants.

- Fear of becoming a victim of specific car-related crimes: We assume that the fear of becoming a victim of car-related crime depends on the kind of crime. Therefore, a distinction in specific car-related crimes seems reasonable. We hypothesize that gender and age influence fear of specific car-related crimes. Additionally, according to [38], becoming a victim of a crime increases the fear of this crime. Therefore, we assume that falling victim to a specific car-related crime once influences the subsequent fear of this crime. Furthermore, the possession of insurance is assumed to reduce fear, since property damage or loss is refunded by the insurance company.

H: There are differences across countries in fear of becoming a victim of specific carrelated crimes.

H: Female participants are more worried about becoming a victim of specific carrelated crimes than male participants.

H: Older participants are more worried about becoming a victim of specific car-related crimes than younger participants.

H: Participants that have already been victims of specific car-related crimes are more worried of being victims of these crimes again.

H: Participants insured against specific car-related crimes are less worried about becoming a victim of these crimes.

- Quality of police work: We assume that the estimated quality and the trust in policing influences fear of crime. We hypothesize that differences across countries exist. In particular, we assume that the estimated ability of the police to recover stolen cars differs across countries.

$\mathrm{H}$ : There are differences across countries in the rating of quality of policing with regards to car-related crime. 
H: There are differences across countries in the rating of the ability of police to recover stolen cars.

- Willingness to have car recovered: We assume that the willingness of participants to get a stolen car back differs across countries. Furthermore, we assume that the possession of insurance covering car theft influences the willingness to get back a stolen car since insured participants receive a payout for their stolen car.

H: There are differences across countries in the willingness to get a stolen car back.

H: Participants without insurance are more likely to get their car back after a theft than participants with insurance.

- Demand for security systems: We assume that participants who feel confident of influencing their chances of becoming a victim of crime tend to make use of tooling or other measures to fight car-related crime. In contrast, participants who feel helpless against crime are unlikely to spend money or resources for tooling, measures or special behavior to tackle crime since they have given up and consider themselves helpless. Furthermore, participants already using security systems and/or measures to control their vulnerability to car-related crime are potential candidates for security functions. These persons actively use tooling to control their likelihood of becoming victims, and thus are likely to need security functions. Overall, we assume that there are differences across countries in the demand for security systems.

H: There are differences across countries in individuals' confidence of influencing whether or not they become a victim of car-related crime.

H: There are differences across countries in the use of security systems by individuals to control whether they become a victim of car-related crime.

H: There are differences across countries in the need for further security systems to tackle car-related crime.

- Importance of security systems: We assume that given different crime rates across countries, the relative importance of security measures in a driver's decision to purchase a car varies. In our opinion, if the importance of security systems is marginal compared to other buying criteria, this is an indication that any future introduction of security functions onto the market will need to involve much effort to convince customers of their value.

H: There are differences across countries in the ratings of the importance of security systems.

The remainder of this chapter is organized as follows. In Section 3.1, we describe the methodology of our survey before presenting the results in Section 3.2. In Section 3.3, we discuss the results as well as limitations of our victimization survey. Finally, we summarize the chapter. 
Table 3.1.: Benefits and drawbacks of online surveys

\begin{tabular}{|c|c|}
\hline \multicolumn{2}{|c|}{ Online surveys } \\
\hline Benefits & Drawbacks \\
\hline $\begin{array}{l}\text { - Monetary costs are kept low } \\
\text { - Work and time to examine question- } \\
\text { naires for correctness and consistency } \\
\text { is kept low } \\
\text { - Effort to analyze data is kept low } \\
\text { - Access to participants is facilitated } \\
\text { since survey is brought to partici- } \\
\text { pants, i.e., sharing a link } \\
\text { - Access to participants from different } \\
\text { countries with different languages is } \\
\text { facilitated } \\
\text { - Time constraints due to different time } \\
\text { zones are avoided }\end{array}$ & $\begin{array}{l}\text { - The survey is unsupervised } \\
\text { - No opportunity exists to clarify aris- } \\
\text { ing questions while respondents are } \\
\text { completing the questionnaire } \\
\text { - Unclear questions may go unan- } \\
\text { swered or lead to "wrong" answers, } \\
\text { discouraging participants }\end{array}$ \\
\hline
\end{tabular}

\subsection{Method}

We conducted our victimization survey in Germany, the USA and Mexico. In Germany and the USA, we have two industrialized countries where the automotive industry and vehicles themselves play an important role. However, these two countries bring with them different legislation and mentalities. Since Germany and the USA are both industrialized countries, we decided to include Mexico as an emerging country. This way, we achieve a broad mix and can compare results across countries.

\subsubsection{Setting}

We decided to conduct an online survey instead of a telephone or face-to-face interview. An online survey comes of course with some drawbacks $[39,40]$ though as can be seen in Table 3.1, the benefits of online surveys outweigh the drawbacks when considering our purposes and opportunities. To implement the questionnaire and host the online survey, we used a free software package. 


\subsubsection{Design}

On the first page of our survey, we introduced the purpose of the survey to provide a common understanding. Additionally, the first page included contact information and the time frame necessary to answer the questionnaire. We also pointed out that the survey would be anonymous and that data would be only used for this thesis.

The questionnaire started with questions being related to the participant's car. Since we were not directly able to influence the choice of participants, car-related information provides a better description of our sample. We also needed this information to test and discuss our hypotheses.

Car-related questions were followed by questions dealing with (car-related) crime and fear of crime. These questions aimed to gather data to research aspects of (car-related) crime and fear of (car-related) crime.

We then asked questions referring to security systems aiming to investigate the demand for them. We need information about the importance of security systems compared to other systems. Additionally, the opinion of respondents is of interest to determine whether or not further security measures are necessary to tackle car-related crime.

At the end of our questionnaire, we asked demographic questions. Deeper knowledge about the demographics of our respondents is important for two main reasons. First, we gain deeper understanding about the sample which supports us in discussing the results. Second, we need this information to test our hypotheses. We put these questions intentionally at the end of the survey. Demographic questions in the beginning of a questionnaire may have a deterrent effect on respondents, leading to an increased abandonment rate [41].

We used closed questions throughout the entire survey, with respondents required to select from predefined answers to facilitate evaluation [42]. We mainly used ordinal scales where choices ranged on a five-point Likert scale, e.g., from "not worried at all" to "very worried". We pursued the same response format as much as possible so that respondents were not forced to become familiar with a new response format for every question. This way, we sought to reduce the abandonment rate and the time taken to complete the survey. Furthermore, we excluded reworded questions to check consistency of answers to avoid lengthening the questionnaire and consequently discouraging respondents $[41,43]$.

On the last page, we provided a field for comments. This way, respondents had the opportunity to leave any free-text comment. The entire questionnaire can be found in the appendix in Section B.1.

\subsubsection{Procedure}

When conducting an unsupervised survey, it is neccesary to pre-test the questionnaire to check whether the questions are understandable or not. Further, pre-testing helps to identify missing, 
irrelevant or unclear questions and instructions. Additionally, it is necessary to evaluate the reliability of the instrument which is used to conduct the survey. Thus, after having designed the questionnaire, we asked several colleagues including native speakers for critique. After that, we implemented the online survey and asked other uninvolved native speaking persons to pre-test the online survey to ensure the clarity of our questions and to check whether the online survey works reliably. We also conducted the survey with different web browsers and different computers to identify possible malfunctions.

In considering our survey, we targeted all members living in the according country who owned or regularly drove a car. To gain participants, we fell back on two non-probabilistic sampling methods: convenience and snowball sampling [44]. We recruited participants by directly sending a link to the online survey via email asking them to participate and to forward the link in order to spur the snowball effect. Then, we advertised our survey on the Internet, mainly on social networks and internet forums. Through this, we were able to gain participants for our surveys despite our limited resources. However, this method meant we had no direct control over participants and consequently, no influence on the sample which formed the subset of our population.

\subsubsection{Subjects}

Table 3.2 provides an overview about survey participation and the estimation of our final samples for each country. The first row shows the number of clicks on our link which led the potential participant to the starting page with a brief description about the survey. The second row contains the number of individuals who decided to participate in the survey by navigating to at least the first page of the questionnaire. The third row shows the number of participants who arrived at the last page, thus finishing the questionnaire. We have a nearly equal abandonment rate of approximately $70 \%$ for each country. Due to the nature of an anonymous online survey, we are not able to contact the relevant participants to check their reasons for abandonment. However, we reviewed the pages as well as questions where participants abandoned their participation, concluding that there was no evidence that systematic bias was responsible for the abandonment. Next, we cleaned up the survey by removing incomplete questionnaires. We also checked the content of questionnaires for consistency, looking, for instance, if a respondent repeatedly selected the first answer and spent only short time on each page. Due to this, we had to discard approximately $20 \%$ of questionnaires from Germany and Mexico and $10 \%$ from the USA. Finally, we also removed questionnaires by respondents who did not have or did not regularly drive a car. Our final sample sizes are shown in the last row of Table 3.2. Contrasting the number of individuals visiting the first page of our survey to the number of final questionnaires, we achieved response rates of approximately $30 \%$ for each country.

\subsubsection{Analysis}

We provide descriptive statistics as well as statistical testing of our hypotheses. To test our hypotheses for significance with two samples, we make use of the Mann-Whitney-U-Test (U-Test), 
Table 3.2.: Overview of participation rates and final samples

\begin{tabular}{rccc}
\hline Number of participants who ... & Germany & USA & Mexico \\
\hline followed the link & 410 & 275 & 484 \\
started the questionnaire & 305 & 135 & 324 \\
finished the questionnaire & 214 & 91 & 222 \\
filled the questionnaire correctly and completely & 174 & 83 & 176 \\
\hline have or regularly drive a car & $\mathbf{1 6 8}$ & $\mathbf{8 0}$ & $\mathbf{1 5 8}$ \\
\hline
\end{tabular}

Table 3.3.: Number of participants by gender and age in participating countries

\begin{tabular}{rcccccc}
\hline & \multicolumn{2}{c}{ Germany } & \multicolumn{2}{c}{ USA } & \multicolumn{2}{c}{ Mexico } \\
\hline Gender & Male & Female & Male & Female & Male & Female \\
Number of subjects & 153 & 15 & 51 & 29 & 120 & 38 \\
\hline Age & $<41$ & $41=<$ & $<41$ & $41=<$ & $<41$ & $41=<$ \\
Number of subjects & 116 & 52 & 63 & 17 & 125 & 33 \\
\hline
\end{tabular}

which is a hypotheses test based on ordinal data with non-parametric distributions and two independent samples. Thereby, samples are not necessarily symmetric [45]. The U-test is robust in comparing small samples and/or samples of different sizes. However, according to [46], the size of each sample should be at least ten to avoid an inadequate p-value. To test the hypotheses comparing results across our three countries, i.e., three samples, we are using the non-parametric Kruskal-Wallis-Test (H-Test), which is the equivalent to the U-Test to test more than two independent samples for significance. If the H-Test shows significance, further U-Tests, are conducted across all countries to identify significances across the according two countries. To decide whether to accept or to reject a null hypothesis, we have chosen a significance level of $\alpha=0.05$, which is a common level of significance in practical use [45, 47, 48] and in our opinion an acceptable level.

Some of our hypotheses aim to research the influence of gender. As can be seen from Table 3.3 the majority of respondents in all countries are male. In Germany in particular there is an unequal distribution, though we gained enough female participants in Germany to be able to test for differences between women and men.

We also asked our participants for their year of birth since it is our aim to see how the hypotheses are influenced by age. To get two samples for each country, i.e., young and old participants, we assign all participants younger than 41 to the "young" group. Participants older than 40 are assigned to the "old" group, respectively. Table 3.3 shows the size of the "young" as well as "old" group for each country.

In the further course of our analysis, we also research the influence of insurance on fear of crime. This data is used to distinguish between respondents who have insurance against car theft and theft of car parts (comprehensive coverage) and respondents who only have third- 
Table 3.4.: Number of participants with comprehensive coverage (car theft, theft of car parts) vs. none, third party liability

\begin{tabular}{lcccccc}
\hline & \multicolumn{2}{c}{ Germany } & \multicolumn{2}{c}{ USA } & \multicolumn{2}{c}{ Mexico } \\
\hline Insurance & Compre- & None, & Compre- & None, & Compre- & None, \\
& hensive & third party & hensive & third party & hensive & third party \\
& coverage & liability & coverage & liability & coverage & liability \\
Number & 147 & 21 & 61 & 19 & 118 & 40 \\
\hline
\end{tabular}

Table 3.5.: Number of participants have been a victim of specific car-related crimes

\begin{tabular}{lcccccc}
\hline & \multicolumn{2}{c}{ Germany } & \multicolumn{2}{c}{ USA } & \multicolumn{2}{c}{ Mexico } \\
& Victim & $\begin{array}{c}\text { No } \\
\text { Victim }\end{array}$ & Victim & No & Victim & $\begin{array}{c}\text { No } \\
\text { Victim }\end{array}$ \\
\hline Car theft & 12 & 156 & 4 & 76 & 33 & 125 \\
Theft of car parts & 50 & 118 & 60 & 20 & 107 & 51 \\
Theft from car & 35 & 133 & 25 & 55 & 77 & 81 \\
Theft of car keys & 4 & 164 & 0 & 80 & 8 & 150 \\
Scratches & 144 & 24 & 63 & 17 & 146 & 12 \\
Destroyed parts & 74 & 94 & 24 & 56 & 93 & 65 \\
Arson of car & 3 & 165 & 0 & 80 & 3 & 155 \\
Carjacking & 0 & 168 & 2 & 78 & 12 & 144 \\
Assault while leav- & 1 & 167 & 0 & 80 & 10 & 148 \\
ing/ entering car & & & & & & \\
\hline
\end{tabular}

party liability or even no insurance. Due to different insurance policies in the studied countries, we grouped respondents in two groups. The first group, comprehensive coverage, contains respondents with insurance against the aforementioned crimes. The second group, none/third party liability, contains respondents with no insurance or insurance cover for accident-related third-party damage only. Table 3.4 shows the distribution between our two groups for each country.

Furthermore, we assume that having already been a victim of specific car-related crimes increases the fear of becoming a victim again. To test this hypothesis, we use the distribution shown in Table 3.5, which is based on answers given by our participants. We only calculate for significance when the number of relevant participants, i.e. the sample size, is at least ten. Hence, as can be seen from Table 3.5, we will not be able to test the influence for all mentioned car-related crimes. 


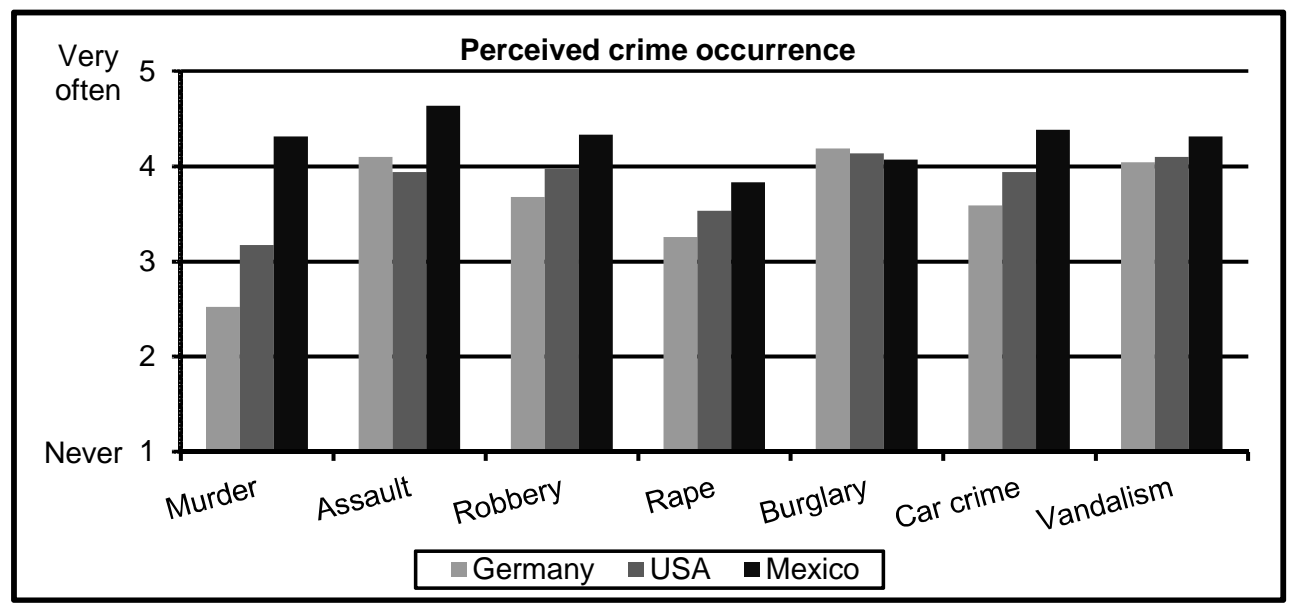

Figure 3.1.: Perceived crime occurrence in Germany, USA and Mexico

\subsection{Results}

\subsubsection{Perceived crime occurrence}

To estimate perceived crime occurrence, we asked our participants to rate on a Likert scale from never (1) to very often (5) the frequency of crime in their country.

\section{$H$ : There are differences across countries in how subjects perceive the occurrence of crime.}

As can be seen from Table 3.6 and Figure 3.1, which show the results, there are differences across countries. Murder and car-related crime differ significantly across all countries. For assault and robbery, we found significant differences between Germany and Mexico as well as between the USA and Mexico. Burglary is the only crime which is non-significant across all three countries. Furthermore, car-related crime is reported to occur amongst other crimes in all the countries, meaning there are no abnormalities in the occurrence of car-related crime related to other crimes. 
Table 3.6.: Perceived crime occurrence

\begin{tabular}{|c|c|c|c|}
\hline \multicolumn{4}{|c|}{ How often do the following crimes occur in your country? } \\
\hline & $\begin{array}{c}\text { Germany } \\
\text { Mean (SD) }\end{array}$ & $\begin{array}{c}\text { USA } \\
\text { Mean (SD) }\end{array}$ & $\begin{array}{c}\text { Mexico } \\
\text { Mean (SD) }\end{array}$ \\
\hline Murder ${ }^{* * *,+t+, ~} \ddagger \ddagger \ddagger$ & $2.5(1.1)$ & $3.2(1.1)$ & $4.3(0.9)$ \\
\hline Sexual offenses ${ }^{\text {t+t }}$ & $3.3(0.9)$ & $3.5(1.0)$ & $3.8(1.0)$ \\
\hline Assault ${ }^{\dagger+t, ~}$ & $4.1(0.8)$ & $4.0(0.9)$ & $4.6(1.3)$ \\
\hline Burglary & $4.1(1.3)$ & $4.1(0.8)$ & $4.0(1.3)$ \\
\hline 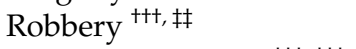 & $3.8(0.9)$ & $4.0(0.9)$ & $4.3(0.8)$ \\
\hline Car-related crime ${ }^{*,+t+, ~} \neq \ddagger \ddagger$ & $3.6(1.0)$ & $3.9(0.9)$ & $4.4(0.8)$ \\
\hline Vandalism $^{++}$ & $4.0(0.9)$ & $4.1(1.0)$ & $4.3(0.9)$ \\
\hline
\end{tabular}

Note. $\mathrm{N}_{\text {Germany: }}$ 168, $\mathrm{N}_{\text {USA }}: 80$, $\mathrm{N}_{\text {Mexico }}: 158$.

Mean (SD) on Likert scale: never (1) to very often (5).

$* \mathrm{p}<0.05 ; * \mathrm{p}<0.01 ; * * * \mathrm{p}<0.001 ;$ differences Germany vs. USA.

$+\mathrm{p}<0.05 ;++\mathrm{p}<0.01 ;+++\mathrm{p}<0.001$; differences Germany vs. Mexico.

$\ddagger \mathrm{p}<0.05 ; \ddagger \ddagger \mathrm{p}<0.01 ; \ddagger \ddagger \ddagger \mathrm{p}<0.001 ;$ differences USA vs. Mexico.

\subsubsection{Fear of car-related crime}

To research the fear of becoming a victim of car-related crime, we asked our participants to answer two questions. First, we asked how worried they felt about being a victim of carrelated crime. Second, we asked to rate how frequently they felt worried about becoming a victim of car-related crime in the previous month.

\section{$\mathrm{H}$ : There are differences across countries in the fear of becoming a victim of car-related crime.}

As can be seen in Figure 3.2, the majority of respondents in Germany (69\%) are not worried or not at all worried about falling victim of car-related crime. In contrast, the majority of Mexicans (69\%) are worried or even very worried. The attitudes of participants in the USA differ significantly with those of Germans and Mexicans. The majority (39\%) moves around the central region, with the remaining participants having a less tendency to fear. We also calculated a significant difference across all three countries as shown in Table 3.7.

The frequency of fear of becoming a victim of car-related crime behaves in a similar fashion, that is, Germans are the least fearful, followed by Americans and Mexicans. As can be seen from Figure 3.3 the majority of Germans (74\%) had not felt fear once in the last month. Only half of Americans (53\%) had no fear of becoming a victim of car-related crime in the last month. Mexicans are far behind with $20 \%$. This trend is also significant as can be seen in Table 3.8. 


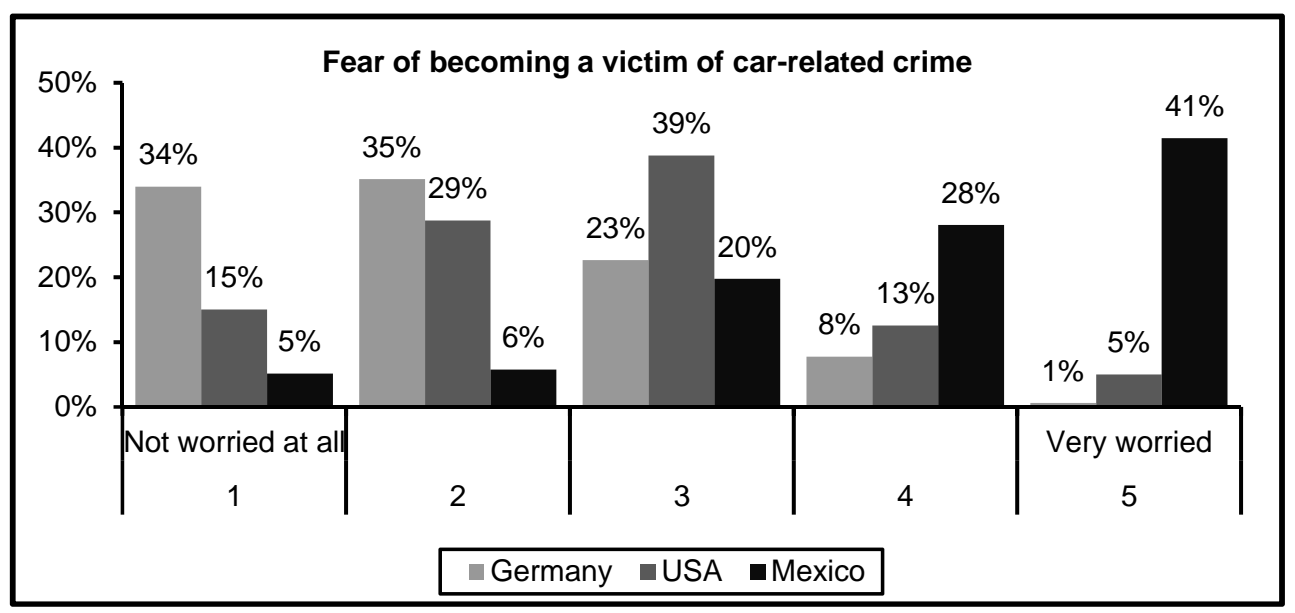

Figure 3.2.: Fear of becoming a victim of car-related crime

Table 3.7.: Fear of becoming a victim of car-related crime

\begin{tabular}{|c|c|c|c|}
\hline \multicolumn{4}{|c|}{ How worried are you of becoming a victim of car-related crime? } \\
\hline & $\begin{array}{c}\text { Germany } \\
\text { Mean (SD) }\end{array}$ & $\begin{array}{c}\text { USA } \\
\text { Mean (SD) }\end{array}$ & $\begin{array}{c}\text { Mexico } \\
\text { Mean (SD) }\end{array}$ \\
\hline All subjects ${ }^{* * *,+t+, ~ f \neq \ddagger ~}$ & $2.0(0.9)$ & $2.6(1.0)$ & $3.9(1.5)$ \\
\hline Male subjects & $2.0(0.9)$ & $2.5(1.1)$ & $3.8(1.6)$ \\
\hline Female subjects & $2.5(1.1)$ & $2.8(0.8)$ & $4.0(1.1)$ \\
\hline Young subjects & $2.0(1.0)$ & $2.7(1.1)$ & $3.8(1.6)$ \\
\hline Old subjects & $2.1(1.0)$ & $2.5(0.9)$ & $4.1(1.0)$ \\
\hline
\end{tabular}

Note. $\mathrm{N}_{\text {Germany }}: 168, \mathrm{~N}_{\mathrm{USA}}: 80, \mathrm{~N}_{\text {Mexico }}: 158$.

Mean (SD) on Likert scale: not worried at all (1) to very worried (5).

$* \mathrm{p}<0.05 ; * * \mathrm{p}<0.01 ; * * * \mathrm{p}<0.001$; differences Germany vs. USA.

$+\mathrm{p}<0.05 ; \mathrm{t} \mathrm{p}<0.01 ;++\mathrm{p}<0.001 ;$ differences Germany vs. Mexico.

$\ddagger \mathrm{p}<0.05 ; \ddagger \ddagger \mathrm{p}<0.01 ;$ 拉 $<0.001$; differences USA vs. Mexico.

$\$ \mathrm{p}<0.05 ; \$ \$ \mathrm{p}<0.01 ; \$ \$ \mathrm{p}<0.001$; female subjects are more worried than male subjects.

ip $<0.05$; iip $<0.01 ;$ iiip $<0.001$; old subjects are more worried than young subjects. 


\section{$\mathrm{H}$ : Female participants are more worried about becoming a victim of car-related crime than male participants.}

Table 3.7 and Table 3.8 also show the results for the gender. There is no significance between females and males, neither in their rating of fear nor their rating of frequency of fear experienced in the last month.

\section{$\mathrm{H}$ : Older participants are more worried about becoming a victim of car-related crime than young participants.}

The influence of age on the fear of becoming a victim of car-related crime as well as on the frequency of fear is non-significant in all the countries, as shown in Table 3.7 and Table 3.8.

\subsubsection{Fear of specific car-related crimes}

We asked participants to rate their fear of becoming a victim of specific car-related crimes, which can be seen in Table 3.9.

\section{$\mathrm{H}$ : There are differences across countries in the fear of becoming a victim of specific car-related crimes.}

Table 3.9 and Figure 3.4 show how participants rated their fear of becoming a victim of specific car-related crimes. Mexicans have a greater tendency to fear, with Germans the least fearful and Americans somewhere in between. This trend is seen across violent crimes, such as carjacking and assault while leaving or entering the car. For property crimes such as car theft, theft of car parts and theft of car keys, Mexicans stand out significantly with a greater fear compared to Germans and Americans, who share a similar level of fear. Only theft from the car, which is also a property crime, significantly follows the trend of violent crimes. For vandalism to a car, we do not have a clear trend. There are no differences across countries for the incidence of scratches to the vehicle. For the incidence of destroyed parts and arson to the car, Mexicans are significantly more worried of becoming victims than Americans. Germans are non-significantly somewhere between Americans and Mexicans. 


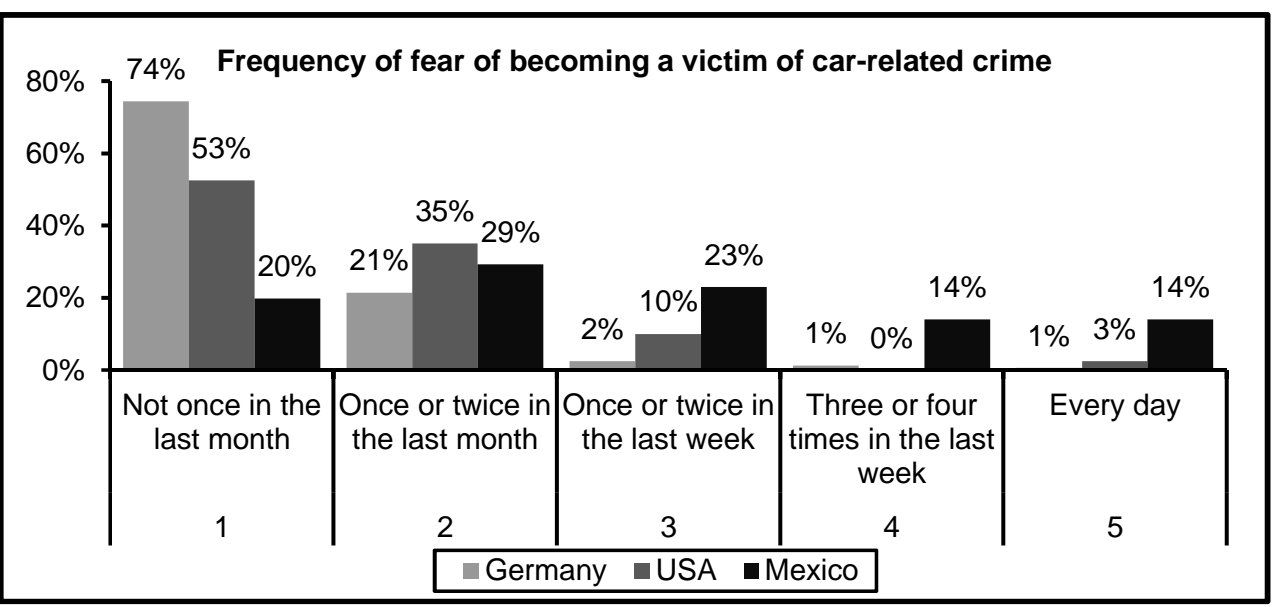

Figure 3.3.: Frequency of fear of becoming a victim of car-related crime

Table 3.8.: Frequency of fear of becoming a victim of car-related crime

How frequently have you felt worried of becoming a victim of car-related crime in the previous month?

\begin{tabular}{lccc}
\hline & $\begin{array}{c}\text { Germany } \\
\text { Mean (SD) }\end{array}$ & $\begin{array}{c}\text { USA } \\
\text { Mean (SD) }\end{array}$ & $\begin{array}{c}\text { Mexico } \\
\text { Mean (SD) }\end{array}$ \\
\hline All subjects ${ }^{* *},++$, fłł & $1.3(0.6)$ & $1.6(0.8)$ & $2.6(1.6)$ \\
\hline Male subjects & $1.3(0.6)$ & $1.6(0.9)$ & $2.7(1.7)$ \\
Female subjects & $1.4(0.5)$ & $1.6(0.7)$ & $2.4(1.2)$ \\
\hline Young subjects & $1.3(0.7)$ & $1.7(0.9)$ & $2.6(1.6)$ \\
Old subjects & $1.2(0.4)$ & $1.4(0.5)$ & $2.9(1.3)$ \\
\hline
\end{tabular}

Note. $\mathrm{N}_{\text {Germany }}: 168, \mathrm{~N}_{\text {USA }}: 80, \mathrm{~N}_{\text {Mexico }}: 158$.

Mean (SD) on Likert scale: not once in the last month (1), once/twice in the last month (2), once/twice in the last week (3), three/four times in the last week (4), every day (5).

$* \mathrm{p}<0.05 ; * * \mathrm{p}<0.01 ; * * * \mathrm{p}<0.001$; differences Germany vs. USA.

$t \mathrm{p}<0.05 ; \mathrm{t} \mathrm{p}<0.01 ;+t+\mathrm{p}<0.001 ;$ differences Germany vs. Mexico.

$\ddagger \mathrm{p}<0.05 ; \ddagger \ddagger \mathrm{p}<0.01 ; \ddagger \ddagger \ddagger \mathrm{p}<0.001 ;$ differences USA vs. Mexico.

$\$ \mathrm{p}<0.05 ; \$ \$ \mathrm{p}<0.01 ; \$ \$ \$ \mathrm{p}<0.001$; female subjects are more worried than male subjects.

ip $<0.05 ;$ iip $<0.01 ;$ iiip $<0.001$; old subjects are more worried than young subjects. 


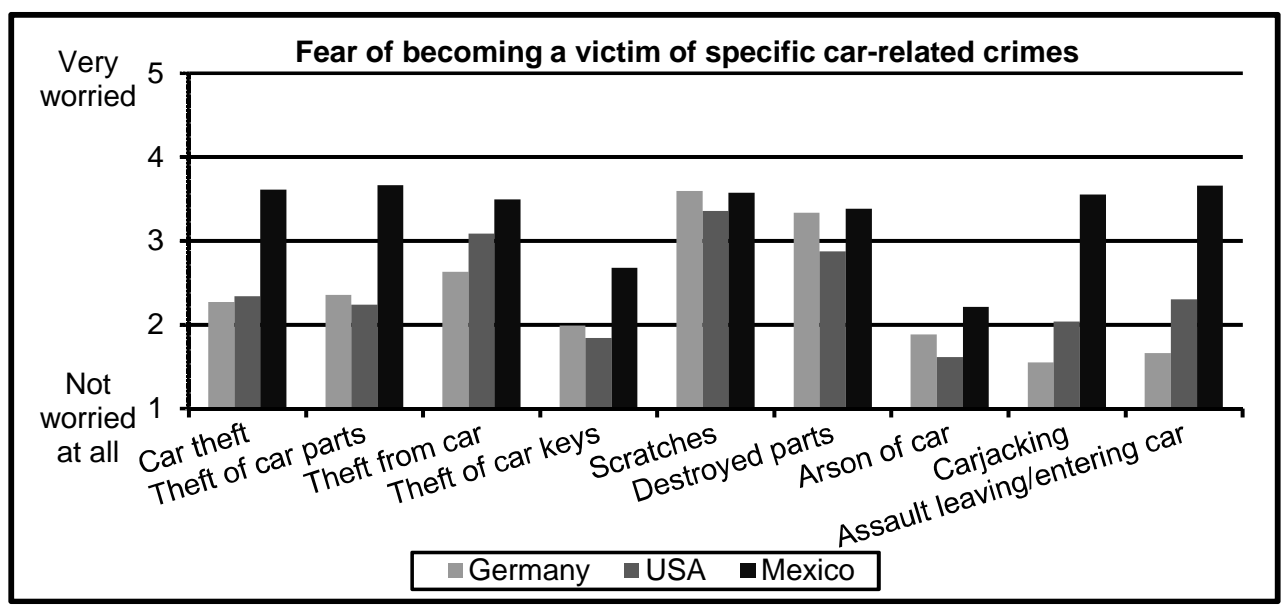

Figure 3.4.: Fear of becoming a victim of specific car-related crimes

Table 3.9.: Fear of becoming a victim of specific car-related crimes

\begin{tabular}{|c|c|c|c|}
\hline \multicolumn{4}{|c|}{ How worried are you of becoming a victim of the following car-related crimes? } \\
\hline & $\begin{array}{l}\text { Germany } \\
\text { Mean (SD) }\end{array}$ & $\begin{array}{c}\text { USA } \\
\text { Mean (SD) }\end{array}$ & $\begin{array}{c}\text { Mexico } \\
\text { Mean (SD) }\end{array}$ \\
\hline Car theft ${ }^{\dagger+t, ~}$ & $2.3(1.1)$ & $2.3(1.1)$ & $3.6(1.2)$ \\
\hline Theft of car parts ${ }^{t+t, ~ f \neq \ddagger ~}$ & $2.3(1.1)$ & $2.2(1.2)$ & $3.7(1.2)$ \\
\hline Theft from car ${ }^{* *,+t+, ~} \ddagger$ & $2.6(1.1)$ & $3.1(1.0)$ & $3.5(1.2)$ \\
\hline Theft of car keys ${ }^{t+t, ~ f ł \ddagger ~}$ & $2.0(1.0)$ & $1.8(1.0)$ & $2.6(1.5)$ \\
\hline Scratches & $3.6(1.2)$ & $3.2(1.9)$ & $3.5(1.6)$ \\
\hline Destroyed parts * $\ddagger$ & $3.3(1.2)$ & $2.9(1.1)$ & $3.3(1.6)$ \\
\hline Arson $\ddagger$ & $1.9(1.0)$ & $1.6(0.9)$ & $2.1(1.5)$ \\
\hline Carjacking ${ }^{* * *},+++$, 抽 & $1.5(1.1)$ & $2.0(1.0)$ & $3.6(1.3)$ \\
\hline $\begin{array}{l}\text { Assault while leaving/ } \\
\text { entering car } \\
* * *,+++, \neq \neq \ddagger\end{array}$ & $1.6(1.2)$ & $2.3(1.2)$ & $3.7(1.3)$ \\
\hline
\end{tabular}

Note. $\mathrm{N}_{\text {Germany }}$ : 168, $\mathrm{N}_{\mathrm{USA}}: 80, \mathrm{~N}_{\text {Mexico }}: 158$.

Mean (SD) on Likert scale: not worried at all (1) to very worried (5)

$* \mathrm{p}<0.05 ; * * \mathrm{p}<0.01 ; * * * \mathrm{p}<0.001$; differences Germany vs. USA.

$+\mathrm{p}<0.05 ;++\mathrm{p}<0.01 ;+++\mathrm{p}<0.001$; differences Germany vs. Mexico.

$\ddagger \mathrm{p}<0.05 ; \ddagger \ddagger \mathrm{p}<0.01 ; \ddagger \ddagger \ddagger \mathrm{p}<0.001$; differences USA vs. Mexico. 


\section{$\mathrm{H}$ : Female participants are more worried about becoming a victim of specific car-related crimes than male participants.}

The influence of gender is mainly evident in Germany, as can be seen in Table 3.10. German females are significantly more worried about becoming a victim of violent crimes, i.e. carjacking and assault while leaving or entering the car. They are also significantly more worried about vandalism, except for scratches and are significantly more worried about becoming a victim of car theft. Similar to Germany, American females are also more worried about violent crimes. In Mexico, gender has no significant influence on attitudes to car-related crime.

Table 3.10.: Fear of becoming a victim of specific car-related crimes (influence of gender)

\begin{tabular}{lcccccc}
\hline \multicolumn{2}{c}{ How worried are you of becoming a victim of the following car-related crimes? } \\
& \multicolumn{2}{c}{ Germany } & \multicolumn{2}{c}{ USA } & \multicolumn{2}{c}{ Mexico } \\
& Male & Female & Male & Female & Male & Female \\
\hline & Mean & Mean & Mean & Mean & Mean & Mean \\
& (SD) & $($ SD) & (SD) & (SD) & (SD) & (SD) \\
\hline Car theft & $2.2(1.0)$ & $2.9(1.4)^{*}$ & $2.2(1.2)$ & $2.5(1.1)$ & $3.5(1.2)$ & $3.4(1.1)$ \\
Theft of car parts & $2.3(1.0)$ & $2.5(1.4)$ & $2.3(1.2)$ & $2.2(1.2)$ & $3.7(1.2)$ & $3.6(1.3)$ \\
Theft from car & $2.6(1.1)$ & $(2.9) 1.2$ & $3.0(1.1)$ & $3.1(1.0)$ & $3.4(1.2)$ & $3.5(1.2)$ \\
Theft of car keys & $2.0(0.9)$ & $2.1(1.4)$ & $1.8(0.9)$ & $2.0(1.2)$ & $2.7(1.6)$ & $2.3(1.1)$ \\
Scratches & $3.6(1.2)$ & $3.9(1.3)$ & $3.2(1.3)$ & $3.2(1.6)$ & $3.5(1.7)$ & $3.5(1.2)$ \\
Destroyed parts & $3.3(1.3)$ & $3.9(0.9)^{*}$ & $2.9(1.2)$ & $2.8(1.0)$ & $3.3(1.6)$ & $3.2(1.3)$ \\
Arson & $1.8(1.0)$ & $2.6(1.2)$ & $1.6(0.9)$ & $1.7(1.0)$ & $2.1(1.3)$ & $2.1(1.3)$ \\
Carjacking & $1.4(1.1)$ & $2.5(1.5)^{* *}$ & $1.8(0.9)$ & $2.3(1.1)^{*}$ & $3.6(1.4)$ & $3.5(1.3)$ \\
Assault while leaving & $1.5(1.2)$ & $2.4(1.3)^{* *}$ & $1.9(1.0)$ & $2.9(1.3)^{* * *}$ & $3.7(1.3)$ & $3.6(1.3)$ \\
or entering car & & & & & & \\
\hline
\end{tabular}

Note. $\mathrm{N}_{\text {Germany }}: 168, \mathrm{~N}_{\text {USA }}: 80, \mathrm{~N}_{\text {Mexico }}: 158$.

Mean (SD) on Likert scale: not worried at all (1) to very worried (5)

$* \mathrm{p}<0.05 ; * * \mathrm{p}<0.01 ; * * * \mathrm{p}<0.001$; female subjects are more worried than male subjects.

\section{$\mathrm{H}$ : Older participants are more worried about becoming a victim of specific car-related crimes than younger participants.}

As can be seen in Table 3.11, age does not significantly influence the fear of becoming a victim of any specific car-related crime. We only found significance for older German participants being more worried about becoming a victim of violent crimes, i.e., carjacking and assault while leaving or entering the car. 
Table 3.11.: Fear of becoming a victim of specific car-related crimes (influence of age)

\begin{tabular}{lcccccc}
\hline \multicolumn{4}{l}{ How worried are you of becoming a victim of the following car-related crimes? } \\
\hline & \multicolumn{2}{c}{ Germany } & \multicolumn{2}{c}{ USA } & \multicolumn{2}{c}{ Mexico } \\
& Young & Old & Young & Old & Young & Old \\
\hline & Mean & Mean & Mean & Mean & Mean & Mean \\
& (SD) & (SD) & (SD) & (SD) & (SD) & (SD) \\
\hline Car theft & $2.2(1.1)$ & $2.3(1.0)$ & $2.3(1.2)$ & $2.2(0.9)$ & $3.6(1.3)$ & $3.6(1.1)$ \\
Theft of car parts & $2.4(1.1)$ & $2.3(1.4)$ & $2.2(1.2)$ & $2.1(1.0)$ & $3.6(1.3)$ & $3.8(1.3)$ \\
Theft from car & $2.7(1.1)$ & $(2.5) 1.1$ & $3.2(1.1)$ & $2.9(1.0)$ & $3.5(1.2)$ & $3.7(1.3)$ \\
Theft of car keys & $2.0(0.9)$ & $2.0(1.1)$ & $1.9(1.1)$ & $1.7(0.8)$ & $2.5(1.6)$ & $2.9(1.2)$ \\
Scratches & $3.6(1.3)$ & $3.5(1.0)$ & $3.3(1.4)$ & $2.6(2.3)$ & $3.5(1.7)$ & $3.2(1.3)$ \\
Destroyed parts & $3.4(1.3)$ & $3.1(1.1)$ & $2.9(1.1)$ & $2.7(1.1)$ & $3.2(1.7)$ & $3.4(1.1)$ \\
Arson & $1.9(1.0)$ & $1.9(1.2)$ & $1.6(1.0)$ & $1.6(0.8)$ & $2.1(1.7)$ & $2.2(1.2)$ \\
Carjacking & $1.4(0.8)$ & $1.5(1.7)^{* *}$ & $2.0(1.1)$ & $1.9(0.7)$ & $3.5(1.4)$ & $3.7(1.2)$ \\
Assault while leaving & $1.5(1.3)$ & $1.9(0.9)^{* *}$ & $2.3(1.2)$ & $2.2(1.0)$ & $3.6(1.3)$ & $3.9(1.0)$ \\
or entering car & & & & & & \\
\hline
\end{tabular}

Note. $\mathrm{N}_{\text {Germany }}: 168, \mathrm{~N}_{\mathrm{USA}}: 80, \mathrm{~N}_{\text {Mexico }}: 158$.

Mean (SD) on Likert scale: not worried at all (1) to very worried (5)

$* \mathrm{p}<0.05 ; * * \mathrm{p}<0.01 ; * * \mathrm{p}<0.001$; old subjects are more worried than young subjects.

\section{$\mathrm{H}$ : Participants that have already been victims of specific car-related crimes are more worried of being victims of these crimes again.}

As summarized in Table 3.12, we found significant results in all countries for the majority of car-related crimes, which provided the opportunity to calculate for significance. We did not find significance in Germany and USA considering theft from car. Car theft was also non significant across all countries.

\section{$\mathrm{H}$ : Participants insured against specific car-related crimes are less worried about becoming a victim of these crimes.}

Our assumption that participants without insurance covering car theft or theft of car parts are more worried than participants with insurance is not confirmed. The results are summarized in Table 3.13 
Table 3.12.: Fear of becoming a victim of specific car-related crimes (influence of victimization)

\begin{tabular}{|c|c|c|c|c|c|c|}
\hline \multicolumn{7}{|c|}{ How worried are you of becoming a victim of the following car-related crimes? } \\
\hline & \multicolumn{2}{|c|}{ Germany } & \multicolumn{2}{|c|}{ USA } & \multicolumn{2}{|c|}{ Mexico } \\
\hline & Victim & $\begin{array}{c}\text { No } \\
\text { Victim }\end{array}$ & Victim & $\begin{array}{c}\text { No } \\
\text { Victim }\end{array}$ & Victim & $\begin{array}{c}\text { No } \\
\text { Victim }\end{array}$ \\
\hline & $\begin{array}{c}\text { Mean } \\
(\mathrm{SD})\end{array}$ & $\begin{array}{l}\text { Mean } \\
\text { (SD) }\end{array}$ & $\begin{array}{l}\text { Mean } \\
\text { (SD) }\end{array}$ & $\begin{array}{l}\text { Mean } \\
\text { (SD) }\end{array}$ & $\begin{array}{c}\text { Mean } \\
(\mathrm{SD})\end{array}$ & $\begin{array}{l}\text { Mean } \\
(\mathrm{SD})\end{array}$ \\
\hline Car theft & $2.0(1.3)$ & 2.2(1.3) & $2.3(1.5)$ & $2.3(1.1)$ & $3.8(1.3)$ & $3.5(1.2)$ \\
\hline Theft of car parts & $2.7(1.1)^{* *}$ & 2.2(1.1) & $2.7(1.3)^{*}$ & 2.1(1.1) & $3.9(1.2)^{* * *}$ & 3.1(1.2) \\
\hline Theft from car & $2.8(1.2)$ & 2.6(1.1) & $3.0(1.1)$ & $3.1(1.0)$ & $3.8(1.2)^{* * *}$ & $3.2(1.1)$ \\
\hline Theft of car keys & ${ }^{\mathrm{a}}$ & $-{ }^{\mathrm{a}}$ & $-{ }^{\mathrm{a}}$ & $-{ }^{\mathrm{a}}$ & $-{ }^{\mathrm{a}}$ & $-{ }^{\mathrm{a}}$ \\
\hline Scratches & $3.7(1.1)^{* * *}$ & $2.8(1.3)$ & $3.3(2.0)^{*}$ & $2.8(1.4)$ & $3.6(1.6)^{* * *}$ & $2.1(1.1)$ \\
\hline Destroyed parts & $3.7(1.2)^{* * *}$ & $3.0(1.3)$ & $3.5(1.0)^{* * *}$ & $2.5(1.0)$ & $3.6(1.7)^{* * *}$ & $2.9(1.2)$ \\
\hline Arson & $-{ }^{\mathrm{a}}$ & $-^{\mathrm{a}}$ & ${ }^{a}$ & $-{ }^{a}$ & $-^{\mathrm{a}}$ & $-{ }^{\mathrm{a}}$ \\
\hline Carjacking & $--^{\mathrm{a}}$ & $-{ }^{\mathrm{a}}$ & $-{ }^{\mathrm{a}}$ & $--^{\mathrm{a}}$ & $4.8(0.6)^{* * *}$ & $3.4(1.4)$ \\
\hline $\begin{array}{l}\text { Assault while leav- } \\
\text { ing/ entering car }\end{array}$ & $-{ }^{\mathrm{a}}$ & $-{ }^{\mathrm{a}}$ & $-^{\mathrm{a}}$ & $-^{\mathrm{a}}$ & $4.7(0.7)^{* *}$ & $3.6(1.3)$ \\
\hline
\end{tabular}

Note. $\mathrm{N}_{\text {Germany }}$ : 168, $\mathrm{N}_{\text {USA }}$ : 80, $\mathrm{N}_{\text {Mexico }}$ : 158.

Mean (SD) on Likert scale: not worried at all (1) to very worried (5)

${ }^{a}$ Less than 10 subject became victim so that no test for significance is conducted.

$* \mathrm{p}<0.05 ; * * \mathrm{p}<0.01 ; * * * \mathrm{p}<0.001 ;$ subjects having already become victim of a specific crime are more worried of becoming a victim.

Table 3.13.: Fear of becoming a victim of specific car-related crimes (influence of insurance)

How worried are you of becoming a victim of the following car-related crimes?

\begin{tabular}{lcccccc}
\hline & \multicolumn{2}{c}{ Germany } & \multicolumn{2}{c}{ USA } & \multicolumn{2}{c}{ Mexico } \\
& $\mathrm{CC}^{\mathrm{a}}$ & $\mathrm{NI}^{\mathrm{b}}$ & $\mathrm{CC}^{\mathrm{a}}$ & $\mathrm{NI}^{\mathrm{b}}$ & $\mathrm{CC}^{\mathrm{a}}$ & $\mathrm{NI}^{\mathrm{b}}$ \\
\hline & Mean & Mean & Mean & Mean & Mean & Mean \\
& $(\mathrm{SD})$ & $(\mathrm{SD})$ & $(\mathrm{SD})$ & $(\mathrm{SD})$ & $(\mathrm{SD})$ & $(\mathrm{SD})$ \\
\hline Car theft & $2.2(1.1)$ & $2.1(1.2)$ & $2.3(1.1)$ & $2.4(1.2)$ & $3.5(1.3)$ & $3.8(1.2)$ \\
Theft of car parts & $2.3(1.1)$ & $2.4(1.2)$ & $2.2(1.2)$ & $2.3(1.3)$ & $3.6(1.2)$ & $3.7(1.3)$ \\
\hline
\end{tabular}

Note. $\mathrm{N}_{\text {Germany }}$ : 168, $\mathrm{N}_{\mathrm{USA}}$ : 80, $\mathrm{N}_{\text {Mexico }}$ : 158.

Mean (SD) on Likert scale: not worried at all (1) to very worried (5)

${ }^{\text {a }} \mathrm{CC}=$ comprehensive coverage (insurance covering car theft and theft of car parts)

b $\mathrm{NI}=$ no insurance or third party liability

$* \mathrm{p}<0.05 ; * * \mathrm{p}<0.01 ; * * * \mathrm{p}<0.001$; subjects without insurance are more worried than subjects with insurance. 


\subsubsection{Quality of police work}

To research our hypotheses, we asked participants to rate the following statements on a Likert scale from strongly disagree (1) to strongly agree (5):

- Regarding car-related crime, the police are doing a very good job.

- If my car is stolen, police will be able to bring it back to me.

\section{$\mathrm{H}$ : There are differences across countries in the rating of quality of policing with regards to car-related crime.}

As can be seen from Figure 3.5, Mexicans (mean:1.7, SD:0.8) rate the quality of policing as worse than Germans (mean:2.6, SD:1.0) and Americans (mean:2.5, SD:1.1). The inferior rating by Mexicans is significant at the 0.001 level compared to both other countries. There is no significant difference between Germany and USA.

\section{$\mathrm{H}$ : There are differences across countries in the rating of the ability of police to recover stolen cars.}

Figure 3.6 shows the estimated ability of police to recover a stolen car. Mexicans (mean:1.7, SD:0.9) rate the ability of police significantly worse at a the 0.001 level when compared to Germans (mean:2.2, SD:1.0) and Americans (mean:2.3, SD:1.0). No significance was found between Germany and USA. 


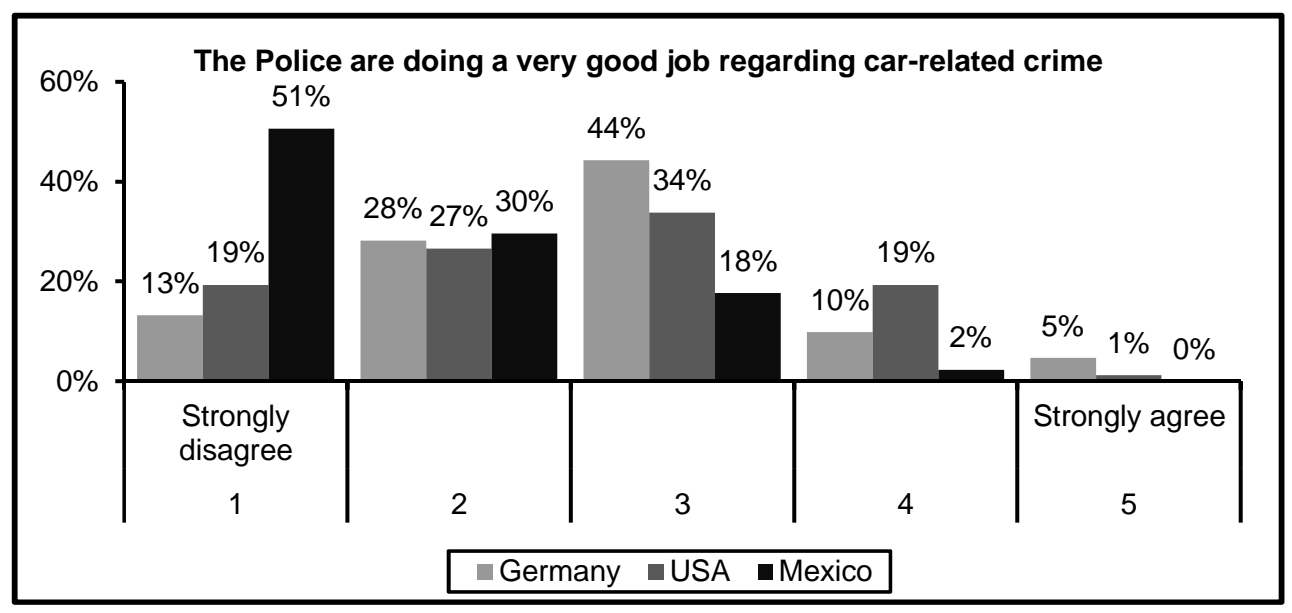

Figure 3.5.: Quality of policing regarding car-related crime

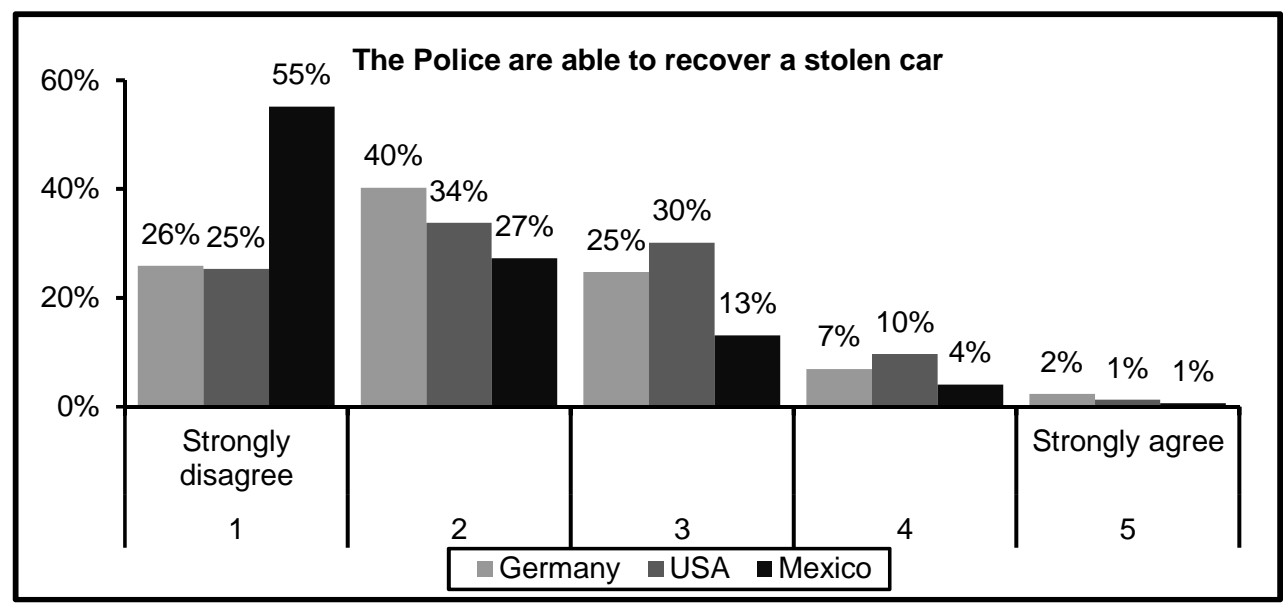

Figure 3.6.: Ability of police to recover a stolen car 


\subsubsection{Willingness to have car recovered}

To research the willingness of participants to get a stolen car back, we asked participants to rate the following statement on a Likert scale from strongly disagree (1) to strongly agree (5): "If my car is stolen, I want my car to be recovered."

\section{$H$ : There are differences across countries in the willingness to get a stolen car back.}

As can be seen in Figure 3.7, Mexicans (mean:4.5, SD:1.1) are more willing to get back their car after a theft than Germans (mean:4.0, SD:1.3) and Americans (mean:4.2, SD:1.1). Mexicans stand out significantly at the 0.05 level when compared with the USA and at the 0.01 level when compared with Germany. No significance was found between Germany and USA.

\section{$\mathrm{H}$ : Participants without insurance are more likely to get their car back after a theft than participants with insurance.}

Table 3.14 shows the results across participants with and without insurance. Only in Germany is there a significantly higher willingness of subjects without insurance to get back their car after a theft. 


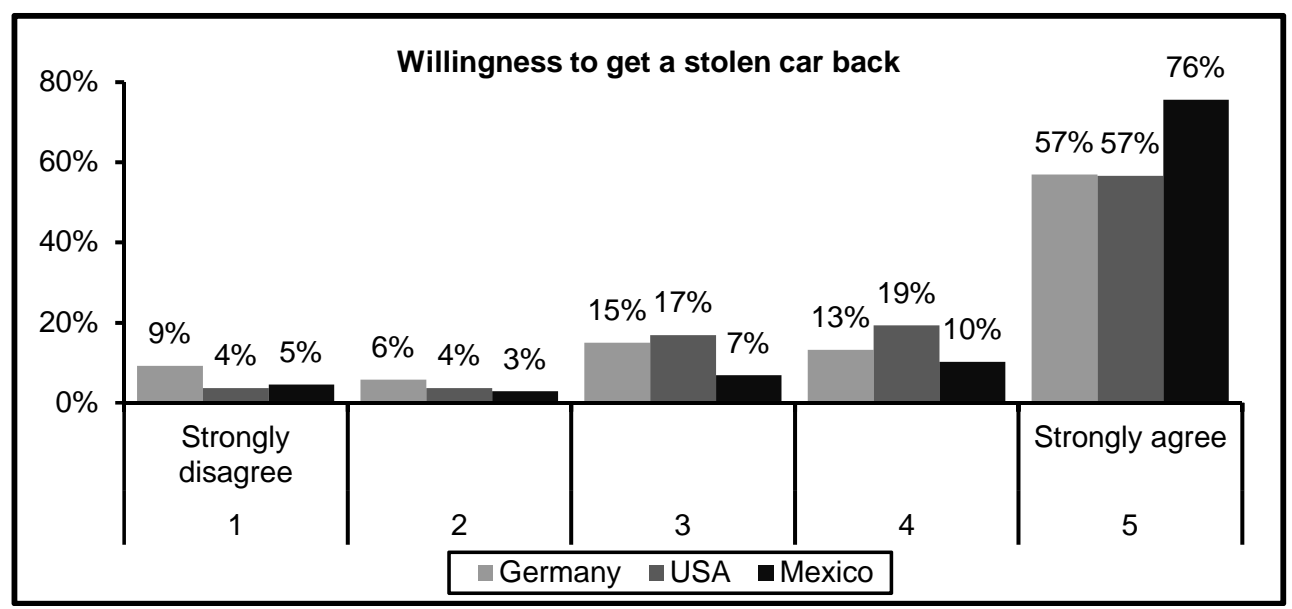

Figure 3.7.: Willingness to get a stolen car back

Table 3.14.: Willingness to get a stolen car back

\begin{tabular}{cccccccc}
\hline \multicolumn{1}{l}{ If my car is stolen, I want my car to be recovered. } & \multicolumn{3}{c}{ MSA } & \multicolumn{2}{c}{ Mexico } \\
\hline \multicolumn{2}{c}{ Germany } & $\mathrm{CC}^{\mathrm{a}}$ & $\mathrm{NI}^{\mathrm{b}}$ & $\mathrm{CC}^{\mathrm{a}}$ & $\mathrm{NI}^{\mathrm{b}}$ \\
\hline $\mathrm{CC}^{\mathrm{a}}$ & Mean & Mean & Mean & Mean & Mean \\
& Mean & Mean & $(\mathrm{SD})$ & $(\mathrm{SD})$ & $(\mathrm{SD})$ & $(\mathrm{SD})$ & $(\mathrm{SD})$ \\
\hline Car recovery & $4.1(1.4)$ & $4.4(0.7)$ & $4.1(1.1)$ & $4.3(1.1)$ & $4.4(1.2)$ & $4.7(0.6)$ \\
\hline
\end{tabular}

Note. $\mathrm{N}_{\text {Germany }}: 168, \mathrm{~N}_{\mathrm{USA}}: 80, \mathrm{~N}_{\text {Mexico }}: 158$.

Mean (SD) on Likert scale: strongly disagree (1) to strongly agree (5)

${ }^{\text {a }} \mathrm{CC}=$ comprehensive coverage (insurance covering i.a. car theft)

${ }^{\mathrm{b}} \mathrm{NI}=$ no insurance or third party liability

$* \mathrm{p}<0.05 ; * * \mathrm{p}<0.01 ; * * * \mathrm{p}<0.001$; subjects without insurance are more willing to get their stolen car

back than subjects with insurance. 


\subsubsection{Demand for security systems}

To research the demand for security systems and test our hypothesis, we asked participants to rate the following statements on a Likert scale from strongly disagree (1) to strongly agree (5):

- I feel confident of influencing whether or not I become a victim of car-related crime.

- I use security systems to control whether or not I become a victim of car-related crime.

- More and better security systems are necessary to tackle car-related crime in Germany/ USA/ Mexico.

\section{There are differences across countries in individuals' confidence of influencing whether or not they become a victim of car-related crime}

There are no significant differences across Germans (mean:3.4, SD:1.2), Americans (mean:3.5, SD:1.1) and Mexicans (mean:3.5, SD:1.1) in the confidence to influence whether or not to become a victim of car-related crime. Furthermore, as can be seen in Figure 3.8, the distribution is resembling across all countries where more than a half of participants in each country (Germany: 60\%, USA: 55\%, Mexico: 50\%) feel confident to influence their victimization of car-related crime.

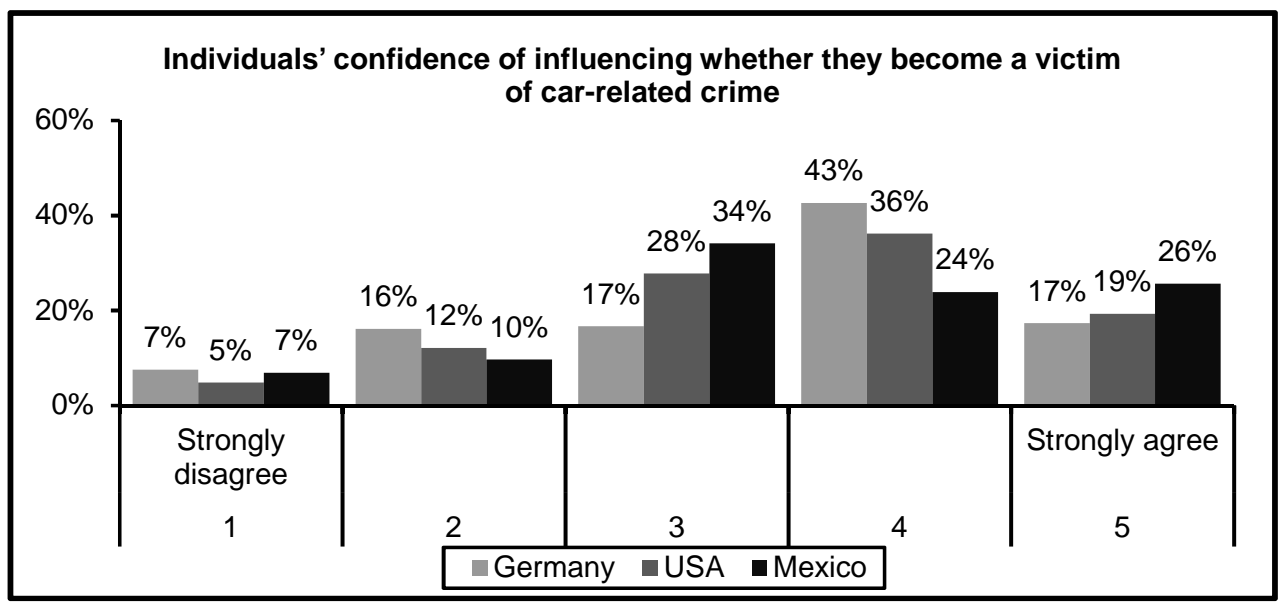

Figure 3.8.: Individuals' confidence of influencing whether they become a victim of car-related crime 
There are differences across countries in the use of security systems by individuals to control whether they become a victim of car-related crime

Mexicans (mean:3.1, SD:1.2) report using significantly more security systems at a 0.001 level to control their vulnerability to car-related crime when compared to Germans (mean:2.4, SD:1.2) and Americans (mean:2.5, SD:1.1). As can be seen in Figure 3.9 half of Germans (52\%) and half of Americans (51\%) claim not to actively use security systems. Only one quarter of Germans $(23 \%)$ and $16 \%$ of Americans claim to actively use security systems. Instead, more than one third of Mexicans (37\%) actively use security systems.

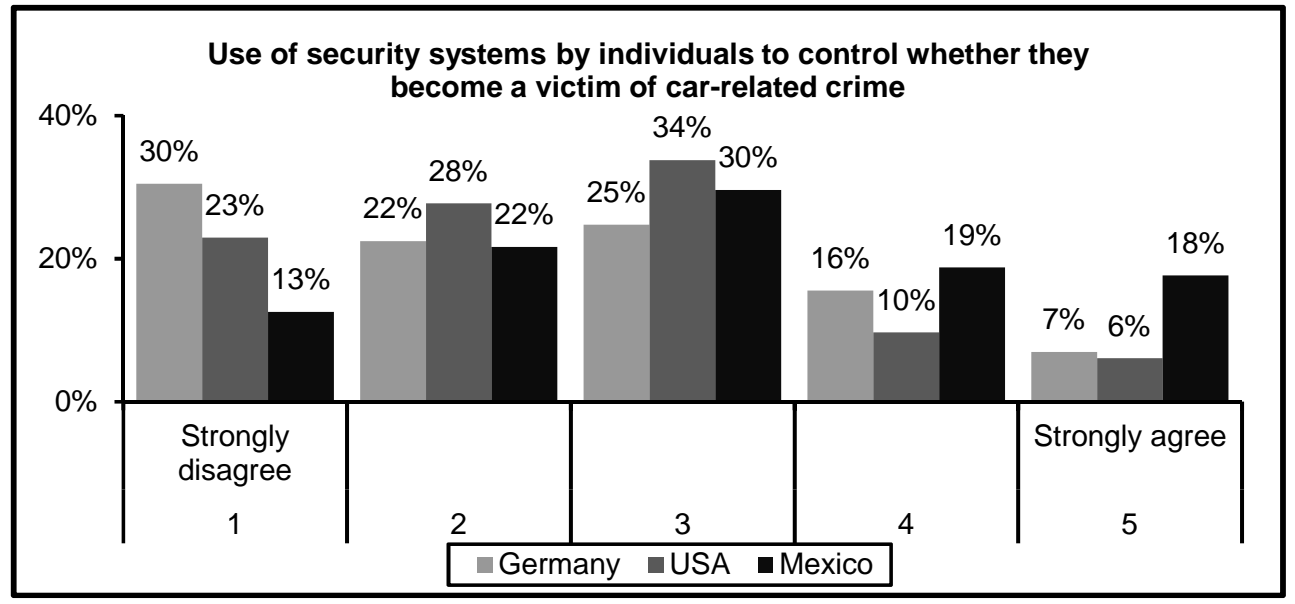

Figure 3.9.: Use of security systems by individuals to control whether they become a victim of car-related crime

There are differences across countries in the need for further security systems to tackle car-related crime

Mexicans (mean:4.2, SD:1.6) report significantly higher agreement at the 0.001 level than Germans (mean:3.5, SD:1.3) and Americans (mean:3.3, SD:1.2) with the argument that more and better security systems are necessary to tackle car-related crime. As can be seen in Figure 3.10, the majority of Mexicans (81\%) agree that further security systems are necessary. In Germany $(52 \%)$ and the USA (44\%) approximately half of subjects agree. 


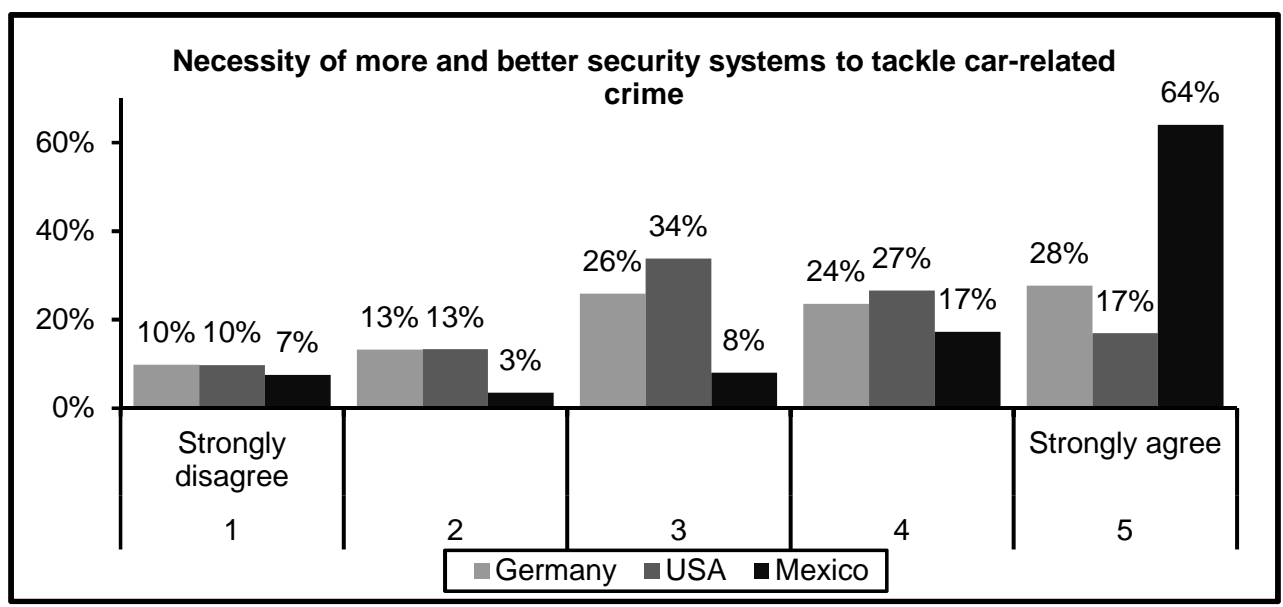

Figure 3.10.: Necessity for more and better security systems to tackle car-related crime

\subsubsection{Importance of security systems}

To find out more about the importance of security systems from the customer's point of view, we asked participants to rate the importance of twelve criteria when buying a car on a Likert scale from not important at all (1) to very important (5). Security systems is one criterion among others.

\section{There are differences across countries in the ratings of the importance of security systems}

Security systems are significantly more important for Mexicans (mean:3.8, SD:1.1) at the 0.001 level than for Germans (mean:3.1, SD:1.2) and Americans (mean:3.2, SD:1.2 ). However, considering the overall importance of security systems, i.e., the importance of security systems compared to the other eleven criteria, security systems are less important for participants in all the countries. In each country, security systems are ranked (Germany: 10, USA: 9, Mexico: 9) in the bottom third of our criteria. Furthermore, the overall importance of all criteria is similarly rated in each country, as can be seen in Figure 3.11. 


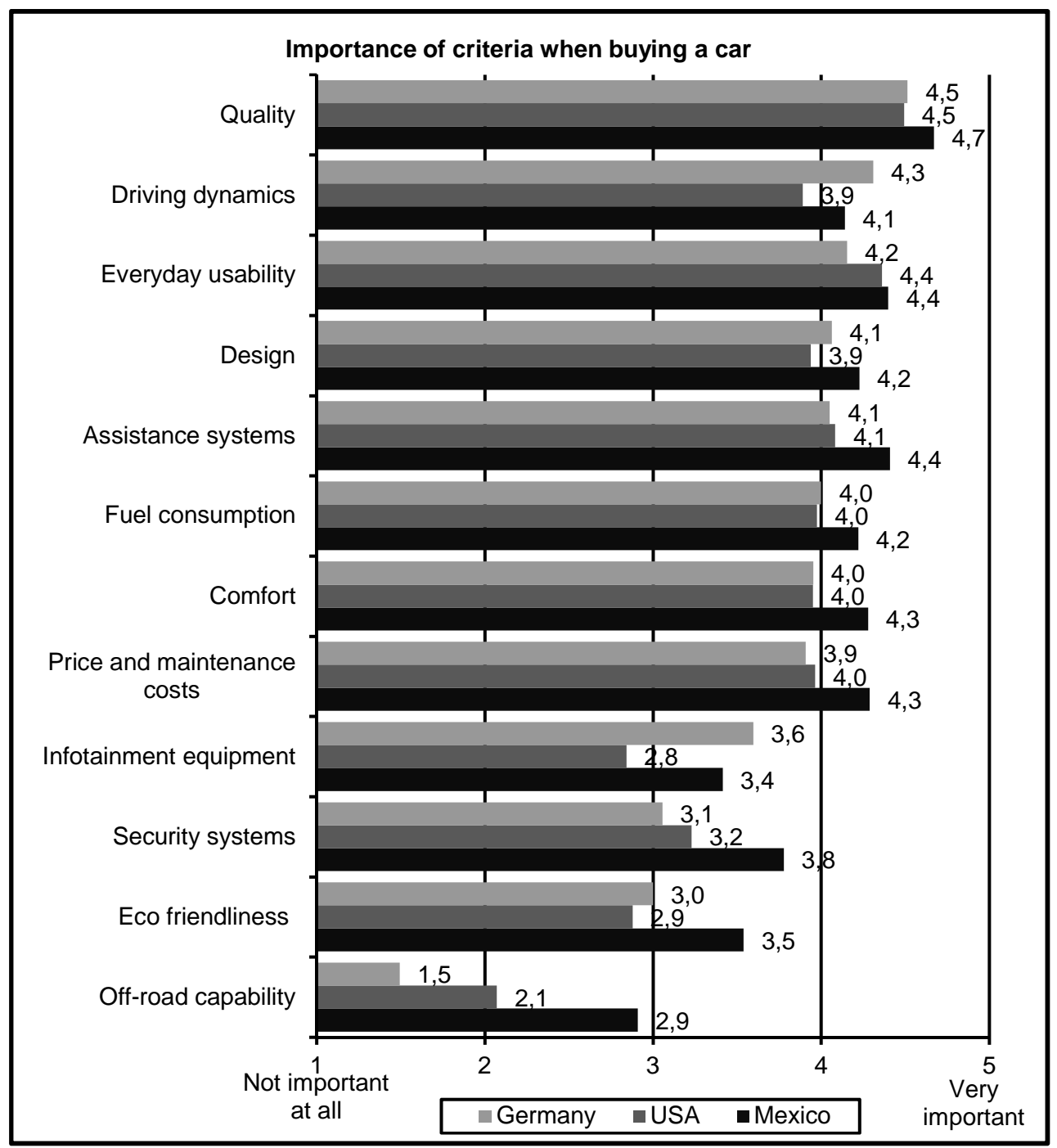

Figure 3.11.: Importance of criteria when buying a car 


\subsection{Discussion}

The current online survey examined several aspects of (fear of) car-related crime and security systems from the automotive field. A deeper understanding of these aspects supports the development of tailored security functions in the further course of this thesis. It is with this in mind that we discuss the results in what follows.

\subsubsection{Perceived crime occurrence}

The results suggest a trend where the majority of crimes are reported in Mexico, followed by the USA and Germany. Violent crimes or crimes that accompany violence tend to show (significantly) larger differences than property crimes. Only assault and burglary do not follow the aforementioned trend. On burglary, in our opinion there are two reasons why Germans rated the incidence of burglary as so high. First, burglary is the only crime in Germany which has increased significantly in the last five years compared to other crimes (Figure 2.3). Second, a few weeks before our survey started, the German Federal Criminal Police Office published crime statistics in which the increasing burglary rate was specifically highlighted. Thus, the growth in burglary was widely present in media [165, 166, 49]. Rates of assault have remained rather constant in recent years in Germany though since 1994 they have increased more than any other crime (Figure 2.3). In contrast, in the USA assault has steadily decreased within this period (Figure 2.4). Car-related crime is reported to occur in association with other crimes in all of the studied countries and so there are no abnormalities in the occurrence of car-related crime relative to other crimes.

Figure 3.12 summarizes the number of reported offenses for several crimes per 100,000 population. As can be seen, for the most part only murder and robbery follow our trend. Considering other crimes, Mexico has the lowest number of offenses per 100.000 population. We think that in Mexico in particular there is a high dark figure due to unreported crimes which are not recorded as crimes in the statistics. Discussing with inhabitants in Mexico, one main reason for not reporting a crime is distrust in the corrupt police, who are even partly involved in crimes. Therefore, the perceived crime occurrence estimated from our survey goes only partly hand-in-hand with the statistical crime rate. 


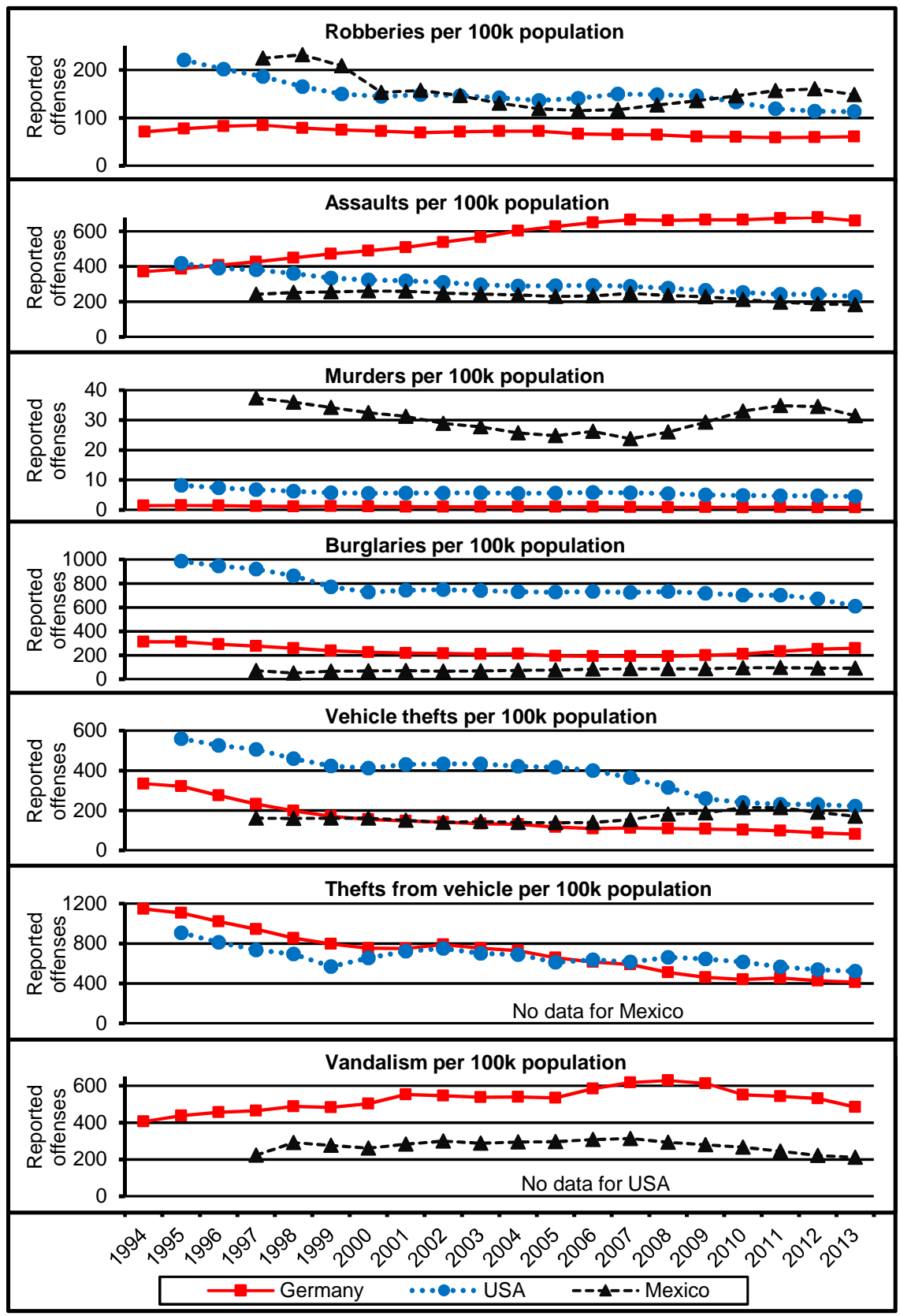

Figure 3.12.: Statistical crime rate in Germany, USA and Mexico 


\subsubsection{Fear of car-related crime}

The term car-related crime covers a wide range of different crimes that involve cars. The term covers crimes relating to property, violence as well as any other form of crimes occurring with car use. Hence, we cannot be certain of how participants interpret car-related crime. In our opinion asking in general terms provides a more general picture of the fear. We can assume, moreover, that answers to this question are influenced by the fear of other crimes. Based on these results, we have significant differences across countries in the fear of car-related crime, that is, Germans are the least worried followed by Americans and Mexicans, who are the most worried. There was however no evidence that gender or age influence the fear of car-related crime. One possible reason for these results is the decision to use the general term car-related crime which provides large leeway for interpretation.

\subsubsection{Fear of specific car-related crimes}

Our trend that Germans are the least worried, followed by Americans and Mexicans is only confirmed for violent car-related crimes, namely carjacking and assault while leaving or entering the car. A possible reason may be the high brutality of crime in Mexico. Although comparing statistical data across countries has to be treated with care as discussed in the previous chapter, Figure 3.12 shows that the number of reported offenses of robbery and especially murder stands out in Mexico followed by USA and Germany. Moreover, as discussed with experts and local inhabitants, there are different weapon laws across countries, affording different opportunities to access weapons. In Germany, access to firearms is significantly stricter than in the USA and Mexico.

Considering property crimes, namely car theft, theft from the inside of car, theft of car parts and theft of car keys, the results indicate a differing trend than that of violent car-related crimes. Germans and Americans experience the same level of fear whereas Mexicans are significantly more worried about the aforementioned crimes. According to our statistical analysis conducted in the previous chapter, vehicle theft rates and theft from vehicle rates per 100,000 registered vehicles are nearly on the same level across our three countries. Discussing with Mexicans, there seems to be a greater tendency not to report crimes to the police due to a high distrust in policing, especially when there is no insurance to cover the damage. Hence, we assume more under-reporting of car-related property crimes in Mexico than in Germany and the USA.

Considering vandalism against the car, namely scratches, the destruction of parts and arson, Germans and Mexicans are on a similar level of fear. Americans are partly significantly less fearful of becoming a victim of vandalism than Germans and Mexicans. One possible explanation for this result is the influence of victimization on fear. As can be seen in Table 3.12, for all car-related vandalism offenses, the number of victims among our participants was smallest in the USA. Additionally, our results show significance in all countries. Having been already once a victim of scratches and destroyed parts increases the fear of becoming a victim again. Therefore, we think that Americans are least fearful of becoming a victim of vandalism since 
American subjects have the smallest victimization rate across our participants considering vandalism.

Considering the influence of gender on fear, there is significant evidence that German and American females are more worried of becoming a victim of violent car-related crimes than males. However, there is no such evidence in Mexico. We assume that due to higher brutality as well as use of violence in Mexico even males feel helpless to protect against violent crimes.

Considering the age, we only found significant influence for violent crimes in Germany. Results suggest that older Germans are more worried than younger Germans to become a victim of violent car-related crimes.

We think that significant results were only found for violent crimes since both carjacking and assault while leaving or entering the car are the only specific crimes in our list where the offender directly meets the victim and makes use of violence to commit the crime. Hence, only during these crimes does the potential victim have the opportunity to counteract and is exposed to danger of becoming (seriously) injured. The other crimes are generally committed in the absence of victims.

The fear of becoming a victim of car theft and theft of car parts is hardly affected by the possession of insurance. Although insurance covers the damage, several restrictions exist. First, insurance does not cover the original value but the present value of the vehicle. Second, some insurance policies calculate an excess. Third, the damage is not adjusted immediately, i.e. the refund is not provided immediately. For example, the payout for a stolen car is generally processed after several weeks since the insurance company awaits the possible recovery of the stolen vehicle. Last but not least, as seen from our analysis of victimization surveys in the previous chapter, car theft as well as the theft of car parts come along with annoyance despite the driver having insurance. Therefore, having insurance does not significantly influence the fear of crime.

\subsubsection{Quality of police work}

The general indication across all countries is for a majority to disagree that the police do a good job tackling car-related crime. Moreover, this trend is continued in the rating of the capability of the police to recover stolen cars. Although there is evidence in all countries that participants are unsatisfied with policing, the dissatisfaction is significantly higher in Mexico than in Germany and the USA. Mexicans suffer from a corrupt police, whose police officers, especially those in local police forces, are often involved in organized crime. In our opinion, the trust in policing partly influences the fear of crime. Therefore, this elevated distrust is a further reason for the higher fear of crime in Mexico. 


\subsubsection{Willingness to have car recovered}

Overwhelming majorities in each country want their car to be recovered after its theft. The willingness differs marginally between Germany and the USA. Mexicans show a significantly higher willingness to get their car back. We tested whether the possession of insurance covering car theft influences the demand for recovery. Based on the mean values in each country there is a tendency for individuals without insurance to be more willing to get their car back. However, the results are not significant. Nevertheless, we think that the possession of insurance explains why Mexican participants would be more committed to recovering their vehicle were it stolen. As can be seen in Table 3.4, Mexican subjects form the smallest proportion across subjects without insurance compared to Germany and the USA.

\subsubsection{Demand for security systems}

In our opinion, subjects feeling confident of influencing whether or not they become a victim of car-related crime are potential customers for security functions. We assume that they tend to make use of tooling or measures, and thus, security functions, to tackle car-related crime. In contrast, participants feeling helpless about their ability to influence their victimization rate probably won't spend money or resources for tooling, measures or special behavior to tackle crime since they have given up and consider themselves helpless anyway. Although there are no significant differences across countries, marginal differences indicate that Mexicans are the least confident about influencing their victimization rate. In contrast, Germans feel the most confident followed by Americans. This trend can be explained with the existing fear of car-related crime. A higher fear of car-related crime eventually increases the feeling of being helpless to influence victimization.

Despite these results, Mexicans stand out significantly by actively using security systems to control whether they become a victim of car-related crime. In contrast, for Germans as well as Americans there are mixed positions with a tendency not to use security systems to control victimization rate. We think that people who actively aim to control their likelihood of becoming a victim are open minded about innovative security functions since they draw on security measures in order to have tooling with which they can control their vulnerability.

Mexicans also stand out, with significant numbers agreeing that more and better security systems are necessary to tackle car-related crime. In contrast, there are mixed positions in Germans and Americans. We think that Mexicans show an increased demand for security systems due to their higher fear of car-related crime. In contrast, Germans and Americans do not necessarily see a need for further security systems to tackle car-related crime.

Overall, Mexicans seem to be the best candidates for the use of security functions, although they tend to be least confident about influencing their victimization rate. 


\subsubsection{Importance of security systems}

The importance of the security systems themselves is significantly higher in Mexico compared to Germany and the USA. This goes hand in hand with the results on the demand for security systems, which is highest amongst Mexicans. This can be explained by the higher fear of carrelated crime amongst Mexicans. However, on the overall importance of security systems, i.e., the importance of security systems compared to other criteria when buying a car, there are no large differences across the countries. Indeed, the prioritization is similar in all three countries. Security systems play a minor role across all countries. Instead, criteria such as quality, price and maintenance costs or assistance systems, play a more important role for buyers. Therefore, we would argue that independent of the country in which security functions are introduced, efforts would need to be made to advertise security functions and to convince customers of the benefits of security functions.

\subsubsection{Limitations}

Our victimization survey comes with some limitations. First, the population of potential subjects within each country is not representative of the population at large. We mainly used the internet, i.e., forums and social networks, as well as personal connections to spread the link to the questionnaire. We also partly sent the link to Volkswagen employees in the USA and Mexico to gain participants. Second, the majority of our participants are young, i.e., between 26 and 40 years old across all countries. A reason could be that we conducted an online survey and younger persons might tend to have a higher affinity for the internet, and thus spend more time using it. Nevertheless, we had sufficient participants to create groups and test our hypotheses. Third, since we have had no opportunity to interview our subjects, we are unaware of their motivation for participating in our survey. It is imaginable that victimized persons or persons who are interested in car-related crime, were especially drawn to the survey.

\subsection{Summary}

We conducted our own victimization survey in Germany, the USA and Mexico to gain a deeper understanding of fear of car-related crime and security systems tackling car-related crime. There were three main reasons for conducting these surveys. First, existing victimization surveys come along with different methodologies so comparability of data across countries is limited. Second, these surveys consider all forms of crime and do not focus on car-related crime. Third, fear of car-related crime as well as the importance and demand for automotive security systems are not covered. Of course, our participant sample sizes were not comparable with the number of participants participating in the CSEW, ICVS and NCVS. Nevertheless, our surveys showed suitable trends considering car-related crime. 
Across most types of crime, Mexicans rate crime occurrence as highest and Germans as lowest. Americans are between both. The fear of crime is mainly similarly graded, with Germans the least and Mexicans the most fearful. However, considering specific car-related crimes, the aforementioned trend is not entirely confirmed. Only car-related crimes associated with violence and bodily injury follow this trend. For car-related property crimes, Mexicans are still the most fearful with Germans and Americans at the same level. Considering vehicle vandalism Germans' and Americans' fear is also at the same level. The likelihood of becoming a victim of these crimes is accordingly rated. Our results additionally showed that in Germany and USA, females are significantly more worried of becoming a victim of violent car-related crimes than males. In Mexico, the participants who had been a victim of most sorts of car-related crime are significantly more worried about becoming a victim again. Furthermore, insurance appears to have no influence on the fear of insured car-related crimes, with the trust in the Mexican police significantly worse than in Germany and USA. In all countries, the majority would want to get their stolen car back. Mexicans show a higher demand for security systems. However, despite differences in the fear of crime, the importance of security systems compared to other criteria when purchasing a car is nearly similar in all countries, that is, less important. So, although the fear of crime is on the whole different in all countries, especially for Mexico, security systems play a minor role in all of the countries compared to other properties relating to the car.

Since car recovery is important for the majority of participants, security functions helping to prevent car theft or to recover a stolen car would seem to satisfy customer demands regardless of country. Security functions tackling violent car-related crimes and aiming to reduce fear of crime seem to be more necessary in Mexico than in Germany and USA. In all countries, security functions will have to be convincing since other systems and properties are more important for customers when buying a car. 


\section{Chapter}

4

\section{Design of structured approach}

In this chapter, we present our methodology SAIAS (Structured Approach to Identify Automotive Security Functions) in order to identify automotive security functions in a structured way. SAIAS is based on two theories from crime science, namely the Rational Choice Perspective (RCP) and Situational Crime Prevention (SCP). We first provide an introduction to both theories, with a focus on crime scripts as a part of the RCP, and the 25 techniques of situational prevention as a part of SCP. We then introduce countermeasures from the automotive field which aim to tackle vehicle-related crime. Developing security functions, deeper knowledge about state-of-the-art countermeasures is essential here. In the third section, we introduce SAIAS where existing countermeasures, a categorization of vehicle-related crime as well as enabling technologies form the main part of SAIAS in collaboration with crime scripts and the 25 techniques.

\subsection{Introduction to crime science}

Surveying the literature, we identified two criminological theories, Rational Choice Perspective and Situational Crime Prevention. These two theories are the basis for our structured approach. In Clarke's opinion [50] both theories can be used to tackle all categories of crime, and thus vehicle-related crime too. Additionally, the success of the theories has been demonstrated in several studies, which are summarized in [51] and [52]. In the following, we present the RCP and SCP, focusing on crime scripts and the 25 techniques of situational crime prevention.

\subsubsection{Rational Choice Perspective}

The Rational Choice Perspective aims to understand crime from the perspective of the offender [50] and deals with the offender's decisions and choices made while committing a crime. Clarke and Cornish [53, 54,55], advocates of the Rational Choice Perspective, suggest several basic propositions. First of all, crimes are committed deliberately and follow a specific purpose. In other words, offenders commit crimes to derive benefits. However, the set of benefits is not limited to cash or material goods. Prestige, sexual satisfaction, fun or excitement can also be benefits from offender's point of view. An example from the automotive field is vehicle 
vandalism, where offenders damage the vehicle either to satisfy their aggressions, to show off in front of peers or for other reasons which do not necessarily imply financial benefits.

Second, decisions and choices vary depending on the offense. A crude distinction between crime categories like vehicle-related crime or burglary is not enough. These categories are too generic and cover a broad spectrum of offenses for which many different skills and methods are needed. To analyze the decision and choice-making process, the offense needs to be described as specifically as possible to limit the scope. For example, Poyner and Webb [56] researched the influence of housing design and layout on crime. Their results show different patterns in residential burglaries targeting cash and jewelry, and burglaries targeting electronic goods. First of all, electronic goods are bulky and need organization of transportation whereas cash and jewelry are much more portable. Second, burglars targeting cash and jewelry are more flexible when considering the escape from the crime scene because it is less likely that they will park a vehicle in the immediate proximity. Last but not least, dealing with electronic goods requires a more organized network. Consequently, depending on the target, different measures are required to prevent domestic burglaries.

Clarke and Cornish's final proposition focuses on the sequence of decisions and choices which an offender makes when conspiring to commit a crime. At this point the script concept, which can be ascribed to Schank and Abelson [57, 58, 59], provides a structured approach. By definition in [58], "a script is a structure that describes appropriate sequences of events in a particular context. A script is made up of slots and requirements about what can fill those slots. The structure is an interconnected whole, and what is in one slot affects what can be in another. Scripts handle stylized everyday situations." That means, scripts consist of sequences of dependent events. Early events in the sequence are mandatory to enable the occurrence of later events. Furthermore, there is a causal chain of scenes which are divided into events resembling a theatre script. The script concept can operate at different levels of abstraction [59]. Schank and Abelson [58] suggest the following terminology to distinguish between different levels of abstraction: universal script, metascript, protoscript, script and track. The universal script represents the most abstract level and track represents the most specific and detailed level. Thus, related scripts can be classified hierarchically. However, the term script is used concurrently, referring to both a specific level of abstraction and to a sequence of events irrespective of the level of abstraction.

A typical example [60] to illustrate the script concept cited in literature [61,62] is the so called "restaurant script" provided by Schank and Abelson [58]. The restaurant script structures the procedure of a restaurant visit as follows: entering the restaurant, waiting to be seated, getting the menu, ordering food, eating, getting the check, paying and exiting. The restaurant script might be subdivided for example into the following scenes: entering, ordering, eating and exiting [61]. In the case of the restaurant script a general script is provided. But within the script, we have different tracks: a fast food track, a cafeteria track or plusher upmarket track [61]. In contrast to the general restaurant script, these different tracks involve different procedures dependent on the kind of restaurant. Hence, the different scripts at the track level are subordinated to the general restaurant script. Leddo and Abelson [63] provide a universal script abstracted into most highly generalized scenes, which are listed in the first column of Table 4.1. Due to the high abstraction level, the universal script can be applied to a wide variety of different scripts [64]. 
Table 4.1.: Universal script and two examples of vehicle-related crime scripts $[62,63,65]$

\begin{tabular}{|c|c|c|}
\hline & Example $1[62,63]$ & Example $2[62,65]$ \\
\hline Universal script: [63] & Vehicle crime & Vehicle crime \\
\hline Metascript: & Theft of property & Theft of property \\
\hline Protoscript: & Auto theft & Auto theft \\
\hline Script: & Temporary use & Temporary use \\
\hline Track: & Performance driving & Transport \\
\hline $\begin{array}{l}\text { Universal script } \\
\text { scenes }\end{array}$ & Script events & Script events \\
\hline Preparation & Gather tools & $\begin{array}{l}\text { Get screwdriver } \\
\text { Get scaffold tube } \\
\text { Select }(2) \text { co-offenders }\end{array}$ \\
\hline Entry & Enter parking lot & Go to public car-park \\
\hline Pre-condition & Loiter unobtrusively & - \\
\hline $\begin{array}{l}\text { Instrumental } \\
\text { pre-condition }\end{array}$ & Select vehicle & $\begin{array}{l}\text { Reject alarmed cars } \\
\text { Choose older Cortina }\end{array}$ \\
\hline $\begin{array}{l}\text { Instrumental } \\
\text { initiation }\end{array}$ & Approach vehicle & $\begin{array}{l}\text { Force lock with screwdriver } \\
\text { Enter vehicle }\end{array}$ \\
\hline $\begin{array}{l}\text { Instrumental } \\
\text { actualization }\end{array}$ & Break into vehicle & $\begin{array}{l}\text { Break off trim } \\
\text { "Scaff" ignition barrel } \\
\text { Remove ignition and steering } \\
\text { lock } \\
\text { Activate starter switch }\end{array}$ \\
\hline Doing & Take vehicle & Drive away and use vehicle \\
\hline Post-condition & Reverse out of bay & Abandon by next day \\
\hline Exit & Leave parking lot & - \\
\hline
\end{tabular}

Crime scripts are specific scripts describing the events during crime perpetration. To illustrate the use of crime scripts, Table 4.1 presents besides the universal script in the first column two examples of vehicle-related crimes cited from literature $[62,63,65]$. The second column shows script events associated with temporary car theft for joyriding. The third column shows temporary car theft for transport. Additionally, the hierarchical levels for both crimes are shown in the first row. Both crimes involve stealing a car for temporary use and differ only at the track level. Although we have the opportunity to describe the occurrence of events at various levels of abstraction, according to [66], only the track level or at least the script level are generally specific enough to generate suitable information to fulfil the purposes of situational crime prevention. 


\subsubsection{Situational Crime Prevention}

Since the early 1970s, Situational Crime Prevention has a long history in criminology [62] where a few authors contributed to establish Situational Crime Prevention as an accepted theory. In the early 1970s, Newman [67] introduced the idea of "defensible space", which refers to residential design with measures like installed alarm systems and well-lit areas to reduce or even stop crime. Concurrently, Jeffery [68] introduced and formulated an approach dealing with crime prevention through environmental design. In contrast to Newman, Jeffery focused on non-residential premises e.g. shops and factories. However, Situational Crime Prevention achieved the breakthrough with the publication of Clarke's collection of successful case studies in the early [51] to late [52] 1990s, which showed the successful application of Situational Crime Prevention.

Situational Crime Prevention makes use of measures to reduce crime opportunities, focusing on specific forms of crime. Thus, Situational Crime Prevention has a crime-specific focus in common with the Rational Choice Perspective. It comprises the immediate setting and aims to increase the risk and difficulty of committing crime as well as reduce the rewards for the offender. To achieve these goals, the Situational Crime Prevention model provides a list of 25 techniques of situational prevention $[69,70]$ which are divided into five categories:

- increase the effort

- increase the risks

- reduce the rewards

- reduce provocations

- remove excuses

The first category summarizes techniques which increase the effort which the offender has to make in order to commit a crime. The second category summarizes techniques which increase the risk of the offender being exposed during the criminal act. The third category includes techniques to reduce the rewards and benefits the offender expects to gain. The fourth category focuses on reducing and avoiding any provocations which may tempt or incite the offender to commit the offense. Techniques in the fifth category aim to counter any excuses which offenders may use to justify their criminal acts.

These 25 techniques have a long history and have been continuously extended and improved. The first formulation of situational prevention techniques was provided by crime scientists in 1980 [71], consisting of eight opportunity-reducing techniques: target hardening, target removal, removing the means to crime, reducing the pay off, formal surveillance, natural surveillance, surveillance by employees and environmental management. However, developments in theory and practice required modifications and adjustments. Therefore, Clarke revised the approach in 1992 [51], with 12 techniques grouped in three categories: increasing effort, increasing the risks and reducing the rewards. In 1997 these 12 techniques were further extended into 16 techniques, and a category, "removing excuses", was introduced [52, 72]. Later, a fifth category, "reducing provocation", joined. To the best of our knowledge, Table 4.2 shows the current approach, consisting of the 25 techniques in five categories, each with five techniques. 
Table 4.2.: 25 techniques of situational prevention [69]

\begin{tabular}{c|c|c|c|c}
\hline \multicolumn{5}{c}{ Main categories of 25 techniques } \\
\hline $\begin{array}{c}\text { Increase the } \\
\text { effort (A) }\end{array}$ & \begin{tabular}{c} 
Increase the \\
risks (B) \\
\multicolumn{5}{c}{ Reduce the } \\
rewards (C)
\end{tabular} & $\begin{array}{c}\text { Reduce } \\
\text { provocations } \\
\text { (D) }\end{array}$ & $\begin{array}{c}\text { Remove } \\
\text { excuses (E) }\end{array}$ \\
\hline $\begin{array}{c}\text { Harden targets } \\
\text { (A1) }\end{array}$ & $\begin{array}{c}\text { Extended } \\
\text { guardianship } \\
\text { (B1) }\end{array}$ & $\begin{array}{c}\text { Conceal targets } \\
\text { (C1) }\end{array}$ & $\begin{array}{c}\text { Reduce } \\
\text { frustrations } \\
\text { and stress (D1) }\end{array}$ & Set rules (E1) \\
\hline $\begin{array}{c}\text { Control access } \\
\text { to facilities } \\
\text { (A2) }\end{array}$ & $\begin{array}{c}\text { Assist natural } \\
\text { surveillance } \\
\text { (B2) }\end{array}$ & $\begin{array}{c}\text { Remove targets } \\
\text { (C2) }\end{array}$ & $\begin{array}{c}\text { Avoid disputes } \\
\text { (D2) }\end{array}$ & $\begin{array}{c}\text { Post } \\
\text { instructions } \\
\text { (E2) }\end{array}$ \\
\hline $\begin{array}{c}\text { Screen exits } \\
\text { (A3) }\end{array}$ & $\begin{array}{c}\text { Reduce } \\
\text { anonymity (B3) }\end{array}$ & $\begin{array}{c}\text { Identify } \\
\text { property (C3) }\end{array}$ & $\begin{array}{c}\text { Reduce } \\
\text { emotional } \\
\text { arousal (D3) }\end{array}$ & $\begin{array}{c}\text { Alert } \\
\text { conscience (E3) }\end{array}$ \\
\hline $\begin{array}{c}\text { Deflect } \\
\text { offenders (A4) }\end{array}$ & $\begin{array}{c}\text { Utilize place } \\
\text { manager (B4) }\end{array}$ & $\begin{array}{c}\text { Disrupt } \\
\text { markets (C4) }\end{array}$ & $\begin{array}{c}\text { Neutralize peer } \\
\text { pressure (D4) }\end{array}$ & $\begin{array}{c}\text { Assist } \\
\text { compliance } \\
\text { (E4) }\end{array}$ \\
\hline $\begin{array}{c}\text { Control tools/ } \\
\text { weapons (A5) }\end{array}$ & $\begin{array}{c}\text { Strengthen } \\
\text { formal } \\
\text { surveillance } \\
\text { (B5) }\end{array}$ & $\begin{array}{c}\text { Deny benefits } \\
\text { (C5) }\end{array}$ & $\begin{array}{c}\text { Discourage } \\
\text { imitation (D5) }\end{array}$ & $\begin{array}{c}\text { Control drugs } \\
\text { and alcohol } \\
\text { (E5) }\end{array}$ \\
\hline
\end{tabular}

The interested reader can find an extensive overview of the 25 techniques with examples in [69].

Critique in the literature points out that opportunity-reducing techniques do not necessarily reduce crime, but rather displace it [73]. However, according to Clarke [50], although displacement is unavoidable, it does not necessarily occur when introducing situational prevention measures. The introduction of measures can even lead to a diffusion of benefits. Hesseling [74] reviewed the literature dealing with displacement and examined 55 studies of which $40 \%$ showed no displacement and the remaining $60 \%$ found relatively minor displacement. Guerette and Bowers [75, 76] also examined evaluations of situational prevention measures. They observed that displacement occurs in only one in every four cases. In return, diffusion of benefits was observed in $27 \%$ of all cases.

\subsection{Security measures in the automotive field}

National governments, the automotive industry, insurance companies and other parties have taken several security measures that seek to fight vehicle-related crime. To provide an overview of existing countermeasures, we suggest a rough separation into four categories: preventive, 
protective, detection and reactive measures. Preventive measures seek to prevent the occurrence of vehicle-related crime. When an offender decides to commit a crime, protective measures increase the effort required for its execution and protect property and personal security. Detection measures seek to detect vehicle-related crime and forward or store information about the offense, eventually initiating a reactive measure to reduce damage or injury and help to investigate the crime.

Of course, security measures exist that do not exactly fit into one of the aforementioned categories or could be placed in two or even more categories. But, a discussion about categorization is beyond the scope of this thesis since our goal is to use these categories to provide an overview of existing measures within the automotive field. For our analysis, a rough categorization is sufficient. Table 4.3 summarizes the aforementioned categories including a brief explanation and examples of according security measures, as presented in the following.

Table 4.3.: Existing security measures in the automotive field

\begin{tabular}{l|l|l}
\hline Category & Explanation & Examples \\
\hline $\begin{array}{l}\text { Preventive } \\
\text { measures }\end{array}$ & prevent the occurrence of VRC & $\begin{array}{l}\text { Preventive navigation, awareness } \\
\text { campaigns, vehicle choice, vehicle } \\
\text { decals }\end{array}$ \\
\hline $\begin{array}{l}\text { Protective } \\
\text { measures }\end{array}$ & $\begin{array}{l}\text { increase the effort to commit the } \\
\text { VRC as well as increase the risk as } \\
\text { they take longer to overcome }\end{array}$ & $\begin{array}{l}\text { Locking systems, armored vehicles, } \\
\text { electronic immobilizer }\end{array}$ \\
\hline $\begin{array}{l}\text { Detecting } \\
\text { measures }\end{array}$ & $\begin{array}{l}\text { detect VRC, forward or store infor- } \\
\text { mation about the VRC and eventu- } \\
\text { ally initiate a reactive measure }\end{array}$ & $\begin{array}{l}\text { Alarm systems, bait cars, automatic } \\
\text { number plate recognition, vehicle } \\
\text { and parts marking }\end{array}$ \\
\hline $\begin{array}{l}\text { Reactive } \\
\text { measures }\end{array}$ & $\begin{array}{l}\text { intervene after VRC has been com- } \\
\text { mitted to reduce the damage / im- } \\
\text { pact / injury or help to investigate } \\
\text { VRC }\end{array}$ & $\begin{array}{l}\text { Vehicle tracking systems, remote dis- } \\
\text { abling }\end{array}$ \\
\hline
\end{tabular}

\subsubsection{Preventive measures}

\section{Preventive navigation}

Information about vehicle-related crime and indeed other forms of crime is used to calculate a secure route. This way, the driver is navigated around dangerous areas. Honda came up with a service for its Japanese navigation systems displaying vehicle-related statistics for the destination area [167]. This service informs the driver about crimes, such as vehicle theft or break-ins. Additionally, high-risk areas around the destination are marked by providing the user with visual and audio hints approaching them. To acquire location based data, Honda collaborates with the Japanese police. 


\section{Awareness campaigns}

Public awareness campaigns are used to raise individual awareness of vehicle-related crime and sense of security. The goal is to raise driver awareness, e.g., to hide valuables so that they are out of sight, to lock cars, not to leave keys in the vehicle etc. For example, the Connecticut Department of Transportation distributed handouts on commuter car parks to inform commuters about measures to better protect their cars while leaving them parked during the day [77]. These efforts rely on drivers themselves taking responsibility, namely by following the awareness suggestions.

\section{Vehicle choice}

Popular selling models and their parts tend to be most stolen. The popularity of mainstream vehicles means both, a continuous stream of buyers and a continuous demand for spare parts. Before buying a vehicle, potential customers can gain information about two main aspects. First, they can inform themselves about secure vehicles and second about the popularity of a vehicle and its parts to be stolen. Information is available in media, in the appropriate statistical offices or at insurers. For example, the German union of insurers (GDV) [168] yearly provides information about the mostly stolen cars in Germany. Moreover, Thatcham's vehicle security department [158] regularly conducts vehicle security assessments to almost every new model including attack tests on the vehicle's mechanical as well as security systems. Security is awarded in a 5-star rating system to indicate both the resistance of vehicles to be stolen and the ability to resist theft from vehicle.

\section{Vehicle decal}

In the 1990s, several states in the USA introduced a program to combat vehicle theft. The name of the programs differs, depending on the state or local area e.g., Watch Your Car or Combat Auto Theft $[169,170,171]$, yet the programs follow a similar idea. The vehicle owner registers their vehicle with the relevant state authority. This way, the owner gives the police permission to stop the vehicle during defined hours, 1 a.m. to 5 a.m., and to check whether the vehicle is legally operated or not. To indicate that a vehicle is participating in the program, a program specific decal (sticker) is placed on the front and/or rear windshield. Figure 4.1 shows the decals on a front and rear windshield in Utah. Some programs also allow owners to require that the vehicle be stopped by the police if the vehicle crosses or is less than 1 mile away from a border or international port. 

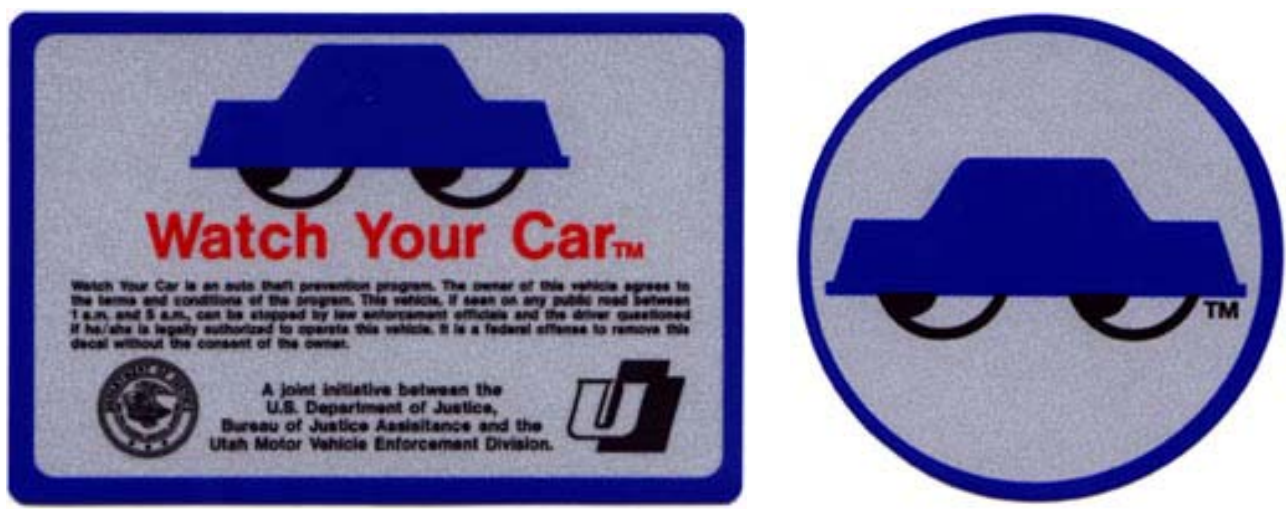

Figure 4.1.: Front and rear decal of Utah's watch your car program [172]

\subsubsection{Protective measures}

\section{Locking systems}

A locking system is probably the most basic security feature within the automotive field. Its main goal is to deny access into the vehicle. Some vehicles are equipped with a double locking system [173], where, after locking doors with the remote key, the door cannot be unlocked even when the inside doorknob is used. Thus when the window is smashed, the door cannot be unlocked from the inside. To disarm the double lock system, either the wireless key needs to be used or the driver's door must be unlocked mechanically with a key. To avoid occupants being locked inside the vehicle, the system is only enabled when the ignition is turned off and keys are removed. Furthermore, some vehicle manufacturers provide a feature where all doors are locked from the outside as soon as the vehicle starts driving and remain locked to avoid intrusion of offenders especially during stops, e.g., at traffic lights.

\section{Armored vehicles}

Armored vehicles have shatterproof windows and additional invisibly integrated reinforcement elements made from special steel to resist gun fire or other attacks. Most manufacturers of high end vehicles also offer armored versions. However, due to the high price, armored vehicles are unavailable to most buyers, tending to be reserved for politicians or wealthy customers. 


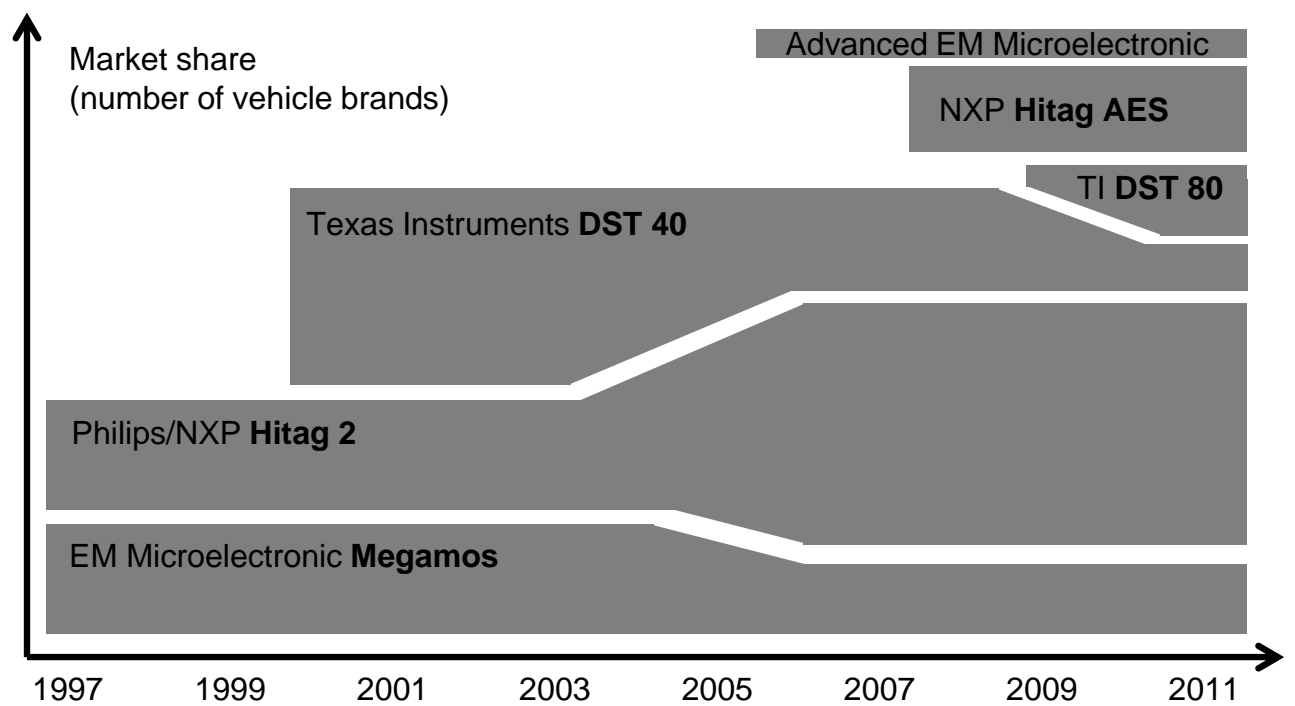

Figure 4.2.: Qualitative overview of the market share of existing immobilizer technologies [82]

\section{Electronic immobilizers}

Electronic immobilizers have been available since approximately 1991 and aim to increase the effort needed to start the vehicle by intruders without the proper key. Due to continuous improvements, several generations of immobilizers have entered the market [78]. Unfortunately, there is not much information on current solutions since vehicle manufacturers and suppliers strictly withhold information about their design [79]. Electronic immobilizers increase the effort to the point where it is beyond the abilities of unskilled and opportunistic vehicle thieves $[80,81]$. Thus, the introduction and continuous improvement of these systems has contributed to the reduction of vehicle theft [81]. Figure 4.2 shows an overview of the market share of existing immobilizer technologies, based on [82].

\subsubsection{Detection measures}

\section{Alarm systems}

An alarm system makes use of several sensors to detect intrusion or an attempt to intrude into the vehicle. As soon as the alarm system is activated, the device gives an acoustic as well as visual signal to attract attention and consequently stop the offender from intruding. Typically, the built-in horn and lights are used to emit signals. The German Automotive Trust (DAT) [174] publishes a report once a year analyzing the German car market. According to their data, 
the number of new cars equipped with alarm systems underlies a decreasing trend. In the last year only one-quarter of all new cars sold in Germany was equipped with an alarm system. The number of used cars equipped with an alarm system is even lower with approximately $20 \%$.

\section{Bait cars}

In North America, especially in the southwestern states of the USA bordering with Mexico, bait car programs have been initiated [83]. Law enforcement agencies use specially modified bait cars to convict car thieves in the act [84]. Popular stolen cars are equipped with GPS devices as well as hidden audio and video recording devices. Additionally, a communication unit is integrated to alert police when the car is driven, towed away or when wheel rims are stolen. Police are also able to shut down the car remotely and lock the occupants inside the car until police arrive at the scene. Movies showing thieves in the act are available at [175].

\section{Automatic number plate recognition}

Automatic number plate recognition (ANPR) is a technology used to capture images of vehicles focusing on the registration plate in order to extract the registration number. In the USA for example, several stakeholders formed a partnership to install automated number plate readers at ports of entry along the US and Mexican border in both directions [84]. The system is connected to local, regional as well as national databases and provides immediate alerts to according law enforcement agencies as soon as suspicious vehicles are identified. Moreover, Mexican law enforcement agencies are notified when stolen vehicles enter Mexico. In Germany, infrastructure also exists on highways to capture the number plates of all passing vehicles. However, data is only intended for the purpose of charging tolls for transportation vehicles. Otherwise, the data must be deleted immediately and must not be used for other purposes, such as crime investigation [176].

\section{Vehicle and parts marking}

In 1987, the Tulsa police department introduced a car and parts marking program, Car Brand It [85]. The vehicle identification number (VIN) was etched on all vehicle's windows, sunroofs and $t$-tops. The goal was to force the thief to replace all visibly marked parts in the vehicle in order to avoid detection when driving the stolen vehicle.

South Africa adopted a law in the beginning of 2012 [86] which forces manufacturers to ensure that new vehicles are fitted with microdot technology [177] before being sold. A number of small dots with a unique code, nearly invisible to the human eye and very difficult to remove, are etched throughout the vehicle on its parts. To detect these dots, an UV light is necessary. In case the vehicle is stolen, police can access a national database which stores the unique codes. 
The South African government anticipates its use will provide a deterrent effect and function as an effective measure to identify stolen vehicles and parts.

\subsubsection{Reactive measures}

\section{Vehicle tracking systems}

Several vehicle manufacturers offer the opportunity to integrate vehicle tracking systems (VTS), such as Cobra [178] or OnStar [179], into their vehicles. The common idea of VTS is the same. A sophisticated "black box" with a GPS receiver, a GSM module and internal battery backup is mounted in a hidden place in the vehicle. As soon as a theft is detected or reported, a silent alert is sent to a service center. Then, the service center tracks the position of the stolen vehicle and forwards the location to the police. Moreover, VTS exist which trigger an alert when the system battery is disconnected, when motion is detected despite a deactivated ignition, when the wiring is cut or when the GSM or GPS signal is jammed. The user is also informed when the vehicle leaves a predefined geo-fence, i.e., a specified area, which can be established via web access.

The Brazilian department of transportation (DENATRAN) [180] takes another way of vehicle tracking and pushes a program, called SINIAV [181] (National System for Automatic Identification of Vehicles). The program intends to equip vehicles with a RFID chip including unique identification data. This way, an automatic identification and tracking of vehicles can be performed through roadside stations as soon as vehicles pass in range. Data is transmitted to a central database where stolen or cloned vehicles are detected.

\section{Remote disabling}

VTS applications such as OnStar [179] also support remote ignition blocking to prevent vehicle restart once the vehicle is turned off. However, the police has to authorize this process. Additionally, police can collaborate with the provider to gradually slow down a vehicle though this approach depends on the legislation in the relevant country or province. 


\subsection{SAIAS - Structured Approach to Identify Automotive Security functions}

In this section, we introduce SAIAS, our approach to identify security functions in a structured way. SAIAS serves primarily as a problem-solving guide and allows perspectives to be acknowledged which might be overlooked when identifying security functions without a structured approach. SAIAS is mainly based on crime scripts and the 25 techniques of situational crime prevention which were introduced in Section 4.1. However, SAIAS additionally depends on a categorization of vehicle-related crime, existing (automotive) countermeasures and enabling technologies. Therefore, we suggest categorizations for the aforementioned fields in the following before finally presenting SAIAS.

\subsubsection{Categorization of vehicle-related crime}

The term vehicle-related crime comprises a broad range of different crimes which relate to vehicles. We mainly focus on passenger cars though other motor-operated road vehicles such as buses, motorbikes and trucks are also considered since they constitute a non-negligible number of vehicles e.g., in Germany one-quarter of registered motor-operated road vehicles [140]. Additionally, with $\mathrm{V} 2 \mathrm{~V}$ communication the involvement of a broad number of vehicles is of great importance, especially to achieve high penetration rates in the roll out phase of V2V communication.

One known vehicle-related crime is vehicle theft. On the motivation to steal a vehicle, several reasons exist [87]:

- Gaining temporary transportation

- Committing another crime

- Joyriding

- Stripping down the vehicle to resale parts

- Reselling the entire vehicle

Furthermore, there are various means and ways of stealing a vehicle. The following list shows possible approaches used to steal a vehicle:

- Theft of closed and unattended vehicles: the thief has no access to keys so physical access has to be gained into the vehicle and the security systems bypassed. Depending on several factors, such as age, make or model, specific and sophisticated skills, especially for newer vehicles, are necessary to circumvent security systems.

- Theft from the home (homejacking) or car dealership (showroomjacking): thieves gain unauthorized access to homes or showrooms to steal the key or even key boxes. Afterwards, they use these stolen keys to access the vehicle. Little effort or sophisticated skills are necessary to gain access into the vehicle and bypass security systems. 
- Opportunistic theft: the thief takes advantage of the drivers' inattention or neglect to acquire the vehicle. For example, in Dubai it is common to leave a running vehicle while visiting gas stations, banks, fast food restaurants or mosques, mainly in order to keep the air conditioning running. However, this has increased the number of opportunistic vehicle thefts [182]. Consequently, Dubai Police plans to fine drivers who keep unattended vehicles running.

- Fraudulent theft: the thief uses fraudulent methods to acquire the vehicle. For example, the offender pretends to be an employee of a valet parking service. This way, the thief gets in possession of the keys, and thus, the vehicle.

- Carjacking: the thief uses violence or the threat of violence, often in connection with weapons, to get into possession of the running vehicle.

Besides the theft of vehicles themselves, further types of crime include the theft of vehicle parts, theft from the inside of vehicles and vehicle vandalism. Additionally, the term vehicle-related crime includes any attacks against the driver as well as passengers while entering, using and exiting the vehicle. These crimes may be committed in various circumstances and for a wide number of different reasons, and so our categorization of vehicle-related crime has to consider any malicious attacks involving a vehicle which are directed against occupants and/or the vehicle, causing any sort of property damage, property loss or bodily injury.

As described in Section 4.1.1, the script concept can be used at different levels of abstraction [62]. This way, different families of scripts can be linked hierarchically beginning with more general cases, i.e., abstract categories of crime, to more specific cases, i.e., crimes specified in detail.

We found a broad categorization of vehicle-related crime in the literature that focuses only on car theft [65]. This categorization proposes six types of theft: theft from vehicles, theft of vehicles for joyriding, theft to commit another crime, theft for immediate transport, theft for longer term transport and theft as part of insurance fraud. We seek to provide a more specific and detailed breakdown as well as a wider scope by looking at vehicle-related crime and not just vehicle theft. Therefore, we follow the hierarchical categorization suggested by Abelson and Schank [58] to distinguish between different levels of abstraction (universal script, metascript, protoscript, script and track). The hierarchical categorization is necessary since a suitable identification of security functions is ideally conducted at the track level. At the track level, the crime commission process is fully specified. Hence, we categorize vehicle-related crime within the aforementioned hierarchical levels. We suggest the categorization shown in Table 4.4, which does not claim to be complete and consequently provides further leeway.

The most abstract level is the universal script. Hence, we assign all vehicle-related crimes to this level. The subsequent level (metascript) contains broad crime categories.

- Theft: the unauthorized taking of personal goods or property of another individual

- Burglary: the breaking into and entering of a house or building of another individual with the intent to steal 
Table 4.4.: Hierarchical categorization of vehicle-related crime

\begin{tabular}{|c|c|c|c|c|c|}
\hline Universal & \multicolumn{5}{|c|}{ Vehicle-related crimes } \\
\hline Metascript & \multicolumn{5}{|c|}{ Theft, burglary, robbery, assault, vandalism } \\
\hline Protoscript & Vehicle theft & $\begin{array}{l}\text { Theft of } \\
\text { parts }\end{array}$ & $\begin{array}{c}\text { Theft from } \\
\text { inside } \\
\text { vehicle }\end{array}$ & Arson & Mugging \\
\hline $\begin{array}{l}\text { Script } \\
\text { (motiva- } \\
\text { tion) }\end{array}$ & $\begin{array}{c}\text { Joyride, } \\
\text { insurance } \\
\text { fraud, strip } \\
\text { down, } \\
\text { commit } \\
\text { another } \\
\text { crime }\end{array}$ & $\begin{array}{c}\text { Sell parts, } \\
\text { personal } \\
\text { use, sponta- } \\
\text { neous }\end{array}$ & $\begin{array}{c}\text { Sell } \\
\text { valuables, } \\
\text { personal use }\end{array}$ & $\begin{array}{c}\text { Spontaneous, } \\
\text { malicious }\end{array}$ & $\begin{array}{l}\text { Sell } \\
\text { valuables, } \\
\text { personal } \\
\text { use, sponta- } \\
\text { neous }\end{array}$ \\
\hline $\begin{array}{l}\text { Track } \\
\text { (influencing } \\
\text { factors) }\end{array}$ & \multicolumn{5}{|c|}{$\begin{array}{c}\text { Location, e.g., (un)attended vehicle, closed structure, lit surroundings, } \\
\text { video surveillance } \\
\text { Time, e.g. day, night } \\
\text { Approach, e.g. fraudulent, opportunistic, with(out) keys } \\
\text { Involved persons, e.g. (co)offender, owner }\end{array}$} \\
\hline
\end{tabular}

- Robbery: the unauthorized taking of personal goods or property of another person in their immediate presence against that person's will by using violence or intimidation

- Assault: the threat of or use of violence or a physical attack on someone with or without a weapon, e.g., handgun or knife

- Vandalism: unauthorized damage to a person's personal goods or property

Theft includes the theft of and from vehicles including parts, accessories and personal effects. As we determined that vehicle-related crime also encloses any attacks against the driver and passengers while entering, using and exiting the vehicle, robbery and assault are also mentioned. Burglary is part of the group as well. Considering homejacking, the burglar unlawfully enters a house to get in possession of car keys. Vandalism includes crimes that intend to cause property damage, especially to vehicles. At the metascript level, crimes can fall into more than one category and these tend to become blurred. Therefore, the metascript row is continuous in Table 4.4, and there is no separation between the aforementioned crime categories. For example, with carjacking the attacker aims to steal the vehicle, which is a theft. But the offense goes hand in hand with an assault against the driver or passengers when the attacker is armed with a firearm or a knife or uses the threat of violence. Homejacking is similar. The burglar enters a house unlawfully to get in possession of the keys. Thus, they commit a burglary before the theft. 
The next more specific level (protoscript) contains crime categories which are subordinated to the metascript categories. Examples of this category are vehicle theft, theft of parts, vehicle arson and mugging.

Next, the script level describes the crime in more detail by defining the offender's motivation to commit the crime. For example, a vehicle theft can be committed either to strip down the vehicle, to use the vehicle to commit another crime or to resell the whole vehicle. Referring to arson, the offense can be committed to cause economic damage to someone's property in order to take revenge. But a randomly chosen vehicle can also be damaged for example as a test of courage or to show off.

The last and most specific level (track) includes influencing factors which describe the crime in deep detail. A crime occurring during the night is influenced by another type of surveillance than a crime occurring during the day. Therefore, information about the crime scene, the time of day, involved parties and other relevant singularities are bundled at the track level. An extensive elaboration on influencing factors can be found in [29].

\subsubsection{Categorization of countermeasures}

To develop the structured approach, we need a set of existing countermeasures. Being aware of existing countermeasures from the automotive field allows us to identify both gaps where new security functions would help and opportunities to improve existing countermeasures. To categorize existing countermeasures, we make use of the five main categories of the 25 techniques presented in Section 4.1.2. We assign to each category examples of existing countermeasures aiming to tackle vehicle-related crime. Table 4.5 presents the set of countermeasures categorized by these five categories. This table does not claim to be complete so there is of course further leeway. Additionally, it is important to keep countermeasures from other domains in mind. Limiting the scope to existing countermeasures from the automotive field might reduce the potential to identify security functions, thus leading to fewer possible security functions. Further examples referring to non-automotive crime can be found in [183]. 
Table 4.5.: Countermeasures grouped by the five categories of the 25 techniques of SCP

\begin{tabular}{|c|c|}
\hline \multicolumn{2}{|r|}{ Examples of countermeasures } \\
\hline $\begin{array}{l}\text { Increase the } \\
\text { effort }(\mathrm{A})\end{array}$ & $\begin{array}{l}\text { Steering column locks, door locks, (electronic) immobilizers, armored ve- } \\
\text { hicles, electronic card access to parking facilities, necessitating ticket for } \\
\text { exit, street closures, preventive navigation, vehicle choice, remote ignition } \\
\text { disabling }\end{array}$ \\
\hline $\begin{array}{l}\text { Increase the } \\
\text { risks (B) }\end{array}$ & $\begin{array}{l}\text { Neighborhood watch, improved street lighting, improved lighting in park- } \\
\text { ing facilities, noting of personal information, copy ID at dealer shops, secu- } \\
\text { rity attendants in parking facilities and mall parking, CCTV surveillance, } \\
\text { police patrols, vehicle alarms, vehicle tracking systems, vehicle decals, bait } \\
\text { vehicles, automatic number plate recognition }\end{array}$ \\
\hline $\begin{array}{l}\text { Reduce the } \\
\text { rewards }(\mathrm{C})\end{array}$ & $\begin{array}{l}\text { Off-street parking, removable car radio, vehicle and parts marking, mon- } \\
\text { itor pawn shops, license street vendors, searching of the web for stolen } \\
\text { goods, electronic component protection }\end{array}$ \\
\hline $\begin{array}{l}\text { Reduce } \\
\text { provocation } \\
\text { (D) }\end{array}$ & $\begin{array}{l}\text { Polite service, youth centers, awareness campaigns, quick repair of van- } \\
\text { dalism (broken-windows theory), vehicle choice considering security and } \\
\text { insurance ratings, security ratings of facilities, pointing out of additional } \\
\text { security measures (blinking LED, decals), provision of good public trans- } \\
\text { port or taxi services }\end{array}$ \\
\hline $\begin{array}{l}\text { Remove } \\
\text { excuses (E) }\end{array}$ & $\begin{array}{l}\text { Rental agreements, posting of instructions, e.g., "No Parking", "Private } \\
\text { Property", wide parking lots, breathalyzers in vehicles }\end{array}$ \\
\hline
\end{tabular}

\subsubsection{Categorization of enabling technologies}

Enabling technologies provide the basis for security functions, and thus need to be considered within our structured approach. Therefore, a categorization of enabling technologies is necessary to define the framework which will support our structured approach. We suggest a categorization with the following three categories:

- Vehicle-to-X (V2X) communication:

V2X communication involves wireless communication and is generally classified into two groups: vehicle to vehicle (V2V) and vehicle to infrastructure (V2I) communication. V2V refers to communication between vehicles and V2I refers to communication between vehicles and infrastructure, e.g., traffic lights, gas stations, construction side beacons and of course a back-end. In the course of a field operational test, the simTD (Safe and Intelligent Mobility Test Field Germany) project [184], the feasibility and everyday usability of V2X communication was demonstrated [88]. Furthermore, according to [185], the National Highway Transportation Safety Administration assumes that $25 \%$ of all vehicles in the USA will have some kind of V2V communication system by 2020. We do not however limit V2X communication to V2V and V2I communication. Communication between vehicles and mobile devices (V2D), such as smartphones or tablets, also plays an important role. Thereby, a connection via Bluetooth or WiFi forms a solu- 
tion for wireless communication over short distances. The use of GSM or 3G technology also provides a suitable approach to establish communication.

\section{- Advanced driver assistance systems (ADAS):}

ADAS cover a vast diversity of assistance systems from the automotive field. They range from basic systems, such as cruise control or acoustic distance parking assistance, to sophisticated assistants, such as dynamic lighting or lane departure warning. Due to these systems, we have sensors, such as front and rear view cameras. Some vehicles have additional cameras in the mirrors and in the front grill to provide a 360 degree view around the vehicle. Moreover, ADAS such as dynamic cornering lights, which light into corners, or adaptive high beam assistants, which detect oncoming traffic and adjust beams accordingly, actively intervene in the vehicle's lighting system. Lighting systems underlie a steady development. Incandescent systems are being continuously replaced by LED systems, partly in combination with xenon lights. But the future of lighting systems will be dominated by LED lighting [186]. The bandwidth of assistance systems is widely spread. Consequently, the number of sophisticated sensors in vehicles is constantly growing. As part of the work of industry and research into fully automated driving, further sensors and actuators will find, and increasingly have found, their way into vehicles.

\section{- Consumer electronics (CE):}

$\mathrm{CE}$ cover electronic devices for everyday use to satisfy our entertainment and/or communication demands. The scope of CE is almost infinite, so we primarily focus on mobile devices, especially smartphones and tablet PCs. These devices continuously gain importance, supporting us in a wide range of daily tasks. They provide increasing processing power and are mostly up to date. Due to small development cycles, smartphones and tablet PCs contain the newest technological features [187]. In the beginning of 2011, the penetration of smartphones amounted to $18 \%$ in Germany and already doubled to $40 \%$ by the beginning of 2013 [188]. Additionally, two thirds of Germans do not leave home without their device. These impressive numbers and especially rates of growth are not limited to Germany but are similar to most countries worldwide [188]. Due to the fact that mobile devices are increasingly an extension of the individual, the automotive industry also incorporates these devices in automotive applications. A basic example is a hands-free phone system where a V2D communication is generally established via Bluetooth. Meanwhile, most OEMs also provide music streaming via Bluetooth to make use of the built-in audio device. Members of the CCC (Car Connectivity Consortium) [189] pursue the goal of developing solutions for smartphone-vehicle connections. The CCC has created a technology standard, namely MirrorLink, to control a nearby smartphone. Furthermore, OnStar [179], for example, provides a smartphone application in collaboration with appropriate hardware in the vehicle to remotely connect to the vehicle in order to monitor fuel and oil levels, check tire pressure, view calling information and even control the vehicle remotely by (un)locking doors, flashing horns and lights as well as starting the engine.

In Table 4.6, we summarize our categorization of enabling technologies with several examples which are used when applying our structured approach in the next chapter. However, in our 
Table 4.6.: Categorization of enabling technologies

\begin{tabular}{|c|c|c|}
\hline V2X communication & Advanced driver assistance systems & $\begin{array}{l}\text { Consumer } \\
\text { electronics }\end{array}$ \\
\hline $\begin{array}{l}\text { Communication } \\
\text { between vehicle and } \\
\text { - vehicle } \\
\text { - infrastructure } \\
\text { - mobile devices } \\
\text { - home }\end{array}$ & $\begin{array}{l}\text { - Adaptive cruise control (radar sensor, } \\
\text { lidar sensor) } \\
\text { - Blind spot warning (ultrasonic sensor, } \\
\text { Radar sensor) } \\
\text { - Advanced (front) lighting systems } \\
\text { (LED, xenon, camera) } \\
\text { - Parking help systems (Ultrasonic } \\
\text { sensors, cameras) } \\
\text { - Lane departure warning systems } \\
\text { (camera) } \\
\text { - Night vision systems (thermographic } \\
\text { camera, IR camera) } \\
\text { - Voice recognition systems } \\
\text { (Microphones) } \\
\text { - Car finder (GPS) } \\
\text { - Navigation systems (GPS, digital maps) } \\
\text { - Hands-free function (microphones) }\end{array}$ & $\begin{array}{l}\text { Mobile devices } \\
\text { - smartphones } \\
\text { - tablet PCs }\end{array}$ \\
\hline
\end{tabular}

opinion a categorization of enabling technologies can put limits on creativity meaning that other interesting technologies from both industry and research that have potential might not be considered. Due to fast technological development, opportunities based on new enabling technologies constantly change. Therefore, our categorization needs to be seen as an orientation but not limitation of enabling technologies.

\subsubsection{Procedure of SAIAS}

SAIAS applies the concept of crime scripts in collaboration with the five categories of 25 techniques to identify security functions in a structured way. The entire procedure is depicted in Figure 4.3. In the following, we explain the procedure based on an example from the literature $[62,89]$, namely, car theft for temporary joyriding.

The identification of potential security functions can hardly be generated by just considering unspecific crimes. Therefore, the first step of SAIAS makes use of the vehicle-related crime categorization introduced in Section 4.3.1 in Table 4.4 to decide on a specific crime. This decision goes hand-in-hand with a crime definition from metascript down to the track level putting the crime in the according categories as well as subcategories and providing details about the motivation as well as influencing factors. Therefore, we use the template shown in Table 4.7 where the results are collected in the right column according to each level. 


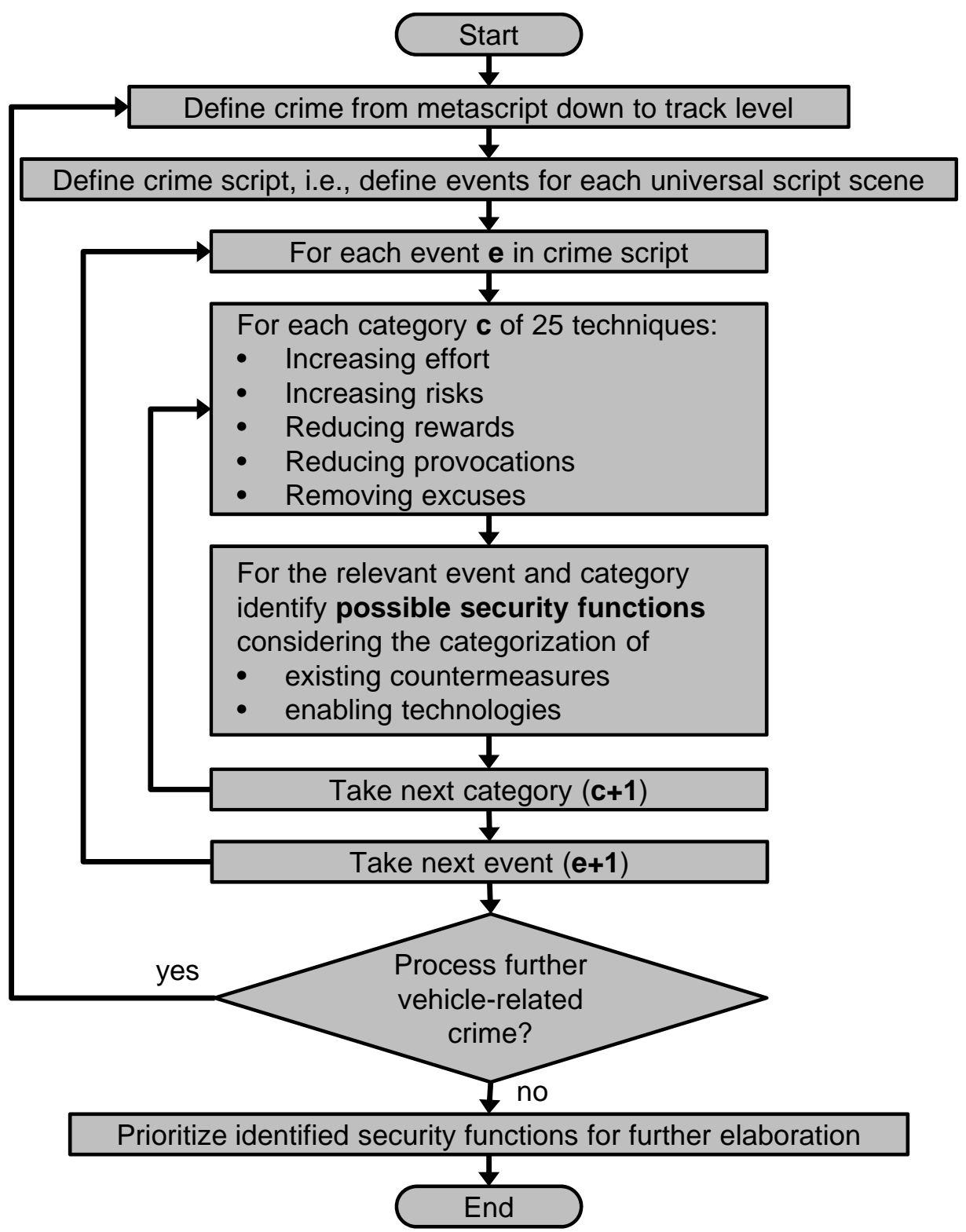

Figure 4.3.: Procedure of SAIAS, the structured approach to identify automotive security functions 
The next step consists of establishing the crime script. A script definition for a universal script is therefore needed describing script scenes of a vehicle-related crime. We have already presented a universal script in Section 4.1 where we presented two examples of vehicle-related crime. However, these crime scripts made use of a general universal script which does not focus on crime scripts but tries to cover a wider field of scripts, such as the restaurant script. Clarke and Eck [89] provide a universal script with a scene definition which has been used to tackle a crime script for joyriding. We use this universal script to describe the universal script scenes of vehicle-related crimes. The according script scenes are shown in the first column of Table 4.8, which is the template to document the events of the crime. That means the relevant scenes are filled with events involved in the specific crime to break down the crime perpetration process at the track level. The second column of Table 4.8 shows the events of our chosen example.

The first universal script scene (preparation) includes events describing the tasks carried out by the offender preparing to perpetrate the crime. The second scene (entering setting) contains events which are made to reach and enter the crime scene. The third scene (enabling conditions) contains activities the offender has to undertake locally to prepare for the crime. The fourth scene (selecting target) contains activities which influence target selection. The fifth scene (completing offense) is a collection of events describing the steps an offender takes to perpetrate the crime. The penultimate scene (exiting setting) includes events describing the escape from the crime scene. The last scene (aftermath) contains activities which the offender undertakes to gain benefit from the crime.

After having specified the events for each scene of the crime, the next step implies the identification of according countermeasures. At this point, the five categories of 25 techniques make their contribution. These five principles are traversed with respect to each event within the crime script and seek to identify existing countermeasures based on the examples in our categorization of countermeasures from Table 4.5. Additionally, the five principles are used in collaboration with the categorization of enabling technologies and existing countermeasures as a problem-solving guide to identify possible security functions for a given event in a structured way. Both, existing countermeasures and identified security functions are documented in the row of the relevant event in the third column of Table 4.8. Identified security functions are highlighted in italics and an upper-case letter is put next to each countermeasure or security function to show they belong to one of the five principles.

Table 4.7.: Template to document hierarchical categorization of specific vehicle-related crimes (Example: car theft for temporary joyriding $[62,89]$ )

\begin{tabular}{ll}
\hline Universal script & Vehicle-related crimes \\
\hline Metascript & Theft \\
\hline Protoscript & Car theft \\
\hline Script & Temporary use \\
\hline Track & Joyriding \\
\hline
\end{tabular}


Table 4.8.: Template to document the application of SAIAS for a specific vehicle-related crime (Example: car theft for temporary joyriding $[62,89]$ )

\begin{tabular}{|c|c|c|}
\hline $\begin{array}{l}\text { Universal } \\
\text { script } \\
\text { scenes }\end{array}$ & Script events & $\begin{array}{l}\text { Possible security functions } \\
\text { and examples of existing counter- } \\
\text { measures }\end{array}$ \\
\hline \multirow[t]{2}{*}{ Preparation } & Get tools & Control sales of equipment (C) \\
\hline & Select co-offender & - \\
\hline $\begin{array}{l}\text { Entering } \\
\text { setting }\end{array}$ & Enter parking lot & $\begin{array}{l}\text { Parking lot barriers (A) } \\
\text { Attendants (A) } \\
\text { Few entrances (B) }\end{array}$ \\
\hline $\begin{array}{l}\text { Enabling } \\
\text { conditions }\end{array}$ & Loiter unobtrusively & $\begin{array}{l}\text { CCTV and/or regular patrols to de- } \\
\text { ter loiterers (B) }\end{array}$ \\
\hline \multirow[t]{2}{*}{$\begin{array}{l}\text { Selecting } \\
\text { target }\end{array}$} & Reject alarmed cars & $\begin{array}{l}\text { Visible protection of tempting vehi- } \\
\text { cles (B) }\end{array}$ \\
\hline & Choose suitable vehicle & - \\
\hline \multirow[t]{3}{*}{$\begin{array}{l}\text { Completing } \\
\text { offense }\end{array}$} & Enter car & $\begin{array}{l}\text { CCTV to monitor suspicious behav- } \\
\text { ior (B) } \\
\text { Improve natural surveillance of lot } \\
\text { (B) }\end{array}$ \\
\hline & Break ignition lock & Vehicle alarm to alert security (B) \\
\hline & Hot wire ignition and start car & Vehicle immobilizer (A) \\
\hline $\begin{array}{l}\text { Exiting } \\
\text { setting }\end{array}$ & Leave parking lot & $\begin{array}{l}\text { Attendants or other exit barriers (A, } \\
\text { B) }\end{array}$ \\
\hline \multirow[t]{2}{*}{ Aftermath } & Use car to joyride & $\begin{array}{l}\text { Vehicle-tracking system activated } \\
\text { (B) } \\
\text { Vehicle curfew program (B) }\end{array}$ \\
\hline & $\begin{array}{l}\text { Abandon car on wasteland and set } \\
\text { fire to car }\end{array}$ & Surveillance of dumping sites (B) \\
\hline
\end{tabular}


Having identified possible security functions, the last step involves the prioritization of potential security functions for further processing, since not all security functions can be further pursued, e.g., due to economical, political, technological or other reasons. Therefore, we suggest defining criteria to support the decision. Considering security functions, we suggest the following criteria:

- Influence on crime: One goal of security functions is to effectively fight at least one vehicle-related crime. So this point represents our expected effectiveness in fighting crime as well as the number of tackled crimes. Of course, a higher rating is achieved when a security function is estimated to be more effective and promises to tackle more than one crime.

- Influence on fear of crime: Security functions also intend to reduce occupants' fear of crime, and thus, increase the feeling of security. This point rates our expected effect on reducing the fear of crime.

- Influence on tangibility: The third goal of security functions is to make security tangible for users. Hence, we give a high rating when the function involves the user in the realization and provides an improved experience factor. The influence on tangibility is listed as separate from the influence on fear of crime, since these two criteria are not necessarily closely coupled. For example, due to user convenience, the tangibility of the electronic immobilizer is effectively not available in today's vehicles. Nevertheless, the fear from vehicle theft is eventually reduced due to the successful achievements of immobilizers in fighting vehicle theft. Furthermore, making a security function tangible may reveal its ineffectiveness and consequently fail to reduce fear of crime.

- Deployment feasibility: Each security function requires several technologies to be realized. From the point of series introduction, high availability and penetration of existing technologies, forming the basis for the according security function, is desirable. Hence, a function based on off-the-shelf and mass components achieves a higher rating than a function based on research technologies.

- Evaluation suitability: The evaluation of a security function comes with several requirements, such as (implementation) costs, human resources and feasibility of evaluation. Thus, security functions suitable for evaluation with means available to us are given high rating.

Each security function is rated considering each criterion. Therefore, we use a scale from low (1) over mid (2) to high (3). Adding these points provides a ranking. Security functions with the highest rating are chosen for further elaboration.

To apply SAIAS in practice, the procedure demands close cooperation across several experts. In the first step, an initiator must come up with a demand for security functions to fight specified vehicle-related crimes. These crimes are ideally specified at least at the script level to limit the frame of possible crime scripts. The initiator can be a governmental institution, a vehicle manufacturer or even a research institution. The initiator then has the responsibility to specify crimes down to the track level, thus giving them the opportunity to draw on the expertise of 
appropriate experts. To identify appropriate experts, the initiator uses the hierarchical crime categorization from Table 4.4. For example, the initiator aims to identify security functions to fight vandalism (metascript) focusing on arson (protoscript). They contact the federal criminal police office and discuss possible reasons for motivation (script). The results show, for instance, that arson is mainly politically motivated and occurs in wealthy districts of large cities. This information is used to get in contact with local police departments in large cities as opposed to rural areas. The initiator can further involve experts working in the field of politicallymotivated crime. With the help of these local and political experts, the initiator specifies typical tracks of politically motivated arson. Additionally, developing the crime from metascript to track level with the help of experts establishes a first expert base which is necessary for the further procedure. Next, with the help of experts the initiator defines the events according to the universal script scenes. Due to this scene definition, the crime perpetration process is divided in several phases from preparation to aftermath. Hence, the initiator draws on their expert base to identify the appropriate experts for each scene of the universal script. This way, the crime commission process is partly achieved. For example, the initiator needs experts to be familiar with the recruitment of attackers to identify events during preparation. Yet other experts are necessary to identify events for exiting the scene after having set the vehicle on fire. Nevertheless, experts can provide their expertise to define events for several scenes of the universal script. When the crime script, i.e. the sequence of events, is defined, the initiator brings its expert base from criminology, research and industry together to discuss and identify possible security functions for each event of the crime script. The expert group draws on the five principles and the categorization of enabling technologies. Before starting to design and implement security functions, the initiator must define the criteria that meet their requirements in order to decide on the security functions to be processed further. This has to be done by the initiator themselves since the criteria differ depending on the interests of the initiator. For example, an initiator working on political research likely pursues different interests and goals than a vehicle manufacturer. Therefore, prioritization criteria as well as the prioritization of security functions should be considered internally. The initiator should however keep their expert base in mind so they may fall back on their expertise to solve arising challenges, e.g., legislation restrictions.

\subsection{Summary}

In this chapter, we introduced crime scripts and the 25 techniques of situational crime prevention. Although both approaches focus on crime in general and not specifically on vehiclerelated crime, they provide in our opinion a suitable basis for a structured approach to identify security functions. Additionally, we used the hierarchical script concept to categorize vehiclerelated crime. Furthermore, we reviewed classical countermeasures from the automotive field which mainly focus on physical target hardening and are far away from any interaction with the user or new technologies. Only VTS, remote disabling and preventive navigation go into the direction of security functions. Hence, there is potential for the development of security functions. To categorize existing countermeasures, we have drawn on the five principles of 25 techniques. Finally, we introduced our methodology SAIAS, which combines crime scripts, 
the five principles and our categorizations to provide a tool to identify security functions in a structured way.

SAIAS comes with several benefits. First of all, the structured approach follows the principle of divide and conquer. According to the script scenes, the crime commission process is subdivided into events which are considered separately. Second, SAIAS supports the merging of knowledge from tailored experts focusing on specific scenes of a crime. Third, since the entire crime process is covered in a structured way, the likelihood of overseeing factors and thus possible security functions is reduced. Moreover, due to the hierarchical definition of VRC, a security function which is identified for a crime script on the track level can be pushed upwards, i.e., to the script or even protoscript level, and thus fighting a broader range of VRCs. Last but not least, SAIAS is not limited to identifying just security functions tackling vehiclerelated crime. The structured approach can be adjusted to tackle all forms of crime and so only a few adjustments need to be made. First the categorization of crime needs to be accordingly adjusted. Second, the categorization of enabling technologies and existing countermeasures needs to be adjusted since we have focused on the automotive field. Third, the universal script as well as the prioritization criteria need to be adjusted. The 25 techniques of situational crime prevention and the script concept provide a core structure surrounded by modules which can be easily replaced as required.

However, SAIAS involves one main drawback which needs to be considered. There are a large number of set-ups, i.e., combinations, to be considered. Processing each event with each category of 25 techniques considering all categorizations implies significant complexity and effort. This complexity would be even greater when replacing the five categories of 25 techniques with the 25 techniques themselves. Complexity can be reduced by excluding specific events for example. A researcher or practitioner may focus on events within one specific script scene, e.g., all events relevant for the scene "completing offense". The complexity may be further reduced by focusing on specific categories within the 25 techniques, so for instance a researcher or practitioner may just consider "increasing effort" and "increasing risk" categories.

Making use of the knowledge from our statistical crime analysis and survey analysis in Chapter 2 and Chapter 3, we apply SAIAS in the next chapter to identify possible security functions. 


\section{Chapter}

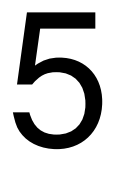

\section{Application of SAIAS to vehicle-related crime}

In this chapter, we apply SAIAS (Structured Approach to Identify Automotive Security functions) to identify possible security functions. Thus, we develop four crime scripts from the metascript down to the track level that aim to define representative crime scripts based on our knowledge gained in Chapter 2 and 3. To cover a wide range of vehicle-related crime, we chose four crime scripts differing at least at the protoscript level according to our vehiclerelated crime categorization from Table 4.4 in Section 4.3.

In the first section of this chapter, we present our four vehicle-related crime scripts including relevant events, existing countermeasures and the security functions we identified. Section 5.2 provides a brief functional description of the identified security functions and additionally shows the relevant set-up within SAIAS which led to the identification. The next section presents the prioritization of our identified security functions including the decision for two security functions for furthermore study. The last section summarizes this chapter.

\subsection{Vehicle-related crime scripts}

In the course of our work, we developed four vehicle-related crime scripts at the track level for the following crimes: car theft, theft from inside a car, vandalism to a car and robbery while going to a car. We consequently applied SAIAS to these crime scripts and traversed the entire process for all crime scripts as shown in Figure 4.3. We did not reduce the complexity by omitting events or categories from the 25 techniques. Since our chosen crimes differ at least at the protoscript level, a wider scope of vehicle-related crime is covered and for the majority of events our crime scripts do not resemble each other. For example, having considered car theft from a public street where the motivation (script level) differs between joyriding and stealing the car to resell the parts, the events would be mostly similar throughout all the scenes of the crime script. Consequently, the measures and security functions working to counteract events were generally similar as well.

In the following, we present our crime scripts as summarized in our templates (Table 4.7 and Table 4.8) introduced in Section 4.3.4. The former template contains the hierarchical catego- 
Table 5.1.: Hierarchical crime categorization for the theft of an unattended car to sell its parts

\begin{tabular}{ll}
\hline Universal script & Vehicle-related crimes \\
\hline Metascript & Theft \\
\hline Protoscript & Car theft \\
\hline Script & Strip down and sell parts \\
\hline Track & $\begin{array}{l}\text { Unattended car, street parking, night, no access to keys, no } \\
\text { persons except the offender and co-offender }\end{array}$ \\
\hline
\end{tabular}

rization of the relevant crime. The latter template contains existing countermeasures as well as our identified security functions in italics.

\subsubsection{Car theft from public street}

The following crime script spells out car theft, a subcategory of theft, where the intention of the thief is to strip down the car and sell the parts. The car is unattended and parked on a public street. The thief steals the car with one co-offender at night and has no access to the car keys. The hierarchical crime categorization is summarized in Table 5.1. The script events of this crime and the relevant countermeasures as well as identified security functions are summarized in Table 5.2. The crime script is explained in the following.

\section{Preparation}

Since the thief aims to sell the parts, they have to decide for a specific make and model first. They choose a car that is easy to steal in order to reduce the time needed to break into the car as well as to easily circumvent relevant security measures. Moreover, a widely-used model is chosen due to the increased demand for spare parts. Car owners can counteract this by considering security or insurance ratings when purchasing their car. Furthermore, the thief has to organize and rent a shop or garage where he can hide and strip down the car. An opportunity to increase the risk of catching the thief is to note the renter's personal information or even copy the ID to reduce anonymity. In order to enter and start the car, the thief must get appropriate tools and skills. Thus, the internet is a useful source. Finally, the thief needs to choose a region where they expect to find the chosen car to steal. A less populated region with good infrastructure to easily leave the scene is suitable.

\section{Entering setting}

According to our script, the thief arrives with an accomplice by car to the scene. Since the car to be stolen is parked on a public street they have no additional hurdles, such as closed parking environment, to get to the car.

\section{Enabling conditions}

Once the thieves arrive in the area, they have to cruise around in the public streets in order to 
find the targeted car type. CCTV surveillance as well as police patrols can be used to identify suspicious persons, and thus, increase their risk of getting caught.

\section{Selecting target}

To select the targeted car, thieves reject cars in well-lit areas. By implication, better street lighting increases the effort needed for the thief to stay unseen. A car visibly showing additional security measures, such as a blinking LED for an alarm system or vehicle decals, reduces its attractiveness as a target. They visualize additional effort and risk when selecting this car so a deterrent effect is created.

\section{Completing offense}

First, the thief has to gain access to the inside of the car. This is realized by smashing the window or using a sophisticated tool, which is obtained during preparation. An alarm system aims to detect this forcible access using several sensors and emits a noisy sound to attract attention. Hence, an alarm system increases the risk of being seen and getting caught in the act. Furthermore, security measures such as electronic immobilizers that protect the car from being illegally started need to be overcome with the help of sophisticated electronic tools.

\section{Exiting setting}

After having gained access and started the car, the thief drives with the stolen car to the rented shop. If the owner detects the theft early enough, a built-in vehicle tracking system can be used to locate the car. A sticker from the vehicle decal program also increases the risk of getting caught when the car is stolen during program hours. Of course, the thief may (try to) remove the sticker. However, this forms an additional task for the thief involving additional effort as well as risk of being detected.

\section{Aftermath}

Finally, the thief must strip down the car and turn the parts into money. Component protection reduces the rewards since additional effort as well as costs are needed to remove the protection of parts involved in the component protection network. Additionally, parts marking facilitates the identification of stolen parts so the thief has to remove these marks, also involving additional costs. Otherwise, the thief runs a higher risk of being revealed. Furthermore, regular monitoring of pawn shops as well as other markets, such as online auctions and shopping websites, disrupts the market and consequently leads to reduced rewards. In the end, any remains which cannot be sold are scrapped. 
Table 5.2.: Crime script for the theft of an unattended car to sell its parts

\begin{tabular}{|c|c|c|}
\hline $\begin{array}{l}\text { Universal } \\
\text { script } \\
\text { scenes }\end{array}$ & Script events & $\begin{array}{l}\text { Possible security functions } \\
\text { and examples of existing counter- } \\
\text { measures }\end{array}$ \\
\hline \multirow[t]{4}{*}{ Preparation } & Choose make and model to steal & $\begin{array}{l}\text { Consider security and insurance } \\
\text { groups when buying car (D) }\end{array}$ \\
\hline & $\begin{array}{l}\text { Organize / rent shop to hide and } \\
\text { strip down car }\end{array}$ & $\begin{array}{l}\text { Note personal information, copy ID } \\
\text { (B) }\end{array}$ \\
\hline & $\begin{array}{l}\text { Get tools (screwdriver, electronic } \\
\text { units) and skills to enter and start car }\end{array}$ & - \\
\hline & Choose region to find car & - \\
\hline $\begin{array}{l}\text { Entering } \\
\text { setting }\end{array}$ & $\begin{array}{l}\text { Use co-offender's car to travel to re- } \\
\text { gion }\end{array}$ & - \\
\hline $\begin{array}{l}\text { Enabling } \\
\text { conditions }\end{array}$ & $\begin{array}{l}\text { Cruise around unobtrusively in re- } \\
\text { gion }\end{array}$ & $\begin{array}{l}\text { CCTV surveillance and police pa- } \\
\text { trols (B) }\end{array}$ \\
\hline \multirow{2}{*}{$\begin{array}{l}\text { Selecting } \\
\text { target }\end{array}$} & Reject cars in well-lit areas & Improved street lighting (B) \\
\hline & Choose suitable car & $\begin{array}{l}\text { Point out additional security mea- } \\
\text { sures (blinking LED, decals) (D) }\end{array}$ \\
\hline \multirow[t]{3}{*}{$\begin{array}{l}\text { Completing } \\
\text { offense }\end{array}$} & $\begin{array}{l}\text { Enter car (smash window, force } \\
\text { lock) }\end{array}$ & $\begin{array}{l}\text { Car alarm (B), cooperative alarm sys- } \\
\text { tem }(B)\end{array}$ \\
\hline & Remove ignition and steering lock & - \\
\hline & $\begin{array}{l}\text { Use electronic unit to bypass immo- } \\
\text { bilizer and start car }\end{array}$ & - \\
\hline $\begin{array}{l}\text { Exiting } \\
\text { setting }\end{array}$ & $\begin{array}{l}\text { Drive with car to rented / organized } \\
\text { shop }\end{array}$ & $\begin{array}{l}\text { Vehicle tracking system (B), vehicle } \\
\text { decal (B), electronic decal (B), visual } \\
\text { vehicle tracking }(B)\end{array}$ \\
\hline \multirow[t]{3}{*}{ Aftermath } & Strip down car & - \\
\hline & Sell parts to pawnbrowkers & $\begin{array}{l}\text { Component protection / parts } \\
\text { marking }(C) \text {, monitor pawnbrowk- } \\
\text { ers }(C)\end{array}$ \\
\hline & Clean up remains & - \\
\hline
\end{tabular}




\subsubsection{Theft of valuables from inside of a car}

According to our hierarchical crime categorization, theft from car is a subcategory of theft. The following crime script comprises the theft of valuables from the inside of a car where the intention is to use the stolen goods for personal purposes. The car is parked in an unattended mall parking garage and the crime is committed during the day. The owner leaves valuables visibly on the back seat and forgets to lock the car. Two offenders collaborate to commit the crime. The hierarchical categorization is summarized in Table 5.3 and the detailed script with relevant events and countermeasures is shown in Table 5.4.

Table 5.3.: Hierarchical crime categorization for the theft of valuables from inside of a car

\begin{tabular}{ll}
\hline Universal script & Vehicle-related crimes \\
\hline Metascript & Theft \\
\hline Protoscript & Theft from vehicle \\
\hline Script & Personal use \\
\hline Track & $\begin{array}{l}\text { Unattended car in mall parking garage, day, driver forgot } \\
\text { to lock doors, valuables are visibly placed on the backseat, } \\
\text { two offenders }\end{array}$ \\
\hline
\end{tabular}

\section{Preparation}

The thieves have to decide on a potential parking garage. They reject well-lit facilities with CCTV surveillance and security attendants. For example, the German automobile club ADAC (Allgemeiner Deutscher Automobil-Club) [190] conducts an annual rating of parking garages in several German cities. The ADAC rates trafficability, usability and pay rates but also security, which has the highest influence on the overall result.

\section{Entering setting}

To get to the scene, the thieves use their own car, though they park it outside of the facility to use it as storage place for stolen valuables. Hence, they have to walk into the garage. Controlling the access, i.e., checking whether entering persons have a parking ticket, increases the effort required to access the facility.

\section{Enabling conditions}

To satisfy the track description, the car owner has to forgotten to lock the car.

\section{Selecting target}

After having entered the parking garage, the offenders loiter unobtrusively in order to observe the scene and find a potential target. Loitering offenders are deterred or even detected by CCTV surveillance. The presence of security attendants enforces the effect.

\section{Completing offense}

One offender follows and observes the victim. This way, the other offender can take valuables from the car without disruption. While completing the offense, CCTV surveillance and security 
patrols might be helpful. However, the offender is not forced to use sophisticated methods to get access to the car since the owner forgot to lock the doors. Thus, criminal behavior is hard to detect.

\section{Exiting setting}

After having hidden the valuables in a backpack, the thief leaves the parking garage and meets their colleague at the car to hide the stolen goods. In the case of smartphones or other trackable devices, the thieves turn them off.

\section{Aftermath}

Dependent on the kind of valuables, the thieves have to eliminate ways of connecting the valuables to the original owner. For example, smartphones are reset to the factory settings or even flashed with new software to remove any spyware leading to the thieves.

Table 5.4.: Crime script for the theft of valuables from inside of a car

\begin{tabular}{lll}
\hline $\begin{array}{l}\text { Universal } \\
\text { script } \\
\text { scenes }\end{array}$ & Script events & $\begin{array}{l}\text { Possible security functions } \\
\text { and examples of existing counter- } \\
\text { measures }\end{array}$ \\
\hline Preparation & Identify potential parking garage & $\begin{array}{l}\text { Improved garage lighting (B), CCTV } \\
\text { surveillance (B), security attendants } \\
\text { (B), security ratings of garages (D) }\end{array}$ \\
\hline $\begin{array}{l}\text { Entering } \\
\text { setting }\end{array}$ & Use own car but park outside & - \\
\cline { 2 - 3 } & Walk into parking garage & Control access to garage (A) \\
\hline $\begin{array}{l}\text { Enabling } \\
\text { conditions }\end{array}$ & Car owner forgets to lock car & Open door/window reminder (A, D, E) \\
\hline $\begin{array}{l}\text { Selecting } \\
\text { target }\end{array}$ & Loiter unobtrusively & CCTV surveillance (B), security at- \\
\hline $\begin{array}{l}\text { Completing } \\
\text { offense }\end{array}$ & Open door and take valuables & CCTV surveillance (B), security at- \\
\hline $\begin{array}{l}\text { Exiting } \\
\text { setting }\end{array}$ & Leave parking garage & - \\
\hline Aftermath & Eliminate connections to original & - \\
\hline
\end{tabular}




\subsubsection{Robbery while going to car}

According to our definition of vehicle-related crime in Section 4.3.1, robbery in general does not fulfill the requirements to be a vehicle-related crime. However, since the robbery in our crime script is committed while the owner walks to the car there is a vehicle relation. The robber mugs the owner's bag to use the content for personal purposes. The offense is committed on a public street during the night. There is no surveillance and the offender acts alone. Table 5.5 shows the hierarchical categorization and Table 5.6 the detailed crime script with countermeasures.

Table 5.5.: Hierarchical crime categorization for a robbery of driver going to car

\begin{tabular}{ll}
\hline Universal script & Vehicle-related crimes \\
\hline Metascript & Robbery \\
\hline Protoscript & Mugging \\
\hline Script & Personal use \\
\hline Track & $\begin{array}{l}\text { Car parked on public street, night, no surveillance, one of- } \\
\text { fender }\end{array}$ \\
\hline
\end{tabular}

\section{Preparation}

The robber must decide on an appropriate scene, ideally with dark and winding streets in order to exit the scene minimizing the risk of being seen and getting caught. Hence, defensible street design and improved street lighting seem promising ways to counteract this. Furthermore, CCTV surveillance and security patrols or neighbor watch contribute in deterring the robber. Thus, the robber examines the scene in advance. Additionally, the robber gets tools or weapons to threaten the victim and for self-defense in case the victim fights back. Strict rules and control of weapon sales increase the effort needed to get in possession of weapons and remove incentives for their use.

\section{Entering setting}

To get to the scene, the robber makes use of public transport since they want to be flexible when running away with stolen goods.

\section{Enabling conditions}

Once the robber arrives in the predestined region, they loiter unobtrusively on the street in order to find a potential victim. CCTV surveillance as well as police patrols can be used to identify suspicious or unknown persons, thus increasing the risks of getting revealed or caught.

\section{Selecting target}

The robber chooses a victim who is physically weaker than them. The victim is alone and distracted, e.g., by using a smartphone or making a call. Hence going out in a group and being attentive reduces one's vulnerability to robbery. 


\section{Completing offense}

To get in possession of the bag, the robber attacks and snatches the bag from the victim.

\section{Exiting setting}

The robber runs away into the dark and winding streets to get away as fast as possible from the crime scene. Defensible street design, improved street lighting, CCTV surveillance, security patrols and neighborhood watch are possible countermeasures in this case.

\section{Aftermath}

Dependent on the kind of goods in the bag, the robber has to eliminate opportunities for connecting the stolen valuables to the original owner, leading to the robber.

Table 5.6.: Crime script for a robbery of driver going to car

\begin{tabular}{|c|c|c|}
\hline $\begin{array}{l}\text { Universal } \\
\text { script } \\
\text { scenes }\end{array}$ & Script events & $\begin{array}{l}\text { Possible security functions } \\
\text { and examples of existing counter- } \\
\text { measures }\end{array}$ \\
\hline \multirow[t]{3}{*}{ Preparation } & Choose scene to commit robbery & $\begin{array}{l}\text { Improved street lighting (B), defen- } \\
\text { sible street design (B), CCTV surveil- } \\
\text { lance (B), security patrols (B), neigh- } \\
\text { borhood watch (B) }\end{array}$ \\
\hline & Examine scene beforehand & - \\
\hline & $\begin{array}{l}\text { Organize tools / weapons to } \\
\text { threaten victim }\end{array}$ & $\begin{array}{l}\text { Set rules and control weapon sales } \\
\text { (E) }\end{array}$ \\
\hline $\begin{array}{l}\text { Entering } \\
\text { setting }\end{array}$ & $\begin{array}{l}\text { Use public transportation to travel } \\
\text { to scene }\end{array}$ & - \\
\hline $\begin{array}{l}\text { Enabling } \\
\text { conditions }\end{array}$ & Loiter unobtrusively & $\begin{array}{l}\text { Improved street lighting (B), CCTV } \\
\text { surveillance (B), security patrols (B), } \\
\text { cooperative home light (B) }\end{array}$ \\
\hline $\begin{array}{l}\text { Selecting } \\
\text { target }\end{array}$ & $\begin{array}{l}\text { Reject inappropriate persons } \\
\text { (strong, not alone, attentive, no } \\
\text { visible bag) }\end{array}$ & $\begin{array}{l}\text { Going out accompanied (B), coopera- } \\
\text { tive home light (B) }\end{array}$ \\
\hline $\begin{array}{l}\text { Completing } \\
\text { offense }\end{array}$ & $\begin{array}{l}\text { Attack victim and snatch the bag } \\
\text { from the victim }\end{array}$ & $\begin{array}{l}\text { CCTV surveillance (B), voice enabled } \\
\text { cooperative alarm system }(\mathrm{B})\end{array}$ \\
\hline $\begin{array}{l}\text { Exiting } \\
\text { setting }\end{array}$ & Run away & $\begin{array}{l}\text { Improved street lighting (B), defen- } \\
\text { sible street design (B), CCTV surveil- } \\
\text { lance (B), security patrols (B), neigh- } \\
\text { borhood watch (B) }\end{array}$ \\
\hline Aftermath & $\begin{array}{l}\text { Eliminate connections to original } \\
\text { owner / robber }\end{array}$ & - \\
\hline
\end{tabular}




\subsubsection{Car vandalism}

The crime script car vandalism describes the scratching of a car by a group of teenagers. As can be seen in Table 5.7, scratching is a subcategory of vandalism. Teenagers loiter without a plan through the streets during the day. The scratched car is parked on a public street.

Table 5.7.: Hierarchical crime categorization for car vandalism

\begin{tabular}{ll}
\hline Universal script & Vehicle-related crimes \\
\hline Metascript & Vandalism \\
\hline Protoscript & Scratching \\
\hline Script & Spontaneous \\
\hline Track & Car is parked on public street, day, group of teenagers \\
\hline
\end{tabular}

\section{Preparation}

The teenagers do not plan to scratch the car. They act spontaneously, though they have to meet each other in order to hang out together. To avoid them meeting up and especially becoming bored, the youths need activities and/or employment. This way, incentives for vandalism are removed since there is no basis for being bored.

\section{Entering setting}

Additional effort to enter the setting is not necessary since public streets are accessible to everyone. Actively monitoring public streets with the help of CCTV surveillance helps identify potential sources of vandalism in advance, i.e., before the act of vandalism happens.

\section{Enabling conditions}

The teenagers must have a tool with them, such as a key or screwdriver, or may find a freelyaccessible tool near the car such as a stone, with which they may inflict the scratches on the car.

\section{Selecting target}

An expensive high end car is tempting in this case since the damage causes higher costs. On the other hand, an old and possibly already damaged car may also be affected. According to the broken-windows theory [27], abandoned and untended property leads to increasing vandalism.

\section{Completing offense}

One teenager takes their keys and scratches the car on the pavement side while passing. CCTV surveillance is not able to prevent the crime, especially when the teenager acts inconspicuously, but recording the scene can help to identify the vandal and solve the crime.

\section{Exiting setting}

Instead of running away, the teenagers simply continue walking since they feel strong in the 
group and want to show off. CCTV surveillance would help to follow the group's way until police or security attendants arrive, if someone detected the act of vandalism.

\section{Aftermath}

Alone at home without peers and thinking about the act, the vandal removes paint marks from the key due to guilty conscience and fear of being convicted.

Table 5.8.: Crime script for car vandalism

\begin{tabular}{|c|c|c|}
\hline $\begin{array}{l}\text { Universal } \\
\text { script } \\
\text { scenes }\end{array}$ & Script events & $\begin{array}{l}\text { Possible security functions } \\
\text { and examples of existing counter- } \\
\text { measures }\end{array}$ \\
\hline Preparation & Meet each other & $\begin{array}{l}\text { Provide activity and / or employ- } \\
\text { ment to youth (E) }\end{array}$ \\
\hline $\begin{array}{l}\text { Entering } \\
\text { setting }\end{array}$ & Loiter in public streets & CCTV surveillance (B) \\
\hline $\begin{array}{l}\text { Enabling } \\
\text { conditions }\end{array}$ & $\begin{array}{l}\text { Teenagers need appropriate tool } \\
\text { (key, screwdriver) }\end{array}$ & - \\
\hline $\begin{array}{l}\text { Selecting } \\
\text { target }\end{array}$ & Reject "boring" cars & $\begin{array}{l}\text { Discourage imitation (broken- } \\
\text { windows theory) (D) }\end{array}$ \\
\hline $\begin{array}{l}\text { Completing } \\
\text { offense }\end{array}$ & Use key to scratch car & $\begin{array}{l}\text { CCTV Surveillance (B), cooperative } \\
\text { alarm system (B) }\end{array}$ \\
\hline $\begin{array}{l}\text { Exiting } \\
\text { setting }\end{array}$ & Walk away & CCTV surveillance (B) \\
\hline Aftermath & Remove leads from key & - \\
\hline
\end{tabular}

\subsection{Identified security functions}

In the former section, we applied SAIAS and identified several security functions. Now, we briefly outline these functions in this section. We provide for each security function a brief functional description extended by a figure visualizing the relevant security function. Additionally, we provide a table for each function showing the set-up of SAIAS which led to its identification, the purpose of the function and incorporated technologies. 


\subsubsection{Cooperative home light}

When the driver walks to or from the vehicle, both the driver's vehicle and other vehicles nearby use their lights to illuminate the driver's surroundings on their way to their vehicle. The driver's own vehicle estimates their position and communicates with vehicles in the surrounding area to involve them in the lighting process, and thus, cooperatively light the way.

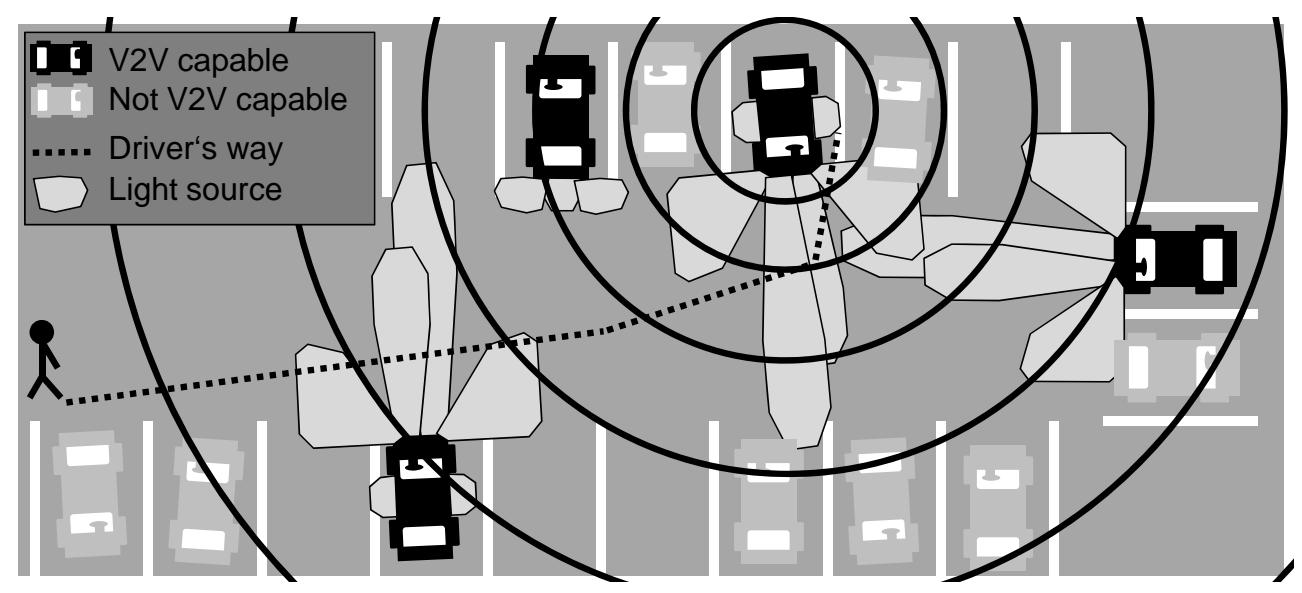

Figure 5.1.: Visualization of the cooperative home light

Table 5.9.: Set-up, purpose and enabling technologies of the cooperative home light

\begin{tabular}{ll}
\hline Set-up & Crime: robbery while going to car; scene: enabling conditions; event: loiter \\
& unobtrusively; category: increase the risks (B) \\
\hline Purpose & $\begin{array}{l}\text { Improve lighting of surrounding when going to or from vehicle } \\
\\
\end{array}$ \\
& $\begin{array}{l}\text { Fight assault and robbery while going to or from vehicle } \\
\text { Tangibility of security }\end{array}$ \\
\hline Enabling & V2V and V2D communication \\
technologies & $\begin{array}{l}\text { Advanced lighting systems in vehicles } \\
\text { Positioning solutions }\end{array}$ \\
\hline
\end{tabular}




\subsubsection{Electronic decal}

As soon as a vehicle is driven off without permission, e.g., due to a missing token, the vehicle continuously broadcasts a message via V2V communication with a request to be checked by passing police vehicles. This way, passing police vehicles in range receiving this message have the opportunity to stop and check the suspected vehicle.

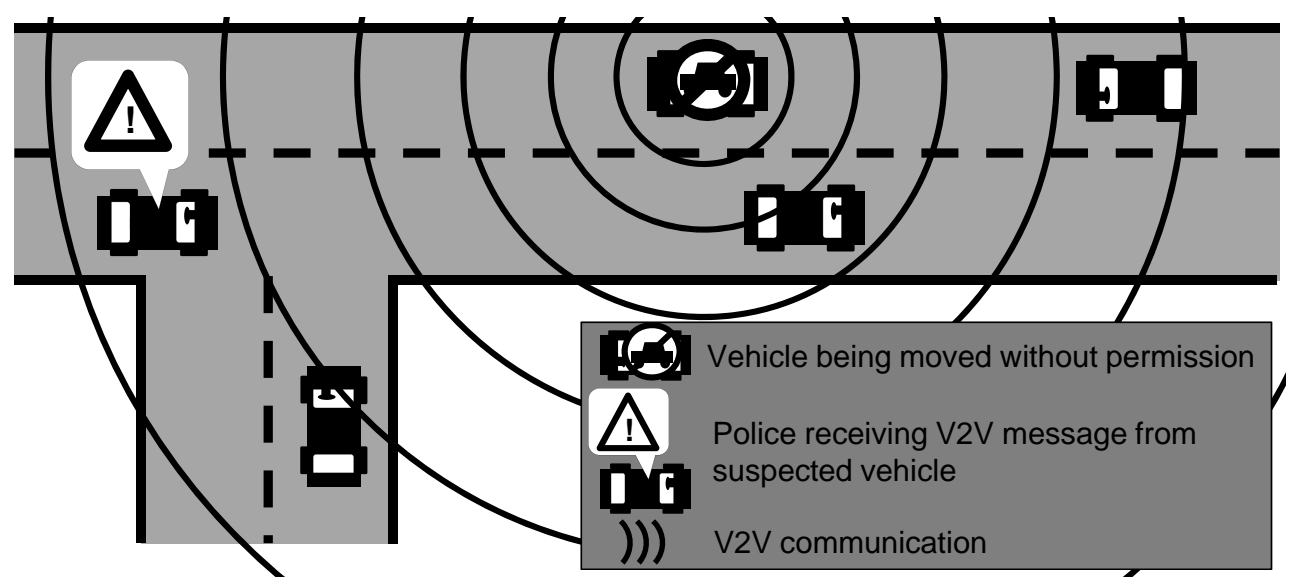

Figure 5.2.: Visualization of the electronic decal

Table 5.10:: Set-up, purpose and enabling technologies of the electronic decal

\begin{tabular}{ll}
\hline Set-up & $\begin{array}{l}\text { Crime: car theft; scene: exiting setting; event: drive with car to } \\
\text { rented/organized shop; category: increase the risks (B) }\end{array}$ \\
\hline Purpose & $\begin{array}{l}\text { Fight vehicle theft } \\
\text { Increase the risk of getting caught while driving a stolen vehicle } \\
\\
\text { Tangibility of security }\end{array}$ \\
\hline $\begin{array}{l}\text { Enabling } \\
\text { technologies }\end{array}$ & V2V and V2I communication \\
\hline
\end{tabular}




\subsubsection{Visual vehicle tracking}

Visual vehicle tracking aims to realize decentralized vehicle tracking. Here the position of a vehicle reported as stolen is estimated by surrounding vehicles. These vehicles use built-in cameras to capture license plate numbers from neighboring vehicles to conduct number plate recognition. A central database, operated by the police or other state authorities, stores number plates of stolen or suspicious vehicles. This list is continuously updated and provided via V2I communication to participating vehicles. This way, vehicles match recognized number plates with a list of suspicious vehicles. As soon as a suspicious vehicle is identified, the position is reported to the central database.

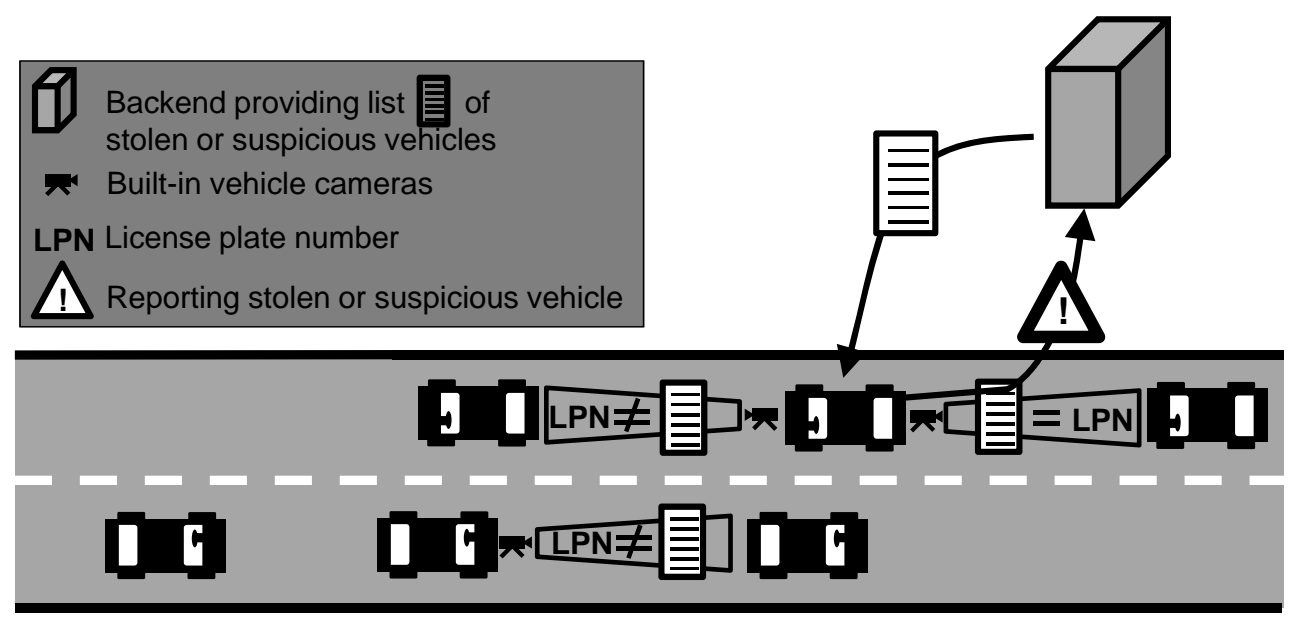

Figure 5.3.: Visualization of visual vehicle tracking

Table 5.11.: Set-up, purpose and enabling technologies of visual vehicle tracking

\begin{tabular}{|c|c|}
\hline Set-up & $\begin{array}{l}\text { Crime: car theft; scene: exiting setting; event: drive with car to } \\
\text { rented/organized shop; category: increase the risks (B) }\end{array}$ \\
\hline Purpose & $\begin{array}{l}\text { Increase the risk of getting caught while driving a stolen vehicle } \\
\text { Increase the overall effort needed to steal a vehicle, decentralization of ve- } \\
\text { hicle tracking } \\
\text { Increase driver's feeling of security } \\
\text { Tangibility of security }\end{array}$ \\
\hline $\begin{array}{l}\text { Enabling } \\
\text { technologies }\end{array}$ & $\begin{array}{l}\text { V2I communication } \\
\text { Cameras built into vehicles incl. number plate recognition }\end{array}$ \\
\hline
\end{tabular}




\subsubsection{Open door / window reminder}

Forgetting to lock the vehicle and/or to close windows obviously reduces the effort needed to gain access into the vehicle. Thus, a smart device, such as smart key or smartphone, can be used to remind the driver about doors or windows left open. As soon as the smart device moves out of a specified range, the vehicle is triggered to check whether doors are locked and windows are closed. If this is not the case, the vehicle informs the driver via V2D communication. Automatically locking the vehicle and closing windows when the driver gets out of range is also imaginable though this could result in locking in vehicle occupants.

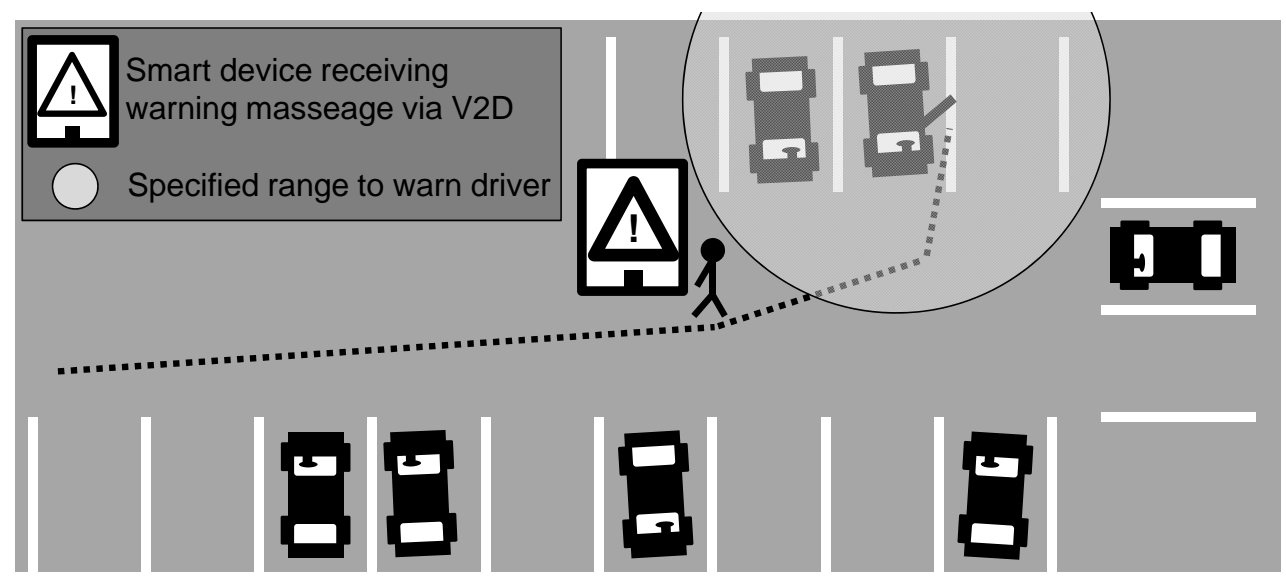

Figure 5.4.: Visualization of the open window/door reminder

Table 5.12.: Set-up, purpose and enabling technologies of the open door/window reminder

Set-up Crime: theft from inside car; scene: enabling conditions; event: car owner forgets to lock car; category: increase the effort (A), reduce provocations (D), remove excuses (E)

\begin{tabular}{ll}
\hline Purpose & $\begin{array}{l}\text { Reduce provocation, motives and incentives for stealing valuables from the } \\
\text { inside of a vehicle } \\
\text { Increase effort needed to gain access to the vehicle } \\
\end{array}$ \\
& $\begin{array}{l}\text { Fight theft from the inside of a vehicle } \\
\text { Reduce driver's fear of crime } \\
\text { Tangibility of security }\end{array}$ \\
\hline $\begin{array}{l}\text { Enabling } \\
\text { technologies }\end{array}$ & $\begin{array}{l}\text { V2D communication } \\
\text { Positioning solutions }\end{array}$ \\
\hline
\end{tabular}




\subsubsection{Voice-enabled crime detection}

In case the driver is robbed or attacked while walking to or entering the vehicle, the opportunities to press the panic button on the remote key are limited due to the exceptional circumstances of the attack. The attacked person would however be able to scream or cry for help eventually. Thus, vehicles could be equipped with microphones directed to the outside in order to detect voices emitted outside of the vehicle. A speech recognition engine searches for keywords, such as "help". The vehicle itself could be pre-trained with additional user-selected words. According to [90], besides speech information which is used to recognise the spoken content, the human voice also contains information about gender and age. Furthermore, voice sounds contain affective information, such as feeling and mood, about the person. Sophisticated speech engines are able to estimate whether the speech is overlaid with fear. Hence, voice could be used as a trigger to enable cooperative surveillance by vehicles and infrastructure, to light up the scene as well as to notify security attendants.

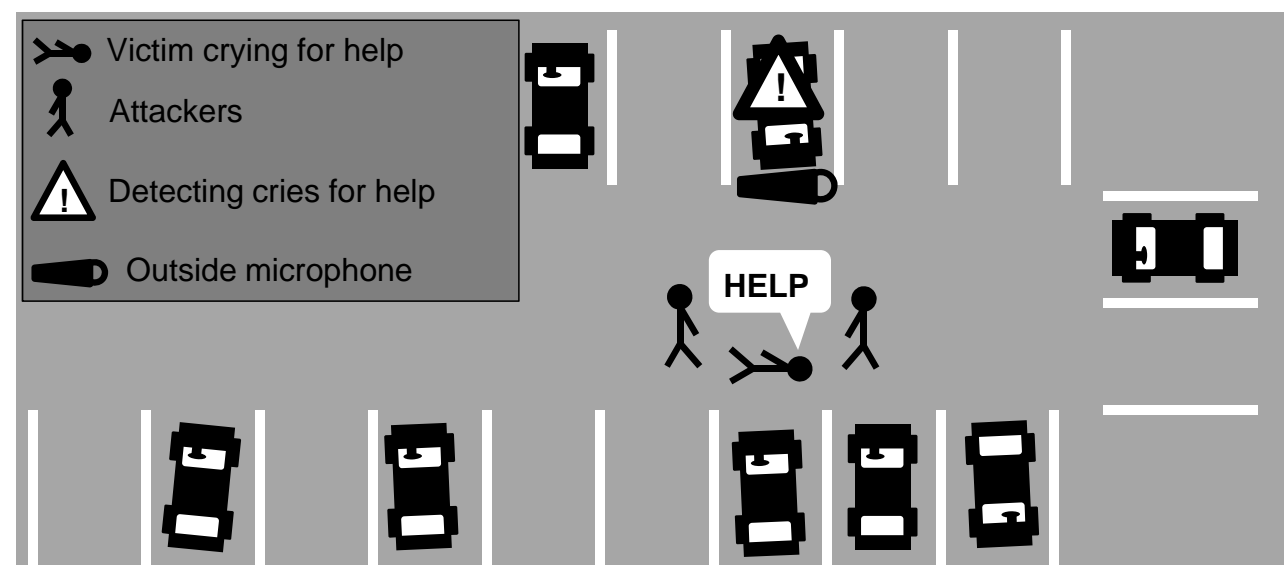

Figure 5.5.: Visualization of voice-enabled crime detection 
Table 5.13.: Set-up, purpose and enabling technologies of voice-enabled crime detection

\begin{tabular}{ll}
\hline Set-up & $\begin{array}{l}\text { Crime: robbery while going to car; scene: completing offense; event: attack } \\
\text { victim and snatch the bag from the victim; category: increase the risks (B) }\end{array}$ \\
\hline Purpose & $\begin{array}{l}\text { Fight assault and robbery while going to or from vehicle } \\
\text { Reduce anonymity } \\
\text { Increase driver's feeling of security } \\
\text { Tangibility of security }\end{array}$ \\
\hline Enabling & $\begin{array}{l}\text { V2V and V2I communication } \\
\text { technologies }\end{array}$ \\
& $\begin{array}{l}\text { Microphones directed to the outside incl. voice processing } \\
\text { Lighting systems in vehicles } \\
\text { Cameras built into vehicles }\end{array}$ \\
\hline
\end{tabular}

\subsubsection{Cooperative alarm system}

As soon as a vehicle detects intrusion and/or vandalism, such as scratches, broken windows or kicks against the exterior, the vehicle tries to attract attention by emitting sound and blinking the lights. In addition, surrounding vehicles, infrastructure and the owner are informed via V2X communication. Neighboring vehicles use their illumination to light the scene and their in-vehicle cameras record the scene. Furthermore, communication with nearby CCTV cameras is supported to record the scene. With actively-controlled CCTV cameras, security guards could be notified and steer the camera towards the criminal act. The owner is informed via smartphone as well.

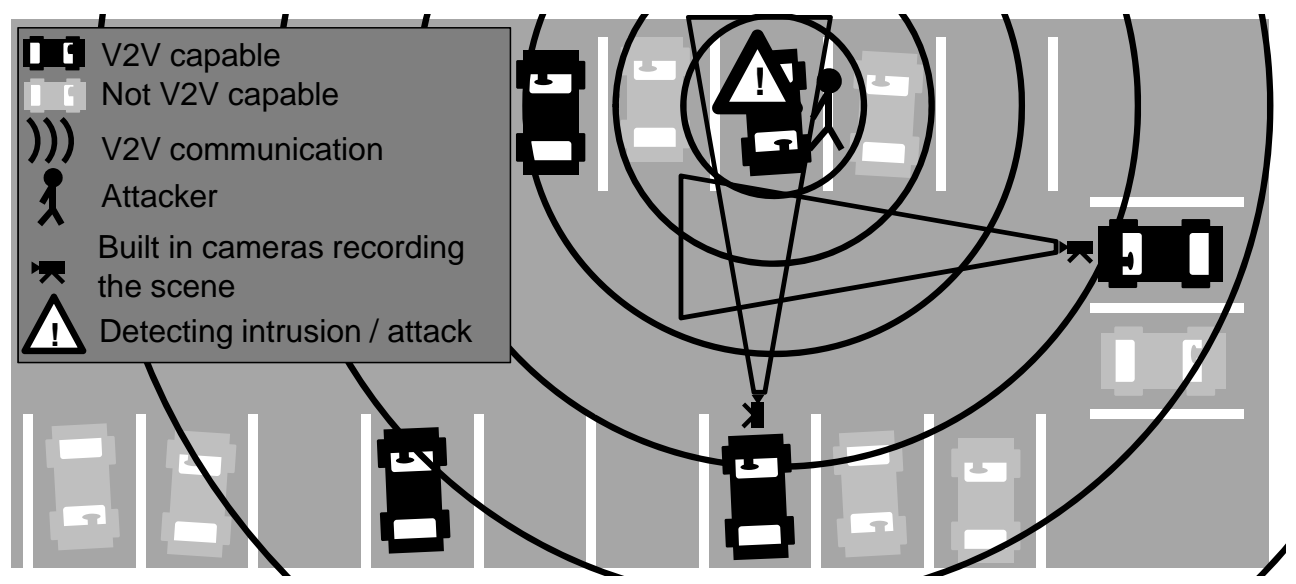

Figure 5.6.: Visualization of the cooperative alarm system 
Table 5.14.: Set-up, purpose and enabling technologies of the cooperative alarm system

\begin{tabular}{ll}
\hline Set-up & Crime: car theft; scene: completing offense; event: smash window, force \\
& lock; category: increase the risks (B) \\
& Crime: car vandalism; scene: completing offense; event: use key to scratch \\
& car; category: increasing risk (B)
\end{tabular}

\subsection{Prioritization of security functions}

In the previous section, we provided a functional description of identified security functions. We will seek to design and evaluate two security functions in more detail to show feasibility and evaluate effectiveness. The effort and costs for deeper design and especially evaluation taking all functions into account is beyond the scope of this thesis. Thus, we use our prioritization criteria from SAIAS presented in Section 4.3.4:

- Influence on crime

- Influence on fear of crime

- Influence on tangibility

- Deployment feasibility

- Evaluation suitability

We rate these criteria using a scale from low (1) over mid (2) to high (3) in order to chose two security functions for furthermore elaboration. We conducted a rating for each security function summarizing the results in Table 5.15. As can be seen, the cooperative home light and the electronic decal got the most points and are thus designed and analysed in the course of this thesis. 
Table 5.15.: Rating of potential security functions

\begin{tabular}{|c|c|c|c|c|c|c|}
\hline \multirow{2}{*}{$\begin{array}{l}\text { Potential security } \\
\text { functions }\end{array}$} & \multicolumn{3}{|c|}{ Influence on } & \multirow{2}{*}{$\begin{array}{c}\text { Deploy- } \\
\text { ment fea- } \\
\text { sibility }\end{array}$} & \multirow{2}{*}{$\begin{array}{l}\text { Evalua- } \\
\text { tion sui- } \\
\text { tability }\end{array}$} & \multirow[t]{2}{*}{ Sum } \\
\hline & crime & $\begin{array}{l}\text { fear of } \\
\text { crime }\end{array}$ & $\begin{array}{l}\text { tangi- } \\
\text { bility }\end{array}$ & & & \\
\hline Cooperative home light & 2 & 3 & 3 & 2 & 3 & 13 \\
\hline Electronic decal & 3 & 1 & 2 & 3 & 2 & 11 \\
\hline $\begin{array}{l}\text { Open door/window } \\
\text { reminder }\end{array}$ & 2 & 2 & 2 & 2 & 2 & 10 \\
\hline Visual vehicle tracking & 2 & 1 & 1 & 2 & 3 & 9 \\
\hline Cooperative alarm system & 2 & 1 & 1 & 3 & 2 & 9 \\
\hline $\begin{array}{l}\text { Voice-enabled crime detec- } \\
\text { tion }\end{array}$ & 1 & 3 & 2 & 1 & 1 & 8 \\
\hline
\end{tabular}

1=low, $2=$ mid and 3=high

\subsection{Summary}

In this chapter, we developed four vehicle-related crime scripts differing at least at the protoscript level and applied SAIAS to identify automotive security functions. All developed crime scripts led to at least one security function. Identified security functions were rated in order to pick two security functions as candidates for additional elaboration. The selection of two security functions is necessary since working out all identified security functions is not manageable within this thesis. The decision was to go for the cooperative home light and electronic decal, whose feasibility and likely effectiveness are considered in what follows.

We have shown that applying SAIAS provides a suitable method to identify security functions. In our opinion, both the detailed step-by-step nature of analyzing specific vehicle-related crimes in a structured way and understanding the sequence of actions necessary to commit the crime supported the identification of security functions since it allowed us to consider factors which might otherwise be overlooked. A crime script considers only one specific crime which is as detailed as possible in order to apply SAIAS. Consequently, to consider the wider scope of vehicle-related crimes a huge amount of crime scripts would have to be regarded. However, due to the modularity and our hierarchical categorization, identified security functions can be partly shifted to a more abstract level, and thus, tackle a wider range of vehiclerelated crimes. For example, the electronic decal fights vehicle theft when the offender exits the scene independent of their motive. Additionally, crime scripts can be partially reused for other vehicle-related crimes so that the necessity to produce similar crime scripts is reduced. Second, traversing throughout all events considering each category of 25 techniques leads to a large number of set-ups, i.e., combinations, which have to be processed. Thus, we recommend wisely filtering before applying SAIAS to reduce the complexity. Focusing on specific scenes or indeed events provides an opportunity to reduce complexity. Omitting some of the five categories may be considered as well. 
Having traversed through the five categories of 25 techniques during the application of SAIAS, it has become clear that innovative ideas for security functions can fall into more than one category. For example, increasing the effort to commit a crime can go hand-in-hand with increasing the risk of the offender being caught. This is not surprising since these five categories are quite generic so they can cover a wide range of different crimes.

In the next chapter, we will show the technical feasibility of the cooperative home light as well as the electronic decal. This is necessary as it shows how both functions can be implemented since they aim to draw on new technologies. 



\section{Chapter}

6

\section{Technical feasibility of the electronic decal and cooperative home light}

In this chapter, we propose a design for the electronic decal (ED) and cooperative home light (CHL). We provide a conceptional realization pursuing the goal of showing the feasibility of both functions. We consider existing standardization and technologies from industry as well as research. Each function is outlined first before discussing the essential technological parts involved in the realization of each function.

Section 6.1 shows the design of the electronic decal and the cooperative home light in Section 6.2. The third section summarizes this chapter.

\subsection{Electronic decal}

The electronic decal (ED) partly transfers the idea of vehicle decal programs [169, 171, 172] into the world of connected mobility. Instead of a visibly-placed decal on the front and/or rear windshield of the vehicle, the vehicle uses the existing on-board communication unit (OCU) integrated in the vehicle for the purposes of V2X communication. For example, the US Department of Transportation is working on proposals to make V2X communication mandatory for new vehicles in order to pave the way for market penetration [191].

Considering the physical decal (PD), specific hours, namely 1a.m. to 5a.m., are defined to indicate whether the vehicle is being illegally moved or not. This approach has the main drawback that the time frame is static. For example, using the vehicle to return from clubbing during the night or simply working as a shift worker increases the risk of being falsely stopped. Additionally, the protective functionality is limited to the program hours.

We aim to make use of V2X communication to replace the visibly-mounted decal and improve functionality. As soon as the vehicle is illegally moved, the vehicle uses the integrated OCU in two ways. First, the vehicle informs the owner via smartphone about potential misuse since it is in the owner's responsibility to verify whether the vehicle is being illegally moved or not. This way, there is opportunity for a quick reaction, i.e., reporting the vehicle stolen. Second, the vehicle continuously broadcasts a message with a request to be checked by police. This way, passing police vehicles are informed about a suspect vehicle, and thus have the opportunity to 
stop and check it. The broadcast message can be additionally evaluated by official checkpoints such as police stations or border crossings. Other vehicles and infrastructure stations in range simply discard the message.

To activate and deactivate the electronic decal, and thus to indicate whether the vehicle is being illegally moved or not, we suggest three approaches:

(De)activation via

- schedule

- vehicle key

- smartphone

The electronic decal introduces extended opportunities and advantages compared to the physical decal. First, the electronic decal is not limited to static times, as we will see in Section 6.1.1 where we present our (de)activation methods. Second, the owner or any other authorized person is informed as soon as the vehicle has been potentially illegally moved. This way, a quick theft report is possible. Third, since there is no visible decal which informs the offender about this functionality, the offender never knows if the electronic decal functionality is supported or even enabled on the targeted vehicle. Last, the electronic decal aims to use standard components, mainly the integrated OCU. To realize the electronic decal, (de)activation methods as well as V2V communication is necessary.

\subsection{1. (De)activation methods}

\section{(De)activation via schedule}

The vehicle owner or another authorized person transfers a detailed schedule to the vehicle detailing the time frames when it is not allowed to be moved. The schedule is managed from home and is transferred via internet to the vehicle. Transferring data from home to the vehicle is already state of the art and provided by several vehicle manufacturers [192, 193, 194]. For example, users can send their directions predefined with Google Maps to their vehicle in order to use them for navigation. The target vehicle therefore needs to be equipped with a communication unit providing access to the internet. Controlling the electronic decal via schedule comes with several advantages but also disadvantages, which are summarized in the following.

\section{Advantages}

- Flexibly adjustable time frames

- Comfortable configuration from home or any device connected to the internet

- Additional security measure (being in possession of the key does not deactivate the electronic decal)

\section{Disadvantages}

- Limitation of spontaneous drives

- Active maintenance of schedule 
In case of a spontaneous drive, a fall back deactivation through a direct input within the vehicle secured by a personal identification number (PIN) is imaginable. Of course, schedules (de)activation needs a motivated and self-disciplined driver who regularly updates the schedule. But even when the schedule is outdated and police stops an "innocent" vehicle, the check is a routine action and can be cleared up quickly when the driver is found to have authorization. In addition, it is still at the police's discretion whether to stop a vehicle or not, though it is better to check once too often rather than once too little.

\section{(De)activation via vehicle key}

The (de)activation goes hand-in-hand with the (de)activation of the immobilizer. However, the functionality is implemented in a separate electronic control unit (ECU), namely the OCU. The vehicle key is the means of (de)activating the electronic decal. The advantages and disadvantages of controlling the electronic decal via vehicle key are as follows.

\section{Advantages}

- Comfortable since no additional action/device needed

- No tangibility for the user

\section{Disadvantages}

- No additional security measure (if key is stolen the electronic decal will be deactivated)

- Additional effort to separate immobilizer from OCU (compromising the immobilizer must have no influence on the electronic decal)

\section{(De)activation via smartphone}

As soon as a smartphone is paired with the vehicle via wireless short-range communication (WSRC) such as Bluetooth or near field communication (NFC), the electronic decal functionality is disabled. Equally, when the smartphone is out of range, the function is enabled. Of course, each smartphone that is intended to control the function needs to be enrolled once with the system. Both WSRC and NFC are state of the art technologies. For example, Hyundai introduced a connectivity concept for its vehicles [195] where the smartphone plays a major role. The smartphone works as key and needs to be waved over the NFC-tag attached to a vehicle window or door. Furthermore, vehicles will soon be equipped with a wireless smartphone docking station in the console in order to use NFC to connect smartphones via MirrorLink to the vehicle. In addition, wireless charging of the phone is supported. The main advantages and disadvantages are summarized in the following.

\section{Advantages}

- Comfortable since no additional action needed

- Additional security measure (being in possession of the key does not deactivate the electronic decal since the smartphone is the token) 


\section{Disadvantages \\ - Dependence on smartphone (empty battery or forgotten smartphone) \\ - Enrollment of smartphones necessary}

To overcome the drawback of a missing or discharged smartphone a fall back solution with the help of entering a PIN is imaginable similar to the schedule approach. Furthermore, although the user needs to take responsibility of the enrollment of mobile devices, the enrollment needs to be conducted only once per device.

\subsubsection{V2V communication}

The core functionality of the electronic decal is to continuously broadcast a message to surrounding (police) vehicles. To enable inter-vehicular communication, efforts have been undertaken in the United States, Europe and Japan to establish a set of communication standards. Unfortunately, these standards are not yet harmonized. Hence, we refer in the further course of this thesis to the standardization from the European Telecommunications Standards Institute (ETSI) [196]. ETSI has already provided basic standardization to pave the way for intelligent transport system communication (ITSC). Figure 6.1 shows the suggested ITSC architecture [91]. To be able to participate in ITSC, ITS sub-systems need to implement an ITS station following the suggested architecture. ITS sub-systems can be personal sub-systems, such as smartphones, vehicle sub-systems or infrastructure sub-systems.

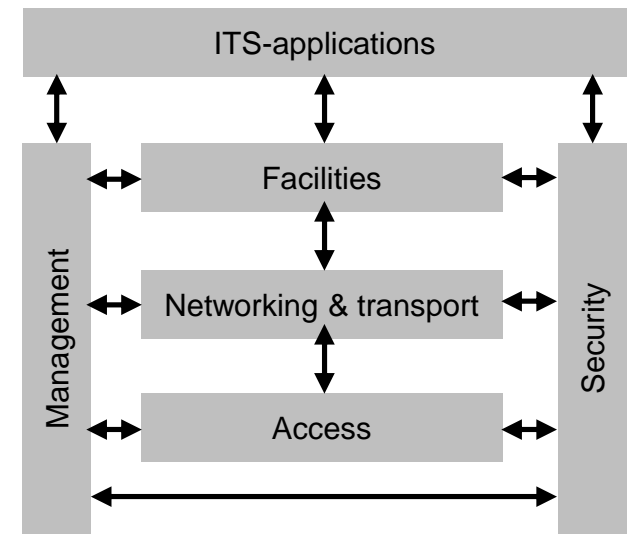

Figure 6.1.: Simplified communication architecture according to ETSI standardization [91]

The three lower-middle entities in Figure 6.1 cover the communication stack. The security entity provides security services to the communication stack, the management entity and ITSapplications. The management entity is responsible for managing the interaction between entities. Each ITS-application needs an application ID (AID). Dependent on the AID, entire processes are accordingly managed by the management entity within the stack. A registration 
authority is ideally established, by which each ITS-application is registered and certified in order to receive an AID and to be considered in the ITSC [92, 93]. Hence, the electronic decal also has to go through the registration process to become part of the ITSC. Nevertheless, the architecture and the standardization process are still in progress, but the basis for V2V, V2I and V2D communication is defined and security mechanisms considered.

\subsubsection{Message format}

Independent of the electronic decal approach, the standardization process is mainly driven by the goal of introducing safety applications as day one use cases. Thus, ETSI defines two message types, the decentralized environmental notification message (DENM) [94] and the cooperative awareness message (CAM) [95]. DENMs are event-triggered and transmitted to alert other users of specific traffic events. In contrast, the CAM is continuously broadcast with a maximum time interval of 1 second and minimum time interval of $100 \mathrm{~ms}$ to ITS stations located within a single hop distance, providing information of presence, position and other ITS station specific data. This way, ITS stations are aware of other stations in their surroundings.

Comparing the CAM and DENM, the CAM is in our opinion a more appropriate message for V2V communication used with the electronic decal. First of all, the CAM is continuously broadcast. In contrast, the DENM is broadcast after a specified event dependent on a geolocation. Second, the CAM already contains some vehicle data necessary to realize the functionality of the electronic decal. Third, CAMs provide the opportunity for extension with optional data containers which can be used to integrate additional data. Hence, using the CAM to realize the electronic decal is in our opinion the more reasonable approach. However, the CAM is similar to the DENM designated for the realization of safety relevant applications. However, safetyrelevant communication is intended to make use of communication channels other than those for non-safety relevant communication in order to achieve prioritization in communication. From this point of view, the CAM is not necessarily the right choice. Additionally, the content of CAMs is not encrypted in order that the content be available to all participants within the vehicular network though we do not see any necessity to encrypt the electronic decal content. Furthermore, the optional container does not need to be integrated in each CAM either so the payload is reduced. Thus, we think that making use of the CAM provides a reasonable solution, especially in the first approach.

The specification of the CAM is still a work in progress. Nevertheless, we propose the integration of an optional container into the CAM shown in Table 6.1, which presents both the intermediate format of the CAM and our extension in italics. The optional container electronicDecalParameters becomes part of the CAM as soon as the vehicle is illegally moved. Since this container is only included in CAMs when the decal is activated, an additional flag is unnecessary. The container includes the activation time (activationTime) at which the electronic decal was activated. In case of the schedule method, the optional field deactivationTime represents the time at which electronic decal will be deactivated. This information is useful as it supports the police in deciding whether to stop the vehicle or not. For example, if the time period is two weeks and the vehicle has moved within that period, it might indicate that the owner is on holiday and the vehicle has been illegally moved. Furthermore, using the current position, 
heading and speed, which are already contained in CAMs, the movement of the suspect vehicle can be visualized in the police vehicle. Moreover, information about the vehicle needs to be included so that police are able to identify and pick the right vehicle. We suggest that the registration number (registration number), make and model (makeAndModel) as well as the vehicle color (color) to be part of the container. The registration number seems to be sufficient at the first glance but license plates can be easily changed. In contrast, modifying the color or make and model is more difficult. Furthermore, the large number of identification attributes increases the redundancy, thus simplifying vehicle identification for the police. Privacy concerns appear to be less critical in this case, since the vehicle should not be moved anyway.

\subsubsection{Security}

We suggest using the CAM to broadcast the stolen vehicle message. According to ETSI standardization, CAMs are not encrypted [96]. However, data corruption and data loss need to be detected to provide data integrity. Furthermore, the sender is not able to reject the sending of a CAM and the authenticity of CAMs has to be assured to avoid manipulation of the sender's address. In addition to integrity, non-repudiation and authenticity, authorization is required to restrict access to legitimate vehicles. To fulfill these requirements, CAMs must be digitally signed. For this purpose, ETSI assumes an ITS security reference model [97] with an enrollment authority (EA), an authorization authority (AA) and ITS-equipped vehicles as well as devices, such as roadside units or personal units. Each ITS station, and thus each vehicle, has a unique prescribed identity which exists for the operational lifetime of the vehicle [98]. The EA validates whether the vehicle is trustworthy and issues enrollment credentials, i.e., longterm certificates, valid within the enrollment domain of the EA. Vehicles use these long-term certificates to apply to an AA in order to receive permissions within the context of the AA, i.e., authorization tickets (short-term/pseudonymous certificates). These certificates are used by vehicles to digitally sign their broadcast CAMs. 
Table 6.1.: CAM specification extended by electronic decal parameters

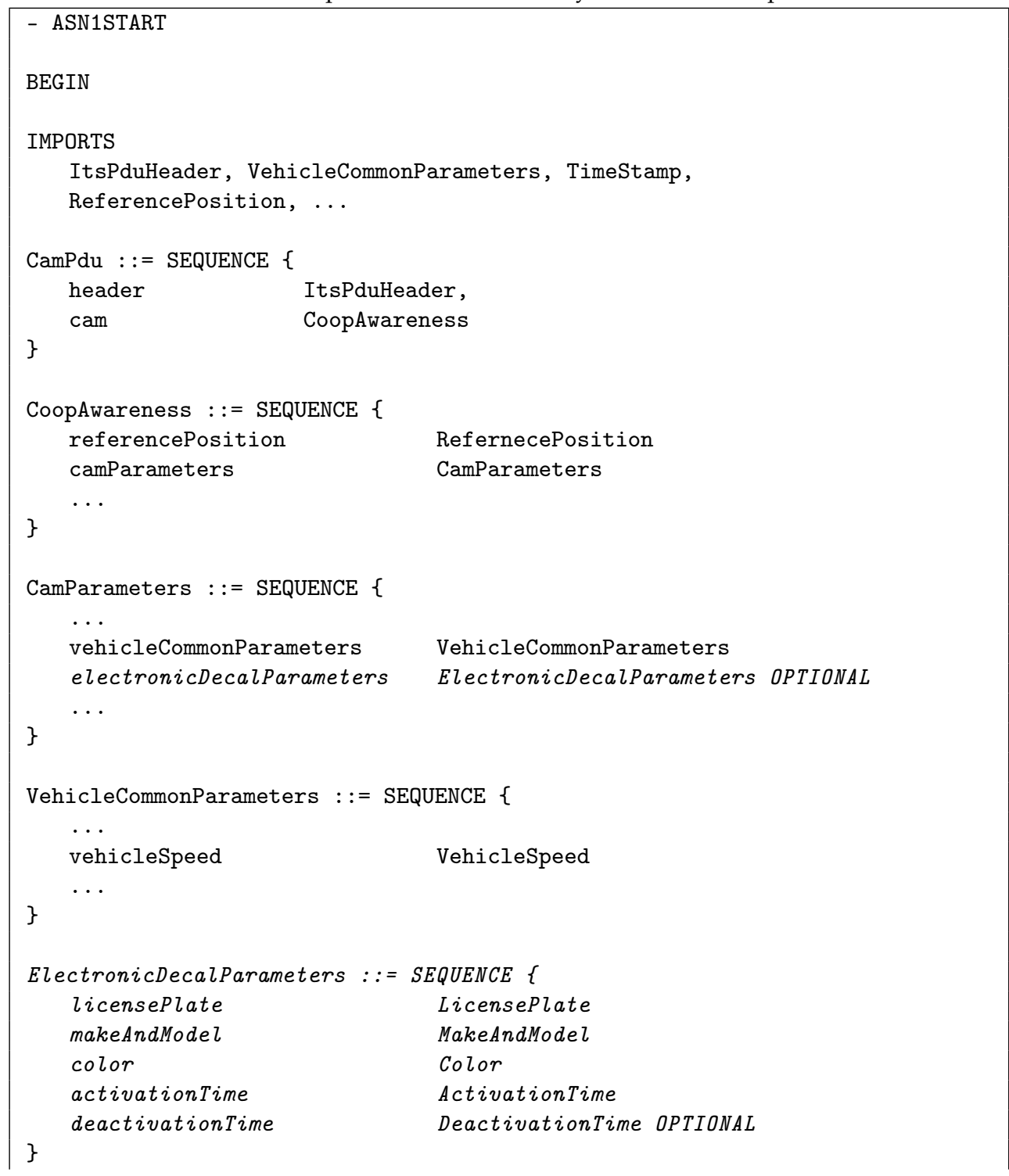


6. Technical feasibility of the electronic decal and cooperative home light

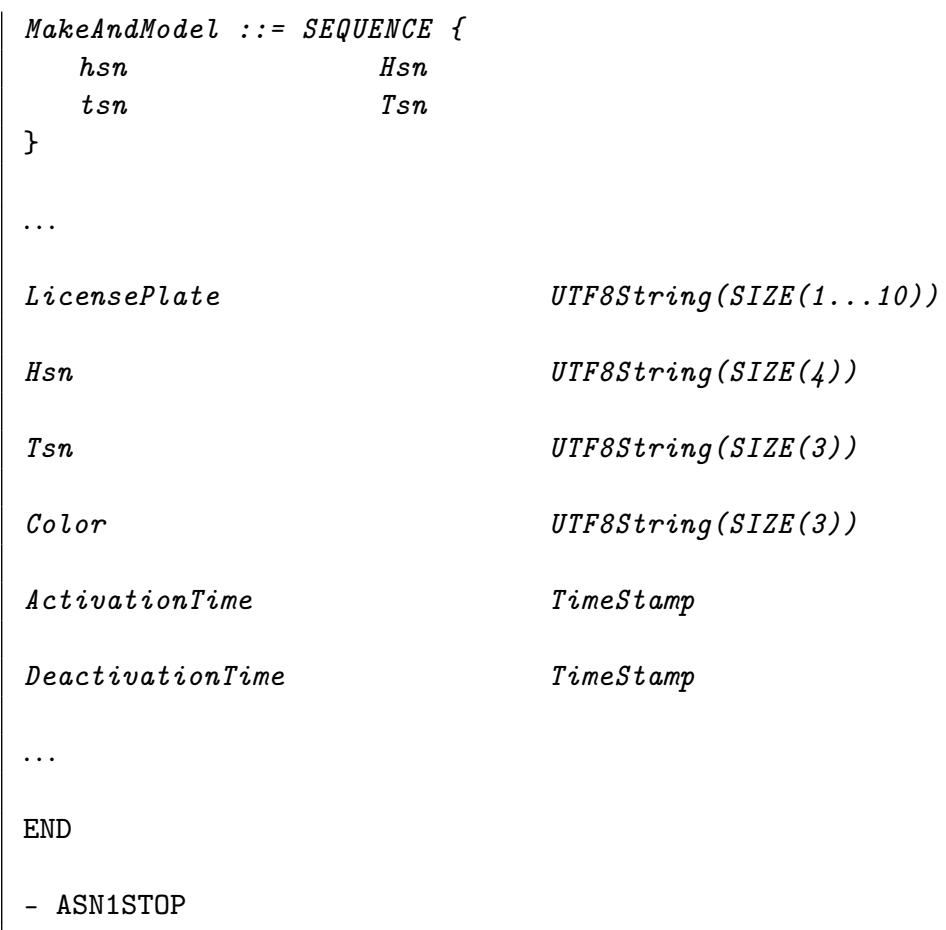




\subsection{Cooperative home light}

Most OEMs provide a so-called coming / leaving home function, which for simplicity is called basic home light (BHL) in the remainder of this thesis. Of course, the functionality differs by OEM specific adjustments. However, the basic idea is similar. When leaving the car, i.e., coming home, low beams, tail lights, lights in the mirror housings, license plate lighting and other available light sources continue lighting (during darkness) for a specified period of time in order to guide the driver "home". The duration can generally be adjusted by the vehicle owner. For the leaving home light, the light sources start lighting as soon as the driver remotely unlocks the vehicle.

The BHL has the drawback of being static. The lighting duration can only be adjusted in the vehicle and it is independent of the driver's position. That means, if the duration is too short, the illumination turns off before the driver even reaches the vehicle or indeed home. Furthermore, the vehicle turns on all light sources though some lights are probably unnecessary since the driver approaches the vehicle from one direction.

Thus, we propose to extend the existing BHL with advanced sensors, sophisticated light systems and V2X communication. We suggest adopting low beams that can be moved vertically and horizontally to light the driver's direct path to the vehicle, of course within mechanical limits. Additionally, only the light sources which help illuminate the path are turned on so that energy consumption is reduced.

To realize the extended home light (EHL), bidirectional communication between the vehicle and a sophisticated key fob is needed. The key fob is a smart device, such as a smart key or smartphone, and must be in possession of the driver.

The position of the key in relation to the vehicle must be known. This may be calculated either by the key or by the vehicle since position data is continuously synchronized via bidirectional communication between both participating partners. The EHL is (de)activated similarly to the BHL. In the case of "leaving home", the EHL is activated as soon as the driver remotely unlocks the vehicle. Additionally, location estimation of the key as well as the two-way communication between key and vehicle are triggered. The position of the key is updated at regular intervals so that the low beams are continuously adjusted. Furthermore, light sources are switched on if they are relevant for lighting the path of the driver. Similarly, lights are switched off if they no longer illuminate the direct path. There is also no need to unlock doors immediately after the EHL is activated via smart key or smartphone. Since the driver's position is known to the vehicle, doors can be unlocked as soon as the driver is close to the vehicle. This way, a potential thief or attacker cannot enter the vehicle or take valuables from the vehicle when the driver is "far away".

Due to physical and mechanical limits, the vehicle alone is not able to illuminate the entire path of the driver. Thus, the EHL can use V2V communication to be enhanced to a cooperative home light (CHL). Vehicles in the surrounding environment are included to illuminate the driver's path. Since our vehicle is always aware of the driver's position, it continuously requests vehicles in the surrounding to participate, thus lighting the path. 


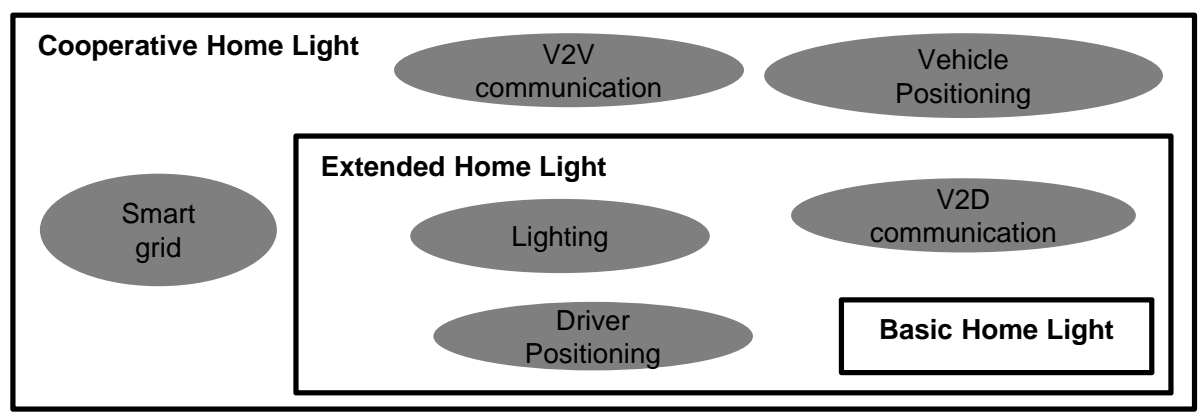

Figure 6.2.: Home light variants with relevant technologies

Considering all three functions, i.e., the BHL, EHL and CHL, only slight differences exist between the coming and leaving mode, so for simplicity we won't distinguish between the two modes unless necessary. Moreover, as can be seen in Figure 6.2, we have a hierarchical dependency of enabling technologies between the BHL, EHL and CHL. The EHL contains all features from the BHL and the CHL has all features from the EHL. The CHL is indeed similar to the EHL when no other vehicles participate in the lighting process.

In the following, we introduce the underlying technologies and approaches necessary for the realization of the CHL.

\subsubsection{Positioning}

The driver position refers to the primary vehicle, i.e. host vehicle, forming a fundamental part of the CHL. Additionally, each vehicle which participates in cooperative lighting needs to be aware of its position. A distinction between indoor and outdoor positioning is also reasonable. Outdoors the Global Positioning System (GPS) is the first approach. Most vehicles and smartphones are equipped with appropriate GPS receivers. However indoors, for example in parking facilities, GPS is not suitable because it needs a clear line of sight to orbital satellites. Thus, solutions involving the integration of additional infrastructure are necessary.

Independent of the positioning system, a common coordinate system for all vehicles representing the parking environment is necessary. Both GPS positions referring to the World Geodetic System 1984 (WGS84) and positions referring to a proprietary coordinate system within a parking facility have to be mapped to the common environmental coordinate system, which we assume is a three-dimensional Cartesian coordinate system. Using three-dimensional Cartesian coordinate systems to represent the environment, vehicles and the driver allows calculation of positions across coordinate systems with the help of homogeneous coordinates [99]. 


\subsubsection{Driver Positioning}

For the CHL ultra-wideband (UWB) and wireless LAN (WLAN) technologies are promising. In the UWB approach, the token, which is in our case the smartphone, estimates the position based on the time difference of arrival (TDOA) of radio signals. Hence, ideally the primary vehicle would be equipped with several transceivers to estimate the position of the smartphone in relation to the vehicle. Transceivers may also be mounted within the facility. With the help of vehicle-to-infrastructure (V2I) communication the facility provides the position to the vehicle, which is able to recalculate driver's position. Several commercial solutions, such as Zebra's Dart [197] or Ubisense [198] exist and show the feasibility of this technology where precisions below $1 \mathrm{~m}$ are achievable.

In the WLAN approach, the position is estimated with the help of the received signal strength. The feasibility has been shown in research systems, such as Microsoft RADAR [100,101] and Horus [102, 103]. Ekahau [199] provides a commercial solution based on the positioning system provided by Kontkanen et al. [104]. WLAN technology can locate position with a precision of a few meters.

The UWB approach provides better position precision and is more suited to customer products. However, this solution requires the smartphone to be equipped with appropriate receiver hardware, though today's smartphones support WLAN technology.

We also found attempts to use smartphones to estimate relative movements with their integrated sensors [105, 106, 107]. We think that data fusion of relative and absolute position information has the potential to improve the overall position estimation significantly, independent of the technology chosen for absolute positioning.

Assuming that the driver position is estimated in relation to the vehicle, driver position relative to the environment can be calculated with the help of Equation 6.1, which can be transposed dependent on available position information.

$$
{ }^{E} \mathbf{p}_{D}={ }^{E} \mathbf{H}_{V} *{ }^{V} \mathbf{p}_{D}
$$

with

${ }^{V} \mathbf{p}_{D}=\left({ }^{V} x_{D},{ }^{V} y_{D},{ }^{V} z_{D}, 1\right):$ Driver position in relation to own vehicle

${ }^{E} \mathbf{p}_{D}=\left({ }^{E} x_{D},{ }^{E} y_{D},{ }^{E} z_{D}, 1\right)$ : Driver position in relation to environment

${ }^{E} \mathbf{p}_{V}=\left({ }^{E} x_{V},{ }^{E} y_{V},{ }^{E} z_{V}, 1\right)$ : Vehicle position in relation to environment

$\mathbf{R}=\mathbf{R}_{x} \cdot \mathbf{R}_{y} \cdot \mathbf{R}_{z}$ : Vehicle orientation in relation to environment (Euler angles) 
$\mathbf{R}_{x}=\left(\begin{array}{ccc}1 & 0 & 0 \\ 0 & \cos \left({ }^{E} \alpha_{V}\right) & -\sin \left({ }^{E} \alpha_{V}\right) \\ 0 & \sin \left({ }^{E} \alpha_{V}\right) & \cos \left({ }^{E} \alpha_{V}\right)\end{array}\right):$ Vehicle orientation to x-axis of environment

$\mathbf{R}_{y}=\left(\begin{array}{ccc}\cos \left({ }^{E} \beta_{V}\right) & 0 & \sin \left({ }^{E} \beta_{V}\right) \\ 0 & 1 & 0 \\ -\sin \left({ }^{E} \beta_{V}\right) & 0 & \cos \left({ }^{E} \beta_{V}\right)\end{array}\right):$ Vehicle orientation to $\mathrm{y}$-axis of environment

$\mathbf{R}_{z}=\left(\begin{array}{ccc}\cos \left({ }^{E} \gamma_{V}\right) & -\sin \left({ }^{E} \gamma_{V}\right) & 0 \\ \sin \left({ }^{E} \gamma_{V}\right) & \cos \left({ }^{E} \gamma_{V}\right) & 0 \\ 0 & 0 & 1\end{array}\right):$ Vehicle orientation to z-axis of environment

${ }^{E} \mathbf{H}_{V}=\left(\begin{array}{cccc} & & & { }^{E} x_{V} \\ & & & { }^{E} y_{V} \\ & & & { }^{E} z_{V} \\ 0 & 0 & 0 & 1\end{array}\right):$ Transformation matrix, vehicle coordinates to environment

\subsubsection{Vehicle positioning}

Estimating a vehicle's position is done in a similar way to estimating driver position, as described above. We also found other approaches in literature. For autonomous parking in particular, research projects such as AIM [200], V-Charge [201] and Audi's automated parking pilot [108] (partly) address positioning challenges. The approaches are largely similar. The parking facility is equipped with sensors, such as LIDAR or cameras, in order to estimate free parking spaces and vehicles are provided with a digital map of the parking facility. Making use of this information, vehicles autonomously drive to a free parking space, supported by onboard sensors, such as cameras, ultra-sonic and radar sensors. Thus, a parked vehicle is aware of its parking position within the facility. For the CHL, participating vehicles do not move and so vehicles are aware of their last parking position.

\subsubsection{Smart grids}

A further challenge on the way towards the CHL is the power supply of involved vehicles. Today's typical vehicles have batteries with a limited charge, posing a high hurdle for the CHL. However, electric mobility is on the advance and pushed not only by academia but by industry and politics. Smart grids will increase continuously in importance as well. Electric vehicles are connected to (intelligent) power grids to be charged when parked. 


\subsubsection{V2X Communication}

We already introduced V2X communication in Section 6.1.2 where we provided the basis to enable the communication to realize the electronic decal. The basis for V2X communication has been defined by ETSI. Therefore, we present our approach for the CHL accordingly.

\subsubsection{V2D communication}

We suggest using a smartphone or a smart key as a mobile device. Since the key only communicates with its owner's vehicle, the common IEEE $802.11 \mathrm{a} / \mathrm{b} / \mathrm{g}$ [202] standard is mostly suitable. The majority of smartphones are equipped with the necessary hardware and indeed some of todays vehicles are equipped with WiFi hotspots. Additionally, the access layer considers WiFi communication in the communication architecture [91]. ETSI also considers mobile devices to be ITS stations, and thus, using the IEEE 802.11p [202] to communicate with other ITS stations, such as vehicles or road side units.

\subsubsection{2. $\mathrm{V} 2 \mathrm{~V}$ communication}

In the course of the introduction of $\mathrm{V} 2 \mathrm{~V}$ communication into the market, vehicles will be equipped with on-board communication units (OCUs), and will support V2V communication from the outset. V2V communication is based on IEEE 802.11p according to [91]. To tackle the challenge of communication with other vehicles in order to support cooperative lighting, we suggest two approaches.

- Basic approach: The host vehicle which requests lighting support continuously broadcasts a message with the driver position, but other vehicles do not reply. This way the communication load is reduced and other vehicles do not reveal any information, such as position or lighting opportunities. However, the host vehicle is not aware about the state of participating vehicles and so is uncertain whether the way is sufficiently lit.

- Sophisticated approach: The host vehicle requests lighting support and willing vehicles reply by reporting their position and lighting capabilities to the host vehicle. This way, the host vehicle is able to create a map of surrounding vehicles and manage the lighting process by requesting only relevant vehicles to consider their lighting capabilities. Of course, this approach comes along with an additional communication load and other vehicles need to reveal information such as their position and lighting capabilities. The benefit is however a more efficient and managed lighting process.

Aiming to introduce safety-relevant applications as day one use cases, ETSI focuses on the standardization of two message types for V2V communication, namely the decentralized environmental notification message (DENM) and the cooperative awareness message (CAM). Considering the sophisticated approach, in our opinion neither the CAM nor DENM are suitable for use with the CHL. Both message types are not intended to be used for bidirectional 
communication. Hence, implementing a tailored message type or even protocol which supports the CHL is the most reasonable solution. The use of the CAM is suitable in the basic approach. The CAM is continuously broadcast and contains necessary information, such as vehicle position. It can also be extended with optional containers including further data, such as driver position.

Security functions aim to benefit from synergies with existing functions and technologies. Thus, we pursue the basic approach in the following. This way the CAM can be used to realize the CHL. An extension of the CAM is shown in Table 6.2. Since the CAM was already extensively introduced in Table 6.1, we only present the extensions necessary for the CHL. We introduce a container coopHomeLightParameters, which is optional and added to the CAM accordingly. A vehicle receiving a CAM evaluates whether coopHomeLightParameters are included or not. If the aforementioned container is included, vehicles check whether they are within the relevanceArea, which is set by the host vehicle asking for lighting help. Position information does not necessarily refer to the World Geodetic System 1984 (WGS84) [109], which is used by GPS, but may refer to another reference system mounted for instance within a parking facility. Thus, the CHL container also contains a referenceSystem parameter to indicate the underlying reference system. This way, each vehicle is able to calculate the driver position (driverPosition) and turn on lights according to the approach suggested in Section 6.2.4. To the best of our knowledge, there is not as yet an approach that considers $\mathrm{V} 2 \mathrm{~V}$ communication when vehicles are not in use, i.e., the ignition is switched off. That means, vehicles need to be in a kind of sleep mode in order to be able to receive and evaluate CAMs.

\subsubsection{Security}

Similar to the electronic decal, we propose using the CAM to communicate with participating vehicles to realize the CHL. Hence, we can use the same security requirements described in Section 6.1.2.2. Besides vehicles, ETSI can consider mobile devices as ITS stations, and so these security requirements can be applied for V2D communication as well. 
Table 6.2.: CAM specification extended by cooperative home light parameters

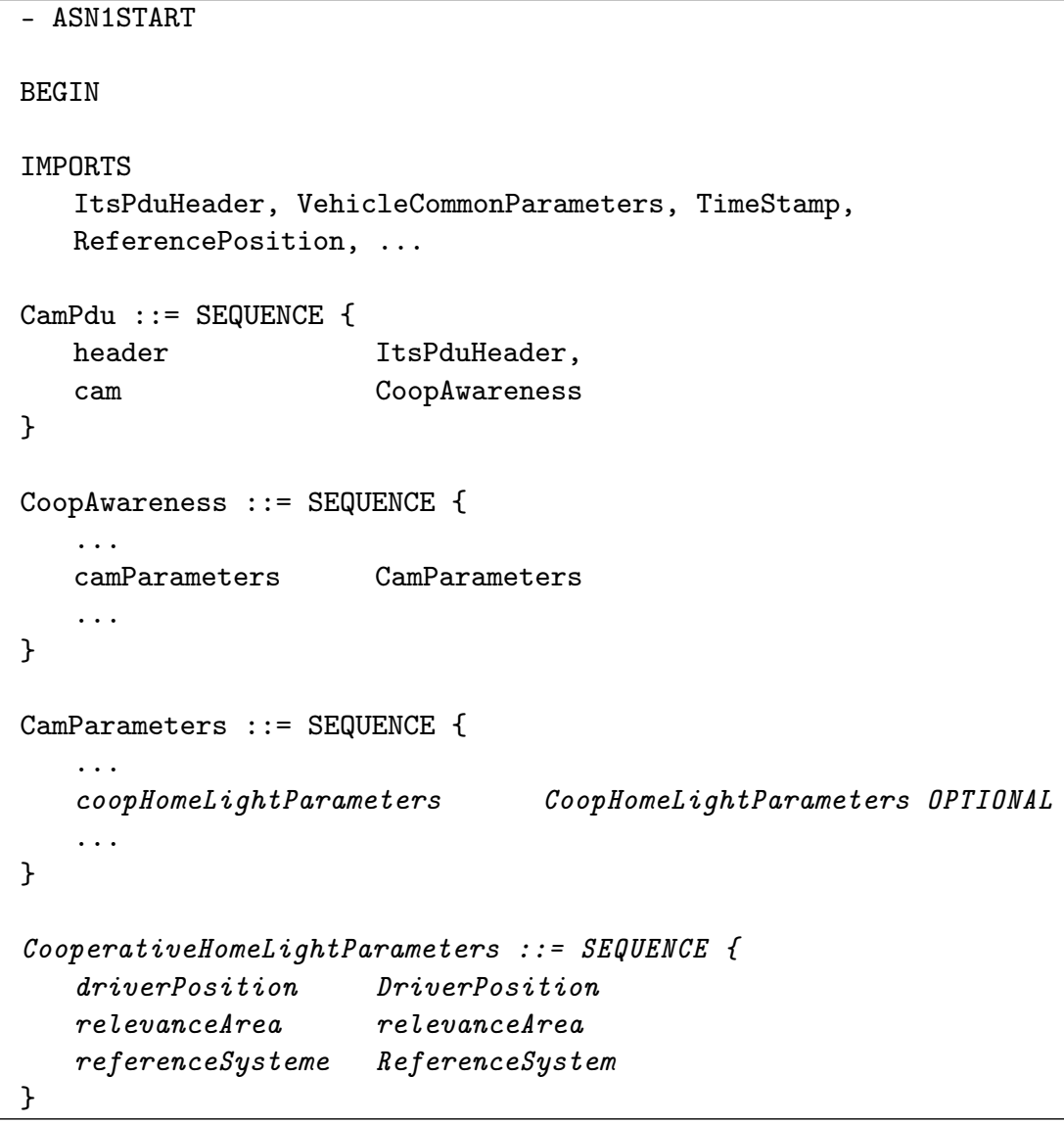

\subsubsection{Lighting}

Dependent on the equipment level, vehicles usually posses at least lighting systems for outside illumination, which are mandatory by according laws and mainly regulated by the UNECE regulations [203]. These regulations form a framework for technical requirements of vehicles, including lighting, and are accepted in the European Union and other regions.

ADAS such as dynamic cornering lights, which light into corners, or adaptive high-beam assistants, which detect incoming traffic and adjust beams accordingly, actively intervene in the vehicle's lighting system. Additionally, lighting systems underlie a steady development where incandescent systems are continuously replaced by LED systems, partly in combination with xenon lights [186]. Researchers, such as Hörter et al. [110], even work on assistance systems 
for rural roads which use moveable lights to precisely position a light spot on pedestrians and animals on the road(side), thus making them visible sooner for the driver. Hence, vehicles are and will be increasingly equipped with sophisticated lighting systems.

According to the UNECE regulations [203] lights are mandatory in vehicles. We suggest using the light sources depicted in Figure 6.3 to realize the CHL. We divide the vehicle surroundings into eight areas, numbered $I$ to $V I I I$. Depending on the driver position in the area, specific light sources are turned on. Table 6.3 summarizes the dependency of light sources and area. In addition to simply turning lights on or off, the opportunity to move low beams in the vertical as well as horizontal pane improves the CHL. Since the driver is moving, low beams are permanently aligned in the direction of the driver, within mechanical limits.

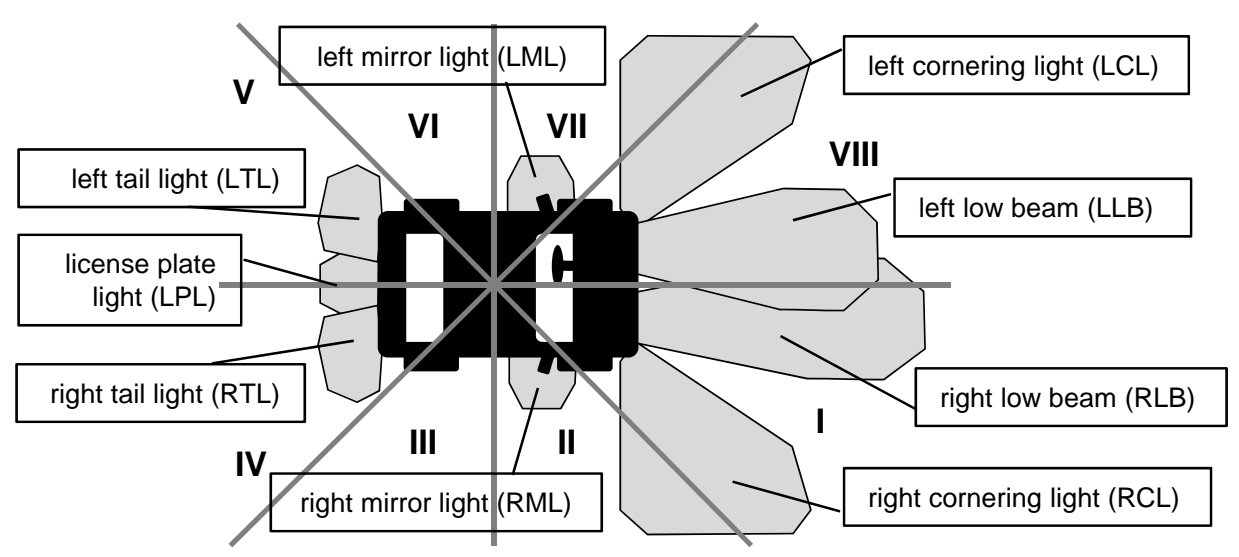

Figure 6.3.: Light sources and areas of CHL

Table 6.3.: Dependency of lighting on driver position within area

\begin{tabular}{r|cccccccc}
\hline Light & \multicolumn{7}{|c}{ Area } \\
source & $\mathrm{I}$ & II & III & IV & V & VI & VII & VIII \\
\hline LLB & $\mathrm{x}$ & - & - & - & - & $\mathrm{x}$ & $\mathrm{x}$ & $\mathrm{x}$ \\
LCL & - & - & - & - & $\mathrm{x}$ & $\mathrm{x}$ & $\mathrm{x}$ & $\mathrm{x}$ \\
LML & - & - & - & - & $\mathrm{x}$ & $\mathrm{x}$ & $\mathrm{x}$ & $\mathrm{x}$ \\
LTL & - & - & - & $\mathrm{x}$ & $\mathrm{x}$ & $\mathrm{x}$ & - & - \\
NPL & - & - & $\mathrm{x}$ & $\mathrm{x}$ & $\mathrm{x}$ & $\mathrm{x}$ & - & - \\
RTL & - & - & $\mathrm{x}$ & $\mathrm{x}$ & $\mathrm{x}$ & - & - & - \\
RML & $\mathrm{x}$ & $\mathrm{x}$ & $\mathrm{x}$ & $\mathrm{x}$ & - & - & - & - \\
RCL & $\mathrm{x}$ & $\mathrm{x}$ & $\mathrm{x}$ & $\mathrm{x}$ & - & - & - & - \\
RLB & $\mathrm{x}$ & $\mathrm{x}$ & $\mathrm{x}$ & - & - & - & - & $\mathrm{x}$ \\
\hline & \multicolumn{7}{|l}{} \\
\hline
\end{tabular}




\subsubsection{Horizontal beam movement}

Horizontal beam movement is mainly driven by the dynamic cornering light, which is intended to be used in rural areas or on highways while driving through corners at higher speed. Low beams are actively moved horizontally into the corner with a typical maximum angle of 15 degrees [204]. Beams are usually controlled by electromotive actuators, with the mechanism to move low beams integrated in vehicles with the aforementioned assistance system.

\subsubsection{Vertical beam movement}

To avoid dazzling incoming traffic, manual level adjustment exists besides the more sophisticated static and indeed dynamic automatic levelling. The static levelling system automatically adjusts the level dependent on vehicle loading. Dynamic systems additionally take the vehicle's acceleration and deceleration into account to adjust the tilt angle dynamically. Hence, actuators to adjust vertical beam movement are also widespread in vehicles. The maximum range of asymmetric low beams is given as approximately $50 \mathrm{~m}$ and $65 \mathrm{~m}$ [111, 112].

\subsection{Summary}

Although a detailed implementation of the electronic decal and the cooperative home light is beyond the scope of this thesis, we have shown the opportunities to realize both functions, and thus, the feasibility of realization. Of course, some technologies are not yet available to the mass market, but we have seen that both functions are technologically realizable since feasibility has at least been shown in the concerned research communities.

The electronic decal, especially when controlled by a key, is of course a function closer to series realization than the cooperative home light. First, the electronic decal is less dependent on other technologies like V2V communication. Second, the introduction of V2V communication is being highly pushed, not only by car manufacturers. Thus, when equipping vehicles with the according OCUs and coming to an understanding around standardization, a door will be opened for the realization of the electronic decal. The CHL in contrast demands, besides V2V communication, further technological extensions within the vehicle as well as appropriately equipped infrastructure. Nevertheless, the technological realization of the CHL is nonetheless feasible too.

A biometric (de)activation of the electronic decal is also imaginable, e.g., making use of biometric face recognition. However, we think that the use of biometric identifiers highly increases the risk of personal injury. An offender would need the relevant person to deactivate the electronic decal since biometric identifiers are the token. This way, the person themselves are necessary to circumvent the electronic decal, increasing risk for that individual. 
It has also become clear that the development and research of enabling technologies within the automotive field is mainly driven by assistance applications, especially for V2V communication. Consequently, the development of security functions ideally uses synergy effects by drawing on technologies that coincide with assistance systems. 


\section{Chapter}

\section{Evaluation of security functions}

Designing and implementing security functions is only one side of the coin. The other side of course involves the evaluation of security functions. Besides the main goal of fighting vehiclerelated crime, security functions also pursue the goal of reducing the fear of crime and to create tangibility of security. In this chapter, we seek to evaluate the electronic decal (ED) and cooperative home light (CHL).

The typical way to estimate the effectiveness of a security measure is to look at the past and to analyze the achieved effect. However, we have designed two security functions in this thesis and want to estimate whether further implementation is feasible. Consequently, we want to tackle the evaluation challenge beforehand. One approach would be to implement each security function and conduct case studies under real conditions. But this approach comes with one considerable drawback. Implementing each security function involves significant financial costs, especially for $\mathrm{V} 2 \mathrm{~V}$ communication where a critical mass of vehicles is necessary to achieve satisfying results.

To overcome this drawback, we suggest identifying comparable functions or countermeasures as a first step. Using relevant evaluation results and transferring them to our security functions provides a first indication of possible effectiveness and behavior. Second, by conducting surveys, participants can rate whether they expect the function to be effective against a given crime and the likelihood of it reducing fear of crime. Participants experience the function without violent or threatening attacks and their opinions are gathered. The survey also covers acceptance and usability issues related to the security function. Knowledge about users' attitudes towards a security function is a factor of success. No matter how effective a security function might be, a security function which is not convenient for users will deter them from making use of it, thus making the function ineffective. Third, expert interviews support evaluation, especially in estimating effectiveness at fighting crime. This is necessary since crime occurrence is non deterministic and cannot be simulated.

The first section summarizes our related work to estimate the potential effectiveness by transferring related research results of similar functions or countermeasures. To evaluate both security functions in deeper detail, we conducted our own survey in the second section. The third section presents our expert interviews estimating the effectiveness of both security functions before summarizing the chapter. 


\subsection{Transfer of related research results}

\subsubsection{Cooperative home light}

To the best of our knowledge, a function similar to the CHL has not yet existed. Thus, no results which can be directly transferred to estimate the effectiveness of the CHL are available. Nevertheless, we think that for the influence of (street) lighting on crime and fear of crime, which has been widely researched in literature, provides a first indication of the effectiveness of the CHL. Research work to evaluate the influence of street lighting in particular has been widely conducted.

On behalf of the US Department of Justice, Tien et al. [113] analyzed over 100 projects and evaluated the results of 15 of them in more detail. In 1979, they concluded that improved lighting generally does not change the occurrence of crime, that is, it neither leads to an increase nor to a decrease in crime. The projects were however seen to have weak project designs, inadequate street lighting and an insufficient consideration for the influence of lighting on specific types of crime, such as robbery, assault, burglary, car theft or larceny.

Ramsay and Newton [114] suggested on the basis of research made in the years before 1991 that light improvements indeed tend to have a positive influence on the feeling of security, but do not influence crime.

A team from the University of Southampton evaluated the influence of street lighting improvement in a high-crime rate area in Britain [115]. According to the overall conclusion, no significant evidence was found that improved street lighting reduces reported crimes. However, a clear improvement was identified in the testing area for the perceived security of women walking alone in the dark. The perception of security during the day or at home remained unaffected. However, residents' reactions showed that measures to improve lighting was positively accepted as a popular measure.

According to [116], while street lighting evaluations were reviewed mainly in the 1990s, newer UK research has shown that more general measures seem to have a crime prevention effect. In contrast, according to older US research, the effect is strongly limited. Additionally, newer studies have shown that improving street lighting increases feelings of security. Improvements are also associated with crime reduction.

In 1999, Painter and Farrington [117] published their results from a survey measuring the effect of installing improved lighting to analyze crime occurrence. Their results showed a significant decrease of crime in the experimental area, a minor decrease in the neighboring area and no decrease or even a slight increase in the control area. They concluded that improved lighting has a preventative effect on crime. Furthermore, people in the experimental area showed a significantly greater improvement in quality of life. People from the control area felt more unsafe to walk after dark in their area. 
In 2002, Farrington and Welsh [118] evaluated the results of US and British studies from previous decades for the British Home Office [205] to estimate the effectiveness of street lighting on crime. They prepared an update of their systematic review [119] for the Swedish National Council for Crime Prevention [206] in 2007. Farrington and Welsh used rigorous criteria for the inclusion of evaluation studies. They only included studies where the main intervention method was improved lighting and excluded studies involving one or more interventions. Furthermore, they ensured they made a differentiation between property and violent crimes, and results were provided for both. The evaluation design had to meet methodological standards involving before and after measures in at least one experimental and one control area. Furthermore, the total number of crimes in each area had to exceed 20, both before and after the measure, to provide sufficient statistical significance to detect changes in crime. The majority of studies included showed a decrease of crime. Moreover, in the main, the studies did not find a greater decrease of night-time crimes than day-time crimes. Hence, Farrington and Welsh concluded that improved street lighting increases community pride and informal social control as opposed to surveillance and deterrence. Thus, increased community pride as well as informal social control are more plausible reasons for crime reduction.

In 2015, researchers [120] analyzed data from 62 of 174 local authorities from England and Wales in order to estimate the influence on crime by reducing lighting at night. They looked at data from 2010 to 2013 and focused on offenses occurring more likely at night such as burglary, theft of or from a vehicle, robbery, violence and sexual assault. Overall, they concluded that there is no evidence between a reduction in street lighting and an increase of crime across England and Wales. The researchers however pointed to the fact that reductions in street lighting need to be planned with care by local authorities. An accompanying study [121] showed that people had strong concerns when light was switched off. Both, urban and suburban residents found street light being important at night. Some residents even felt less safe in the dark. Switching off lights raised the perception of an area being neglected by the local authority who were removing a "public good".

In a nutshell, the research on the effect of lighting on crime indicated equivocal results. Studies exist showing a reducing effect on crime. But, studies also exist showing that lighting is unlikely to reduce crime. However, more consistency exists that street lighting has a positive effect on community pride and self-confidence. Furthermore, a reducing effect on fear of crime as well as positive influence on quality of life is largely assumed. Given the aforementioned results, the CHL has the potential to fight crime if people are convinced to use it and if it succeeds in improve people's self-confidence. This way, a positive effect on the fear of crime can be also achieved.

\subsubsection{Electronic decal}

A security function equivalent to the electronic decal is not yet available. However, vehicle decal programs with a physical decal (see Section 4.2.1) were widely introduced in the USA and UK in the early 1990s. Evaluation results from the physical decal thus provide a tentative indication of the scheme's effectiveness. 
In 1992, the National Highway Traffic Safety Administration (NHTSA) [207] prepared an auto theft-resistance study evaluating the effectiveness of specific theft-resistance measures for the United States Congress. The NHTSA, amongst other things, took a stand on decal programs which were seen as relatively inexpensive and a useful measure to reduce vehicle theft, having had some success.

Brown [122] conducted a study in Gwent (UK) and concluded that despite many influencing factors, the implementation of the decal program led to a decrease in vehicle thefts for participating members. Furthermore, the implementation had an overall impact on vehicle-related crime and even reduced fear of crime. In addition, members' security awareness increased, with some even fitting additional security devices to their vehicles.

Within the Hartlepool Safer Cities Project in the beginning of the 1990s [123], the vehicle decal was also evaluated. According to the results, the probability of theft for vehicles not registered with the vehicle watch program was four times higher that that of registered vehicles. However, the authors admit that there was no evidence that the vehicle watch scheme was solely responsible for the drop in theft, since program participants tended to be more conscious in their security behavior.

Honess and Maguire [123] conducted a study in the Newport area of the UK. They could not find any indication for an overall reduction of vehicle theft but they concluded that the individual probability of becoming a victim of vehicle theft is two times lower for members than for non-members. Furthermore, they conducted a street survey and found several differences between members and non-members. Vehicle watch members were older and had a higher tendency to park their vehicle in a garage at night. Additionally, members also tended to park the vehicle in their field of view when possible and had vehicles with more security features. However, the authors could not say whether the aforementioned difference existed prior to the membership or had resulted from the membership.

Ethridge and Sorensen [124] evaluated the vehicle decal program implemented by the McAllen Police Department in Texas, USA. Interpreting the raw figures (i.e., the entire number of registered vehicles, the vehicles registered with the program and the number of stolen vehicles from both groups) program members had a lower probability of becoming victims of vehicle theft. The majority of program members were however temporary residents of Texas and so did not spend the entire year there, consequently reducing their risk of having a vehicle stolen in Texas.

The Arizona Criminal Justice Commission published a vehicle theft study in 2004 [84] including interviews with victims as well as offenders. The commission concluded that the decal program is highly effective in Arizona. An additional deterrent effect was achieved through media reports about the success of the initiative and people's increased security awareness. More than half of participants said that the decal program was responsible for them taking additional precautions against vehicle theft.

A decade after their introduction in 1994, Merta [125] aimed in part to estimate the success of Michigan, New York and Illinois's decal programs. He concluded that no convincing facts and figures that showed the success or failure of the decal programs were available. 
The majority of studies have, in sum, concluded that decal programs have a reducing effect on an individual's chance of having their vehicle stolen. Additionally, there is a general consensus about the positive effect they have on people's security awareness. Some authors also ascribe a reducing effect on fear of crime to the programs since the visibility of the decal reduces people's vulnerability to vehicle theft. Potential thieves discard vehicles with a decal, swapping it for a vehicle without a decal in order to reduce effort and their probability of getting stopped by police. The electronic decal is however not visible to the thief, and so we think that its effect on an individual's chances of getting their vehicle stolen is less than with the physical decal. However, the overall risk and deterrence for the thief is higher with the electronic decal since they do not know whether a targeted vehicle is equipped with the electronic decal. Furthermore, the aforementioned evaluations do not provide information about the chances of the thief being stopped by police when illegally driving a vehicle.

\subsection{Customer survey}

Conducting our survey, we pursue several goals. We aim to estimate the effectiveness of both functions in fighting intended vehicle-related crime and reducing fear of crime. We also seek to gain knowledge about the usability and participants' acceptance of the two functions. Additionally, we are interested in the opinion of participants on the approach of using new technologies to tackle vehicle-related crime. To reach our goals, we analyzed the following topics and tested several hypotheses.

\section{Cooperative home light}

- Effectiveness at reducing fear of crime: We assume that the cooperative home light is effective at reducing the fear of robberies and assaults against occupants while going to their car. Additionally, we hypothesize that the CHL is more effective at reducing fear of crime than the basic home light function (BHL) since the CHL provides better lighting. We additionally think that gender, age and technological proficiency influence the estimation of the effectiveness of both the CHL and BHL.

H: The CHL is more effective than the BHL at reducing fear of crime.

H: Female subjects expect the BHL/CHL to be more effective at reducing fear of crime than male subjects.

H: Older subjects expect the BHL/CHL to be more effective at reducing fear of crime than younger subjects.

H: More technologically-proficient subjects expect the BHL/CHL to be more effective at reducing fear of crime than less technologically-proficient subjects.

- (Expected) effectiveness at fighting crime: We assume that the cooperative home light is expected to be effective in preventing robberies and assaults against occupants while going 
to their car. Furthermore, we hypothesize that the $\mathrm{CHL}$ is more effective in fighting these crimes than the BHL. We also assume that gender, age and technological proficiency influence the expected effectiveness for both the CHL and BHL.

H: The CHL is more effective than the BHL at fighting crime.

H: Female subjects expect the BHL/CHL to be more effective at fighting crime than male subjects.

H: Older subjects expect the BHL/CHL to be more effective at fighting crime than younger subjects.

H: More technologically-proficient subjects expect the BHL/CHL to be more effective at fighting crime than less technologically-proficient subjects.

- Desire for cooperative lighting: In our opinion, it is important to get an idea of whether subjects would provide their own car to light the way for someone else. Setting a vehicle up to contribute to cooperative lighting could be influenced by drivers' fears of their car's battery being exhausted, leaving them unable to start the car. Additionally, battery longevity is reduced due to more load cycles, necessitating earlier battery exchange. Moreover, lights are switched on and off more frequently, leading to decreased lamp life and necessitating earlier exchange.

- Willingness to use a smartphone: For the CHL to work, a hardware device that is "attached" to the driver and estimates their position is necessary. We suggest using a smartphone and thus want to estimate the willingness of individuals to use a smartphone to approach the positioning challenge.

- Surcharge for CHL: From an economic perspective, knowing the maximum amount participants are willing to pay for the CHL is of interest. Introducing the technology involves development costs which need to be reclaimed through sales.

- User feedback: We aim to gain feedback that goes beyond our predefined questions. Whilst posing questions with predefined answer scales facilitates evaluation, it may lead participants into a specific pattern. Therefore, we have provided free-text fields to provide them the opportunity to comment on drawbacks, benefits and propositions relating to the CHL.

\section{Electronic decal}

- Effectiveness at reducing fear of crime: The electronic decal (ED) is assumed to be effective at reducing the fear of vehicle theft. Moreover, we hypothesize that the ED is more effective at reducing fear than the physical decal (PD) since the ED makes use of sophisticated technologies. We also think that gender, age and technological proficiency influence the estimation of effectiveness for both the ED and PD.

H: The ED is more effective at reducing fear of crime than the PD. 
H: Female subjects expect the ED/PD to be more effective at reducing fear of crime than male subjects.

H: Older subjects expect the ED/PD to be more effective at reducing fear of crime than younger subjects.

H: More technologically-proficient subjects expect the ED/PD to be more effective at reducing fear of crime than less technologically-proficient subjects.

- (Expected) effectiveness at fighting crime: We suggest that the electronic decal would be effective in fighting vehicle theft. We further hypothesize that the ED would be more effective in fighting vehicle theft than the ED. Moreover, we suggest that gender, age and technological proficiency influence the expected effectiveness of both the ED and PD.

H: The ED is more effective at fighting vehicle theft than the PD.

H: Female subjects expect the ED/PD to be more effective at fighting crime than male subjects.

H: Older subjects expect the ED/PD to be more effective at fighting crime than younger subjects.

H: More technologically-proficient subjects expect the ED/PD to be more effective at fighting crime than less technologically-proficient subjects.

- Acceptance of false stops: Whether it concerns the PD or ED, there is always the risk of drivers being falsely stopped by the police. For the PD, which has a definite time frame, the risk is even higher. For example, a driver using their car at the weekend when returning from clubbing would likely encroach into the time frame. The ED in contrast is more flexible, though some risk remains, especially when (de)activating the ED via schedule or smartphone. The schedule might be outdated, an authorized driver might make spontaneous use of the car, or the smartphone becomes unavailable or is discharged. We are therefore interested in the degree to which subjects would accept the risk of being falsely stopped. On the one hand, we do not identify a difference between the acceptance of false stops due to the PD and those due to the ED, since the effort to check drivers' documents and investigate the situation is the same regardless of which countermeasure is responsible. On the other hand, the ED is clearly less prone to false stops due to flexible time periods. Subjects might therefore have higher expectations about the trustworthiness of the ED.

H: There is a difference between the ED and PD in users' acceptance of being falsely stopped.

- Acceptance of $V 2 V$ communication: $\mathrm{V} 2 \mathrm{~V}$ communication is a technology which has been researched from a technological perspective and its feasibility is confirmed. However, $\mathrm{V} 2 \mathrm{~V}$ communication is still largely unknown by the public since the technology is still in 
development and its introduction into the market is planned over the next years. People will thus be confronted with something new, raising privacy concerns and meaning that the willingness of participants to allow their car to continuously broadcast a "stolen vehicle" message to passing police vehicles is of interest. The same is true of the "stolen vehicle" message which is forwarded by vehicles in the surrounding area to increase the sending range. In this case not just police vehicles but a wider group of cars are involved in the communication.

- Acceptance of (de)activation methods: When designing the electronic decal, we suggested three opportunities in Section 6.1 to control its operation. These opportunities involve different benefits and drawbacks. We aim to estimate the acceptance for our proposed (de)activation methods as well as the preferred method for (de)activating the ED. Knowing the acceptance rate supports future implementation.

- Acceptance of fallback via PIN: The electronic decal can be controlled in three ways. The (de)activation via schedule and smartphone involve the risk of the system sending alarm messages despite the vehicle use being authorized. We have thus suggested a fallback in the form of PIN entry to (de)activate the ED for when the smartphone is discharged or unavailable, if the vehicle is borrowed or if the schedule is not up to date.

- Surcharge for ED: Knowing the maximum surcharge participants are willing to pay for the CHL is of interest. Similar to the CHL, the system comes with development costs which need to be met through sales.

- User feedback for ED: As with the CHL, participants had the opportunity to leave comments on benefits, drawbacks and propositions regarding the ED, thus providing feedback beyond our predefined questions.

\section{Security functions}

- Attitudes towards security functions: We aim to provide a general overview about the work on security functions to round up our survey. Participants' opinions about the use of new technologies to tackle vehicle-related crime partly influences future work on security functions.

- Importance of tackling specific vehicle-related crimes: We suggest a dependency between ratings of the use of new technologies to tackle vehicle-related crime and the kind of crime. Hence, finding a ranking of the vehicle-related crimes which should be tackled first and those which could be neglected supports the work on security functions. Furthermore, we aim to estimate whether an individual coming into deeper contact with specific security functions influences their attitude towards security functions. We believe three scenarios are possible. First, coming into contact with security functions has no influence on subjects since their opinion is already established, and thus hard to influence. Second, a better understanding of the potential of security functions leads to a positive attitude. Third, a better understanding of security functions may also lead to the opinion that security functions are meaningless. 
H: Coming into contact with security functions influences attitudes about security functions.

\subsubsection{Method}

\subsubsection{Design}

We designed our own supervised one-to-one survey where a professional examiner conducted the experiment with each participant separately. Each participant filled out a questionnaire. The experiment was structured in the following four modules.

- Sociodemographic module: This module seeks to gain information about the participants, such as gender, age and technological proficiency. We also introduce assistance systems and technologies providing the basis for the cooperative home light and the electronic decal. This is important for the understanding and evaluation of security functions. Additionally, this way, we get all participants on a similar level of understanding.

- Module to evaluate the cooperative home light: In this module, participants rate two topics of (expected) effectiveness. First, they rate the potential of the cooperative home light for preventing robberies and assaults against the driver while entering or exiting the vehicle. Second, they rate its potential for decreasing the fear of falling victim to a robbery or assault. Participants also rate these two topics with reference to the basic home light. Additionally, their willingness to purchase the CHL and allow their own vehicle to light the way for someone else is covered.

- Module to evaluate the electronic decal: The system's (expected) effectiveness at fighting vehicle theft and reducing fear of vehicle theft is covered. The physical decal is also rated for comparison. Furthermore, our three opportunities to (de)activate the electronic decal are covered. Moreover, privacy issues and customer willingness to purchase the system are considered.

- Module to evaluate security functions in general: This module covers ratings about security functions in general as well as the necessity to tackle specific vehicle-related crimes.

We designed a questionnaire as well as the survey relevant to these four modules. The questionnaire mainly consisted of questions to be answered on a five-point Likert scale with relevant labelling. To get more granularity, we also subdivided each category of the five-point Likert scale into three parts. Consequently, we had an overall answer depth of 15 possible answers. Table 7.1 shows an example of a 5x3 Likert scale rating importance. Using predefined questions with a judgment scale (Likert scale) facilitated the evaluation of our questionnaire. We also used comment fields in order to provide the opportunity to leave comments on functions. The original questionnaire in German can be found in the Appendix B.2. 
Table 7.1.: Example of a 5x3 Likert scale to rate importance

\begin{tabular}{|c|c|c|c|c|c|c|c|c|c|c|c|c|c|c|}
\hline \multicolumn{3}{|c|}{$\begin{array}{l}\text { Not important } \\
\text { at all }\end{array}$} & \multicolumn{3}{|c|}{$\begin{array}{c}\text { Not } \\
\text { important }\end{array}$} & \multicolumn{3}{|c|}{ Neutral } & \multicolumn{3}{|c|}{ Important } & \multicolumn{3}{|c|}{$\begin{array}{c}\text { Very } \\
\text { important }\end{array}$} \\
\hline 1 & 2 & 3 & 4 & 5 & 6 & 7 & 8 & 9 & 10 & 11 & 12 & 13 & 14 & 15 \\
\hline
\end{tabular}

\subsubsection{Setting}

We decided to use a professional examiner to conduct the survey. First of all, an experienced examiner is trained to conduct surveys. Second, and even more important in our view, the examiner was not involved in the subject of security functions. Consequently, (indirect) influence on participants during the survey was minimized. We introduced the examiner to the survey and conducted several test runs. Although we did not participate during the survey, the examiner and participants always had the opportunity to contact us in person to solve arising questions. Furthermore, the examiner ensured that the questionnaire was filled in fully. This was very important to achieve the predefined number of participants to be able to conduct our statistical tests. The survey was conducted in a separate room to avoid distraction, with each session conducted successively with one participant. The entire survey took about two weeks. The room could be darkened and was equipped with an 42-inch LCD-TV.

\subsubsection{Procedure}

We decided to use two different sequences to answer the questions from our four modules. We equally but randomly divided our participants by gender and age into two groups, group 1 and group 2, filling in the four modules according to sequence 1 and sequence 2 shown in Figure 7.1. Participants of group 1 filled in the security functions module before rating the CHL and the ED and group 2 members filled this module in last. This way, we sought for order effects and to test whether the deeper explanation of the two security functions influenced attitudes towards security functions in general. We prepared the questionnaires in advance of the survey so that the examiner always knew beforehand which questionnaire to use. The detailed procedure of all modules is described in the following.

\section{Sociodemographic module}

In the beginning, participants filled out the sociodemographic module, which consisted of three topics:

\section{Participants' information}

We asked participants to provide their gender and age. To get more knowledge about our participants, and thus to be able to analyze and interpret any unexpected evaluation results, we also asked subjects for:

- position in the company

- make, model and construction year of driven car 

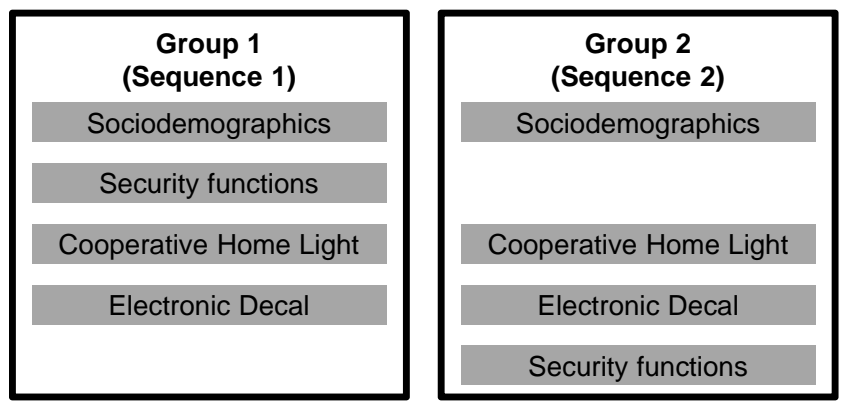

Figure 7.1.: Sequence of modules during survey

- property situation of driven car

- insurance against car theft of driven car

- importance of getting a stolen car back

\section{Technological proficiency information}

Questions cover the importance of having a smartphone with internet access, using a smartphone as a car key, participants' interest in technology, and equipment levels of cars with innovative technologies.

\section{Knowledge about specific automotive systems}

We wanted participants to be on a similar level of understanding regarding new technologies, especially technologies and assistance systems involved in the realization of the electronic decal and cooperative home light. Thus, participants had to answer whether they knew about the technologies and assistance systems listed below, which in the questionnaire were briefly described:

- Basic leaving home function: Unlocking the car using the remote control switches on low beams, taillights, lights in the mirror housings, license plate lighting and other available light sources.

- Dynamic cornering light: Dependent on a pre-specified speed, the cornering low beams follow the course of the road up to 15 degrees, i.e., low beams light up corners.

- Static cornering light: The static cornering light serves to light the cornering area. The light is switched on when either the turning signal is activated or the steering wheel is turned with the speed below the common speed limits in urban areas.

- Vehicle-to-vehicle communication: $\mathrm{V} 2 \mathrm{~V}$ is the wireless exchange of information between vehicles.

- Electronic immobilizer: An electronic immobilizer is an electronic theft protection system. After removing the key from the ignition, the immobilizer is activated and 
using the engine control unit it prohibits unauthorized persons from starting the vehicle.

Afterwards, the examiner went through these systems and showed a brief video explaining each system and its functionality. This way, we provided an additional visual explanation in order to facilitate understanding and to avoid misunderstanding when a system was rated as known.

\section{Cooperative home light module}

Due to high costs, the implementation of a real-world prototype involving several communicating cars was not realizable within this thesis. In cooperation with the Volkswagen AG department for visual communication, we were able to implement a real world animation of one specific scenario allowing participants to experience the CHL. We chose to model a parking garage with several parked cars. The animation was made from the first-person view, where the car owner used a smartphone to unlock the car, thus activating the CHL. Figure 7.2 illustrates some pictures of this animation. We implemented two additional animations in an identical surrounding and with the car owner walking the same path. One animation was with no function and the other with the basic home light (BHL).

To display the animations to participants, our first approach was to use an off-the-shelf headmounted display or video glasses to create a feeling of virtual reality. After discussions with experts within our company and having surveyed the literature [126, 127, 128], we decided against the use of a head-mounted display or video glasses since the benefits were not clear. Indeed, the drawbacks even outweighed the benefits. In our animation, the car owner walked on a static path to the car and we did not consider any interactions, such as head movements. Hence, an immersion into virtual reality was limited to the visual experience. Off-the-shelf head-mounted displays do not really convey the feeling of being within the scene due to limited display properties. Low resolutions as well as small angles of view rather give the viewer the impression of sitting close to a flat screen. An additional drawback is cyber sickness [208], where the eyes observe movement though the subject stands still. This contradictory information to sensory organs often leads to sickness. Consequently, we decided to show the animation in our darkened room on a 42 inch LCD-TV.

To compare the cooperative home light with the basic leaving home function, participants were asked to rate both functions. To consider order effects when rating both functions and reduce potential bias, we additionally divided all participants during survey planning in two equal groups, group A and B. As can be seen from Figure 7.3, participants in group A answered questions regarding the basic home light first and participants in group B afterwards.

The procedure to rate a function consisted of three steps. First, the examiner briefly introduced the function. Second, the relevant animation was shown to the participant. Third, the participant filled in the relevant questions on the questionnaire. Figure 7.3 shows the detailed procedure for both groups. As can be seen, regardless of the group they belonged to, the examiner showed the animation without the function to all participants in the beginning so that they were familiar with the surrounding and walking path in the animation. 

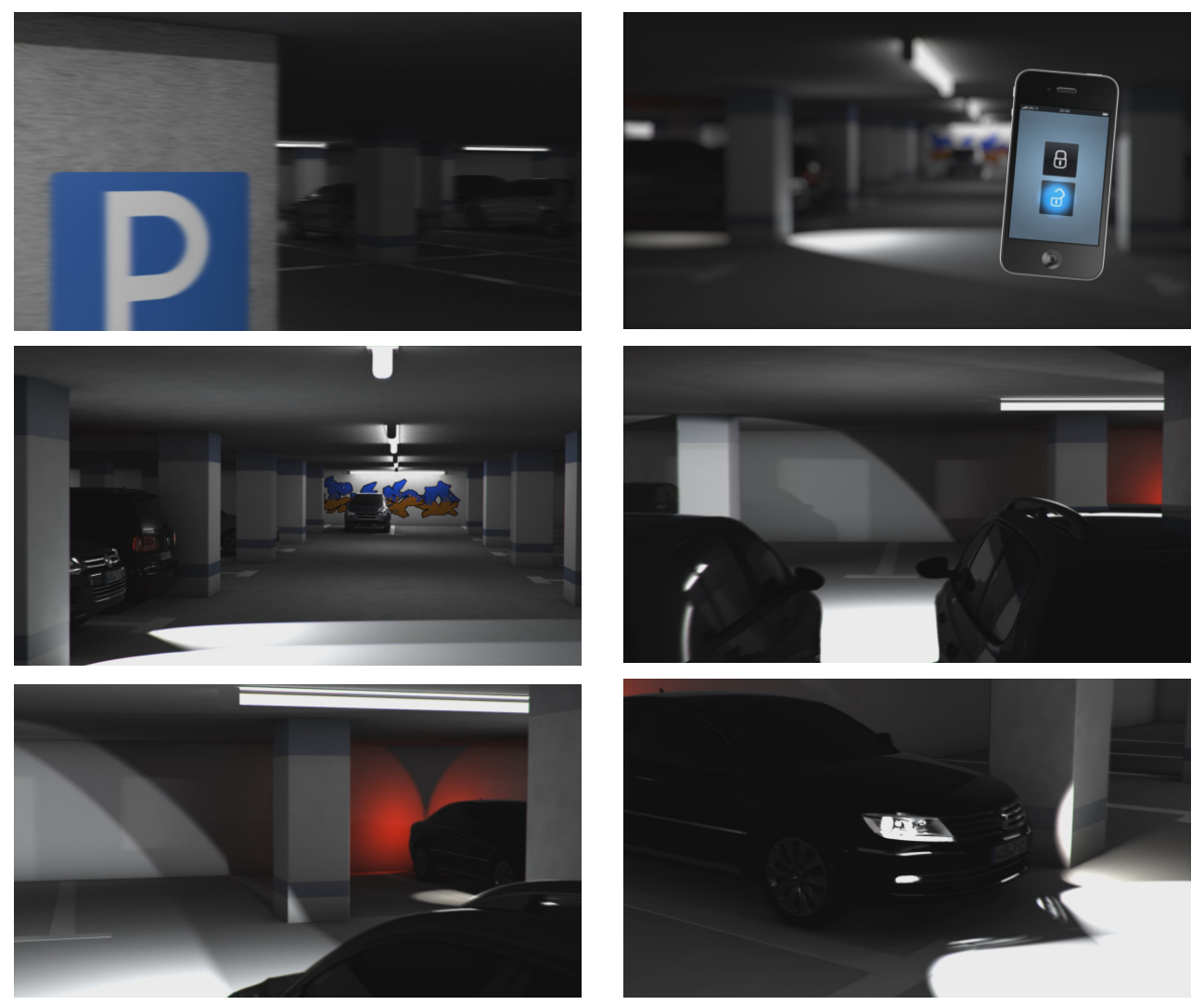

Figure 7.2.: Screenshots of the cooperative home light animation

\section{Electronic decal module}

To present and explain the electronic decal to subjects, the examiner used electronic slides. First, the examiner presented the physical decal as introduced in Section 4.2.1 before presenting the electronic decal. This way, both functions were presented in succession. Afterwards, the examiner showed our three methods to (de)activate the electronic decal.

(De)activation via

- schedule

- vehicle key

- smartphone

After having viewed this information, participants answered the questions regarding the physical and electronic decals. We divided our participants again into two groups in order to consider order effects, using the same groups as for the evaluation of the cooperative home light. 


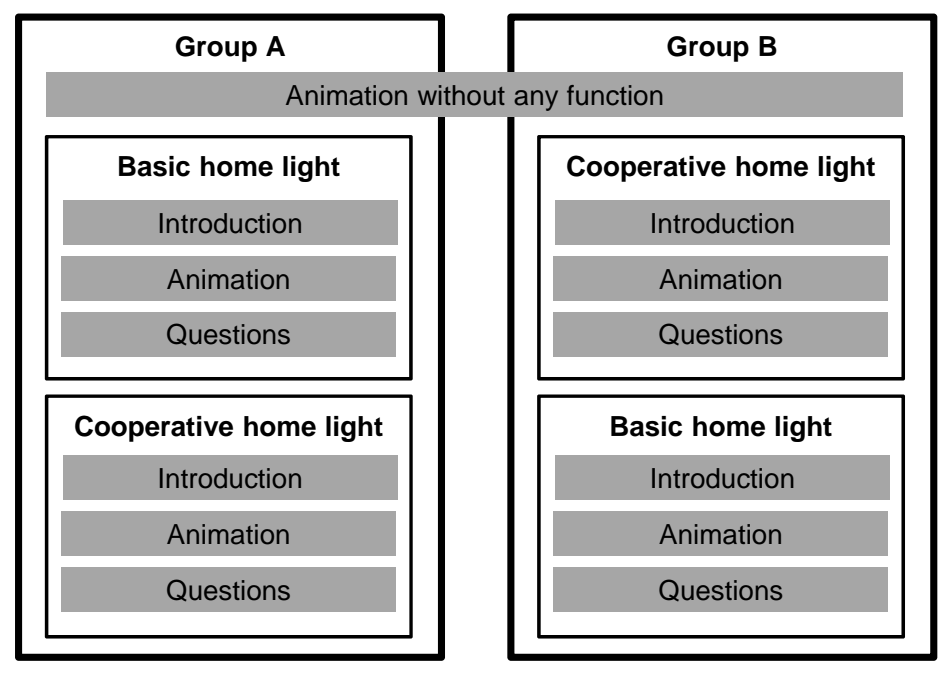

Figure 7.3.: Procedure of the module to evaluate the cooperative home light

This time, participants from group A first got questions regarding the more sophisticated function, the electronic decal, followed by questions regarding the physical decal. Participants from group B filled the questions in the opposite order. Figure 7.4 summarizes the procedure for the electronic decal module.

\section{Security functions module}

No additional measures were necessary to complete the questions about the security functions module. Half of our participants completed the security functions module before completing the cooperative home light and electronic decal modules. The other participants completed this module at the end, as shown in Figure 7.1.

\subsubsection{Subjects}

To recruit participants, we made use of an internal database from Volkswagen, which lists participants in a lower four-digit range who are willing to participate in customer surveys. All of them are Volkswagen employees. We used this database to invite participants to participate in our survey. To estimate an appropriate sample size which would meet the requirements both in terms of resources and sample size, we conducted an a priori power analysis. We made use of a power analysis tool, G-Power for statistical tests [129]. According to Cohen [130], the sample size $N$ is calculated as determined by the required power level $(1-\beta)$, a previously specified significance level $(\alpha)$ and the population effect size $(d)$. 


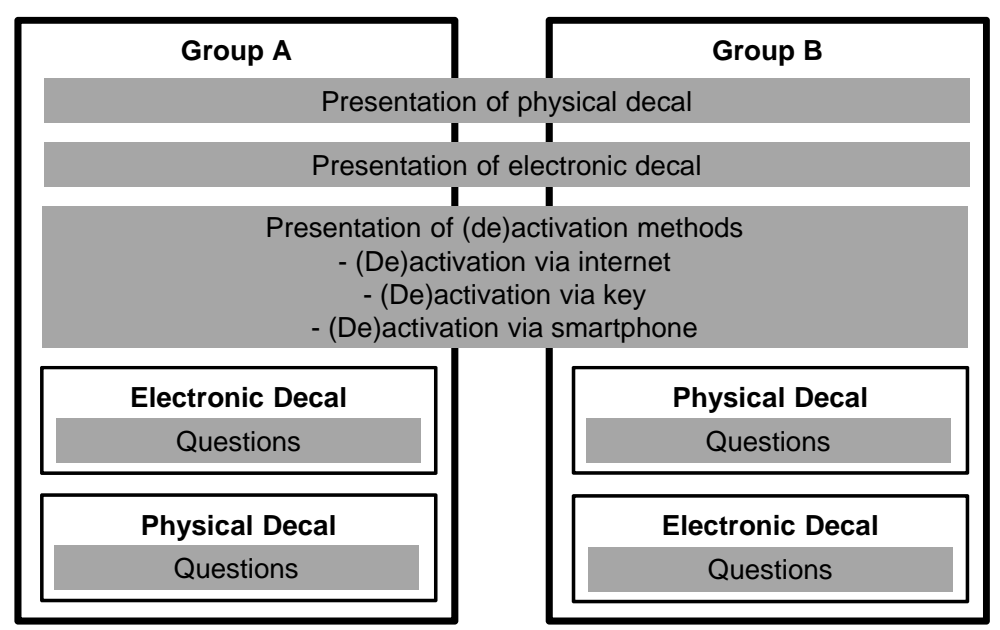

Figure 7.4.: Procedure of the module to evaluate the electronic decal

The main purpose of the survey was to estimate the (expected) effectiveness of our security functions. We also sought to estimate whether our security functions provide an improvement compared to the relevant basic functions. Consequently, each subject rated both the basic function and the proposed security function. Thus, we have matched pairs, i.e., dependent groups. Since we tested for improvement, a one-sided tail was chosen. Furthermore, we decided to choose a significance level of $\alpha=0.05$ and power of $1-\beta=0.95$, which are common levels in social sciences. With these settings, we computed a required sample size of 47 participants detecting medium effect size $(d=0.5)$.

We aimed to test for differences between genders and ages. Since we had the opportunity to control these attributes while inviting participants, we decided to have equal groups for both gender and age. Testing for differences between males and females as well as between younger and older participants necessitates two independent groups. Furthermore, we focused on onesided testing and chose a significance level of $\alpha=0.05$. A power of $1-\beta=0.95$ and a medium effect size $(d=0.5)$ would require a total sample size of 184 participants, i.e., 92 participants per group. This is beyond our resources and so we decided for a power of $1-\beta=0.8$ and a smaller effect size, $d=0.8$. According to [130], a type two error being four times $\alpha$, i.e., $\beta=0.2$, is still reasonable and we be able to detect at least large effects. Used these values for calculation, we needed a total sample size of at least 42 participants, i.e., 21 per group. Table 7.2 summarizes our settings for G-Power to calculate an appropriate sample size.

To have a margin security whilst remaining within the limits of our resources, we decided to invite 56 participants for the survey, equally divided by gender. For age, we invited equally grouped participants, i.e., younger and older participants, younger being under 36 and older being over 44 . Table 7.3 shows the distribution of gender and age. All participants regularly 
Table 7.2.: G-Power settings to estimate sample size

\begin{tabular}{l|l|c|c|c|c|c}
\hline \multicolumn{1}{c|}{ Objective } & \multicolumn{1}{|c|}{ Statistical test } & Tail & $\begin{array}{c}\text { Effect } \\
\text { size }(\mathrm{d})^{\mathrm{a}}\end{array}$ & $\begin{array}{c}\text { Signifi- } \\
\text { cance } \\
\text { level }(\alpha)\end{array}$ & $\begin{array}{c}\text { Power } \\
(1-\beta)\end{array}$ & $\begin{array}{c}\text { Min } \\
\text { total } \\
\text { sample } \\
\text { size }\end{array}$ \\
\hline $\begin{array}{l}\text { Effectiveness } \\
\text { estimation of }\end{array}$ & $\begin{array}{l}\text { U-Test (Wilcoxon): } \\
\text { two dependent } \\
\text { security } \\
\text { functions } \\
\text { pairs), } \\
\text { non-parametric }\end{array}$ & $\begin{array}{c}\text { one- } \\
\text { sided }\end{array}$ & $\begin{array}{c}0.5(\mathrm{me}- \\
\text { dium) }\end{array}$ & 0.05 & 0.95 & 47 \\
\hline $\begin{array}{l}\text { Estimation } \\
\text { of demo- } \\
\text { graphic } \\
\text { differences }\end{array}$ & $\begin{array}{l}\text { U-Test (Wilcoxon): } \\
\text { two independent } \\
\text { groups, same size, } \\
\text { non-parametric }\end{array}$ & $\begin{array}{c}\text { one- } \\
\text { sided }\end{array}$ & $\begin{array}{c}0.8 \\
(\text { large) }\end{array}$ & 0.05 & 0.8 & \\
\hline
\end{tabular}

a Effect size: small (0.2), medium (0.5), large (0.8)

Table 7.3.: Distribution of participant gender and age

\begin{tabular}{r|c|c}
\hline & Male & Female \\
\hline Young $(<36)$ & 14 & 14 \\
\hline Old $(>44)$ & 14 & 14 \\
\hline
\end{tabular}

drove a car, which they either owned, leased or had as a company car. The participants were employees from different working fields, distributed as seen in Figure 7.5.

\subsubsection{Analysis}

To be able to test for differences due to gender and age, we made use of the opportunity to control the gender and age of the invited participants. As already shown in Table 7.3, we had 56 subjects, equally divided into one half female and the other male. Additionally, one half were younger participants $(<36)$ and the other half older participants $(44<)$.

Furthermore, we had several items (i.e. questions) to measure the same construct, for example fear of crime. Hence, we had to combine data from related items. To test whether these questions sought to measure the same construct, we calculated Cronbach's alpha, the coefficient of internal consistency. The value ranges from 0 to 1 , where a value of 1 shows total reliability between the relevant items. However, very high reliabilities, such as those higher than 0.95 , indicate that items are probably redundant [131]. To estimate whether related items are reliable, Nunnally and Bernstein [132] recommend a value of between 0.7 to 0.8 for basic research. According to [133], a well-accepted value for Cronbach's alpha is between 0.70 and 0.90 . Ferreira and Palhares [134] suggest a value higher than 0.7, although references exist accepting values 


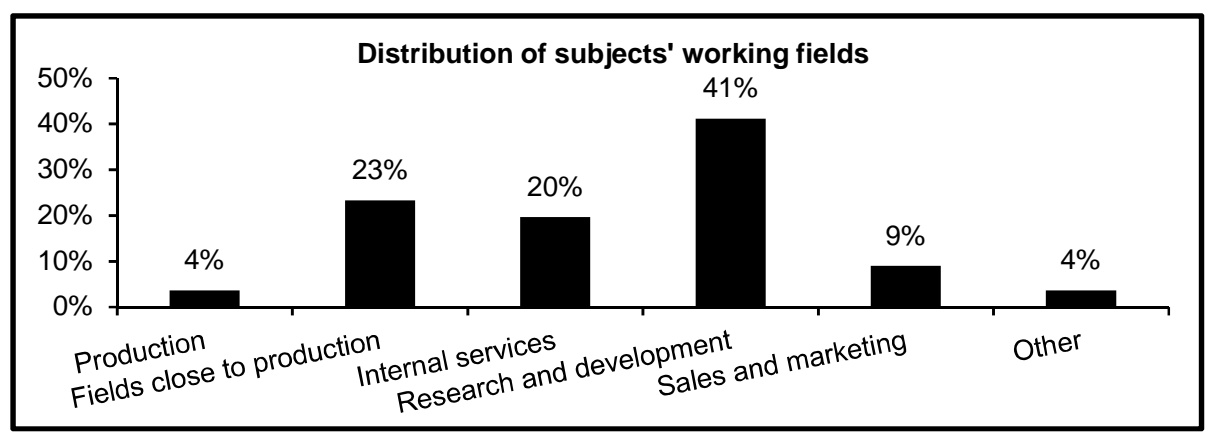

Figure 7.5.: Distribution of participants' working fields

Table 7.4.: Cronbach's alpha for technological proficiency if item was deleted

\begin{tabular}{r|c|c|c|c|c}
\hline Item & 1 & 2 & 3 & 4 & 5 \\
\hline Alpha if item deleted & 0.75 & 0.74 & 0.80 & 0.77 & 0.77 \\
\hline
\end{tabular}

lower than 0.7. So, in our opinion an alpha value between 0.7 and 0.95 is a suitable choice to estimate reliability and potential redundancy between items.

We also tested the influence of technological proficiency. To estimate the technological proficiency of our participants, we asked them to rate the following five items on our 5x3 Likert scale.

1. Fascination for technological devices (not present at all to very present)

2. Use of smartphone as car key (not attractive at all to very attractive)

3. Importance of having a smartphone with internet access (not important at all to very important)

4. Importance of having car equipment with new technologies (not important at all to very important)

5. Dedication to examining technologies (not present at all to very present)

We used these five items to represent participants' technological proficiency. We calculated Cronbach's alpha (0.80) to test for reliability, which was within our required range. We also examined the effect of deleting items to see whether Cronbach's alpha increased. The results are summarized in Table 7.4 where it can be seen that not removing any items increases reliability.

To get two groups, one which was technologically-proficient and the other not, we combined all five answers of each subject calculating the mean to represent the technological proficiency. Dependent on this value, we split our subjects into two equal groups, half with the lowest means and half with the highest means. This way, we achieved our two groups to test for significance. 


\subsubsection{Results}

In this section, we present the results of our survey. We first show the results for the cooperative home light, followed by the results of the electronic decal. Then, we show the results rating the work on security functions in general.

\subsubsection{Cooperative home light}

\section{Effectiveness at reducing fear of crime}

We used two items to rate the effectiveness at reducing the fear of crime. First, subjects rated the suitability of the BHL (mean: 8.9, SD: 2.9) and the CHL (mean: 11.4, SD: 2.5) to reduce the fear of assaults and robberies during the way to the car. Then, we asked them to rate the system's ability to increase feelings of security on the way to the car (BHL mean: 8.9, SD: 3.2; CHL mean: 11.7, SD: 2.5). A 5x3 Likert scale ranging from not suitable at all (1) to very suitable (15) was used. For both items, the reliability of the BHL is 0.90 and of the CHL 0.92. Hence, we combined both items for each function to represent fear of crime. As can be seen from Table 7.5, all subjects considered the CHL to be generally suitable (mean: 11.6, SD: 2.4) for reducing drivers' fears of assaults and robberies on the way to the car. This trend can be also seen in Figure 7.6, which shows the distribution of expected suitability for this measure for the BHL and CHL.

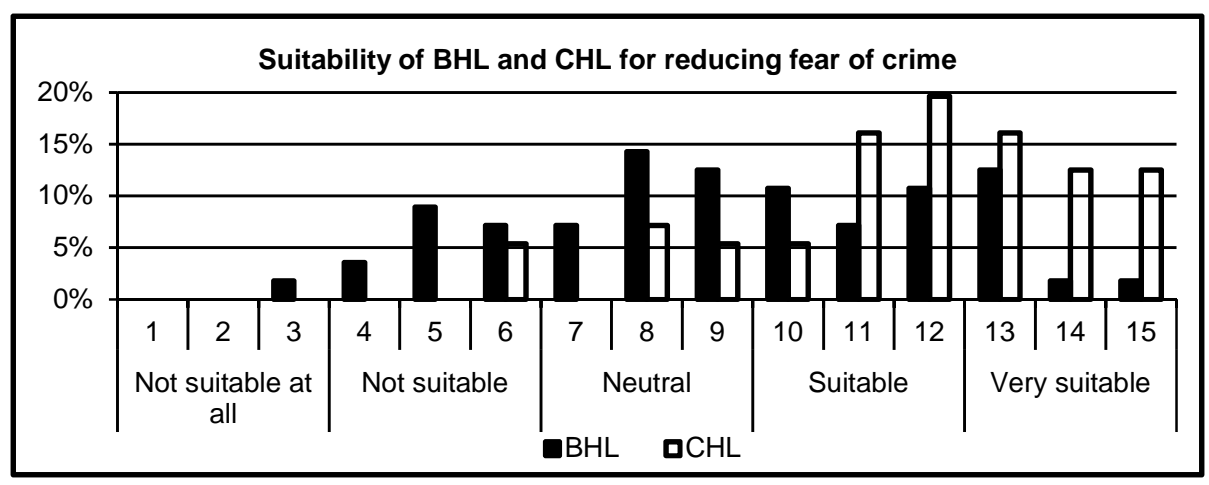

Figure 7.6.: Distribution of suitability of BHL and CHL for reducing fear of crime

$\mathrm{H}$ : The CHL is more effective than the BHL at reducing fear of crime.

As shown in Table 7.5, all subjects expect the CHL to be significantly more suitable than the BHL at reducing fear of crime. Taking group A and B separately, the CHL is also expected to be significantly more effective than the BHL for both groups. So, no matter if the BHL or the $\mathrm{CHL}$ is rated first, the CHL is expected to be more effective. We found however a significant effect while testing for a difference between group A and B in their ratings of the BHL. Group $\mathrm{B}$, which rated the BHL afterwards, rated it as significantly less effective than subjects from group A. 
Table 7.5.: Test results showing the effectiveness of the BHL and CHL at reducing fear of crime

\begin{tabular}{|c|c|c|}
\hline \multicolumn{3}{|c|}{ Effectiveness of the BHL and CHL at reducing fear of crime } \\
\hline & Basic home light (BHL) & Cooperative home light (CHL) \\
\hline & Mean (SD) & Mean (SD) \\
\hline All subjects ${ }^{* * *}$ & $8.9(2.9)$ & $11.6(2.4)$ \\
\hline Group $\mathrm{A}^{\mathrm{a}, * * *}$ & $10.3(2.8)^{t+}$ & $11.8(2.0)$ \\
\hline Group B ${ }^{\mathrm{a}, * * *}$ & $7.6(2.5)^{+t}$ & $11.3(2.7)$ \\
\hline
\end{tabular}

Note. $\mathrm{N}=56$. Mean (SD) on Likert scale: not suitable at all (1) to very suitable (15)

a Group A rated BHL first, group B rated CHL first

$* \mathrm{p}<0.05 ; * * \mathrm{p}<0.01 ; * * * \mathrm{p}<0.001$; the CHL is more effective than the BHL.

$+\mathrm{p}<0.05 ;++\mathrm{p}<0.01 ;+++\mathrm{p}<0.001$; difference between group A and B rating the effectiveness.

$\mathrm{H}$ : Female subjects expect the BHL/CHL to be more effective at reducing fear of crime than male subjects.

Results in Table 7.6 show that female subjects expect the BHL (mean: 9.4, SD: 2.5) and the CHL (mean: 11.9, SD: 2.0) to be slightly more effective than male subjects (BHL mean: 8.4, SD: 3.3; CHL mean: 11.2, SD: 2.7). However, the differences are non-significant.

$\mathrm{H}$ : Older subjects expect the BHL/CHL to be more effective at reducing fear of crime than younger subjects.

With age, no significant differences were found either. Older subjects expected both the BHL (mean: 8.7, SD: 3.0) and CHL (mean: 11.4, SD: 2.0) to be indeed slightly less effective than the younger subjects did (BHL mean: 9.1, SD: 2.9; CHL mean: 11.7, SD: 2.8).

H: More technologically-proficient subjects expect the BHL/CHL to be more effective at reducing fear of crime than less technologically-proficient subjects.

The technological proficiency shows no significance either. The results, especially those for the $\mathrm{CHL}$, are nearly identical across subjects with higher proficiency levels (mean: 11.5, SD: 2.6) and lower proficiency levels (mean: 11.6, SD: 2.4). 
Table 7.6.: Test results showing the effectiveness of the BHL and CHL at reducing fear of crime (sociodemographic influences)

\begin{tabular}{lcc}
\hline \multicolumn{2}{l}{ Effectiveness of the BHL and CHL at reducing fear of crime } \\
\hline & $\begin{array}{c}\text { Basic home light (BHL) } \\
\text { Mean (SD) }\end{array}$ & $\begin{array}{c}\text { Cooperative home light (CHL) } \\
\text { Mean (SD) }\end{array}$ \\
\hline Female & $9.4(2.5)$ & $11.9(2.0)$ \\
Male & $8.4(3.3)$ & $11.2(2.7)$ \\
\hline Old & $8.7(3.0)$ & $11.4(2.0)$ \\
Young & $9.1(2.9)$ & $11.7(2.8)$ \\
\hline Proficient & $9.3(2.9)$ & $11.5(2.6)$ \\
Not proficient & $8.8(3.0)$ & $11.6(2.4)$ \\
\hline
\end{tabular}

Note. $\mathrm{N}=56$. Mean (SD) on Likert scale: not suitable at all (1) to very suitable (15)

$* \mathrm{p}<0.05 ; * * \mathrm{p}<0.01 ; * * * \mathrm{p}<0.001 ;$ female/old/technologically proficient subjects rate the BHL/CHL

to be more effective than male/young/not technologically proficient subjects.

\section{Expected effectiveness at fighting crime}

We combined two items to estimate both the BHL and the CHL's expected effectiveness at fighting crime, with subjects rating two items as equal per function. The first item asked subjects to rate the suitability of the BHL/CHL for deterring a potential attacker from attacking a driver walking to their car (BHL mean: 8.3, SD: 3.1; CHL mean: 10.8, SD: 2.4). The second concerned the suitability of the BHL/CHL for reducing robberies and attacks on a driver walking to their car, and was rated (BHL mean: 7.8, SD: 2.8; CHL mean 10.9, SD: 2.5). Both items made use of a $5 \times 3$ Likert scale ranging from not suitable at all (1) to very suitable (15). Cronbach's alpha was 0.85 for the BHL and 0.95 for the CHL. Hence, we combined both items to represent the effectiveness at fighting crime. The CHL is considered on average by all subjects to be suitable for fighting crime, as summarized in Table 7.7. Figure 7.7 shows the relevant distribution.

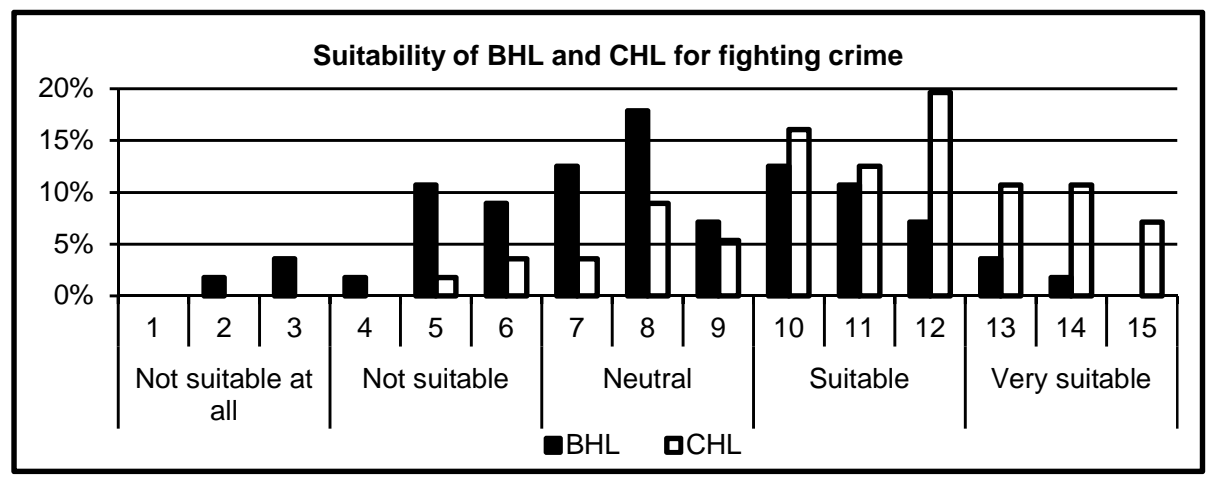

Figure 7.7.: Distribution of suitability of BHL and CHL for fighting crime 
$\mathrm{H}$ : The CHL is more effective than the BHL at fighting crime.

Looking at our test results in Table 7.7, the CHL was rated as significantly more effective at fighting crime than the BHL. There was also no difference between group A and B, with both groups showing a significant result. Furthermore, analyzing the answers of group A and B rating the CHL (Table 7.7), no significant difference between the two groups is seen. With the BHL however, a significant difference between group A and B was found, with group B rating the effectiveness of the BHL at fighting crime significantly worse than group A.

$\mathrm{H}$ : Female subjects expect the BHL/CHL to be more effective at fighting crime than male subjects

We tested for influence of gender. Although female subjects (BHL mean:8.4, SD: 2.4; CHL mean: 11.4, SD:2.2) expected on average both functions to be more effective than male subjects did (BHL mean: 7.7, SD: 3.0; CHL mean: 10.4, SD: 2.6), there was no evidence for significance, as can be seen in Table 7.8.

$\mathrm{H}$ : Older subjects expect the BHL/CHL to be more effective at fighting crime than younger subjects.

Older subjects (BHL mean:7.6, SD: 2.6; CHL mean: 10.7, SD:2.2) rated the effectiveness as even lower than younger subjects did (BHL mean:8.4, SD: 2.8; CHL mean: 11.1, SD:2.7). As summarized in Table 7.8 the results were non-significant.

$\mathrm{H}$ : More technologically-proficient subjects expect the BHL/CHL to be more effective at fighting crime than less technologically-proficient subjects.

There are only slight differences between technologically-proficient (BHL 8.2, SD: 2.6; CHL mean: 10.7, SD: 2.5) and not technologically-proficient subjects (BHL 8.0; SD: 3.0, CHL mean: 11.1, SD: 2.5). Consequently, no significance was evident.

Table 7.7.: Test results showing the expected effectiveness of the BHL and CHL at fighting crime

\begin{tabular}{|c|c|c|}
\hline \multicolumn{3}{|c|}{ Expected effectiveness of the BHL and CHL at fighting crime } \\
\hline & Basic home light (BHL) & Cooperative home light (CHL) \\
\hline & Mean (SD) & Mean $(\mathrm{SD})$ \\
\hline All subjects ${ }^{* * *}$ & $8.0(2.7)$ & $10.9(2.4)$ \\
\hline Group $\mathrm{A}^{\mathrm{a}, * * *}$ & $9.3(2.4)^{t+}$ & $11.4(2.2)$ \\
\hline Group $\mathrm{B}^{\mathrm{a}, * * *}$ & $6.8(2.5)^{t+}$ & $10.3(2.6)$ \\
\hline
\end{tabular}


Table 7.8.: Test results showing the expected effectiveness of the BHL and CHL at fighting crime (sociodemographic influences)

\begin{tabular}{lcc}
\hline \multicolumn{3}{l}{ Expected effectiveness of the BHL and CHL at fighting crime } \\
\hline $\begin{array}{c}\text { Basic home light (BHL) } \\
\text { Mean (SD) }\end{array}$ & $\begin{array}{c}\text { Cooperative home light (CHL) } \\
\text { Mean (SD) }\end{array}$ \\
\hline Female & $8.4(2.4)$ & $11.4(2.2)$ \\
Male & $7.7(3.0)$ & $10.4(2.6)$ \\
\hline Old & $7.6(2.6)$ & $10.7(2.2)$ \\
Young & $8.4(2.8)$ & $11.1(2.7)$ \\
\hline Proficient & $8.2(2.6)$ & $10.7(2.5)$ \\
Not proficient & $8.0(3.0)$ & $11.1(2.5)$ \\
\hline
\end{tabular}

Note. $\mathrm{N}=56$. Mean (SD) on Likert scale: not suitable at all (1) to very suitable (15)

$* \mathrm{p}<0.05 ; * * \mathrm{p}<0.01 ; * * * \mathrm{p}<0.001 ;$ female/old/technologically proficient subjects rate the BHL/CHL

to be more effective than male/young/not technologically proficient subjects.

\section{Willingness among car owners to contribute in cooperative lighting}

We asked three questions rated on a 5x3 Likert scale ranging from not willing at all (1) to very willing (15). First, we asked subjects simply to rate their willingness to provide their car to others for cooperative lighting. As can be seen in Figure 7.8(a), the willingness is indeed widely spread. However, there is a general tendency to be willing to support cooperative lighting (mean: 10.6, SD: 3.1). A few questions later, we asked our subjects again to rate their willingness. However, this time, we provided an explanation before the question detailing an energy management system which would avoid a complete discharge of the battery so that the car could still be started. We additionally pointed out that battery lifespan would be reduced due to more load cycles, thus necessitating earlier battery replacement (mean: 9.9, SD: 3.0). According to the results shown in Figure 7.8(b), the willingness decreased. Moreover, the decrease is significant $(\mathrm{p}<0.01)$. The third question was then asked, and this time, we pointed out that the car lights would be switched on and off more frequently. This would reduce bulb life, necessitating earlier lamp replacement (mean: 9.4, SD: 3.2). Figure 7.8(c) shows the relevant results, which again decreased significantly compared to the second question $(\mathrm{p}<0.01)$. 


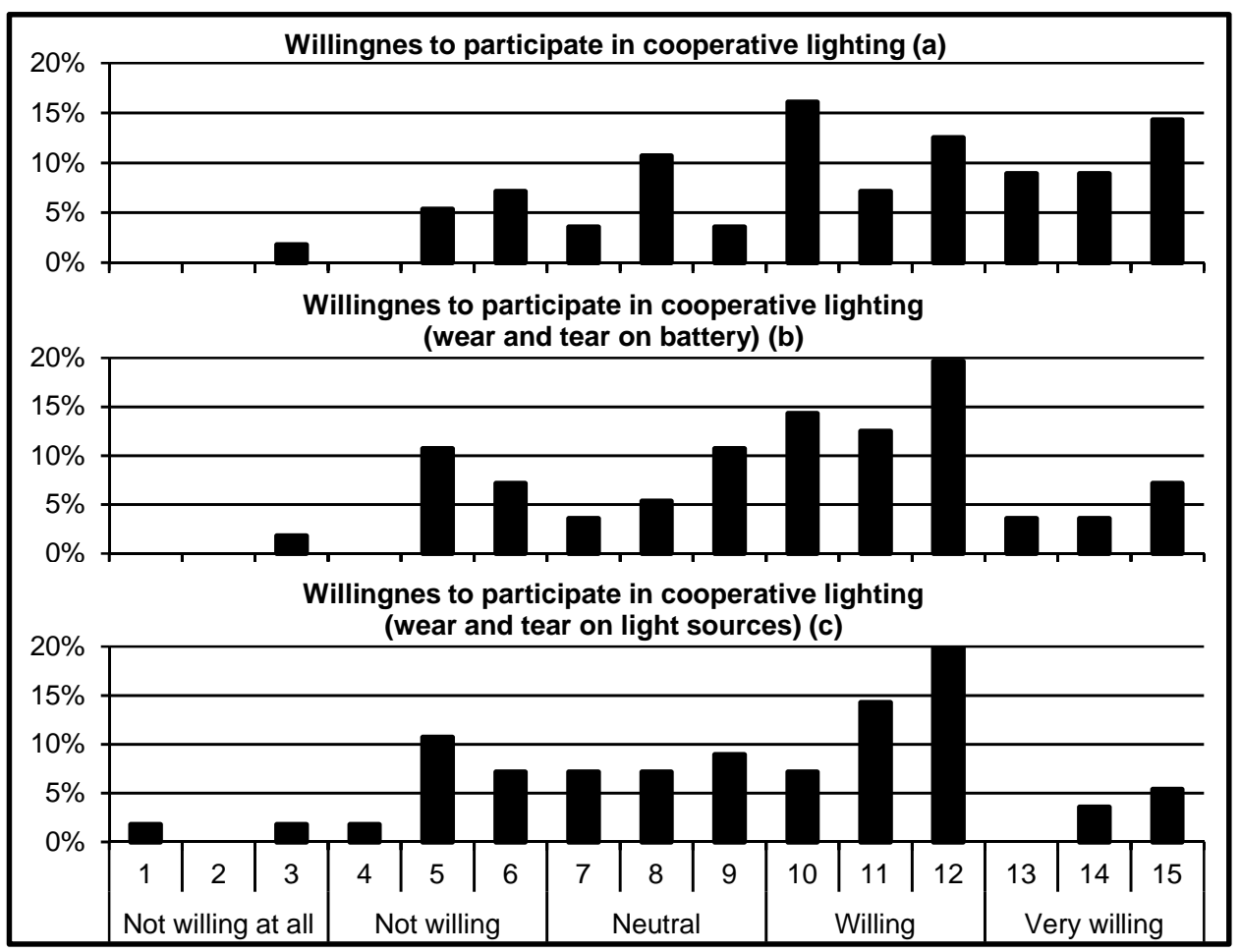

Figure 7.8.: Participants' willingness to provide their car for cooperative lighting

\section{Willingness to use a smartphone}

According to the results shown in Figure 7.9(a), the majority are willing to make use of a smartphone to operate the CHL (mean: 11.0, SD: 3.1). In the sociodemographic part of our questionnaire, we additionally asked subjects to rate the attractiveness of the smartphone as car key. As can be seen in Figure 7.9(b), subjects show variance (mean: 9.0, SD: 3.5).

\section{Surcharge for CHL}

We asked our subjects to mark the maximum surcharge on a number line ranging from $0 €$ to $1000 €$ which they would be willing to pay for the CHL. Figure 7.10 shows the results, with the surcharge shown in relation to the relevant participant ID. There were a few participants who were not willing to pay anything and indeed a few subjects which would be willing to pay far above the average amount of $244 €$. However, the majority ranged from $100 €$ to $300 €$. 


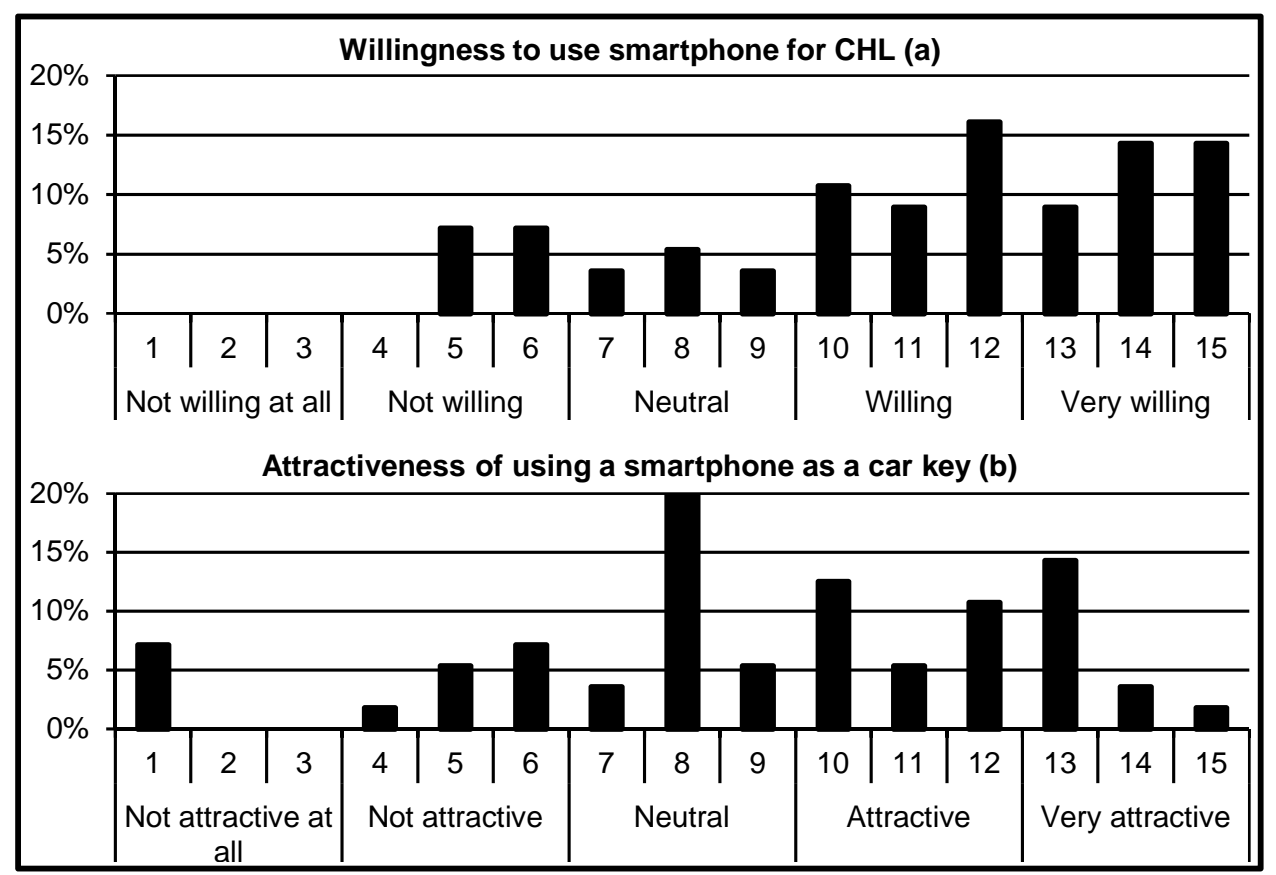

Figure 7.9.: Participants' willingness to use their smartphone for CHL operation

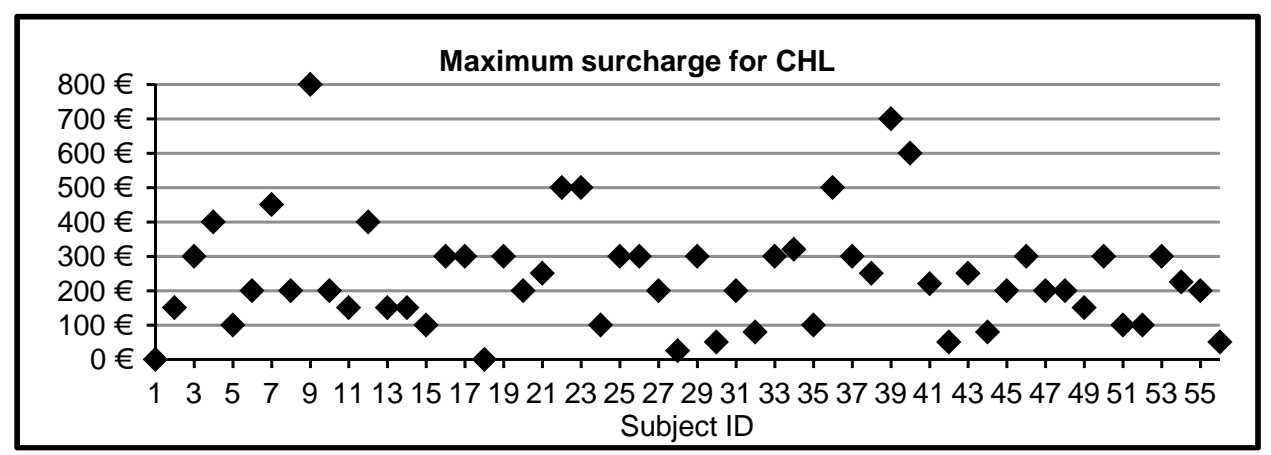

Figure 7.10.: Participants' maximum surcharge for the CHL 


\section{User feedback}

Our questionnaire provided the opportunity for participants to leave comments on both the BHL and the CHL. For this, we provided two text fields covering the benefits and drawbacks of the relevant function and a third text field for general comments on the given function. Furthermore, the examiner documented questions as well as remarks arising during the survey. In what follows, we summarize the feedback.

Several subjects stated that they would like to make use of the BHL, especially in order to find their car. One subject also added that after finishing work and going to his car, which is parked at the parking area in front of his workplace with thousands of other cars of the same make and even model, the BHL would be ideal for identifying his car in the mass. Some subjects criticized the $\mathrm{CHL}$, arguing it would complicate the process of finding their own car since several cars would turn on their lights.

Subjects worry that the CHL would lead to confusion, especially if numerous drivers made use of the CHL. One subject was afraid that operating the system for multiple drivers would require an additional exchange of (position) data. The multitude of light sources would also create a lot of shadows which might be irritating. Hence, the desired effect is lost. One subject also mentioned that other cars' lights would irritate since they would not know whether the lights were on because of the CHL or if a driver had started their car and wanted to leave the parking lot.

Furthermore, several subjects first unlock their car when it is in their range of sight. They would be afraid of indicating their unlocked car through the light to potential attackers. Furthermore, since the doors are immediately unlocked, the attacker could enter the car before the subject arrives.

For the CHL, most subjects would be concerned about economic issues such as battery longevity and reduced bulb life, which would bring additional costs. Associated with this, subjects doubt their willingness to provide their car for cooperative lighting, especially when there is no benefit. They also mention the chicken-egg-problem, i.e., the necessity of having a critical mass of cars that support the CHL. First users won't really benefit since the penetration rate is too low. However, two subjects claimed not to care about the additional wear, and would offer their car for cooperative lighting as long as they had a leased car which is driven only for a limited period of time before being returned.

The parking garage is in fact not seen as the place where the CHL could provide the most potential and benefits. A parking garage is generally lit. Even if some light sources are out of order there is still enough light. The main use is seen as being on side roads which have insufficient illumination, on streets with lamps hidden by treetops or other dark outdoor places where no illumination is available or the lights are shut down to save money for example. One subject reported wanting to connect the CHL with his carport, his house, and his wife's car which was parked on the driveway. Another subject argued that the CHL would show its potential in countries such as Mexico and Brazil as opposed to Germany.

The compatibility with other cars and smartphone manufacturers raised concerns. A noticeable preference was for participants to want to use a key instead of a smartphone, in order to avoid 
having to many devices. A smartphone or other device with an appropriate display capability could however be used to show an availability map of participating vehicles within the CHL network.

\subsubsection{Electronic decal}

\section{Effectiveness at reducing fear of crime}

We used two items to rate the effectiveness of the physical (PD) and electronic decal (ED) at reducing fear of crime. First we asked subjects to rate suitability for reducing the fear of car theft (PD mean: 7.5, SD: 3.5; ED mean: 11.9, SD: 1.7). Then we asked participants to rate suitability for increasing drivers' feelings of security in relation to car theft (PD mean: 7.5, SD: 2.9; ED mean: 11.6, SD: 1.9). We used a $5 \times 3$ Likert scale ranging from not suitable at all (1) to very suitable (15). Cronbach's alpha was 0.87 for the BHL and 0.90 for the CHL. Hence, we combined both items for the BHL as well CHL to represent fear of crime. As can be seen from Table 7.9, on the whole the ED was seen by all subjects to be suitable for reducing fear of crime (mean: 11.8, SD: 1.7). This trend is also evident in Figure 7.11.

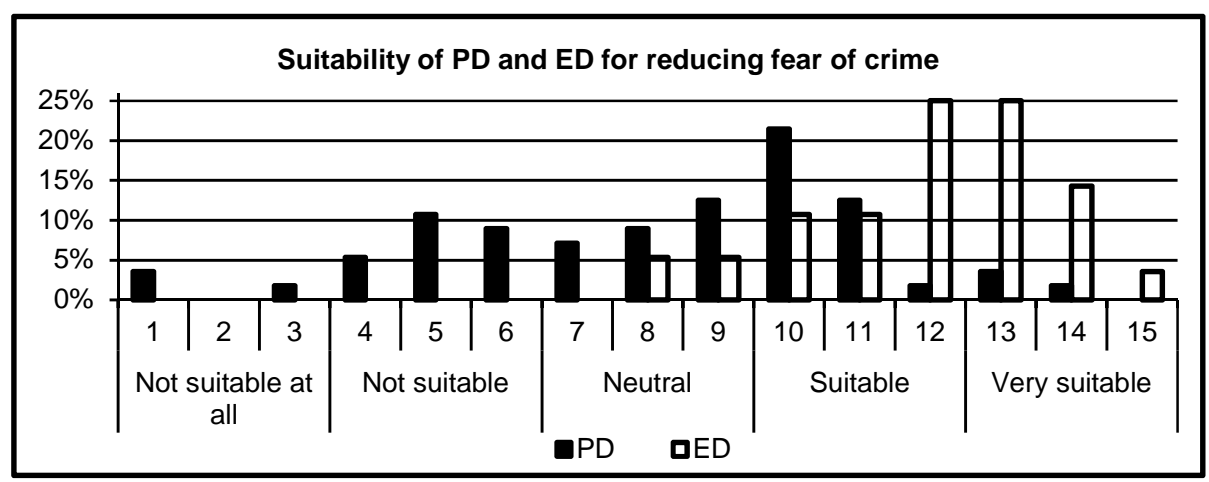

Figure 7.11.: Distribution of suitability of PD and ED for reducing fear of crime

$\mathrm{H}$ : The ED is more effective at reducing fear of crime than the PD

As shown in Table 7.9, the ED is rated by all subjects (mean: 11.8, SD: 1.7) to be significantly more suitable for reducing fear of crime than the PD (mean: 7.5, SD: 3.1). For group A and B separately, the ED is also rated as significantly more effective than the PD for both groups. Independent of the sequence of rating the PD and ED, the ED is seen to be more effective. In testing for a difference between group $A$ and $B$, we found no significant effect for either the PD or ED .

H: Female subjects expect the ED/PD to be more effective at reducing fear of crime than male subjects.

As can be seen in Table 7.10, female subjects rated both the PD (mean: 8.1, SD: 2.8) and the ED 
Table 7.9.: Test results of the effectiveness of the PD and ED at reducing fear of crime

\begin{tabular}{|c|c|c|}
\hline \multicolumn{3}{|c|}{ Effectiveness of the PD and ED at reducing fear of crime } \\
\hline & Physical decal (PD) & Electronic decal (ED) \\
\hline & Mean (SD) & Mean (SD) \\
\hline All subjects ${ }^{* * *}$ & $7.5(3.1)$ & 11.8 (1.7) \\
\hline Group $\mathrm{A}^{\mathrm{a}, * * *}$ & $7.9(3.0)$ & $11.8(1.7)$ \\
\hline Group $B^{\mathrm{a}, * * *}$ & $8.1(2.1)$ & $11.7(1.8)$ \\
\hline \multicolumn{3}{|c|}{ Note. $\mathrm{N}=56$. Mean (SD) on Likert scale: not suitable at all (1) to very suitable (15) } \\
\hline \multicolumn{3}{|c|}{${ }^{a}$ Group A rated ED first, group B rated PD first } \\
\hline \multicolumn{3}{|c|}{$* \mathrm{p}<0.05 ; * * \mathrm{p}<0.01 ; * * * \mathrm{p}<0.001 ;$ the ED is more effective than the PD. } \\
\hline$t p<0.05 ;+t p<$ & .001 ; difference between & he effec \\
\hline
\end{tabular}

(mean: 11.9, SD: 1.5) to be slightly more effective than male subjects (BHL mean: 7.9, SD: 3.0; CHL mean: 11.6, SD: 2.0). However, the differences are non-significant.

H: Older subjects expect the ED/PD to be more effective at reducing fear of crime than younger subjects.

For the age, no significant differences were found. Older subjects rated both, the PD (mean: 7.9, SD: 2.8) and ED (mean: 11.9, SD: 1.9), to be even slightly less effective than younger subjects (PD mean: 8.0, SD: 3.0; ED mean: 11.6, SD: 1.6).

H: More technologically-proficient subjects expect the ED/PD to be more effective at reducing fear of crime than less technologically-proficient subjects.

The results rating the PD and ED are broadly similar for technologically-proficient individuals (PD mean: 7.7, SD: 2.7; ED mean: 11.7, SD: 2.0) and less technologically-proficient individuals (PD mean: 8.1, SD: 3.2; ED mean: 11.8, SD: 1.5). No significance was evident. 
Table 7.10.: Test results of the effectiveness of the PD and ED at reducing fear of crime (sociodemographic influences)

\begin{tabular}{lcc}
\hline \multicolumn{2}{l}{ Effectiveness of the PD and ED at reducing fear of crime } \\
\hline $\begin{array}{c}\text { Physical decal (PD) } \\
\text { Mean (SD) }\end{array}$ & $\begin{array}{c}\text { Electronic decal (ED) } \\
\text { Mean (SD) }\end{array}$ \\
\hline Female & $8.1(2.8)$ & $11.9(1.5)$ \\
Male & $7.9(3.0)$ & $11.6(2.0)$ \\
\hline Old & $7.9(2.8)$ & $11.9(1.9)$ \\
Young & $8.0(3.0)$ & $11.6(1.6)$ \\
\hline Proficient & $7.7(2.7)$ & $11.7(2.0)$ \\
Not proficient & $8.1(3.2)$ & $11.8(1.5)$ \\
\hline
\end{tabular}

Note. $\mathrm{N}=56$. Mean (SD) on Likert scale: not suitable at all (1) to very suitable (15)

$* \mathrm{p}<0.05 ; * * \mathrm{p}<0.01 ; * * * \mathrm{p}<0.001 ;$ female/old/technologically proficient subjects rate the PD/ED

to be more effective than male/young/not technologically proficient subjects.

\section{Expected effectiveness at fighting crime}

To examine the expected effectiveness, we combined two items for both the PD and the ED. The first item asked subjects to rate the suitability of the relevant function for detering car thieves. The second item asked about the suitability for reducing car theft. Both items were rated on our $5 \times 3$ Likert scale ranging from not suitable at all (1) to very suitable (15). Since Cronbach's alpha is within our required range of 0.7-0.95 for both the PD (0.92) and the ED (0.82), we combined these two items to represent the effectiveness of fighting crime overall. Our subjects considered the ED to be suitable for fighting car theft (mean: 11.5, SD: 1.9). The distribution can be found in Figure 7.12.

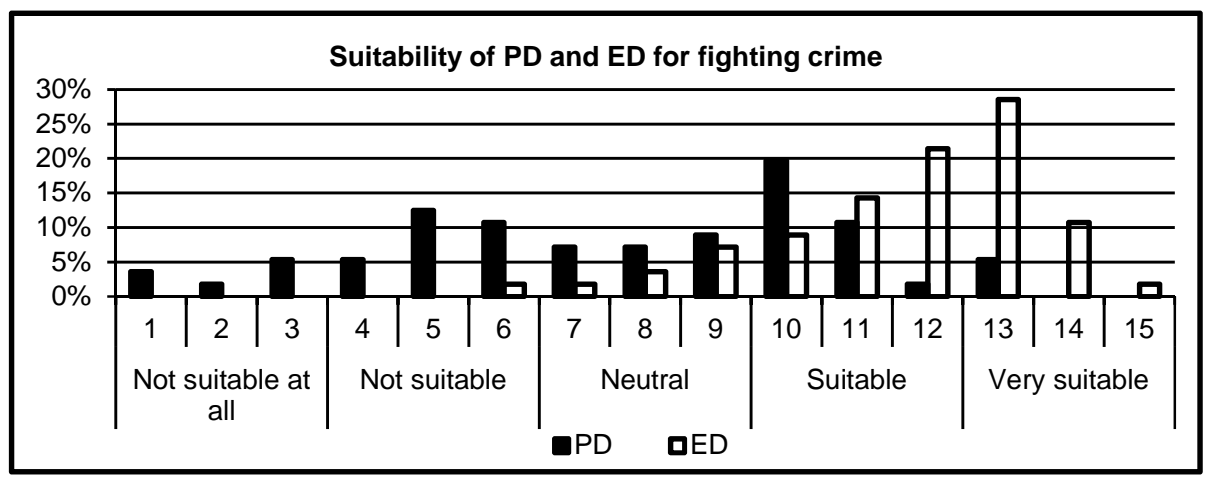

Figure 7.12.: Distribution of suitability of PD and ED for fighting crime

H: The ED is more effective at fighting vehicle theft than the PD.

As shown in Table 7.11, the ED is rated by all subjects (mean: 11.8, SD: 1.7) to be significantly 
Table 7.11.: Test results of the expected effectiveness of the PD and ED at fighting crime

\begin{tabular}{|c|c|c|}
\hline \multicolumn{3}{|c|}{ Expected effectiveness of the PD and ED at fighting crime } \\
\hline & Physical decal (PD) & Electronic decal (ED) \\
\hline & Mean (SD) & Mean (SD) \\
\hline All subjects ${ }^{* * *}$ & 7.5 (3.1) & 11.8 (1.9) \\
\hline Group $\mathrm{A}^{\mathrm{a}, * * *}$ & $7.1(3.1)$ & $11.3(2.0)$ \\
\hline Group B $\mathrm{B}^{\mathrm{a}, * * *}$ & $7.9(3.1)$ & $11.7(1.8)$ \\
\hline \multicolumn{3}{|c|}{ Note. $\mathrm{N}=56$. Mean (SD) on Likert scale: not suitable at all (1) to very suitable (15) } \\
\hline \multicolumn{3}{|c|}{${ }^{a}$ Group A rated ED first, group B rated PD first } \\
\hline \multicolumn{3}{|c|}{$* \mathrm{p}<0.05 ; * * \mathrm{p}<0.01 ; * * * \mathrm{p}<0.001 ;$ the ED is more effective than the PD. } \\
\hline
\end{tabular}

more suitable for reducing car theft than the PD (mean: 7.5, SD: 3.1). Group A and B both rated the ED as significantly more effective. Independent of the sequence rating between the PD and ED, the ED is seen to be significantly more effective. Additionally, there is no significant difference between group A and B's ratings of both the PD and the ED.

H: Female subjects expect the ED/PD to be more effective at fighting crime than male subjects.

As can be seen in Table 7.12, female subjects (mean: 7.5, SD: 2.9) rated the PD equally on average to male subjects (mean: 7.5, SD: 3.4). Indeed the ED was rated as slightly less effective by females (mean: 11.3, SD: 1.7) than by males (mean: 11.8, SD: 2.0). Nevertheless, there are no significant differences for gender.

$\mathrm{H}$ : Older subjects expect the ED/PD to be more effective at fighting crime than younger subjects.

The ratings are entirely non-significant. Older (mean: 11.5, SD: 2.1) and younger subjects (mean: 11.5, SD: 1.6) rated the ED as equally effective on average. The average rating for the PD differs only slightly between older (mean: 7.3, SD: 3.1) and younger subjects (mean: 7.7, SD: 3.2).

H: More technologically-proficient subjects expect the ED/PD to be more effective at fighting crime than less technologically-proficient subjects.

The results rating both the PD and the ED are similar for technologically-proficient subjects (PD mean: 7.1, SD: 3.0; ED mean: 11.7, SD: 1.9) and less technologically-proficient subjects (PD mean: 7.5, SD: 3.3; ED mean: 11.3, SD: 1.9). No significance was estimated. 
Table 7.12.: Test results showing the expected effectiveness of the PD and ED at fighting crime (sociodemographic influences)

\begin{tabular}{lcc}
\hline \multicolumn{2}{l}{ Expected effectiveness of the PD and ED at fighting crime } & \\
\hline & $\begin{array}{c}\text { Physical decal (PD) } \\
\text { Mean (SD) }\end{array}$ & $\begin{array}{c}\text { Electronic decal (ED) } \\
\text { Mean (SD) }\end{array}$ \\
\hline Female & $7.5(2.9)$ & $11.3(1.7)$ \\
Male & $7.5(3.4)$ & $11.8(2.0)$ \\
\hline Old & $7.3(3.1)$ & $11.5(2.1)$ \\
Young & $7.7(3.2)$ & $11.5(1.6)$ \\
\hline Proficient & $7.1(3.0)$ & $11.7(1.9)$ \\
Not proficient & $7.5(3.3)$ & $11.3(1.9)$ \\
\hline
\end{tabular}

Note. $\mathrm{N}=56$. Mean (SD) on Likert scale: not suitable at all (1) to very suitable (15)

$* \mathrm{p}<0.05 ; * * \mathrm{p}<0.01 ; * * * \mathrm{p}<0.001 ;$ female/old/technologically proficient subjects rate the PD/ED

to be more effective than male/young/not technologically proficient subjects.

\section{Acceptance of false stops}

We asked our subjects to rate the acceptance of being falsely stopped by the police on our $5 \times 3$ Likert scale ranging from not acceptable at all (1) to very acceptable (15). Independent of the function, on average the majority would accept being wrongly stopped (PD mean: 10.2, SD: 2.8; ED mean: 10.8, SD: 2.3). Figure 7.13 shows the distribution of the rating which can be summarized as normally distributed around acceptable with a slight tendency towards neutral.

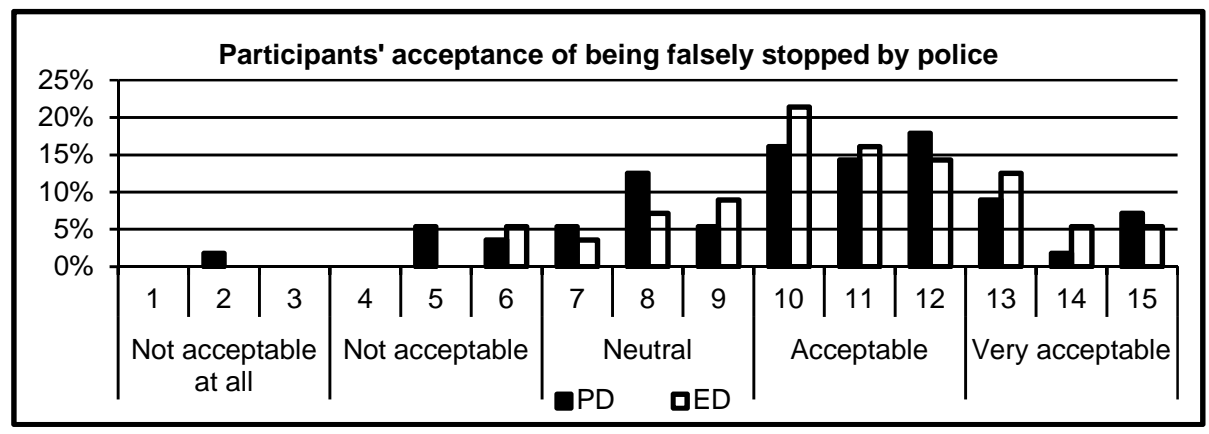

Figure 7.13.: Participants' acceptance of being falsely stopped by the police (PD and ED)

H: There is a difference between the ED and PD in users' acceptance of being falsely stopped. There is no significant difference in participants' claimed acceptance to be falsely stopped by the police between the PD and ED, as shown in Table 7.13. Furthermore, no evidence was found for order effects since there is no significant difference between group A and B. 
Table 7.13.: Test results of participants' acceptance of being falsely stopped by the police (PD and ED)

\begin{tabular}{lcc}
\hline Acceptance of being falsely stopped by police (PD/ED) & \\
\hline & $\begin{array}{c}\text { Physical decal (PD) } \\
\text { Mean (SD) }\end{array}$ & $\begin{array}{c}\text { Electronic decal (ED) } \\
\text { Mean (SD) }\end{array}$ \\
\hline All subjects*** & $10.2(2.8)$ & $10.8(2.3)$ \\
Group A $^{\text {a,*** }}$ & $9.9(2.6)$ & $10.2(2.2)$ \\
Group B B ${ }^{a * * *}$ & $10.5(3.0)$ & $11.3(2.3)$ \\
\hline
\end{tabular}

\section{Acceptance of V2V communication}

We wanted subjects to rate their willingness to have their vehicle continuously broadcast the "stolen vehicle" message were their car to be stolen. Furthermore, we asked them to rate their willingness to use other vehicles in the surrounding to anonymously forward the message in order to increase the sending range. None of the questions included the term privacy since our personal experience has shown that mentioning this term introduces emotionality and reduces rationality. The rating was done on our $5 \times 3$ Likert scale, ranging from not willing at all (1) to very willing (15) and the results are shown in Figure 7.14.

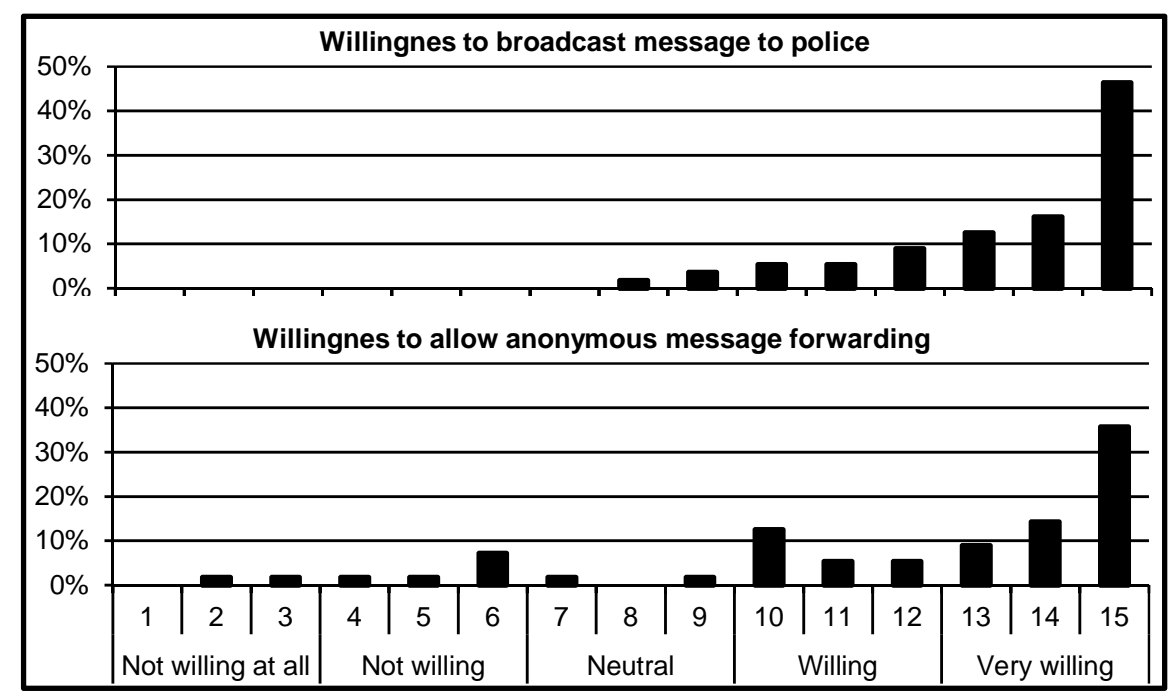

Figure 7.14.: Willingness to allow V2V communication 
As can be seen, nearly all subjects were willing to have their vehicle broadcast a message to the police were it to be stolen (mean: 13.5, SD: 1.9)). For anonymous message forwarding using other vehicles, a majority remained willing to have messages forwarded, though there were subjects who were not willing (mean: 12.0, SD: 3.6). We even found a significant shift $(\mathrm{p}<0.001)$.

\section{Acceptance of (de)activation methods}

We asked participants to rate the constraints in daily use associated with the (de)activation methods. Rating was done on our $5 \times 3$ Likert scale, ranging from not restrictive at all (1) to very restrictive (15). Figure 7.16 shows the results, in which (de)activation via car key was rated on average as not restrictive at all, and thus the most convenient method (mean: 2.8, SD: 1.6). In contrast, the schedule was seen by the majority as restrictive (mean: 10.0, SD: 2.9), and thus was the least convenient method. The smartphone tended to be somewhere between both (mean: 6.6, SD: 3.5).

Furthermore, subjects assigned a ranking to all three methods, where the method with number 1 was the most favorable method to (de)activate the ED and number 3 the least favorable. Figure 7.15 summarizes the results. For the aforementioned results, it is not surprising that the method with the car key achieved first place, with two-thirds, followed by the smartphone method $(27 \%)$. The schedule method lagged far behind with only $5 \%$ of first rank ratings.

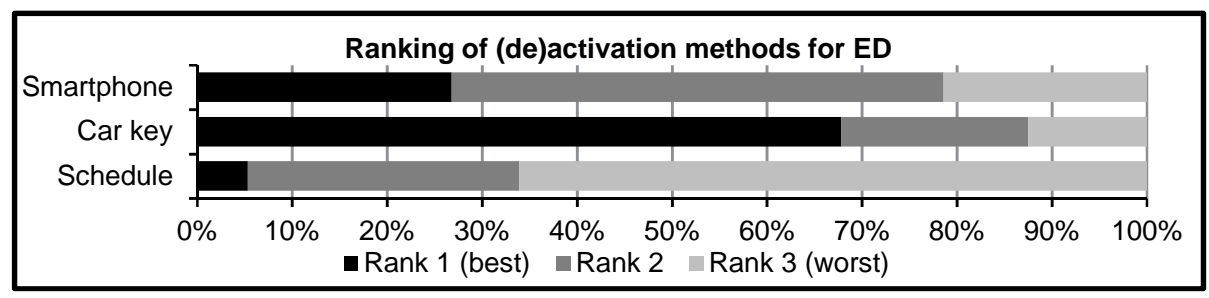

Figure 7.15.: Ranking of (de)activation methods 


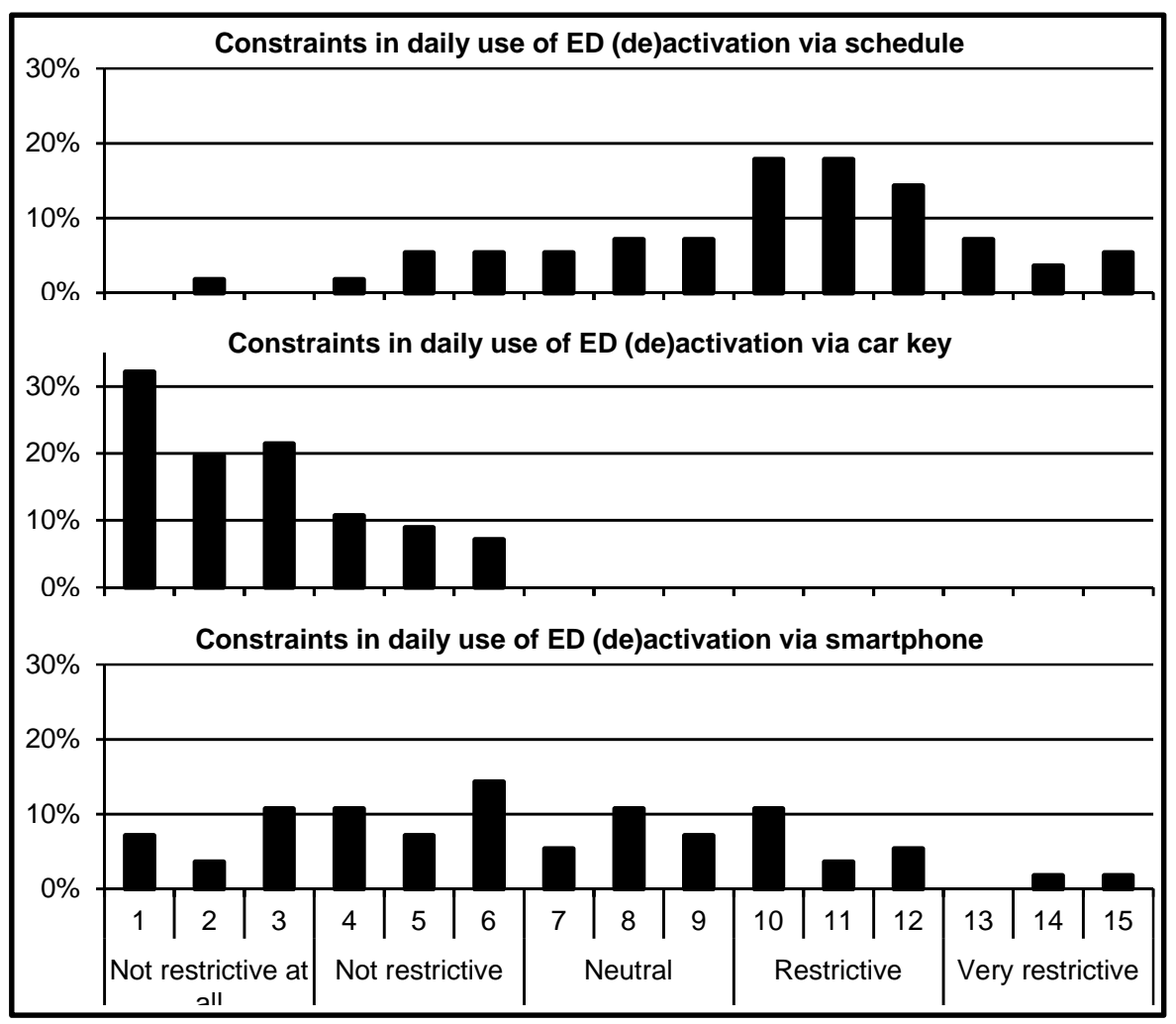

Figure 7.16.: Constraints in daily use of (de)activating the ED via schedule / car key / smartphone

\section{Acceptance of fallback via PIN}

Subjects rated their acceptance of having PIN-entry as a fallback for (de)activating the ED on our $5 \times 3$ Likert scale ranging from not acceptable at all (1) to very acceptable (15). Figure 7.17 shows the result of the acceptance (mean: 11.5, SD: 3.3$)$. For the majority of subjects (80\%), a PIN-entry is (very) acceptable.

\section{Surcharge for ED}

We asked subjects to rate the surcharge for all three (de)activation methods on a number line ranging from $0 €$ to $1000 €$. Figure 7.18 shows the relevant box plots for each (de)activation method where the whiskers are at $10 \%$ and $90 \%$. As can be seen, all three box plots look nearly similar, meaning they have the same median of $200 €$, with a spread of around $200 €$. For the mean values, the results were largely similar. Ratings differed however in their standard deviations and spread whiskers. Detailed values can be found in the Table of Figure 7.18. 


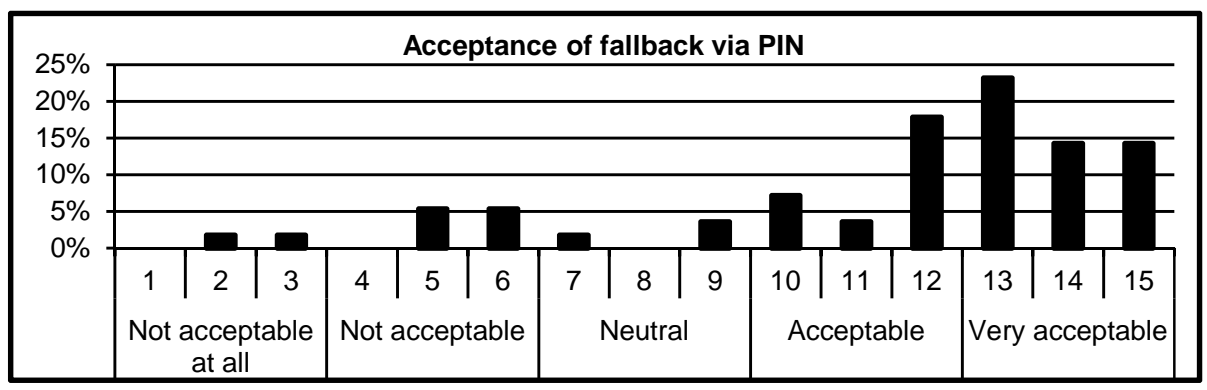

Figure 7.17.: Participants' acceptance of using a PIN as a fallback

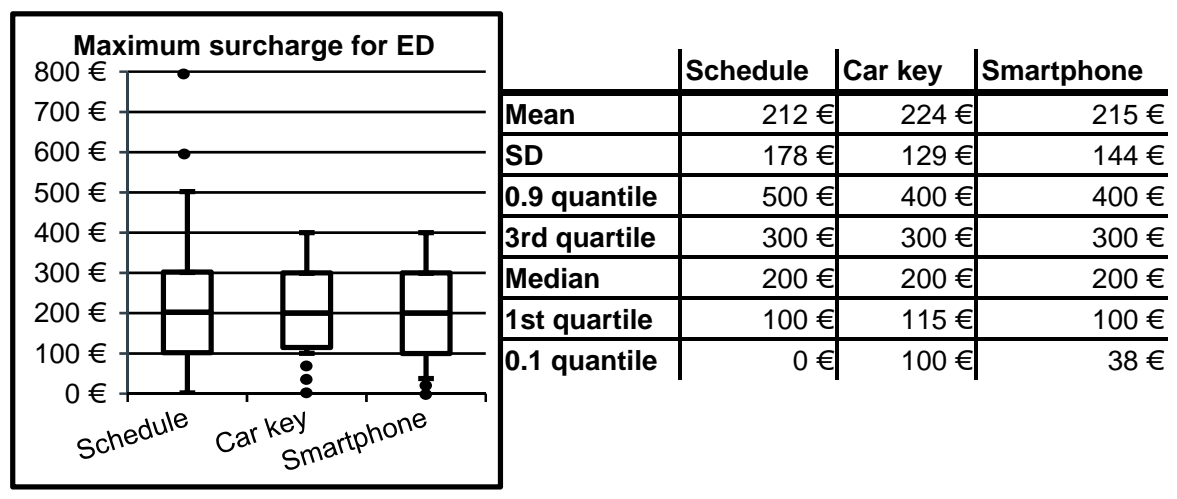

Figure 7.18.: Maximum surcharge participants would pay for the ED with (de)activation via schedule / car key / smartphone

\section{User feedback}

Our questionnaire gave participants the opportunity to comment on both the PD and the ED with its different (de)activation methods. We had two text fields covering benefits and drawbacks of the relevant function, and for the ED the (de)activation method. A third text field was provided for general comments. Furthermore, the examiner documented questions as well as remarks arising during the survey. The feedback is summarized in the following.

The majority of our subjects considered the PD useless. One subject compared the PD to warning labels on packets of cigarettes, which were in their opinion also completely useless. Most subjects also questioned whether there would be sufficient police patrols on the streets. Additionally, subjects raised concerns that police are not able to see the decal between other stickers, such as the environmental and toll badges, or during the night, especially in poorly lit areas. Furthermore, subjects agreed that removing the decal would not be a challenge for thieves. A further interesting factor was mentioned by shift workers. They stated that the PD is only a countermeasure for people who work during the day, and thus they disagreed entirely with 
using a PD with static times. The main doubts were about the effectiveness of the PD for combatting vehicle theft. The decal's inflexibility was thus considered peripheral.

The schedule method was seen by the majority as unpractical, in view of the additional work it would involve. First of all, subjects criticized the fact that the schedule would need to be regularly updated. This would lead to confusion, especially for families with several drivers. If one family member were to update the schedule others may be unaware of the change. Second, having the system synchronize with an existing online calender was something considered by only one person. Furthermore, most subjects said they did not use an online calender to manage personal appointments, using an "old-fashioned" paper calender instead. They would thus have double the work to keep the electronic schedule updated.

As long as all users stick to the schedule, subjects confirmed two main benefits. First, no additional token or device is necessary in the car and no further action is required when using the car within the time frame. Second, time frames are flexible compared to the PD. According to the majority, the ED has this benefit when the car is not used for a longer period of time, during holidays for instance.

Most subjects emphasized that the use of a computer at home is convenient. At home, one typically has a larger screen and more sophisticated input methods than in the car. Lack of allowance for spontaneous car use was highlighted in particular.

Several subjects also considered the necessity of internet access and computer knowledge as a hurdle for the schedule method. One subject stated that lack of technological knowledge would lead to user uncertainty about the scheduled ED, leading them to abandon the system entirely.

Looking at the survey results, (de)activation via car key was rated as mostly convenient. This was also evident in the comments. An absence of additional required devices, a lack of required effort, and simplicity of use were tempting. However, most subjects were also aware of the lack of system redundancy. They expressed doubts and fears that loss or theft of the car key would suspend the functionality of the ED.

For smartphone control, opinions differed. Participants either liked this approach or not. Furthermore, some subjects noted that Bluetooth would need to be enabled constantly on their smartphone, especially in order to allow a smooth connection when getting in the car. Doubts surrounded the fact that many users switch off Bluetooth to save energy consumption. Dependency on an additional device was also mentioned as a bother, not because of the kind of device but because the user has to make sure they are carrying the device. In part related to the critique on the problem of having an additional device, individual's "fear" of forgetting their smartphone or having a flat battery was noticeable. The opportunity to teach the system with several users was positively highlighted by the majority.

Two subjects mentioned their fear of getting in trouble with their insurer after having the ED installed. They were concerned that if their car were to be stolen they would have to prove to their insurer that they used and activated the ED correctly. This would involved additional hassle and so these participants would prefer not to make use of the ED at all. 


\subsubsection{Security functions}

\section{Attitudes towards security functions}

We asked subjects to rate the approach of using new technologies from the automotive field to tackle vehicle-related crime. Rating was done on our $5 \times 3$ Likert scale ranging from not meaningful at all (1) to very meaningful (15). As can be seen in Figure 7.19, the vast majority of subjects (mean: 12.9, SD: 1.6) stated that the use of new technologies to tackle vehicle-related crime was (very) meaningful. Additionally, Table 7.14 summarizes the results where it can be seen that there is no significant difference between group 1 (mean: 12.8, SD:1.7) and group 2 (mean: 13.1, SD: 1.5).

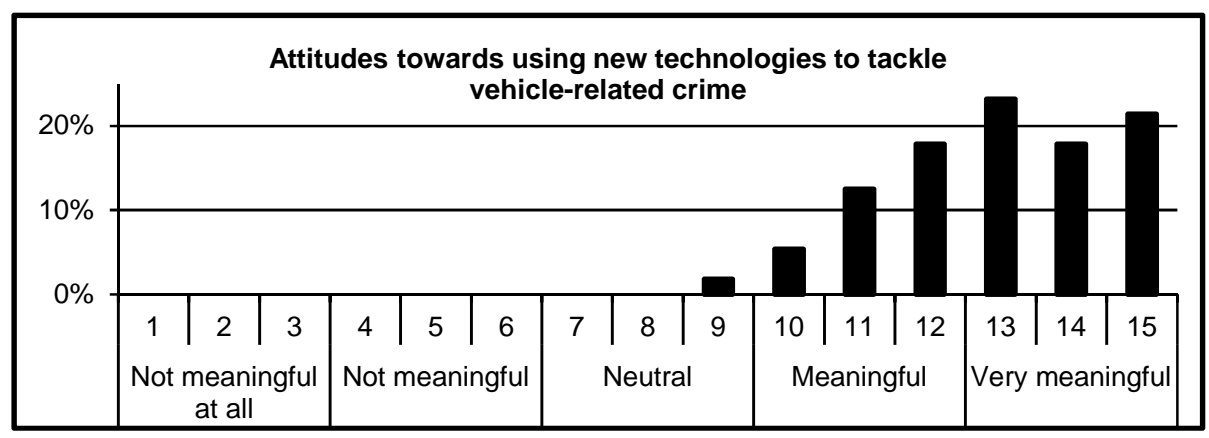

Figure 7.19.: Participants' attitude towards using new technologies to tackle vehicle-related crime

Table 7.14.: Test results of attitudes towards new technologies to tackle vehicle-related crime

\begin{tabular}{cc}
\hline Attitudes towards new technologies to tackle vehicle-related crime \\
\hline & Mean (SD) \\
\hline All subjects & $12.9(1.6)$ \\
Group 1 $^{\text {a }}$ & $12.8(1.7)$ \\
Group 2 $^{\text {a }}$ & $13.1(1.5)$ \\
\hline
\end{tabular}

Note. $\mathrm{N}=56$. Mean (SD) on Likert scale: not meaningful at all (1) to very meaningful (15)

${ }^{a}$ Group 1 rated question in the beginning of survey, group 2 in the end.

$* \mathrm{p}<0.05 ; * * \mathrm{p}<0.01 ; * * * \mathrm{p}<0.001$; difference between group 1 and 2 . 


\section{Importance of tackling specific vehicle-related crimes}

Subjects were asked to rate the use of new technologies to tackle the following specific carrelated crimes:

- Car theft

- Theft of valuables from the inside of the car

- Theft of car parts

- Theft of car keys

- Scratches to the car

- Damage of car parts

- Arson attacks on the car

- Robbery / assault while entering or exiting the car

The rating is shown in Figure 7.20. We show the average rating of all subjects and also distinguish between group 1 and 2. New technologies should tackle car theft (mean: 13.1, SD: 2.2) in the first place followed by tackling robberies / assaults on drivers exiting or entering their car (mean: 12.0, SD: 3.2). Theft of car keys (mean: 11.6, SD: 3.9), theft of valuables from the inside car (mean: 11.2, SD: 3.6) and theft of car parts (mean: 10.5, SD: 3.9) rank in the middle field and are in positions three to five. Damage to car parts (mean: 10.1, SD: 4.1), scratches to the car (mean: 9.7, SD: 4.2) and arson attacks on the car (mean: 9.6, SD: 4.6) take positions six to eight.

\section{$\mathrm{H}$ : Coming into contact with security functions influences the attitude about security func- tions.}

We sorted the answers of both groups by the mean. Table 7.15 shows the ranking in which a general attitude is clear. Subjects from group 2 consistently rated the use of new technologies to tackle vehicle-related crimes as less meaningful than subjects from group 1 . Half of these differences are significant. However, for the overall ranking both series resemble each other. Tackling car theft plays the most important role in both groups, with the theft of car keys also far in front. Furthermore, protection from physical attacks, which is included in robbery and assault on drivers entering or exiting their cars, seems to be important to participants as well. Close behind, we have smaller property crimes, the theft of valuables and of car parts. Vandalism is the crime category to which respondents assigned the lowest degree of importance when asked about crime prevention. 
Table 7.15.: Meaningfulness of using new technologies to tackle specific vehicle-related crimes

\begin{tabular}{c|cc|cc}
\hline Ranking & \multicolumn{2}{|c|}{ Group 1 $^{\mathrm{a}}$} & \multicolumn{2}{c}{ Group 2 $^{\mathrm{a}}$} \\
& Crime & Mean (SD) & Crime & Mean (SD) \\
\hline 1 & Car theft & $13.1(1.7)$ & Car theft & $13.0(2.6)$ \\
2 & Theft of car key $^{* *}$ & $13.0(2.3)$ & Robbery / Assault & $11.3(3.6)$ \\
3 & Robbery / Assault & $12.7(2.6)$ & Theft of valuables * $^{*}$ & $10.3(4.3)$ \\
4 & Theft of valuables* $^{*}$ & $12.0(2.6)$ & Theft of car key $^{* *}$ & $10.1(4.6)$ \\
5 & Theft of car parts $^{*}$ & $11.5(3.1)$ & Theft of car parts & $9.5(4.4)$ \\
6 & Arson of car & $11.4(3.8)$ & Damage to car parts & $9.3(4.4)$ \\
7 & Damage to car parts & $10.9(3.7)$ & Scratches & $8.9(4.4)$ \\
8 & Scratches & $10.5(3.9)$ & Arson of car & $7.9(4.8)$ \\
\hline
\end{tabular}

Note. $\mathrm{N}=56$. Mean (SD) on Likert scale: not meaningful at all (1) to very meaningful (15)

${ }^{a}$ Group 1 edited ranking in the beginning of survey, group 2 in the end.

$* \mathrm{p}<0.05 ; * * \mathrm{p}<0.01 ; * * * \mathrm{p}<0.001 ;$ difference between group 1 and 2 . 


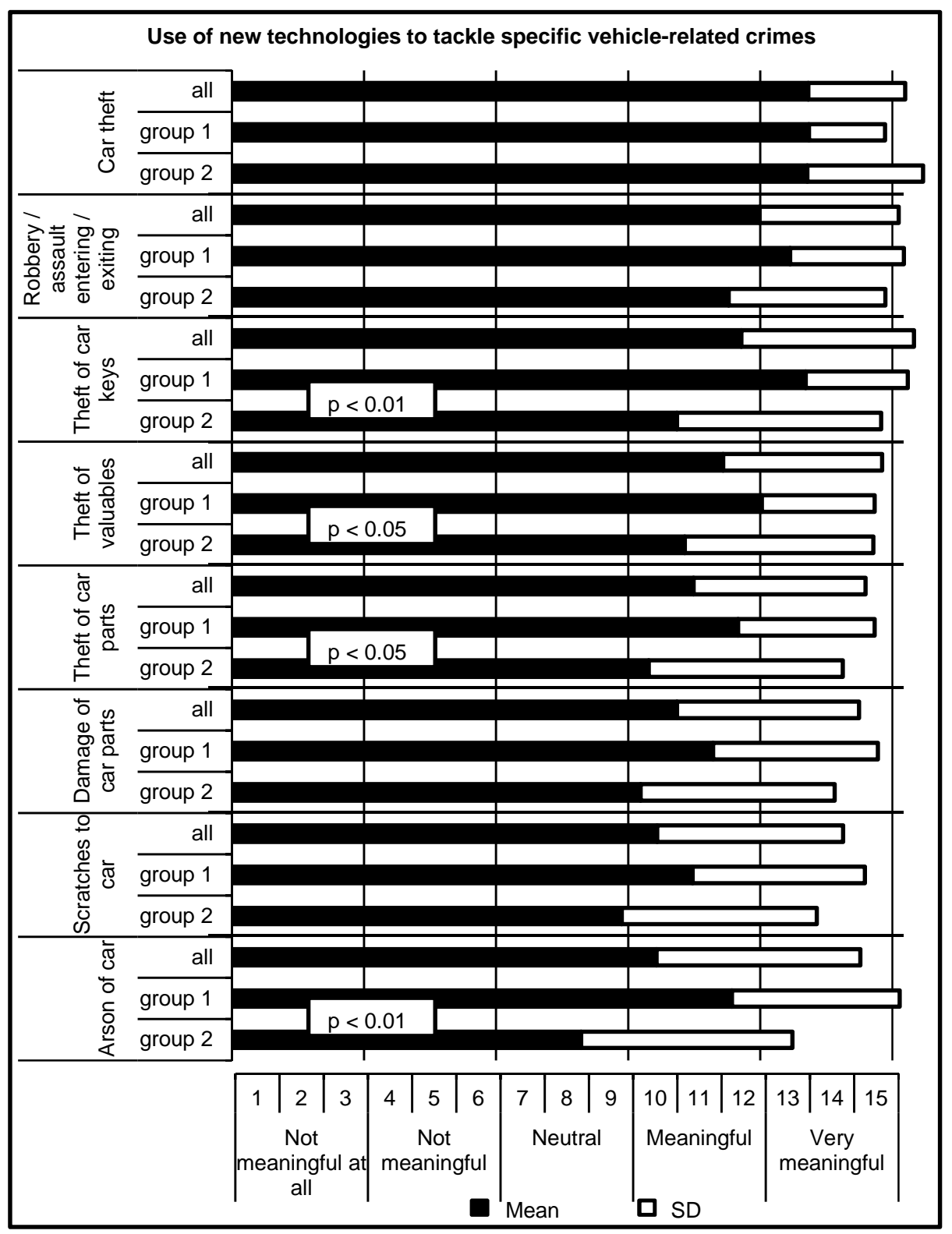

Figure 7.20.: Participants' views on the use of new technologies to tackle specific vehiclerelated crimes 


\subsubsection{Discussion}

This section discusses our survey results and is structured according to the preceding section which presented our results. Additionally, we discuss the limitations of our survey to conclude.

\subsubsection{Cooperative home light}

\section{Effectiveness at reducing fear of crime}

The CHL was seen by the majority to be (very) suitable for reducing the fear of assaults and robberies on drivers making their way to their cars. The CHL was even rated as significantly more suitable than the BHL. Thus, we conclude that improved lighting also reduces the fear of the aforementioned crimes. Furthermore, regardless of whether the BHL or CHL was rated first, the CHL was always seen to be more effective, though we found a significant effect when testing for a difference between group A and B's ratings of the BHL. Group B, which rated the BHL afterwards, rated the BHL as significantly less effective than subjects from group A. In our opinion, this significance results from the question order. Since the mean of both groups for the CHL is nearly equal, we think that knowing the CHL broadens subjects' horizons around what is and can be possible with new technologies, and thus they rated the BHL as less effective than the participants who had not known about the CHL did.

Neither gender, age nor technological proficiency influenced the reported effect of the BHL and CHL on fear of crime. We think that the effects of our sociodemographic factors are not large enough to be detected with our sample size of 56 participants. As shown in Section 7.2.1 in Table 7.2, we can only identify large sociodemographic effects with our sample size.

\section{Expected effectiveness at fighting crime}

According to the majority of participants, the CHL was expected to be (very) suitable at fighting assaults and robberies. Additionally, the CHL provided a significant improvement to the BHL. Hence, improved lighting is positively rated by participants. In our opinion, these results also reflect the acceptance of the CHL, and thus, show the degree to which the CHL is of interest from the customers' point of view. When customers do not consider the CHL effective, they are unlikely to spend money on it. Moreover, having doubts about a countermeasure does not reduce fear of crime.

Furthermore, there was no evidence that gender, age or technological proficiency influenced the expected effectiveness. We believe the sample size was to small to detect these effects.

\section{Willingness for cooperative lighting}

We asked subjects to consider three questions asking them to estimate their willingness to contribute in cooperative lighting. For the results of the first question, subjects seemed to be generally willing to provide their car for cooperative lighting. However, the enthusiasm significantly decreased when considering the second and third question. We think that two rea- 
sons are responsible for the reduced enthusiasm. Mentioning possible (economic) drawbacks for the respondent's own car when used with the CHL made it clear to participants that additional costs may arise. Second, since willingness decreased in all participants, they presumably thought that other drivers would not be inclined to provide their cars either.

\section{Willingness to use a smartphone}

Participants were generally willing to use their smartphones as a positioning device for the CHL. However, participants were less willing to use their smartphones as car keys. We think that it is necessary to provide customers with additional automotive functions that involve smartphones. Further integration of smartphones could increase the overall acceptance of using them for automotive functions. This way, the inclination to use smartphone to operate the CHL would increase as well. Additionally, having a smartphone working as key replaces a familiar behavior, namely using a physical key. Thus, the views towards using the smartphone as a key reflect conservative attitudes. However, as soon as an additional benefit was shown, a new security function for example, this reticence seemed to be weakened. Nevertheless, using a smartphone to realize the CHL implies that the smartphone is an additional device, not replacing but rather complementing existing car keys.

\section{Surcharge for $\mathrm{CHL}$}

We think that a customer price of around $200 €$ seems to be acceptable for the majority. However, this is a maximum amount. We have to consider that car manufacturers and suppliers need to implement the system at a cost far below the estimated customer price. They have to finance the entire development process and additionally need to achieve a specific profit margin. Hence, the CHL should draw extensively on existing sensors and hardware associated with other assistance or infotainment systems. This way, the advantage of synergies is felt.

\section{User feedback}

Although subjects admitted to feeling more comfortable due to the lit surroundings provided by the BHL, the BHL was mainly seen as a car finder. The CHL however works against its function as a car finder since several vehicles turn their lights on at the same time. The owner's vehicle would thus need unique lighting to be identified among other vehicles. Colored interior lighting could be used to distinguish the owner's vehicle from the others. This way, the CHL would retain its use as a car finder. Furthermore, participants stated that the CHL and the BHL were seen mainly as providing additional features to make drivers feel more comfortable. We think that a comfortable driver is self-confident and thus less fearful.

Participants also expressed the fear that a potential attacker could enter the vehicle as soon as the car is remotely unlocked to activate the BHL or CHL. Thus an additional button on the remote control or a second press of the same button is suggested as a way to unlock the doors. For the CHL, the position of the driver could even be used to unlock the vehicle when the driver reaches a predefined distance from the vehicle. 
Moreover, we would aim to provide improved lighting of the surrounding area with the help of the CHL. However, concerns were expressed that improved lighting following the path of the driver would actually "highlight" them, letting any attacker know where to wait.

\subsubsection{Electronic decal}

\section{Effectiveness at reducing fear of crime}

Participants rated the ED as effective at reducing the fear of vehicle theft. One possible reason for this rating is that simply knowing that there is work in progress to tackle vehicle theft with the help of new technologies increases the general feeling of security. Furthermore, we think that participants rated the ED as more effective than the PD in reducing the fear of crime since they believe that the effort required to defeat the ED would be higher than removing a sticker. However, participants might have been unaware of the possibility of easily defeating the ED with the help of a signal jammer. Nevertheless, the ED constitutes an additional countermeasure which needs to be overcome and considered during a vehicle theft. Additionally we think that the tangibility of the ED may have led to increased self-confidence. Participants feel confident of being able to influence their risk of becoming a victim of vehicle theft, thereby reducing their fear of crime.

None of our sociodemographic results showed significant differences. Hence, if effects exist they must be medium or indeed small that we were not able to detect them since the sample size was to small. Of course, it is also possible that the influence of the ED on the fear of crime did not vary at all. Our sample group was recruited in Germany where vehicle theft tends to be committed in the absence of the owner. This way, owners are generally not in danger of becoming victims of violence and bodily injury.

\section{Expected effectiveness at fighting crime}

The ED was seen as being suitable for fighting vehicle theft. Since the ED was rated as significantly more effective than the $\mathrm{PD}$, the majority of participants were unaware about the possibility of using a signal jammer to disturb the communication, circumventing the ED. Removing a sticker (PD) requires a similar effort to switching on a signal jammer while driving a stolen vehicle. Hence, we think that the use of V2V communication, which was seen as a new and innovative technology, raises expectations. Furthermore, the ED was seen as an extension of existing countermeasures, since it draws on a new technology. This way, the ED represents a further measure which needs to be considered by thieves.

Similar to the effectiveness of reducing fear of crime, our sociodemographic factors did not play a role here. Differences are marginal for average values. Moreover, since there was no difference between technologically-proficient and less technologically-proficient participants, our assumption that participants did not have the use of signal jammers in mind was supported.

\section{Acceptance of $\mathrm{V} 2 \mathrm{~V}$ communication}

Although the forwarding is done anonymously and for the purpose of improving the function- 
ality of the ED, participants' willingness to have their car communicate with other vehicles was rated as less permitting communication with the police. The difference was indeed statistically significant. Communication with other vehicles seems to raise privacy concerns despite the beneficial intention. Hence, convincing customers and making them aware that their privacy is guaranteed will provide a challenge for car manufacturers and other institutions involved in the realization of $\mathrm{V} 2 \mathrm{~V}$ communication.

\section{Acceptance of (de)activation methods}

Associated with the less everyday hassle, the (de)activation of the ED via car key is the most favored method. Hence, the goal of making the ED tangible seems to have had a deterrent effect on participants due to the additional constraints and efforts involved in everyday use. The (de)activation via schedule was clearly not accepted by the majority as practical for everyday use. We think that the schedule approach is only useful as an extension in cases when vehicles are not used for longer periods, e.g., for holidays. The smartphone showed the highest standard deviation, reflecting the highest uncertainty. We therefore additionally tested for a difference between technologically-proficient and less technologically-proficient participants, since we were assuming that it was less technologically-proficient subjects that would have less interest in smartphones and thus assume the smartphone approach to be more restrictive in everyday use. However, the results entirely contradicted our expectations. Technologicallyproficient participants (mean: 5.7, SD: 3.2) assumed the restrictions in everyday use to be significantly higher $(\mathrm{p}<0.05)$ than the less technologically-proficient participants (mean: 7.8, SD: 3.4). One possible explanation is that technologically-proficient participants are more aware of the drawbacks involved in smartphone use, such as having a flat battery or forgetting the device, since they use their phone regularly in their everyday lives. In addition, technologicallyproficient participants are likely better informed about actual technologies, and thus are more familiar with associated drawbacks and limitations.

\section{Acceptance of fallback via PIN}

The use of a PIN as fallback solution was accepted by the majority. In our opinion, this was not surprising. The procedure of entering a PIN for authentication is commonly accepted and widespread in everyday life, for instance when switching on a cell phone, using a credit card or logging into an email account. Hence, the fallback via PIN should be considered while implementing the ED.

\section{Surcharge for ED}

Independent of the (de)activation method, the average surcharge for the ED was broadly similar. Attention should be drawn to the different standard deviations and the differently spread whiskers. Although the mean of the schedule method is the lowest, we have subjects willing to pay above average. We think that the wide distribution represents high uncertainty in participants and the sceptical attitudes towards the schedule method. Furthermore, we did not identify any relationship between the (de)activation method and the maximum surcharge individuals were willing to pay. We expected that subjects would be willing to pay more when they rated a (de)activation method as more convenient. However, there was no evidence for 
this effect, and so we discussed the results with the examiner. The theory that subjects are willing to spend more when the (de)activation method is more convenient is only one side of the coin. There were also subjects who rated the surcharge rationally and not emotionally. They analyzed the additional components and costs necessary to realize the relevant (de)activation method, aside from the convenience. From this point of view, these subjects of course rated the surcharge for the car key method as lower when compared to the other methods. They argued that the car key is already available, making the technological realization easiest. So, on the one hand the willingness to pay for the ED was influenced by emotionality, i.e. the convenience of the system, and on the other hand by rationality, i.e. the expected economic influence of a system.

\section{User feedback for ED}

In analyzing participants' comments, it became clear that tangibility of security can lead to reduced acceptance if users are bothered with the constraints of a system in everyday use. Thus, pursuing the goal of making security functions tangible to customers has to be treated with care.

\subsubsection{Security functions}

\section{Attitudes towards security functions}

The majority of participants support the work on security functions. Furthermore, participants who ultimately rated this question and thus were aware of the idea of security functions and the two specific examples, the CHL and ED, supported the use of new technologies to tackle vehicle-related crime to a similar extent. Hence, neither the CHL nor the ED deterred participants. This reflects however only the general attitude of participants.

\section{Importance of tackling vehicle-related crimes}

For the overall meaningfulness and ranking of using new technologies to tackle specific vehiclerelated crimes, there is a related opinion between both groups. Car theft is ranked as the most important, closely followed by protection of personal health and property theft, followed lastly by vandalism. Hence, coming into contact with security functions did not influence respondents' prioritizations on which vehicle-related crimes are tackled. We already found a similar trend of importance in our cross-country survey presented in Chapter 3. Tackling car theft played the most important role in both groups and theft of car keys was far in front as well. This is not really surprising since the theft of car keys implies an easy car theft, leading to high economic loss and inconvenience. In Germany, car theft is mainly committed without use of violence and thieves avoid coming into contact with car owners. Thus we think that high economic loss and inconvenience are the main reasons for tackling the highest priorities.

Preventing assaults and robberies on drivers going to their cars is nearly as important as preventing car theft. As presented in Section 2.2, assaults have had the largest growth rate in Germany in recent years. Additionally, we think that physical safety is more important for participants than damaged parts and valuables or indeed some scratches. 
Smaller property crimes, such as the theft of parts, theft from the inside of vehicles, and vandalism to vehicles are the lowest priorities in vehicle crime. These crimes involve less economic loss and inconvenience. For example, getting a smashed window repaired may take a few days or even hours with the vehicle quickly available for use again. For arson, the economic damage and inconvenience is indeed comparable with car theft but participants rated arson to be less important. We think that participants estimated that their probability of being victim of arson was distinctly lower than that of car theft. Their estimation goes hand-in-hand with recorded data in Germany. In 2013, there were approximately 1.000 recorded offenses of arson of cars compared to 100.000 vehicle thefts [139].

We also estimated interesting behavior. Subjects from group 2, who answered questions at the end, rated the use of new technologies for tackling vehicle-related crimes as consistently less meaningful than subjects from group 1 . Half of these differences were significant. In our opinion, several reasons may have led to these results. First, the differences result from an intuitively-conducted risk analysis by subjects. They weighed up the risk of becoming a victim of a crime against related material and injury consequences. For example, car theft and arson were associated with the highest material damage within the crimes mentioned. Nevertheless, participants saw the use of new technologies to tackle car theft as more useful than using them to prevent arson. Yet the probability of becoming a victim of car theft is higher than it is for arson. Second, uncertainty or indifference about crimes may play a role. This can be seen by the high standard deviations. Furthermore, there is a trend that the standard deviations decrease with increasing importance of crimes. Car theft, which showed the smallest difference between both groups had the lowest standard deviations in both groups. In contrast, vandalism to the car, i.e., arson, damage to car parts and scratches, showed the largest standard deviations. Third, the different results may be an indication of improved understanding, and thus, a more experienced assessment of the potential of security functions. In the beginning, subjects were enthusiastic about the use of new technologies to tackle vehicle-related crime and were full of expectations. However, after having considerd the effectiveness and their acceptance of the ED and CHL, subjects moved from giving emotional to giving rational ratings. Their extended knowledge and experience gathered during the survey steered their later ratings.

\subsubsection{Limitations}

Our survey comes with several limitations which need to be considered. First of all, we were not able to estimate the effectiveness of fighting crime with our survey. Our participants were not experts and were only able to estimate an expected effectiveness.

Furthermore, the sample size of 56 participants is probably too small, especially for estimating sociodemographic effects. We were only able to test for large sociodemographic effects. In order to test for medium effects, we would need a sample size of 106 (53 in each group), and to test for small effects we would need 650 participants (325 in each group), based on the settings which were summarized in Table 7.2 on page 154.

Our sample was also not representative since all participants were Volkswagen employees. Although they were distributed over different working fields, all of them were nonetheless 
employed by a car manufacturer. Furthermore, all of the participants lived in the same area of Germany.

\subsection{Interviews}

This section presents the results of our interviews to estimate the effectiveness of the cooperative home light (CHL) and the electronic decal (ED). The focus of the interviews was the systems' effectiveness at fighting crime. Since both functions aim to fight different crime categories, we need different experts in each case. To estimate the effectiveness of the CHL, we need experts in the field of lighting as well as experts on robberies and aggravated assaults. To evaluate the ED, we need experts familiar with vehicle theft.

The first subsection covers the ED followed by the CHL. In both subsections, we first show a brief guideline which was used as an orientation to gather our information about the effectiveness. Before the interview, all experts were introduced with the help of a presentation introducing the relevant security functions.

\subsubsection{Electronic decal}

\section{Guideline}

To estimate the effectiveness of the electronic decal, we discussed the following topics.

1. Deterrent effect: Would the ED deter thieves from stealing vehicles?

2. Hardening effect: Would the ED make theft more difficult for thieves?

3. Increasing risk: Would the ED increase the risk of thieves getting caught while driving the stolen vehicle, thus helping to solve the crime and recover the vehicle?

4. Drawbacks / hurdles: What are the main drawbacks and hurdles associated with the ED?

5. Benefits / values: What are the benefits and values provided by the ED?

6. (De)activation methods: What are the drawbacks and benefits of the (de)activation methods?

7. General assessment: Is the ED generally a useful security function for fighting vehicle theft?

\section{Vehicle theft experts}

To conduct our interviews, we contacted the following two vehicle theft experts.

a) An expert from a German OEM 
b) An expert from a US research institute for criminology and criminal justice

\section{Interview summary}

In the following, we present our summarized interview results from the experts relevant to each topic from our interview guideline.

1. Deterrent effect

a) The ED needs to make use of the surprise effect. The OCU or ECU, which implements the ED, needs to be mounted in an unknown place in the vehicle. Additionally, it cannot be known to the thief whether the vehicle is equipped with the ED or not. Unexpected measures bring deterrent effects.

b) The ED could have a deterrent effect if a sufficient number of users adopt the technology. But one needs to decide whether to visibly advertise the ED or whether to keep its functionality hidden. A vehicle visibly advertising that it is equipped with the ED might lead to a direct deterrent effect, i.e., a potential thief will not attempt to steal the vehicle. However, visibly advertising the ED gives a potential thief the cue to use a signal jammer. Without offenders knowing which vehicles actually utilize this security function, a more general deterrent effect would be achieved, resulting even in displacement of crime or diffusion of benefits.

2. Hardening effect

a) The OCU or ECU would need to be mounted in an unknown place and additionally be hard to be physically reached. As a rule of thumb, the thief must need five minutes as a minimum to reach and tamper with the hardware. As soon as the thief identifies that a vehicle is equipped with the ED, they will probably tend to use a signal jammer to disrupt the communication rather than trying to tamper with the hardware.

b) There would be more of a deterrent effect than a hardening effect since thieves would still be able to remove the vehicle, e.g., by towing the entire vehicle away.

3. Increasing risk

a) The risk can be increased if a private security service such as COBRA is involved, due to two reasons which are mainly based on the evaluation of COBRA's vehicle tracking system. COBRA's reaction time is faster than that of the police. Furthermore, COBRA can act across borders since they provide their service in several countries. In contrast, policing ends at the border of the relevant country. Furthermore, the ED should send its message at least for one hour. This time frame derives from experience with vehicle tracking systems.

In some cases, thieves steal vehicles and leave them nearby in an unobtrusive place 
in order to observe the vehicle over several days or even weeks to find out whether the vehicle is equipped with a tracking system. This approach could be used to detect ED as well.

b) This seems to be the greatest impact of the ED. Depending on the area and distance needed for police to detect the vehicle, it is reasonable to think that a decent percentage of stolen vehicles pass in close proximity to police vehicles or law enforcement stations immediately after they are stolen. From looking at vehicle theft databases in the US, there is normally a significant delay between the time a crime is committed and the time it gets reported. The ED would partially address this issue.

4. Drawbacks / hurdles

a) The legislation and insurance requirements would be hard to fulfill. Vehicle manufacturers need to ensure they fulfil these requirements, though as soon as third party hardware and/or software is involved the responsibilities become unclear.

b) One of the biggest challenges with all vehicle theft prevention measures is relying on citizen action. Thus the challenge is in facilitating the (de)activation of the ED and making it as simple as possible. The electronic immobilizer has been particularly successful because it does not rely on drivers taking any action.

5. Benefits / values

a) The ED is an additional security measure. Each security measure increases the effort required to steal a vehicle.

b) The greatest benefit would be for areas where quick reaction is necessary, e.g., thefts occurring near borders and ports or where significant numbers of professional vehicle thefts take place.

6. (De)activation

a) Generally, vulnerabilities in ECUs provide thieves the opportunity to compromise security measures, allowing them steal the vehicle. Adding additional hardware and functionality complicates the identification of potential vulnerabilities. This can lead to an increased number of vulnerabilities.

Increasing the number of connection opportunities, i.e. providing more interfaces to the outside world, also increases the vulnerability of a vehicle. Hence, none of the methods is supported. In contrast, the number of possible interfaces should be reduced to a minimum.

The smartphone has the drawback that the vehicle manufacturer has no way of controlling the device. Storing the secret (key) to (de)activate the ED on the smartphone or on the subscriber identification module (SIM) is outside of the influence of the vehicle manufacturer. Furthermore, the lifetime of a smartphone or SIM is clearly shorter than the lifetime of a vehicle. 
Tangibility of security functions could lead to higher customer expectations. Since there is no complete protection against vehicle theft, customers might be more disappointed when their vehicle is stolen despite having used the ED. Hence, the goal of increasing tangibility could harm vehicle and manufacturer reputations.

b) (De)activation via key is the preferred method since the reliance on citizen action is reduced. One concern would be if offenders get in possession of the key, which is reportedly happening more often in recent years. In this case the ED will be useless.

Furthermore, only a small number of people will probably be willing to create a detailed schedule to indicate when the vehicle will not be moved. Minimizing the need for actions on the part of the owner is a factor of success. Thus, the (de)activation via key is the most appropriate approach, with the schedule approach the least appropriate. (De)activation via smartphone is somewhere in between.

7. General assessment

a) The ED provides an additional hurdle for thieves. The ED would aim primarily to tackle spontaneous or non-professional thefts. Since vehicle theft is continuously shifting from casual towards professional thefts, the ED would play a secondary role. Existing countermeasures, especially the fifth generation of electronic immobilizers, are sufficient to fight vehicle theft. It will take a few years until this new generation of electronic immobilizers has spread, however. Nevertheless, it is hard to identify whether a security function is effective, since it often remains unclear exactly how a vehicle is stolen. Furthermore, monitoring several markets is unavoidable. Markets come along with different market-specific requirements, meaning that the ED might only be effective in specific markets. Furthermore, use of the ED could lead to increased violence against the driver or owner of the targeted vehicle in some markets.

b) The ED could be a useful addition to the array of existing measures fighting vehicle theft. These measures have partly exhausted their effect to some degree. However, the ED will not replace existing countermeasure. It might be a good complement to traditional target-hardening strategies like electronic immobilizers and vehicletracking systems. Thereby, the ED will be most successful if people view it as a convenience, with the (de)activation via key likely being the most appropriate.

\subsubsection{Cooperative home light}

\section{Guideline}

To discuss the effectiveness of the cooperative home light, we suggested the following topics. 
1. Deterrent effect: Would the cooperative lighting of several cars deter criminals from robbing or assaulting the driver while going to / leaving their car?

2. Reducing effect (crime): Would the cooperative lighting of several cars reduce robberies / assaults against the driver while going to / leaving their car?

3. Reducing effect (fear): Would the cooperative lighting of several cars reduce the fear of robberies / assaults?

4. Drawbacks /hurdles: What are the main drawbacks and hurdles with the cooperative lighting?

5. Benefits /values: What are the benefits and values provided by the cooperative lighting?

6. General assessment: In general, is cooperative lighting a useful function with the potential to prevent robberies and assaults?

\section{Experts on influence of lighting on crime}

To conduct our interviews, we contacted the following four experts who have worked on the influence of lighting on crime.

a) An expert from US research institute for criminal justice

b) An expert from US research institute for criminal justice, law and public safety

c) An expert from the Dutch research institute for the study of crime and law enforcement

d) An expert from Australian research institute for criminology and criminal justice

\section{Interview summary}

Only the first expert was able to reply to our questions. The other experts mainly agreed that due to the novelty and singularity of the cooperative home light, estimating the effectiveness at fighting robberies and assaults cannot be reliably done without a larger field of study. Nevertheless, using existing results from former case studies researching the influence of (street) lighting on crime can be used to draw some first conclusions and implications about the effectiveness. We have already used existing research results in the beginning of this chapter in Section 7.1.

1. Deterrent effect

a) Cooperative lighting will have a deterrent effect on criminals. However the system should not use too many cars for the cooperative lighting, e.g., only the nearest five cars.

2. Reducing effect (crime)

a) A reducing effect is possible if the cooperative lighting allows the users to feel comfortable. A further approach is to put motion-activated lights on cars, which are activated as soon as the driver locks and leaves his car at dark. This will protect 
his car, the car next to it and anybody walking by the activated car on the way to their own car.

3. Reducing effect (fear)

a) A reducing effect on fear of crime is assumed. But, as already mentioned above, the system should not use too many vehicles. This could lead to a contrary effect. If too many vehicles are giving off light, individuals may consider the surrounding areas unsafe since they would remain unlit.

4. Drawbacks / hurdles

a) The cooperative lighting needs to avoid glaring into pedestrians' eyes. It is very important that the cooperative lighting is not obnoxious. There is no need for too much lighting. Only few cars nearby should be used.

5. Benefits / values

a) A positive effect can be easily achieved since only few cars are necessary. However, these cars need to be nearby.

6. General assessment

a) The cooperative home light has the potential to reduce robberies and assaults as well as fear of these crimes, whilst involving low costs.

\subsection{Summary}

In this chapter, we evaluated the electronic decal and the cooperative home light. We first considered results from similar countermeasures and gained a first glance at the possible effectiveness of the two security functions. Second, we conducted our own survey to gain further knowledge about the (expected) effectiveness at fighting crime and reducing fear of crime. Participants rated on the one hand the effectiveness of the potential security function and on the other hand an existing similar security measure. This way, we were able to estimate whether our security functions provide an improvement in (expected) effectiveness. The cooperative home light was compared with the basic home light and the electronic decal with the physical decal. In the context of evaluating the effectiveness, we also examined whether perceived effectiveness depends on socio-demographics, namely gender, age and technological proficiency. Furthermore, in our survey we considered customer acceptance, involving tangibility of security functions. The survey also included a section to find out more about the demand of security functions in general. Third, we conducted expert interviews to estimate the effectiveness of focusing on fighting crime in order to substantiate our results.

Based on the related work results, the electronic decal will not reduce an individual's chances of having their vehicle stolen if it is not evident to the thief that the vehicle they are targeting is 
equipped with this function. Furthermore, the electronic decal has the potential to create security awareness, and thus, indirectly fight vehicle-related crime and reduce fear of crime due to creating security awareness. The effect of the cooperative home light in reducing robberies and attacks against the driver while leaving or entering the vehicle seems achievable if community pride and self-confidence are improved with the help of the CHL. A positive effect on fear of crime can be mainly assumed.

Based on our sample of participants, we state that the effectiveness of the CHL to reduce robberies and assaults on drivers entering and exiting their cars is expected to be significantly improved when compared to the BHL. The effectiveness in reducing fear of robberies and assaults is improved as well. The electronic decal was compared with the physical decal. We found that the ED is also expected to significantly improve measures to prevent car theft as well as reducing people's fears of becoming victims of car theft. Hence, effectiveness is expected by our subjects. Socio-demographics did not show any abnormalities in ratings of the effectiveness of both security functions.

Both security functions were generally well accepted by participants. However, their willingness to provide their own car for cooperative lighting would necessitate a benefit for them to offset the economic drawbacks and increase people's willingness to use the function. For the ED, opinions on (de)activation methods showed large differences. (De)activation via car key was seen as the least hassle in everyday use and generally convenient, although subjects were aware that the car key method may be circumvented in the event the key is stolen. In contrast, (de)activation via schedule was rated as the least usable, mainly due to poor flexibility. (De)activation via smartphone was rated somewhere in between. The additional security of the smartphone as an additional "token" was highlighted but also criticized since it would make users dependent on having an additional device in everyday use. Hence, features that involve increased effort in everyday use and do not fit users' daily routines decrease the attractiveness of a security function, despite its effectiveness. This does not mean that people are not willing to invest in additional effort, but an clear benefit must be visible. The maximum surcharge for the end customer should stay below $200 €$ for the CHL as well as for the ED, independent of the (de)activation method.

According to our participants, security functions should mainly tackle car theft and theft of car keys, which is linked to car theft. Focusing on protecting users from physical attacks and bodily injury plays an important role as well. Smaller property crimes and especially vandalism have minor importance. Thus, future security functions should focus on these crimes.

Our expert interviews suggest that implementations should hide the fact that a vehicle is equipped with the ED and mount the OCU in an unknown place. This way the ED will produce a deterrent as well as hardening effect and increases the risk of a thief getting stopped by the police while driving the stolen vehicle. As soon as a thief is aware that the vehicle is equipped with the ED, a signal jammer may be used to disturb communication. Furthermore, experts prefer (de)activation via car key. First, the number of possible interfaces to the vehicle must be reduced to a minimum in order to reduce vulnerability. Second, dependence on citizen action should be reduced to a minimum as well. In general, the ED must be seen as a complement to existing countermeasures, and not as a replacement. 
One expert testified the cooperative home light as being effective to fight crime and reduce fear of crime. Thus, a small number of nearby cars is necessary. Due to the novelty and singularity of the cooperative home light, other experts mainly agree that a larger field of study is necessary to draw reliable conclusions about its effectiveness at fighting assault and robbery. 



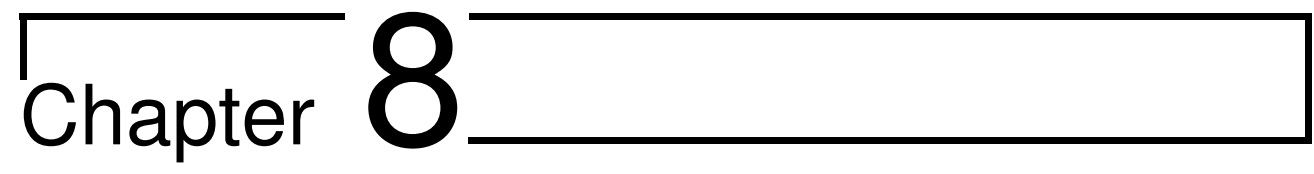

\section{Simulation to evaluate the cooperative home light}

A complementary means of evaluating security functions, and thus, measure the effectiveness is by making use of simulations. This approach arises from engineering demands and needs a definition of measurable criteria representing the effectiveness of a security function. This way, we gain knowledge about the effectiveness of a security function in addition to the related research results, surveys and expert interviews which we applied in Chapter 7.

In this chapter, we simulate the cooperative home light (CHL) with the help of a simulation environment in order to estimate its effectiveness. We define the duration of the driver in a lit surrounding as a measurable criterion. The CHL is classified as effective, in reducing both crime as well as fear of crime, when the driver is in a lit surrounding. The improvement over the basic home light (BHL) in terms of the number of participating vehicles is of additional interest. In other words, the length of time the driver's surroundings are lit is dependent on the penetration rate of vehicles participating in $\mathrm{V} 2 \mathrm{~V}$ communication, and as such is our measurement criterion.

In the beginning of this chapter, we introduce the simulation environment with its requirements to simulate our lighting functions and describe the implementation of our simulation environment. Section 8.2 shows our simulation settings having been used to conduct simulations. The simulation results are presented in the next section before closing this chapter with a summary.

\subsection{Simulation environment}

We need a simulation environment which enables us to freely model different parking arrangements which allow us to vary the number of vehicles able to communicate. The simulation environment is implemented in two dimensions, that is in bird's-eye view. Additionally, we need to be able to specify the driver's path to or from the vehicle and to configure the lighting capabilities of vehicles. To the best of our knowledge, there is no simulation environment that supports a simulation of the CHL. Consequently, we implemented a simulation environment $[4,135]$ that is able to simulate diverse parking arrangements, and thus, evaluate the CHL. 


\subsubsection{Requirements}

\section{Parking Arrangements}

The number of possible parking arrangements is infinite, since a driver's paths are numerous and vehicles are positioned in different ways. Therefore, our simulation environment needs to provide the opportunity to load a background image from Google Maps [209] or Bing maps [210], for example. The scale is of course adjusted to our scale factor within the simulation environment. Then, we have the opportunity to add, i.e., overlay, and freely position vehicles at positions where vehicles are parked when the picture was taken. Furthermore, inserting rectangular obstacles, such as walls, and circular obstacles, such as trees needs to be supported. For parking arrangements, areas up to $100 \mathrm{~m} \times 100 \mathrm{~m}$ are in our opinion a reasonable approach since typical remote keys and low beams tend to work up to this distance.

\section{Vehicles}

Each vehicle has a set of light sources to light the environment, according to Figure 6.3. Each vehicle must be able to be configured separately so that vehicles with different equipment levels can be simulated. Furthermore, four types of vehicles are necessary in order to consider vehicle classes from real parking arrangements. Considering only passenger cars, low-, mid-market and high-end vehicles as well as sport utility vehicles (SUVs) are in our opinion sufficient in the first approach since passenger cars represent the majority of vehicles.

\section{Lighting and shadowing}

Lighting is approximated by a surface created with the help of polygons. The lit area needs to be adjustable for each vehicle separately to model different lighting technologies. To implement light polygons, the following sources [111, 112] provide a good orientation. We additionally verified the behavior with a real vehicle equipped with an incandescent lighting system in a darkened light-testing facility. We then decided to decrease the lighting range of low beams from the theoretically maximum lighting range of asymmetric low beams, given as $50 \mathrm{~m}$ and $65 \mathrm{~m}[111,112]$, to $40 \mathrm{~m}$ and $50 \mathrm{~m}$. The other light sources remain unchanged. The required lighting configuration is depicted in Figure 8.1(a). Figure 8.1(b) shows the horizontal movement of low beams which is adjusted when the driver approaches the vehicle to avoid dazzling. Figure 8.1(c) shows the horizontal low beam movement with a maximum angle of 15 degrees on both sides. Furthermore, simplified ray tracing is implemented to consider obstacles, such as other vehicles and walls. As can be seen in Figure 8.1(d), our ray tracing blocks lighting. Reflection and indirect lighting are however not implemented. 


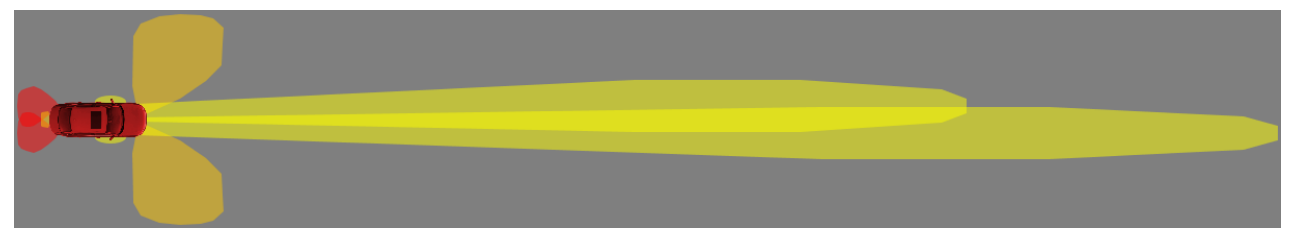

(a) Light sources of vehicles in the simulation environment

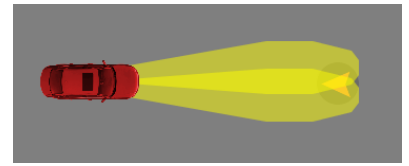

(b) Vertical low beam movement

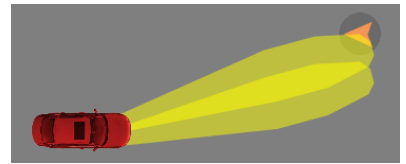

(c) Horizontal low beam movement

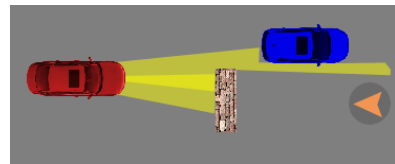

(d) Ray tracing and shadowing

Figure 8.1.: Lighting and shadowing implementation in the simulation environment

\section{Driver's Path}

The driver's path is modeled with the help of anchor points, which are freely inserted in the simulation environment. However, the driver does not move from one anchor point to the next in each simulation step. Instead, we connect these anchor points to build a path. Based on the adjustable simulation resolution and walking speed, we calculate the distance to be covered in each simulation step. For example, the simulation resolution is adjusted to $10 \mathrm{~ms}$, meaning that the entire simulation setting is recalculated every $10 \mathrm{~ms}$. The walking speed is adjusted to $1 \mathrm{~m} / \mathrm{s}$. Hence, the driver moves in each simulation step $1 \mathrm{~cm}$ on the path. This distance is further recalculated to fit simulation scale.

\section{Communication}

The propagation of electromagnetic waves varies greatly according to many influencing factors. For example, Kwoczek et al. [136] investigated the influence of roof curvature, roof racks and panorama glass roofs on the antenna gain in the communication frequency band reserved for V2V communication and found amongst other things a high loss of gain caused by glass roof. Additionally, packet collision and channel congestion were found to influence communication. Hence, it is highly challenging to consider and simulate all influencing factors.

We consider the basic approach of the CHL where only the host vehicle broadcasts messages. This approach reduces the communication load to a minimum. According to [137], the defined transmission power enables communication up to $1000 \mathrm{~m}$. In this thesis, we consider simulation areas with a size of approximately $100 \mathrm{~m} \times 100 \mathrm{~m}$. We also only consider parked vehicles so effects due to moving objects can be neglected as well. Consequently, we assume communica- 
tion among all vehicles. Nevertheless, the simulation environment implements a communication manager, which can be extended by communication models to influence communication when necessary.

\section{Home light functions}

The simulation environment provides the opportunity to choose between our three lighting functions, i.e., the basic home light (BHL), the extended home light (EHL) and the cooperative home light (CHL) based on the basic approach. The EHL behaves similarly to the CHL when no vehicles participate in the cooperative lighting process, i.e., a penetration rate of $0 \%$ of vehicles being able to communicate. Each vehicle must run its own lighting function and behave according to its settings.

\subsubsection{Implementation}

We implemented a simulation environment, shown in Figure 8.2, fulfilling our requirements from Section 8.1.1. As can be seen, the simulation environment is implemented in two dimensions, that is, from bird's-eye view, and provides a graphical user interface (GUI).

Our simulation environment is implemented as a two-tier architecture. The presentation tier, our GUI, and the logic tier, process the simulation. Although our simulation environment supports saving simulation scenarios as well as statistical data, the saving of data and settings is implemented within the logic tier since we are not relying on a database. Both tiers are implemented decoupled. This way, changes in one tier do not influence the other tier, giving high cohesion. To realize the decoupling, we use two design patterns. First, we make use of the facade pattern. This way, the logic tier provides specific interfaces for the presentation tier. Second, the model-view-controller (MVC) pattern is implemented, where the view is implemented within the presentation tier and the others within the logic tier. Thereby, we use the observer pattern, which is a key part of the MVC pattern, to update the GUI. 


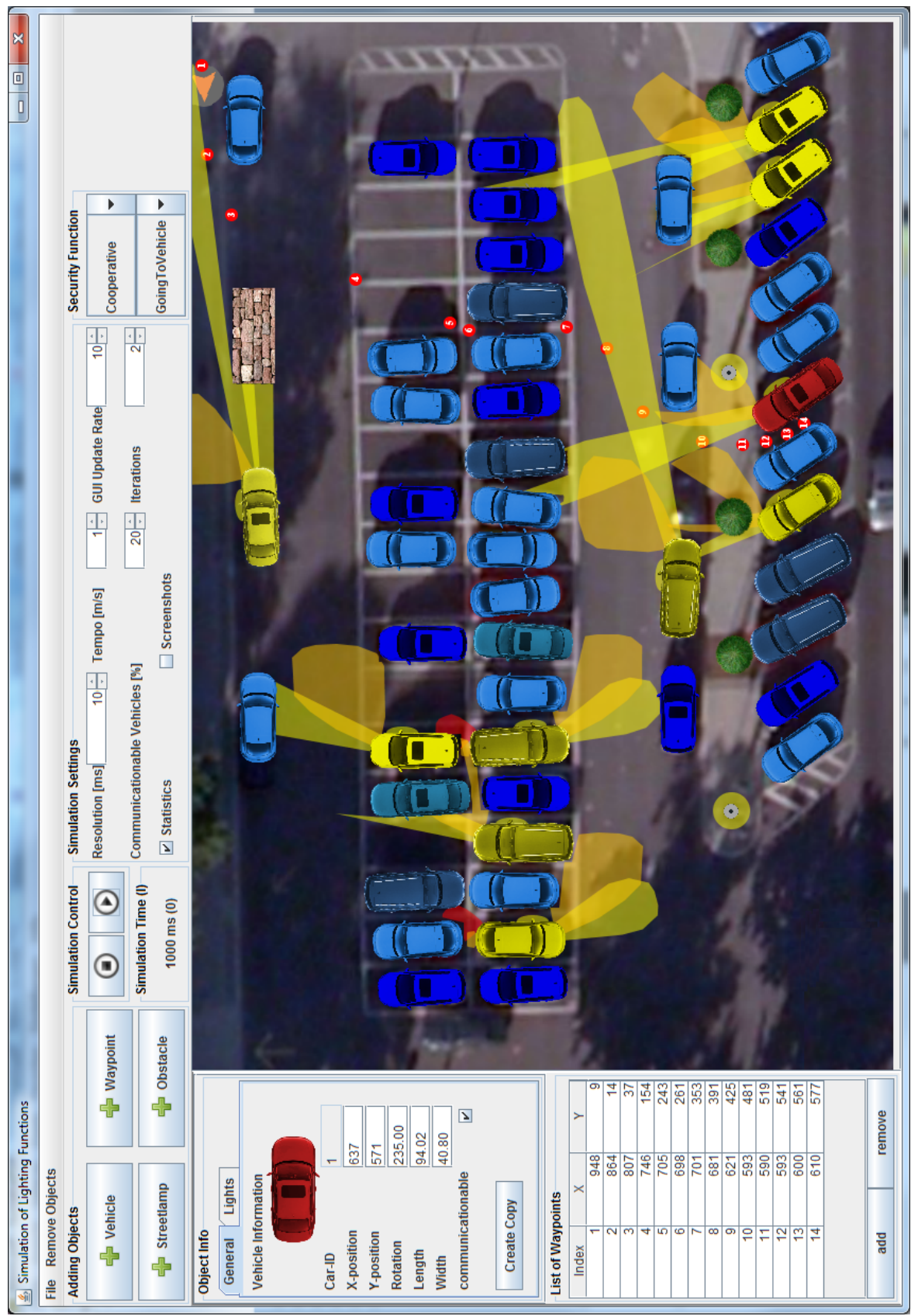

Figure 8.2.: Simulation environment to evaluate the CHL 


\subsection{Simulation settings}

In the best case, the driver remains in a lit surrounding for $100 \%$ of their journey to the vehicle, and the penetration rate of participating vehicles is as low as possible. Hence, our metric is the duration the driver remains in a lit surrounding on the way to the vehicle. To estimate the effectiveness, we choose five parking arrangements from urban areas to simulate our home light functions. These parking arrangements are summarized in the following and reflected in the relevant figures. We did not consider rural parking arrangements since people living in rural areas typically have a driveway or indeed a garage and thus do not cover long distances to get to their vehicle.

- Consecutive parking (Figure 8.3)

- Consecutive and skewed parking (Figure 8.5)

- Side-by-side parking (Figure 8.7)

- Side-by-side and skewed parking (Figure 8.9)

- Consecutive, side-by-side and skewed parking (Figure 8.11)

We configured the same lighting setup for all vehicles as shown according to Figure 8.1(a). This implies all vehicles are equipped with equally capable lighting technologies. We modeled three possible walking paths for each parking arrangement. Each walking path led to a different vehicle. The starting point of the driver was identical for each parking arrangement. We avoided equal paths since lighting behavior is obviously equal on equal paths. To be able to model distinct paths, driver's vehicles are spread in the parking arrangement. Parking vehicles, obstacles and paths are modeled considering the scenario taken from Google [209] or Bing maps [210]. Our parking arrangements showing all paths and the relevant vehicles of the driver are depicted in Figures 8.3 to 8.11.

Each path was simulated for the BHL and the CHL with penetration rates of participating vehicles from $0 \%$ to $100 \%$ in $10 \%$ steps. A penetration rate of $0 \%$ means that the CHL behaves similarly to the EHL, i.e., making use of the opportunity to move low beams in the driver's direction as well as only turning on necessary light sources without any help of other vehicles. A penetration rate of $100 \%$ means that all vehicles in the scenario participate in lighting the path. The BHL and CHL were simulated with $0 \%$ and $100 \%$ penetration rates once, since they are clearly deterministic. In contrast, the simulation of the CHL for penetration rates from $10 \%$ to $90 \%$ was conducted 100 times per penetration rate. For each simulation iteration, we randomly estimated vehicles that were able to communicate in the scenario, i.e., vehicles participating in the cooperative lighting. The driver walked with a walking speed of $1 \mathrm{~m} / \mathrm{s}$ to the host vehicle, where the position was updated, i.e., broadcasted to other vehicles, every $100 \mathrm{~ms}$. This is the maximum broadcast rate of CAMs [95]. 


\subsection{Simulation results}

\subsubsection{Consecutive parking arrangement}

Figure 8.4 shows the results from the consecutive parking arrangement depicted in Figure 8.3. As can be seen, the $\mathrm{CHL}(0 \%)$ without any participating vehicles only provides an obvious improvement compared to the BHL for path 2 . The capability of moving low beams into the driver's direction has no effect for path 1 and 3. There are mainly three reasons. First, the gap between host vehicle 2 and the vehicle in front is on average larger than for the other host vehicles. Second, the driver approaches host vehicle 2 from the front so low beams can have their full effect. Low beams have the greatest influence on lighting the surroundings. Third, the driver approaches vehicle 2 at an angle smaller than 15 degrees, which is within the mechanical limits of moving low beams. For path 1 and 3, at least one of the aforementioned reasons is not fulfilled.

Furthermore, we can see from Figure 8.4 that the unfavorable vehicle position of host vehicle 1 and 3 is not compensated by an increased penetration rate. That means, there is a nearly constant gap in the mean duration between all three paths independent of the penetration rate. So, the position of the host vehicle itself seems to play a clear role.

In common with all three paths, the driver's duration in a lit surrounding increases up to a penetration rate of approximately $50 \%$. From a penetration rate of $50 \%$ there is a kind of saturation. That means, the increase of participating vehicles contributes only marginally to the mean duration that surroundings are lit. However, the increasing penetration rate provides more reliable lighting which can be seen by the decreasing standard deviation (SD) of the duration. The variation is reduced with an increasing penetration rate.

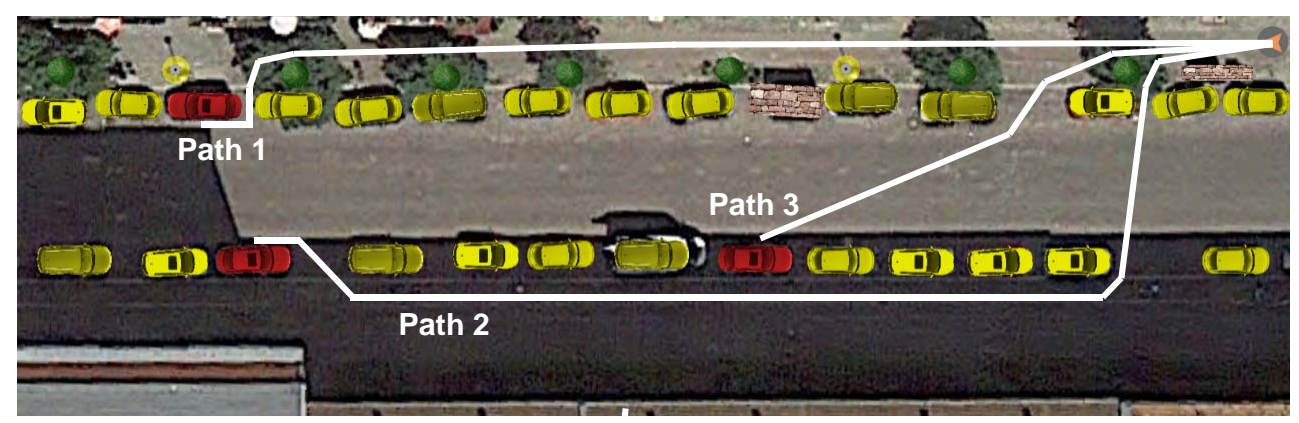

Figure 8.3.: Consecutive parking arrangement 


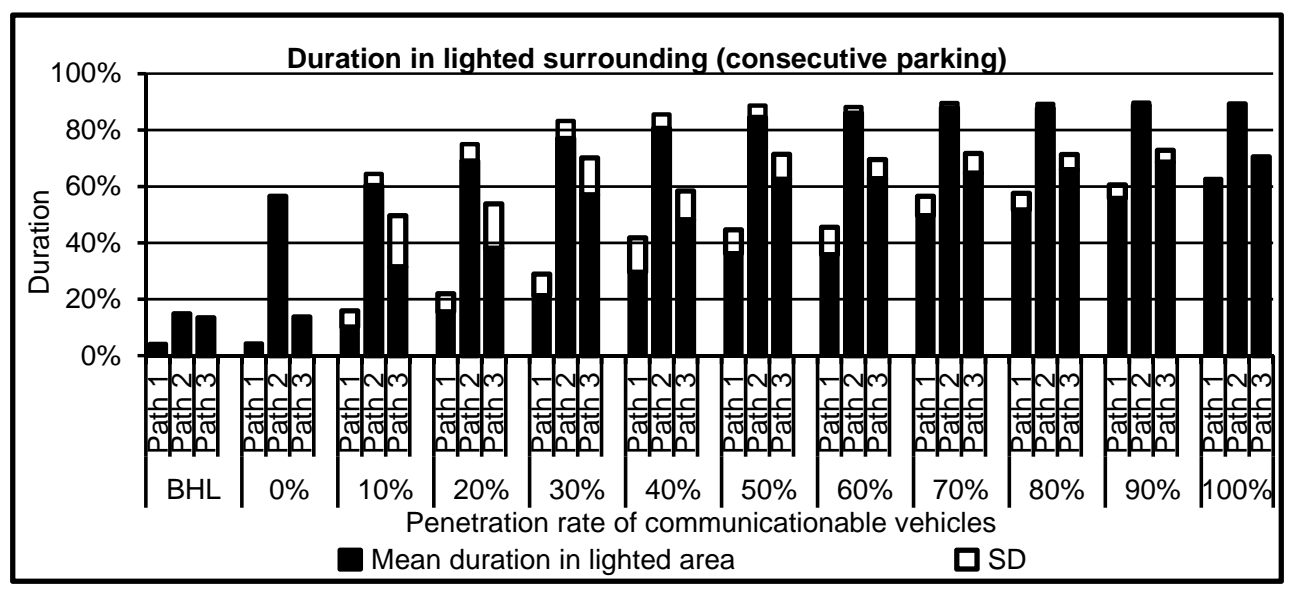

Figure 8.4.: Results of driver's time in a lit surrounding for a consecutive parking arrangement

\subsubsection{Consecutive and skewed parking arrangement}

According to the results (Figure 8.6) for the consecutive and skewed parking arrangement (Figure 8.5), the influence of the position of the host vehicle is clear. This can be seen especially when comparing the BHL with the CHL $(0 \%)$. Considering path 1 , the host vehicle cannot benefit from the moving low beams due to its unfavorable orientation towards the driver. The right cornering light adopts the lighting of the path when the driver approaches the vehicle. In contrast, host vehicle 3 is able to move its low beams to a large extent. The driver approaches host vehicle 3 within mechanical limits and no obstacles obstruct the lighting. The vehicle in front is indeed parked close by, but due to the capability of low-beam movement, low beams partly illuminate past the vehicle in front. For path 2 there is only a slight improvement between the BHL and the CHL $(0 \%)$. The main reason is the tree besides the vehicle in front, which additionally shadows the lighting.

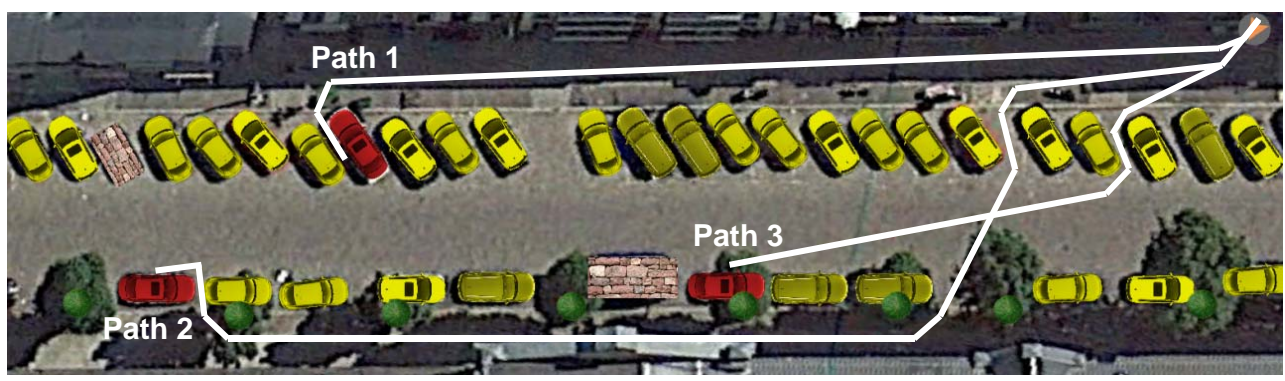

Figure 8.5.: Consecutive and skewed parking arrangement 
Considering the cooperative lighting, we achieve a saturation as soon as the penetration rate of participating vehicles is $40 \%$. There is however an improvement in lighting duration for path 2 starting from a penetration rate of $60 \%$. In this scenario, we have obviously two sub scenarios, namely a skewed scenario and a consecutive scenario. Path 1 mainly depends on vehicles parked in a skewed manner since all skewed vehicles point in the same direction. Path 2 as well as path 3 mainly depend on vehicles being parked in a consecutive manner. Skewed vehicles are mechanically not able to light path 2 and 3 since these paths are out of the lighting range of skewed vehicles. In contrast, consecutive vehicles are for the most part not able to light path 1 . Moreover, there are two times as many skewed vehicles as there are consecutive vehicles and the ability of vehicles to participate in communication is estimated randomly. Therefore, the lighting of path 1 is better than that of the other two paths. This effect is however reduced considering path 3 due to the favorable position of vehicle 3 which takes over the main part of lighting, especially for lower penetration rates.

The reliability of lighting increases with the penetration rate of vehicles participating in cooperative lighting. Hence, the variation reduces with an increasing penetration rate. Nevertheless none of the paths achieve a duration of $100 \%$ illumination.

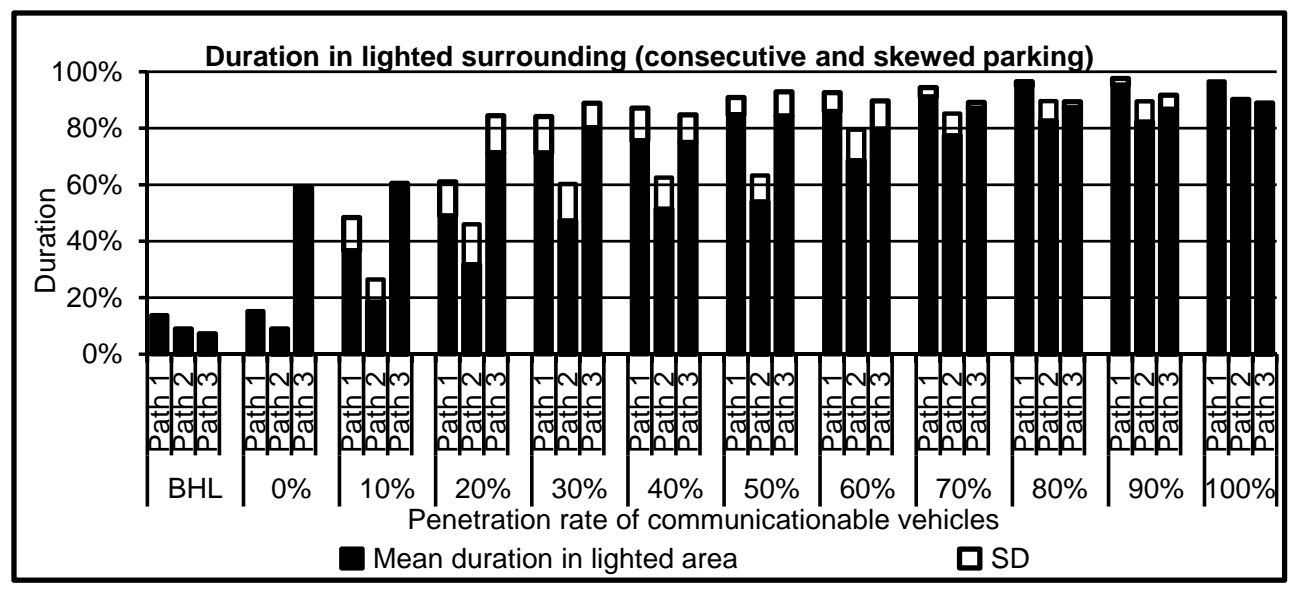

Figure 8.6.: Results of driver's time in a lit surrounding for a consecutive and skewed parking arrangement

\subsubsection{Side-by-side parking arrangement}

Figure 8.8 shows the simulation results related to the side-by-side parking arrangement from Figure 8.7. Since the driver approaches each host vehicle from the side, moving low beams does not provide an improvement in lighting duration. Hence, in this scenario there is no difference between the BHL and the $\mathrm{CHL}(0 \%)$ as can be seen in Figure 8.8. 


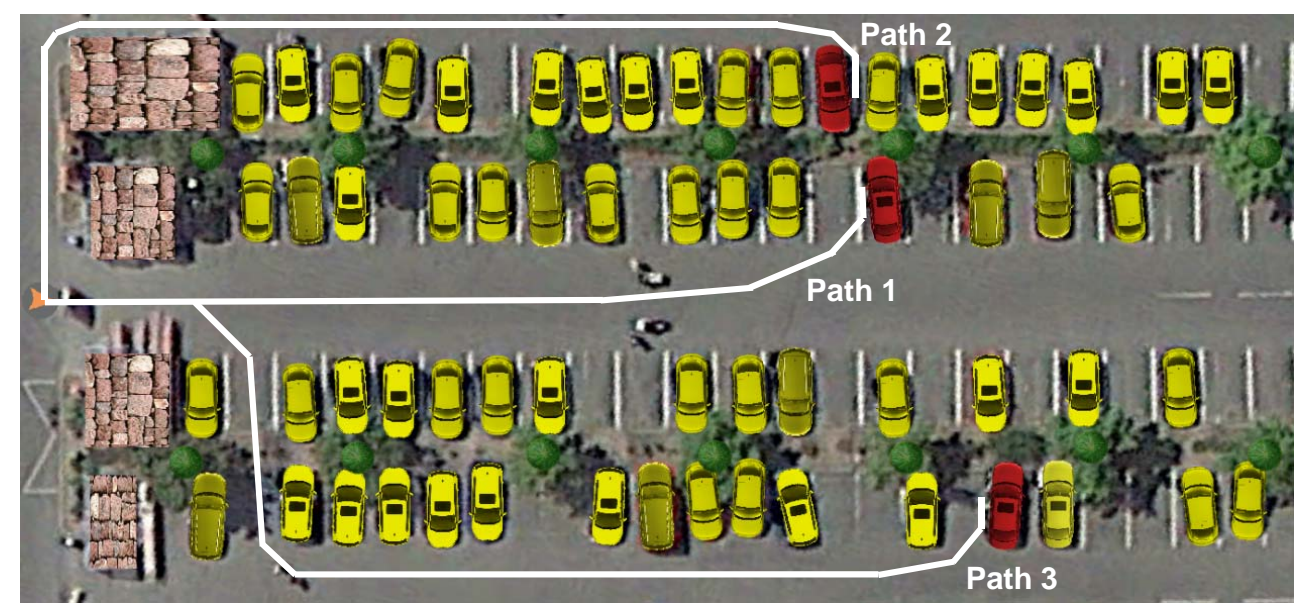

Figure 8.7.: Side-by-side parking arrangement

Considering path 2, the lighting duration is noticeably worse than for the other two paths. There are two main reasons for this result. First, only one vehicle in the top row is parked backwards, and thus able to use low beams and cornering lights to light the path. Second, although several vehicles from the middle rows are pointing towards path 2, their lighting is obstructed by vehicles parked in the top row. In the low parking row, half of vehicles are parked backwards. Therefore, path 3 permits a longer lighting duration than path 2 . The results of Path 1 are comparable with path 3 since the number of vehicles being directed to the path is largely similar.

In this scenario, none of the host vehicles provide the benefit of moving low beams since the driver approaches each host vehicle sideways. Hence, the influence of host vehicles is highly limited. Nevertheless, the lighting duration increases constantly for all paths achieving the saturation effect with a penetration rate of approximately $60 \%$. That means that other vehicles clearly increase the duration of illumination despite the shadowing effects caused by parked vehicles, especially in scenarios like path 2 . 


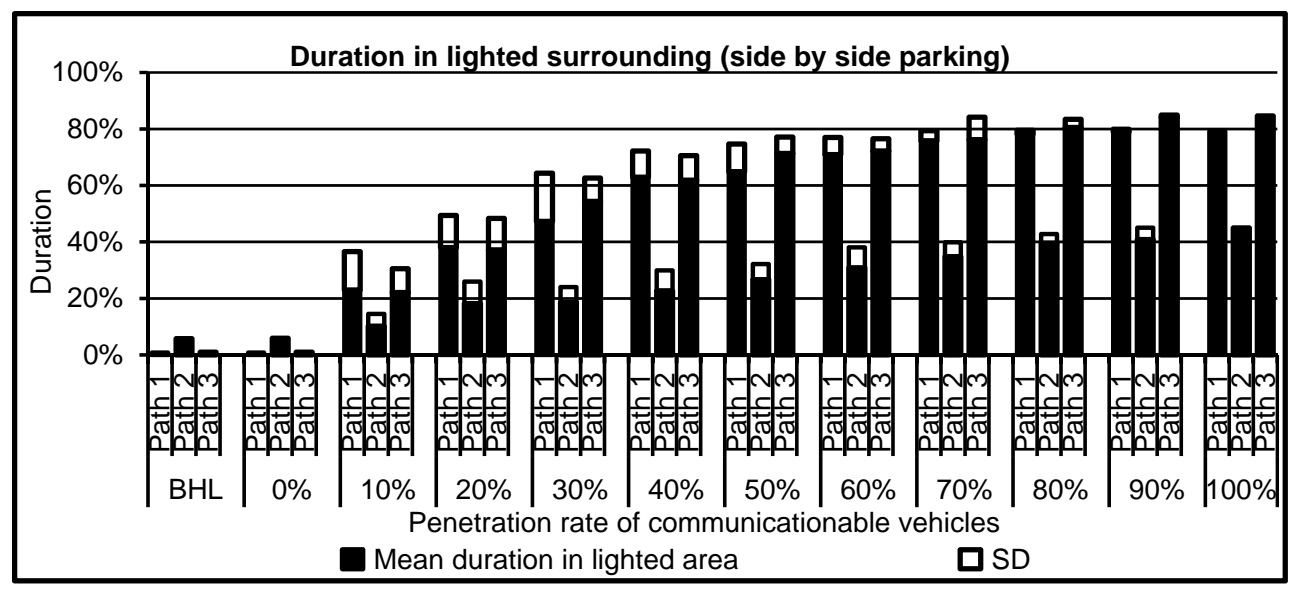

Figure 8.8.: Results of driver's time in a lit surrounding for a side-by-side parking arrangement

\subsubsection{Side-by-side and skewed parking arrangement}

As can be seen in Figure 8.9, only the driver who used path 3 approaches the host vehicle from the front within moving limits of low beams. Therefore, using path 3 the $\mathrm{CHL}(0 \%)$ provides an improvement compared to the BHL. Considering path 1 and 2, the movement of low beams still has no effect since the driver is outside of mechanical limits.

For cooperative lighting, the time the driver is in a lit area increases constantly for all three paths before achieving the saturation effect from a penetration rate of approximately $50 \%$. The illumination time for path 2 is noticeably worse than paths 1 and 3 . The main reason is that there are only a few vehicles able to light this path. Additionally, the hedge obstructs the lighting.

The variation of lighting duration, which is represented by SD, is in this scenario noticeably reduced from a penetration rate of $50 \%$. 


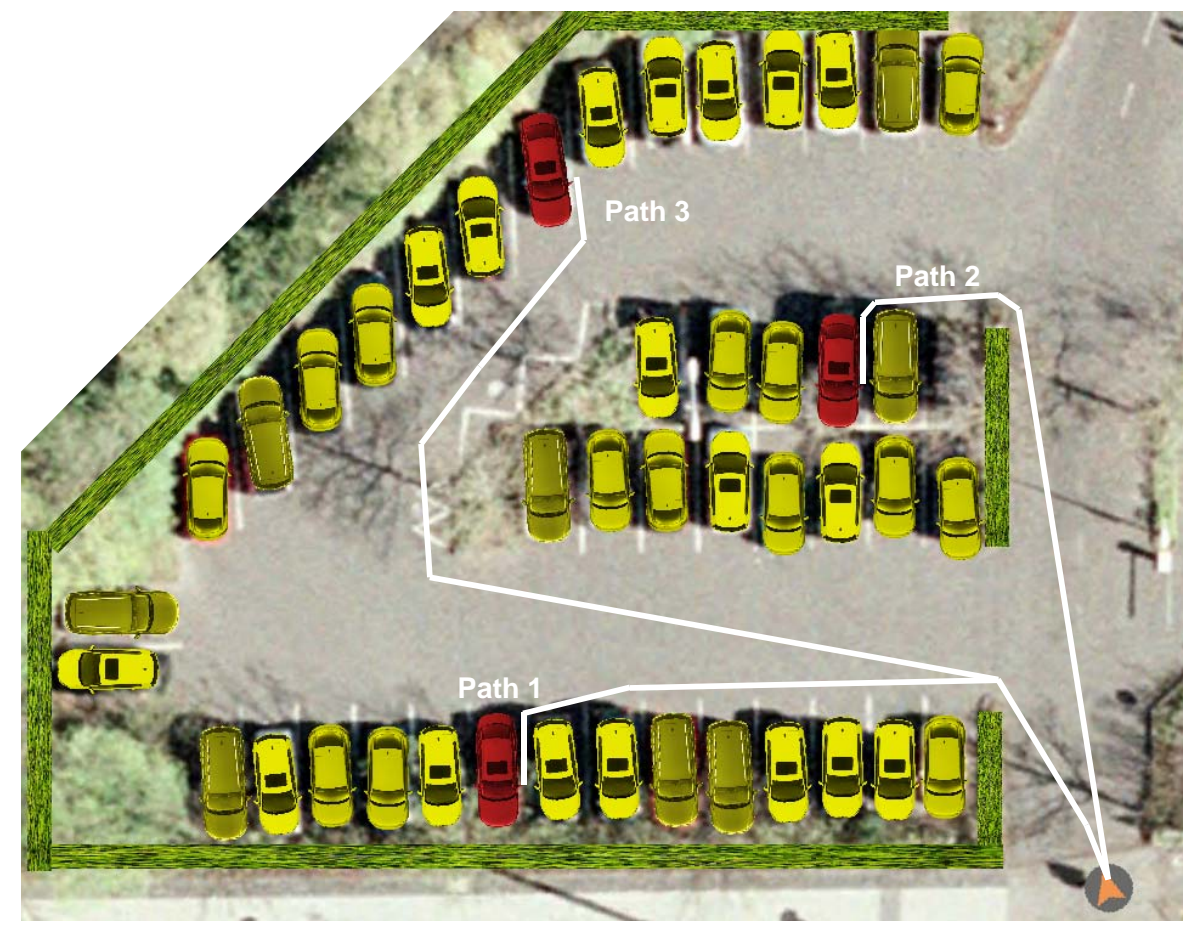

Figure 8.9.: Side-by-side and skewed parking arrangement

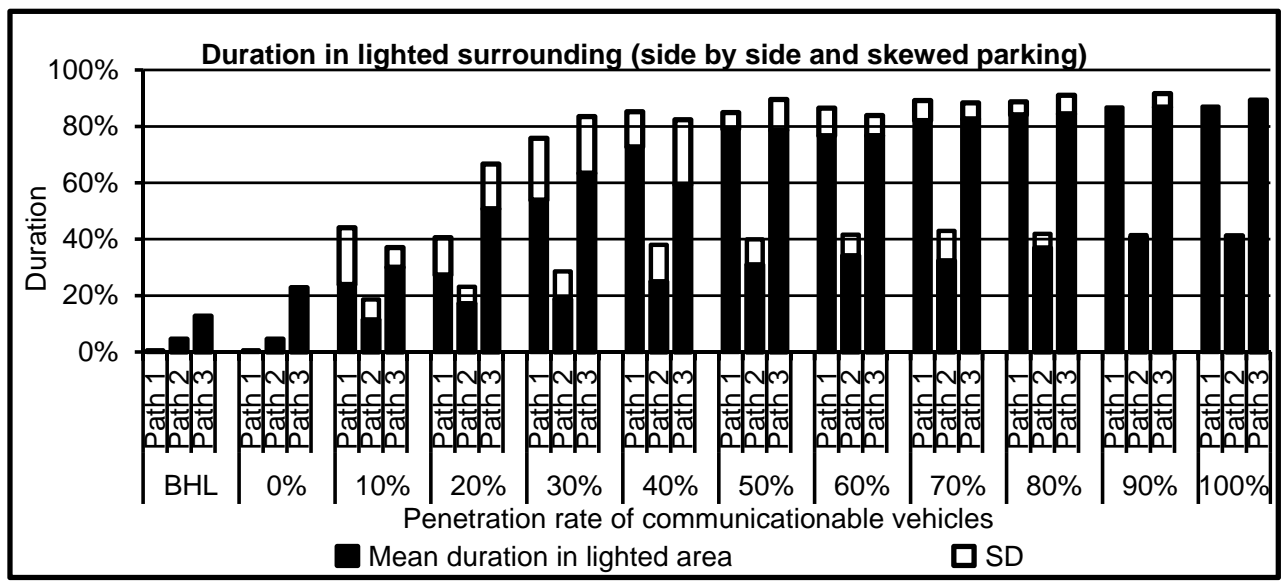

Figure 8.10.: Results of driver's duration in a lit surrounding for a side-by-side and skewed parking arrangement 


\subsubsection{Consecutive, side-by-side and skewed parking arrangement}

Figure 8.12 summarizes the results from the parking arrangement depicted in Figure 8.11. First of all, the $\mathrm{CHL}(0 \%)$ provides an improvement in lighting compared to the BHL when the driver approaches from the front. This way, the CHL has the ability to move low beams into the direction of the driver. For path 2 in particular, the benefit of moving low beams is obvious. Due to moving low beams the host vehicle is able to light past the surrounding vehicles.

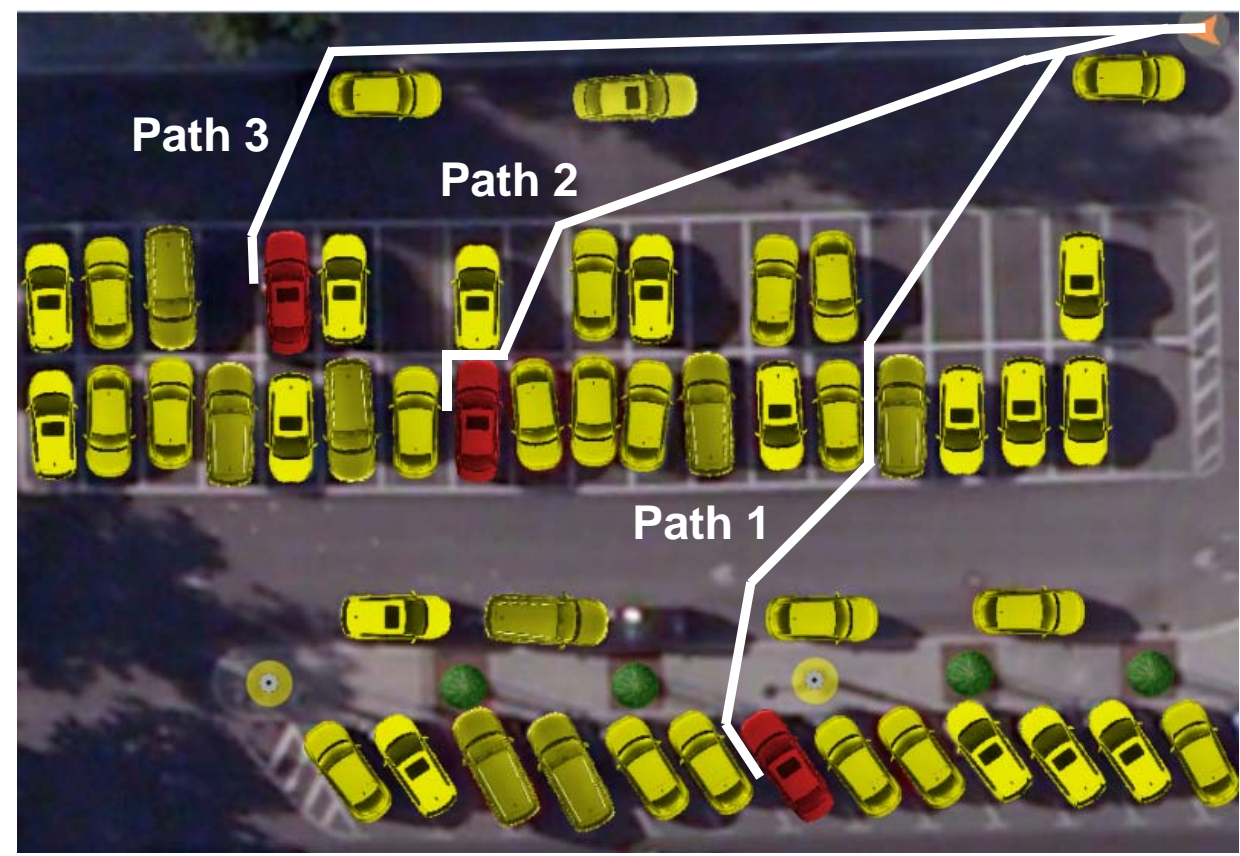

Figure 8.11.: Paths for the mixed (consecutive, side-by-side and skewed) parking arrangement

Furthermore, up to a penetration rate of $50 \%$, the average duration increases constantly up to $80 \%$. Hence, on average an acceptable lighting coverage is achieved with $50 \%$ of vehicles. However, the SD is approximately by $20 \%$ considering penetration rates smaller than $50 \%$. This shows possible variations in the lighting duration, which depend on parking positions of participating vehicles.

Up from penetration rates of $60 \%$, the average duration increases only slightly up to a duration of $90 \%$ in a lit surrounding and the SD decreases. That means, high penetration rates do not necessarily provide much higher lighting durations, though they provide lower variations. Moreover, saturation is achieved with $90 \%$ of lighting duration. 


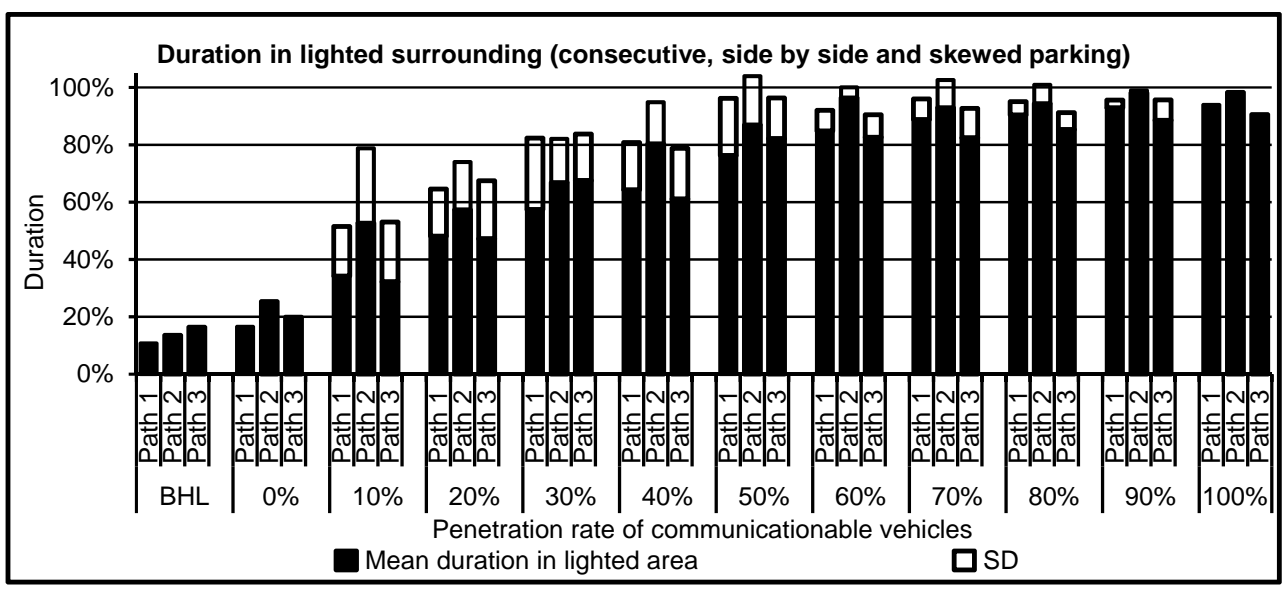

Figure 8.12.: Results of driver's duration in a lit surrounding for consecutive, side-by-side and skewed parking arrangements

\subsection{Summary}

To gain further insights about the effectiveness of the cooperative home light, we made use of our simulation environment and simulated the cooperative home light (CHL). We also simulated the basic home light (BHL) as well as the extended home light (EHL), which is the CHL without other participating vehicles. We compared all three lighting functions with each other. The effectiveness criterion is defined as the time the driver's surroundings are lit as they make their way to the vehicle. We modeled five different parking arrangements and considered several penetration rates of vehicles participating in cooperative lighting.

Simulation results revealed that the effect of moving low beams only provides an improvement when the driver approaches the vehicle from the front within mechanical limits of movable low beams. Using the capability of moving low beams sideways reveals its benefit, especially when vehicles are consecutively parked. This way, the light emitted by low beams is not entirely covered by the vehicle in front. When the driver approaches the vehicle from the side, moving low beams have no improving effect. Instead, static cornering lights mainly light this area. When the driver approaches from the back to the vehicle, moving low beams do not provide any improvement either. Considering our simulation results, the $\mathrm{CHL}(0 \%)$ with no participating vehicles sufficed for $40 \%$ of the paths, i.e., 6 of 15, an increase of the duration in a lit surrounding compared to the BHL. The increased duration was only in a lower one-digit range.

Due to their lighting properties, low beams and cornering lights have the main effect on illumination. These light sources are intended to light surroundings, in contrast to tail lights for example, which mainly serve as orientation lights. Simulation results for all parking arrangements showed that parking positions of participating vehicles greatly influence the time that 
the driver is in a lit surrounding. In the worst case, none of the participating vehicles is within lighting range. Thus, even if there are vehicles participating in the cooperative lighting they have no influence on the lighting. Consequently, mixed parking arrangements provide better results, especially considering lower penetration rates, than uniform parking arrangements. A mixed parking arrangement lights a wider area, so the probability that the driver's surroundings remain lit increases. In contrast, uniform parking arrangements often mean having several vehicles pointing in the same direction.

To provide a reasonable effect to customers associated with arguable benefits beyond the BHL and EHL, we think that a penetration rate of $50 \%$ of participating vehicles is necessary. Considering lower penetration rates, the CHL would depend greatly on the parking arrangement, and thus, would provide only partial improvement to the BHL and EHL. This could lead to customer dissatisfaction and disappointment, and thus may reduce the acceptance of the CHL. 



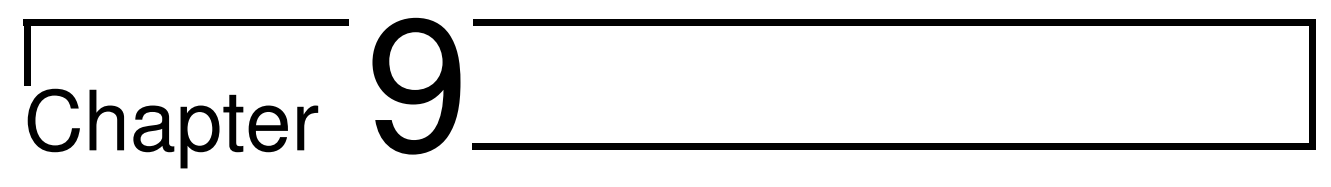

\section{Summary}

This chapter summarizes the achievements of this work by revisiting our research questions. Next, we outline any open issues as well as opportunities for future research work before concluding the thesis.

\subsection{Contributions}

We formulated the following main research hypothesis in the introductory chapter:

Main research hypothesis: New technologies are enablers for a novel class of advanced and cooperative security functions in the automotive field.

We derived from our main research hypothesis two main research questions which were further subdivided into sub research questions, helping to analyze the potential of new technologies in enabling automotive security functions. In the following, we summarize the contributions of this thesis for each research question.

Main research question 1: How can we identify automotive security functions?

$R Q$ 1.1: How can we gain deeper understanding of the factors leading to (fear of) vehiclerelated crime?

- We conducted a statistical (vehicle-related) crime analysis for several industrialized and emerging countries. This way, we provided an overview about the development and trends in vehicle-related crime. In industrialized countries, vehicle theft has steadily decreased since the 1990s, but a bottom line seems to be reached. Theft from vehicles follows nearly a similar trend. However, theft has moved from occasional to professional theft. In emerging countries, vehicle theft rates have changed in a contrary direction, due 
partly to population growth and increased numbers of registered vehicles. Nevertheless, theft rates are not significantly higher than in industrialized countries. The use of violence however seems to be higher than in industrialized countries which can be seen in the high rates of carjackings. In the course of this analysis, we additionally showed the limitations of statistical analysis, especially when comparing across countries. Furthermore, it became obvious that data quality and quantity decreases from industrialized to emerging countries.

- As a counterpart of the statistical analysis, we took a look at three victimization surveys. Due to different methodologies across the surveys studied, the comparability of the data was limited. Furthermore, these surveys mainly focus on vehicle theft and consider only partly theft from vehicle. The aforementioned limitations led us to implement and conduct our own survey in Germany, the USA and Mexico. This way, we had comparable results focusing on several vehicle-related crimes, fear of crime and security systems fighting vehicle-related crime. The occurrence of crime without violence and bodily injury is rated similarly across our three countries. As soon as violence is involved, Mexicans are more fearful than Germans and Americans. Our results additionally showed that in Germany and the USA females are significantly more worried of becoming a victim of violent car-related crime than males. Furthermore, Mexicans show a higher demand for security systems. However, the importance of security systems compared to other criteria when purchasing a car is nearly similar in all countries, namely less important.

- The results from both the survey and statistical analysis can be used to get an (international) overview of the development and trends regarding vehicle-related crime.

$R Q$ 1.2: How can we identify tailored automotive security functions in a structured way?

- We suggested a methodology, namely SAIAS, which is an approach to identify automotive security functions in a structured way. SAIAS combines crime scripts with the 25 techniques of situational crime prevention. We additionally proposed a hierarchical classification of vehicle-related crime, which is based on the different levels of the script concept and forms an essential part of SAIAS. Additionally, we showed the suitability of SAIAS by applying SAIAS to developed crime scripts for specific vehicle-related crimes. We identified the following security functions.

- Cooperative home light

- Electronic decal

- Open door / window reminder

- Visual vehicle tracking

- Cooperative alarm systems

- Voice enabled crime detection

- SAIAS can be used by experts to identify automotive security functions in a structured way. 
Main research question 2: How can we evaluate the effectiveness of automotive security functions?

$R Q$ 2.1: How can we evaluate the effectiveness of fighting crime?

- Estimating the effectiveness of countermeasures to fight crime is not manageable a priori. We can only provide indications or expectations of whether a security function will effectively fight crime.

- We transferred existing evaluation results from similar security measures. To imply the expected effectiveness of the electronic decal (ED), we reviewed evaluation results from the physical decal. To evaluate the cooperative home light, we reviewed results evaluating the influence of (street) lighting on crime.

- We conducted a case study where participants experienced the CHL. Therefore, we implemented a real world animation of a specific scenario with the CHL. We also showed the electronic decal within our case study. The expected effectiveness of crime fighting was rated by participants. Moreover, participants also rated existing countermeasures so that we could estimate the expected improvement of both security functions.

- We interviewed experts to substantiate the expected effectiveness of the CHL and ED to fight crime. The ED was generally seen as a complement to existing countermeasures but not a replacement. Due to the singularity and novelty of the CHL, experts agreed that the effectiveness of the CHL cannot be reliably estimated without a larger field of study.

- We defined measurable criteria representing the effectiveness of the CHL and implemented a simulation environment to conduct simulations. We estimated a penetration rate of $50 \%$ of participating vehicles to achieve a reasonable effect for customers.

$R Q$ 2.2: How can we evaluate the effectiveness of reducing fear of crime?

- We reviewed existing evaluation results from the physical decal and the influence of (street) lighting on fear of crime. We used these results to draw conclusions about the effectiveness of the ED and CHL in reducing fear of crime. Both security functions provide the potential to reduce fear of crime.

- We further sought to estimate whether the ED and CHL reduce fear of crime within our customer survey. Both functions were rated as having a reducing effect on fear of crime.

$R Q$ 2.3: How can we evaluate customer acceptance of security functions? 
- We considered customer acceptance within our customer survey from an economic and usability perspective. We evaluated subjects' feedback towards security functions in general. Additionally, we focused on the acceptance of the CHL and ED.

\subsection{Future work}

This thesis addressed challenges related to automotive security functions. Despite the results of the thesis, there are still open issues and opportunities for further work.

- To gain understanding of vehicle-related crime, we focused on a macroscopic statistical and survey analysis. This way, we were able to compare crime development and characteristics of fear of crime across countries. However, we have seen that there are differences across countries. Hence, a microscopic analysis within each country by researchers and experts familiar with country-specific backgrounds in social, economical, legislative, technological and political circumstances is necessary to continue work on tailored security functions.

- We developed several crime scripts and applied SAIAS to identify security functions, and thus showed the suitability of SAIAS. Nevertheless, we see potential to identify further security functions. Ideally, researchers and experts from involved domains apply SAIAS in collaboration. An initiator, e.g., from industry, research or government, pursuing the goal of introducing security functions, needs to bring experts together. The hierarchical categorization of vehicle-related crime can be used to identify appropriate participants. Due to the variety of vehicle-related crimes, participants need to be involved according to their knowledge covering the specific crime script at the track level. For example, experts exist who focus on circumventing electronic immobilizers. However, they neglect the aftermath of vehicle thefts, such as dealing with stolen vehicles or parts. Other experts and researchers concentrate for example on the preparation of specific crimes or the organizational structures. In a nutshell, a close collaboration of technologists, criminologists and social scientists may be highly helpful.

- We showed the suitability of SAIAS to identify security functions. Nevertheless, we think that SAIAS could be further extended by involving economic factors. That means estimating economic requirements and commitments for each countermeasure, providing the opportunity to decide on further implementations. Additionally, involving possible counter-attacks by offenders is also imaginable. This however has to be treated with care to avoid a never-ending back and forth between security functions and possible counter-attacks by offenders.

- We designed two security functions, namely the electronic decal and the cooperative home light and showed the feasibility of implementation. However, these security functions depend only partly on series technologies. Therefore, further research on core technologies needs to be undertaken. For example, V2V communication has not been introduced yet, and thus, it forms an unknown variable despite a lot of research and indeed 
field trials having been carried out. Furthermore, reliable driver positioning, e.g. with the help of smartphones, forms a wide research field as well.

- The expected effectiveness at fighting crime and reducing fear of crime was evaluated for both security functions by transferring existing evaluation results, conducting a survey and interviewing experts. For the customer survey, our sample was made up of Volkswagen employees. They were widely distributed according to their sociodemographic status and their position within the company but they represented best case German citizens. Hence, our (expected) effectiveness estimation can be seen as not more than a trend for Germany. Conducting the same survey in other countries, such as USA and Mexico, would provide an interesting research topic. This way, we could see whether trends from our online surveys are confirmed or not. Furthermore, to estimate the effectiveness of a security function to fight crime requires real world implementation. Additionally, a long-term use of the security function needs to be supported to gather sufficient and especially detailed data to conduct a statistical analysis. The time frame would ideally cover several consecutive years in order to be able to identify trends.

- We also considered customer acceptance within our survey. Hence, considering customer feedback for further development of both security functions would be reasonable. For example, we suggested three (de)activation methods for the electronic decal, with all three methods having proponents and opponents. Therefore, a mixed (de)activation approach seems to be the best solution satisfying a wider range of customer demands. Different modes, such as a holiday mode, provide higher flexibility for customers. When the vehicle remains unused for a longer period because of holiday, (de)activating the electronic decal via a schedule provides a favorable approach. However, for daily use, the smartphone or key (de)activation seems to be more reasonable. Intelligently combining our proposed (de)activation methods and extending them with further identification characteristics, such as biometrics, may increase the robustness, and thus acceptance of the electronic decal.

- To estimate the effectiveness of crime fighting and reducing fear of crime, we suggested within this thesis making use of simulations. Thus, a definition of measurable criteria representing the expected effectiveness for a given security function is necessary. We showed this approach exemplarily for the cooperative home light. Consequently, an evaluation of the electronic decal with the help of simulation provides potential for future research. A possible measurable criterion is the time taken before a stolen vehicle is detected by a police vehicle, i.e., a police vehicle receiving the stolen vehicle message. Additionally, the number of police vehicles receiving the message during the route describes a possible criterion. A comprehensive framework, such as VSimRTI [211], which was designed to couple different simulators, can be used as a simulation environment by coupling a traffic simulator, such as SUMO [212] with a communication simulator, such as NS3 [213]. A specific path of the stolen vehicle is predefined and the number of police vehicles as well as other traffic is modeled with different penetration rates to simulate different traffic densities. Furthermore, agent-based modeling [138] might be considered as a further means of assessing the possible effect of (specific) security functions on crime. 
- Privacy and IT-security, which were not addressed in this thesis, form crucial aspects for security functions. Neglecting these elements can lead to serious malfunctions and customer rejection of security functions. Since cases from other domains also demand privacy and IT-security, especially those based on V2V communication, these issues are widely considered. Nevertheless, there are still blind spots and so research on privacy and IT-security needs to be continued involving security functions.

\subsection{Conclusion}

This work has provided a solid understanding of the role of security functions in the automotive field. Based on our knowledge of vehicle-related crime, which was set out in the beginning of this work, we made use of our suggested methodology to identify tailored security functions in a structured way, and thus have shown the suitability of this methodology. We further showed the feasibility of security functions specifically for the electronic decal and the cooperative home light. Moreover, we tackled the challenge of evaluating security functions.

In our opinion the evaluation of security functions forms the main challenge relating to the development. An evaluation targeting the effectiveness of fighting crime can only be conducted retrospectively. The security function has to be implemented, deployed and crime statistics covering the targeted crime have to be analyzed. Other approaches only provide an expected effectiveness.

The estimation of an expected effectiveness also comes with challenges. Due to ethical constraints, threatening with violence, attacking or even involving test persons in real crimes is irresponsible. Additionally, implementing each security function and conducting case studies under real conditions comes with high financial costs, especially relating to V2V communication where a number of vehicles are necessary to achieve satisfying results. Therefore, we transferred results from similar security measures, conducted surveys and interviewed experts to estimate the (expected) effectiveness. Additionally, we defined measurable criteria for our security functions representing factors of effectiveness, and thus, provided the opportunity to conduct simulations. These evaluation steps provided solid findings and first trends about the (expected) effectiveness for the electronic decal, the cooperative home light and also for security functions in general.

From the technological point of view, security functions are without doubt realizable with comparable effort to other assistance and infotainment functions from the automotive field. However, security functions seem to generally play a secondary role and are less important for customers compared to other functions. This small importance was identified across all the countries we surveyed, despite noticeable differences in crime and fear of crime. It seems unlikely that customers are willing to pay high surcharges for security functions and to undertake additional actions in daily life. Hence, security functions lack convincing business cases, and thus, they will not become a driver for the introduction of new technologies in the automotive field, such as V2V communication. Consequently, generating synergies with existing 
technologies in cooperation with assistance or infotainment functions will be necessary when developing security functions.

Furthermore, there is a fine line between tangibility of security and annoyance by security functions. Caution is required so that security functions are not associated by potential users with additional effort, constraints and responsibilities that disturb their daily life. Hence, security functions ideally need to be integrated into daily operations to reduce the risk of alienating users.

A further fine line arises with improved security. Security functions aim to increase the effort needed by offenders to gain benefit from their crimes. Consequently, improved security may bring human beings more into the focus of attackers and increase the danger of bodily attacks and injuries. Hence, finding a balanced trade-off between security on the one hand and protection of persons on the other hand needs to be kept in mind.

In our opinion, automotive security functions provide the potential to complement existing countermeasures to fight crime and to reduce fear of crime. The key to successfully tackling vehicle-related crime is the collaboration of a wide spectrum of measures from different disciplines where security functions have the potential to make their contribution. Additionally, as soon as a technology is established, and is widely available in vehicles and familiar to users, vehicle manufacturers will look for further functions to stand out from competitors to achieve a unique selling point and improve the brand image. Security functions will provide an opportunity to fill this gap. 



\section{Appendix}

\section{Abbreviations}

A

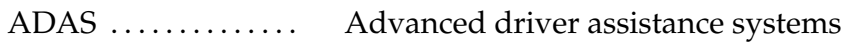

AAS .............. (Aggravated) assault

\section{B}

BCS

BUR

British Crime Survey

BHL

Burglary

Basic home light

C

$\mathrm{CE}$

$\mathrm{CHF}$

Consumer electronics

CHL

Coming home function

CSEW

Cooperative home light

Crime Survey for England and Wales

E

ECU

Electronic control unit

ED

Electronic decal

EHL

Extended home light

G

GUI

Graphical user interface

H

H-Test

Kruskal-Wallis-Test

I

ICVS

International Crime Victims Survey

L

LHF

Leaving home function

M

MO

Modus operandi

MUR

Murder

MVC

Model-view-controller 
N

NCVS

NFC

O

OCU

\section{P}

PCC

PD

R

RCP

ROB

\section{$S$}

SAIAS

SCP

SEX

$\mathrm{T}$

TFV

THE

\section{U}

U-Test

USA

UWB

V

V2I

V2V

V2X

VIN

VAN

VRC

VTH

VTS

VTV

W

WSRC
National Crime Victimization Survey

Near field communication

On-board communication unit

Pearson correlation coefficient

Physical decal

Rational Choice Perspective

Robbery

Structured Approach to identify automotive security functions Situational Crime Prevention

Sexual offense

Theft from vehicle

Larceny / theft

Mann-Whitney-U-Test

United States of America

Ultra-wideband

Vehicle-to-infrastructure

Vehicle-to-vehicle

Vehicle-to-X

Vehicle identification number

Vandalism

Vehicle-related crime

Vehicle theft

Vehicle tracking system

Vandalism to vehicle

Wireless short range communication 


\section{Appendix}

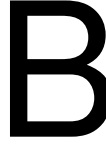

\section{Questionnaires}

\section{B.1. Questionnaire for online survey in Germany, USA and Mexico (English version)}

\section{Survey to research aspects of car related crime}

Dear Madam or Sir

As part of my thesis, I developed a survey to research aspects of car related crime. I would like to clarify that the treatment of this survey is anonymous and there is no opportunity to identify you. Your responses will be treated confidentially and used only for my thesis.

To obtain valuable results, it is very important that you answer the entire questionnaire and each question carefully. It will take about 10 minutes to answer the questions.

\section{Thank you for your contribution}


1. Do you have or regularly drive a car?

yes

- no

2. What brand is this car?

[Please choose]

3. What model year is this car?

[Please choose]

4. What model is this car? (e.g. Yukon, Escalade)

5. Which type(s) of car insurance(s) do you have for this car?

third party liability coverage

car theft

theft of car parts

comprehensive coverage

none 
6. When buying a new car, how important are the following criteria for your decision?

price and maintenance costs

not important

at all

very

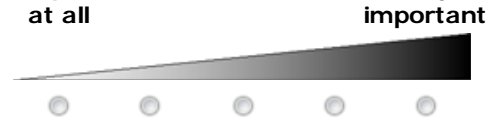

eco friendliness

design

driving dynamics

comfort

quality

safety systems to avoid / mitigate accidents

(e.g. airbags)

security systems against crimes (e.g.

immobilizer, electronic tracking via GPS)

fuel consumption

off-road capability

infotainment equipment (e.g. audio,

navigation system, cell phone integration)

everyday usability

7. In your opinion, how often do the following crimes occur in the U.S.?

murder

rape / sexual assault

assault / attack

burglary

mugging / robbery

car related crimes

vandalism

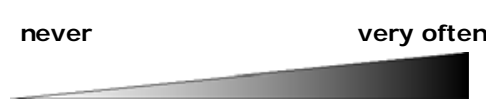

\section{How worried are you of becoming a victim of car related crimes?}


9. How frequently have you felt worried of becoming a victim of car related crimes during the previous month?

not once in the last month once or twice in the past month once or twice in the past week three or four times in the past week every day

10. How worried are you of becoming a victim of following car related crimes?

car theft

theft of car parts (e.g. tires, mirrors, radio)

theft from car (valuables, e.g. bag, laptop)

car keys being stolen

scratches

destroyed parts (e.g. mirror, lights, tires)

arson of car

assault while leaving/entering car

carjacking

\section{Were you already a victim of the following car related crimes?}

car theft

theft of car parts (e.g. tires, mirrors, radio)

theft from car (valuables, e.g. bag, laptop)

car keys being stolen

scratches

destroyed parts (e.g. mirror, lights, tires)

arson of car

assault while leaving/entering car

carjacking 
12. Please judge following statements

strongly disagree

strongly agree

"I feel confident to influence whether or not I become a victim of car related crime."

"I use security systems to control whether or not I become a victim of car related crimes."

"More and better security systems are necessary to reduce car related crimes in the U.S.."

\section{Please judge following statements}

strongly disagree

strongly agree

"If my car is stolen, I want my car to be recovered."

"Regarding car related crimes, police is doing a very good job."

"If my car is stolen, police will be able to bring it back to me."

\section{Please select your gender?}

female

male

\section{What is your year of birth?}

[Please choose]

\section{Please feel free to leave any comments}

\section{Thank you for your time and contribution}




\section{B.2. Questionnaire for face-to-face survey in Germany}

\begin{tabular}{|l|}
\hline Vom Versuchsleiter auszufüllen \\
Gruppe A: $1-7,10-15,8-9,16-17$
\end{tabular}

\section{Soziodemographische Fragen}

\subsection{Geschlecht (DE01)}
$\square$ weiblich
$\square$ männlich

1.2 Geburtsjahr (DE02)

Jahr:

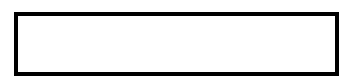

1.3 Angaben zum Beschäftigungsbereich (DE03)

$\square$ Produktion

(z.B. Fertigung, Montage etc.)

$\square$ Produktionsnahe Bereiche

(z.B. Logistik, Instandsetzung, Arbeitsvorbereitung QS etc.)

$\square$ Einkauf, Vertrieb, Marketing

$\square$ Forschung und Entwicklung

$\square$ Interne Dienstleistungen

(z.B. IT, Finanzwesen, Personal, Controlling, Kantine etc.)

$\square$ Sonstiges:

1.4 Welches Fahrzeug fahren Sie derzeit privat am häufigsten (bitte nur 1 Fahrzeug eintragen!)?

Marke (DE04):

Modell (DE05):

Baujahr (DE06):

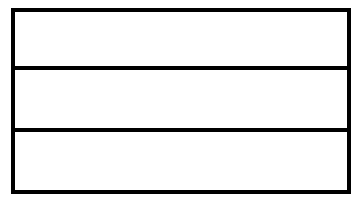

1.5 Zugehörigkeit des Fahrzeugs (DE07)
$\square$ WA-Leasing
$\square$ Privat-Leasing
$\square$ Dienstwagen
$\square$ Privatbesitz

1.6 Ist das Fahrzeug gegen Diebstahl versichert? (DE08)
$\square$ ja
$\square$ nein 
1.7 Wie bewerten Sie Ihre Faszination für technische Geräte? (DE09)

\begin{tabular}{|c|c|c|c|c|c|c|c|c|c|c|c|c|c|c|}
\hline $\begin{array}{c}\text { Überhaupt } \\
\text { nicht } \\
\text { vorhanden }\end{array}$ & \multicolumn{3}{|c|}{$\begin{array}{c}\text { Eher nicht } \\
\text { vorhanden }\end{array}$} & \multicolumn{3}{|c|}{ Neutral } & \multicolumn{3}{c|}{$\begin{array}{c}\text { Eher } \\
\text { vorhanden }\end{array}$} & \multicolumn{3}{|c|}{$\begin{array}{c}\text { Sehr } \\
\text { vorhanden }\end{array}$} \\
\hline 1 & 2 & 3 & 4 & 5 & 6 & 7 & 8 & 9 & 10 & 11 & 12 & 13 & 14 & 15 \\
\hline
\end{tabular}

1.8 Wie bewerten Sie die Nutzung des Smartphones als Fahrzeugschlüssel? (DE10)

\begin{tabular}{|c|c|c|c|c|c|c|c|c|c|c|c|c|c|c|}
\hline \multicolumn{2}{|c|}{$\begin{array}{c}\text { Überhaupt } \\
\text { nicht attraktiv }\end{array}$} & \multicolumn{3}{|c|}{$\begin{array}{c}\text { Eher nicht } \\
\text { attraktiv }\end{array}$} & \multicolumn{3}{|c|}{ Neutral } & \multicolumn{4}{|c|}{ Eher attraktiv } & \multicolumn{3}{|c|}{ Sehr attraktiv } \\
\hline 1 & 2 & 3 & 4 & 5 & 6 & 7 & 8 & 9 & 10 & 11 & 12 & 13 & 14 & 15 \\
\hline
\end{tabular}

1.9 Wie wichtig ist Ihnen ein Smartphone mit Internetzugang? (DE11)

\begin{tabular}{|c|c|c|c|c|c|c|c|c|c|c|c|c|c|c|}
\hline \multicolumn{2}{|c|}{$\begin{array}{c}\text { Überhaupt } \\
\text { nicht wichtig }\end{array}$} & \multicolumn{3}{|c|}{$\begin{array}{c}\text { Eher } \\
\text { unwichtig }\end{array}$} & \multicolumn{3}{c|}{ Neutral } & \multicolumn{3}{c|}{ Eher wichtig } & \multicolumn{3}{c|}{ Sehr wichtig } \\
\hline 1 & 2 & 3 & 4 & 5 & 6 & 7 & 8 & 9 & 10 & 11 & 12 & 13 & 14 & 15 \\
\hline
\end{tabular}

1.10 Wie wichtig ist Ihnen die Ausstattung Ihres Fahrzeugs mit neuen Technologien? (DE12)

\begin{tabular}{|c|c|c|c|c|c|c|c|c|c|c|c|c|c|c|}
\hline \multicolumn{2}{|c|}{$\begin{array}{c}\text { Überhaupt } \\
\text { nicht wichtig }\end{array}$} & \multicolumn{3}{|c|}{$\begin{array}{c}\text { Eher } \\
\text { unwichtig }\end{array}$} & \multicolumn{3}{c|}{ Neutral } & \multicolumn{3}{|c|}{ Eher wichtig } & \multicolumn{3}{|c|}{ Sehr wichtig } \\
\hline 1 & 2 & 3 & 4 & 5 & 6 & 7 & 8 & 9 & 10 & 11 & 12 & 13 & 14 & 15 \\
\hline
\end{tabular}

1.11 Wie wichtig wäre Ihnen, Ihr Fahrzeug nach einem Diebstahl wiederzubekommen? (DE13)

\begin{tabular}{|c|c|c|c|c|c|c|c|c|c|c|c|c|c|c|}
\hline \multicolumn{2}{|c|}{$\begin{array}{c}\text { Überhaupt } \\
\text { nicht wichtig }\end{array}$} & \multicolumn{3}{|c|}{$\begin{array}{c}\text { Eher } \\
\text { unwichtig }\end{array}$} & \multicolumn{3}{c|}{ Neutral } & \multicolumn{3}{|c|}{ Eher wichtig } & \multicolumn{3}{|c|}{ Sehr wichtig } \\
\hline 1 & 2 & 3 & 4 & 5 & 6 & 7 & 8 & 9 & 10 & 11 & 12 & 13 & 14 & 15 \\
\hline
\end{tabular}

1.12 Wie bewerten Sie Ihren Spaß an der Auseinandersetzung mit Technik? (DE14)

\begin{tabular}{|c|c|c|c|c|c|c|c|c|c|c|c|c|c|c|}
\hline $\begin{array}{c}\text { Überhaupt } \\
\text { nicht } \\
\text { vorhanden }\end{array}$ & \multicolumn{3}{|c|}{$\begin{array}{c}\text { Eher nicht } \\
\text { vorhanden }\end{array}$} & \multicolumn{4}{|c|}{ Neutral } & \multicolumn{3}{|c|}{$\begin{array}{c}\text { Eher } \\
\text { vorhanden }\end{array}$} & \multicolumn{3}{|c|}{$\begin{array}{c}\text { Sehr } \\
\text { vorhanden }\end{array}$} \\
\hline 1 & 2 & 3 & 4 & 5 & 6 & 7 & 8 & 9 & 10 & 11 & 12 & 13 & 14 & 15 \\
\hline
\end{tabular}




\subsection{Kennen Sie ...}
1.14.1 ... die Leaving Home Funktion? (DE15)
$\square \mathrm{ja}$
$\square$ nein

Beim Öffnen des Fahrzeugs mit der Funkfernbedienung (Leaving Home) werden das Abblendlicht, die Umfeldleuchten in den Außenspiegelgehäusen, das Schlusslicht der Heckleuchten und die Kennzeichenbeleuchtung eingeschaltet.
1.14.2 ... das dynamische Kurvenlicht? (DE16)
$\square$ ja
$\square$ nein

Ab einer Fahrgeschwindigkeit von $10 \mathrm{~km} / \mathrm{h}$ folgt das dynamische Kurvenlicht dem Verlauf von Fahrbahnkurven mit einem maximalen Schwenkwinkel von $15^{\circ}$. Die Scheinwerfer leuchten quasi in die Kurve hinein.
1.14 .3
... das statische Abbiegelicht? (DE17)
$\square$ ja
$\square$ nein

Das statische Abbiegelicht dient dazu, den Abbiegebereich auszuleuchten. Bei eingeschlagenem Lenkrad oder gesetztem Blinker wird das Licht automatisch an Kreuzungen oder Einmündungen unterhalb von $40 \mathrm{~km} / \mathrm{h}$ zugeschaltet.

\subsection{4 ... Fahrzeug-zu-Fahrzeug Kommunikation? (DE18) $\square$ ja $\square$ nein}

Mit Fahrzeug-zu-Fahrzeug Kommunikation bezeichnet man den drahtlosen Austausch von Informationen und Daten zwischen Kraftfahrzeugen.

1.14.5 ... die elektronische Wegfahrsperre? (DE19) $\quad \square$ ja $\quad \square$ nein

Die Wegfahrsperre ist eine elektronische Diebstahlsicherung. Nach dem Abziehen des Zündschlüssels wird sie aktiv und verhindert über das Motorsteuergerät, dass der Wagen durch Unbefugte gestartet werden kann.

\section{Bitte um Rücksprache mit Versuchsleiter}




\section{Fragen zur Leaving Home Funktion}

Eigenes Fahrzeug schaltet Licht beim Öffnen per

Funkschlüssel ein

2.1 Wie bewerten Sie die Eignung der Leaving Home Funktion Ihre Angst vor Übergriffen und Überfällen auf Ihrem Weg zum Fahrzeug zu reduzieren?

\begin{tabular}{|c|c|c|c|c|c|c|c|c|c|c|c|c|c|c|}
\hline $\begin{array}{c}\text { Überhaupt } \\
\text { nicht geeignet }\end{array}$ & \multicolumn{2}{|c|}{$\begin{array}{c}\text { Eher nicht } \\
\text { geeignet }\end{array}$} & \multicolumn{3}{|c|}{ Neutral } & \multicolumn{3}{|c|}{ Eher geeignet } & \multicolumn{3}{|c|}{ Sehr geeignet } \\
\hline 1 & 2 & 3 & 4 & 5 & 6 & 7 & 8 & 9 & 10 & 11 & 12 & 13 & 14 & 15 \\
\hline
\end{tabular}

2.2 Wie bewerten Sie die Eignung der Leaving Home Funktion einen potentiellen Angreifer von einem Übergriff auf den Fahrer auf dem Weg zum Fahrzeug abzuschrecken?

\begin{tabular}{|c|c|c|c|c|c|c|c|c|c|c|c|c|c|c|}
\hline \multicolumn{2}{|c|}{$\begin{array}{c}\text { Überhaupt } \\
\text { nicht geeignet }\end{array}$} & \multicolumn{3}{|c|}{$\begin{array}{c}\text { Eher nicht } \\
\text { geeignet }\end{array}$} & \multicolumn{3}{c|}{ Neutral } & \multicolumn{3}{|c|}{ Eher geeignet } & \multicolumn{3}{|c|}{ Sehr geeignet } \\
\hline 1 & 2 & 3 & 4 & 5 & 6 & 7 & 8 & 9 & 10 & 11 & 12 & 13 & 14 & 15 \\
\hline
\end{tabular}

2.3 Wie bewerten Sie die Eignung der Leaving Home Funktion Ihr Sicherheitsgefühl auf dem Weg zum Fahrzeug zu erhöhen?

\begin{tabular}{|c|c|c|c|c|c|c|c|c|c|c|c|c|c|c|}
\hline $\begin{array}{c}\text { Überhaupt } \\
\text { nicht geeignet }\end{array}$ & \multicolumn{3}{|c|}{$\begin{array}{c}\text { Eher nicht } \\
\text { geeignet }\end{array}$} & \multicolumn{3}{|c|}{ Neutral } & \multicolumn{3}{|c|}{ Eher geeignet } & \multicolumn{3}{|c|}{ Sehr geeignet } \\
\hline 1 & 2 & 3 & 4 & 5 & 6 & 7 & 8 & 9 & 10 & 11 & 12 & 13 & 14 & 15 \\
\hline
\end{tabular}

2.4 Wie bewerten Sie die Eignung der Leaving Home Funktion Übergriffe und Überfälle auf den Fahrer auf dem Weg zum Fahrzeug zu reduzieren?

\begin{tabular}{|c|c|c|c|c|c|c|c|c|c|c|c|c|c|c|}
\hline \multicolumn{2}{|c|}{$\begin{array}{c}\text { Überhaupt } \\
\text { nicht geeignet }\end{array}$} & \multicolumn{2}{|c|}{$\begin{array}{c}\text { Eher nicht } \\
\text { geeignet }\end{array}$} & \multicolumn{4}{|c|}{ Neutral } & \multicolumn{3}{c|}{ Eher geeignet } & \multicolumn{3}{|c|}{ Sehr geeignet } \\
\hline 1 & 2 & 3 & 4 & 5 & 6 & 7 & 8 & 9 & 10 & 11 & 12 & 13 & 14 & 15 \\
\hline
\end{tabular}

Haben Sie Kommentare / Anmerkungen / Feedback / Kritik I Verbesserungsvorschläge ... zur Leaving Home Funktion? 


\section{Andere Fahrzeuge helfen beim Ausleuchten des Weges zum \\ 3 Fragen zur Kooperativen Home Funktion \\ eigenen Fahrzeug}

3.1 Wie bewerten Sie die Eignung der Kooperativen Home Funktion Ihre Angst vor Übergriffen und Überfällen auf Ihrem Weg zum Fahrzeug zu reduzieren?

\begin{tabular}{|c|c|c|c|c|c|c|c|c|c|c|c|c|c|c|}
\hline \multicolumn{2}{|c|}{$\begin{array}{c}\text { Überhaupt } \\
\text { nicht geeignet }\end{array}$} & \multicolumn{2}{|c|}{$\begin{array}{c}\text { Eher nicht } \\
\text { geeignet }\end{array}$} & \multicolumn{3}{|c|}{ Neutral } & \multicolumn{3}{|c|}{ Eher geeignet } & \multicolumn{3}{|c|}{ Sehr geeignet } \\
\hline 1 & 2 & 3 & 4 & 5 & 6 & 7 & 8 & 9 & 10 & 11 & 12 & 13 & 14 & 15 \\
\hline
\end{tabular}

3.2 Wie bewerten Sie die Eignung der Kooperativen Home Funktion einen potentiellen Angreifer von einem Übergriff auf den Fahrer auf dem Weg zum Fahrzeug abzuschrecken?

\begin{tabular}{|c|c|c|c|c|c|c|c|c|c|c|c|c|c|c|}
\hline \multicolumn{2}{|c|}{$\begin{array}{c}\text { Überhaupt } \\
\text { nicht geeignet }\end{array}$} & \multicolumn{3}{|c|}{$\begin{array}{c}\text { Eher nicht } \\
\text { geeignet }\end{array}$} & \multicolumn{3}{|c|}{ Neutral } & \multicolumn{3}{|c|}{ Eher geeignet } & \multicolumn{3}{|c|}{ Sehr geeignet } \\
\hline 1 & 2 & 3 & 4 & 5 & 6 & 7 & 8 & 9 & 10 & 11 & 12 & 13 & 14 & 15 \\
\hline
\end{tabular}

3.3 Wie bewerten Sie die Eignung der Kooperativen Home Funktion Ihr Sicherheitsgefühl auf dem Weg zum Fahrzeug zu erhöhen?

\begin{tabular}{|c|c|c|c|c|c|c|c|c|c|c|c|c|c|c|}
\hline \multicolumn{2}{|c|}{$\begin{array}{c}\text { Überhaupt } \\
\text { nicht geeignet }\end{array}$} & \multicolumn{2}{|c|}{$\begin{array}{c}\text { Eher nicht } \\
\text { geeignet }\end{array}$} & \multicolumn{3}{|c|}{ Neutral } & \multicolumn{3}{|c|}{ Eher geeignet } & \multicolumn{3}{|c|}{ Sehr geeignet } \\
\hline 1 & 2 & 3 & 4 & 5 & 6 & 7 & 8 & 9 & 10 & 11 & 12 & 13 & 14 & 15 \\
\hline
\end{tabular}

3.4 Wie bewerten Sie die Eignung der Kooperativen Home Funktion Übergriffe und Überfälle auf den Fahrer auf dem Weg zum Fahrzeug zu reduzieren?

\begin{tabular}{|c|c|c|c|c|c|c|c|c|c|c|c|c|c|c|}
\hline \multicolumn{2}{|c|}{$\begin{array}{c}\text { Überhaupt } \\
\text { nicht geeignet }\end{array}$} & \multicolumn{2}{|c|}{$\begin{array}{c}\text { Eher nicht } \\
\text { geeignet }\end{array}$} & \multicolumn{3}{|c|}{ Neutral } & \multicolumn{3}{|c|}{ Eher geeignet } & \multicolumn{3}{|c|}{ Sehr geeignet } \\
\hline 1 & 2 & 3 & 4 & 5 & 6 & 7 & 8 & 9 & 10 & 11 & 12 & 13 & 14 & 15 \\
\hline
\end{tabular}


3.5 Wie bewerten Sie Ihre Bereitschaft anderen Teilnehmern Ihr Auto zum kooperativen Ausleuchten zur Verfügung zu stellen?

\begin{tabular}{|c|c|c|c|c|c|c|c|c|c|c|c|c|c|c|}
\hline \multicolumn{3}{|c|}{$\begin{array}{l}\text { Überhaupt } \\
\text { nicht bereit }\end{array}$} & \multicolumn{3}{|c|}{$\begin{array}{c}\text { Eher nicht } \\
\text { bereit }\end{array}$} & \multicolumn{3}{|c|}{ Neutral } & \multicolumn{3}{|c|}{ Eher bereit } & \multicolumn{3}{|c|}{ Sehr bereit } \\
\hline 1 & 2 & 3 & 4 & 5 & 6 & 7 & 8 & 9 & 10 & 11 & 12 & 13 & 14 & 15 \\
\hline
\end{tabular}

3.6 Wie bewerten Sie Ihre Bereitschaft ein Smartphone zur Realisierung der Kooperativen Home Funktion zu nutzen?

\begin{tabular}{|c|c|c|c|c|c|c|c|c|c|c|c|c|c|c|}
\hline \multicolumn{2}{|c|}{$\begin{array}{c}\text { Überhaupt } \\
\text { nicht bereit }\end{array}$} & \multicolumn{3}{|c|}{$\begin{array}{c}\text { Eher nicht } \\
\text { bereit }\end{array}$} & \multicolumn{3}{c|}{ Neutral } & \multicolumn{3}{c|}{ Eher bereit } & \multicolumn{3}{c|}{ Sehr bereit } \\
\hline 1 & 2 & 3 & 4 & 5 & 6 & 7 & 8 & 9 & 10 & 11 & 12 & 13 & 14 & 15 \\
\hline
\end{tabular}

3.7 Ein Energie-Management der Kooperativen Home Funktion sorgt dafür, dass Sie ihr Fahrzeug jederzeit starten können und die Batterie nicht vollständig entladen wird. Jedoch wird die Lebensdauer der Batterie auf längere Sicht beeinträchtigt und erfordert ein früheres Austauschen.

Wie bewerten Sie in diesem Fall Ihre Bereitschaft anderen Teilnehmern Ihr Auto zum kooperativen Ausleuchten zur Verfügung zu stellen?

\begin{tabular}{|c|c|c|c|c|c|c|c|c|c|c|c|c|c|c|}
\hline \multicolumn{3}{|c|}{$\begin{array}{l}\text { Überhaupt } \\
\text { nicht bereit }\end{array}$} & \multicolumn{3}{|c|}{$\begin{array}{l}\text { Eher nicht } \\
\text { bereit }\end{array}$} & \multicolumn{3}{|c|}{ Neutral } & \multicolumn{3}{|c|}{ Eher bereit } & \multicolumn{3}{|c|}{ Sehr bereit } \\
\hline 1 & 2 & 3 & 4 & 5 & 6 & 7 & 8 & 9 & 10 & 11 & 12 & 13 & 14 & 15 \\
\hline
\end{tabular}

3.8 Da bei der Kooperativen Home Funktion die Lichtquellen häufiger ein- und ausgeschaltet werden wird die Lebensdauer der Leuchtmittel auf längere Sicht beeinträchtigt und erfordert ein früheres Austauschen.

Wie bewerten Sie in diesem Fall Ihre Bereitschaft anderen Teilnehmern Ihr Auto zum kooperativen Ausleuchten zur Verfügung zu stellen?

\begin{tabular}{|c|c|c|c|c|c|c|c|c|c|c|c|c|c|c|}
\hline \multicolumn{2}{|c|}{$\begin{array}{c}\text { Überhaupt } \\
\text { nicht bereit }\end{array}$} & \multicolumn{3}{|c|}{$\begin{array}{c}\text { Eher nicht } \\
\text { bereit }\end{array}$} & \multicolumn{3}{|c|}{ Neutral } & \multicolumn{3}{c|}{ Eher bereit } & \multicolumn{3}{c|}{ Sehr bereit } \\
\hline 1 & 2 & 3 & 4 & 5 & 6 & 7 & 8 & 9 & 10 & 11 & 12 & 13 & 14 & 15 \\
\hline
\end{tabular}

3.9 Welchen Aufpreis würden Sie maximal für die Kooperative Home Funktion bezahlen?

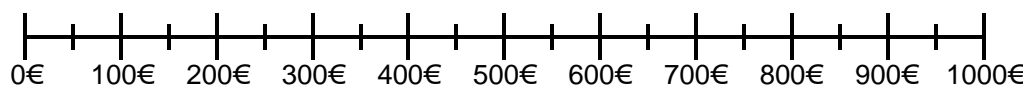


3.10 Welche Vorteile I Vorzüge haben Sie bei der Kooperative Home Funktion erkannt?

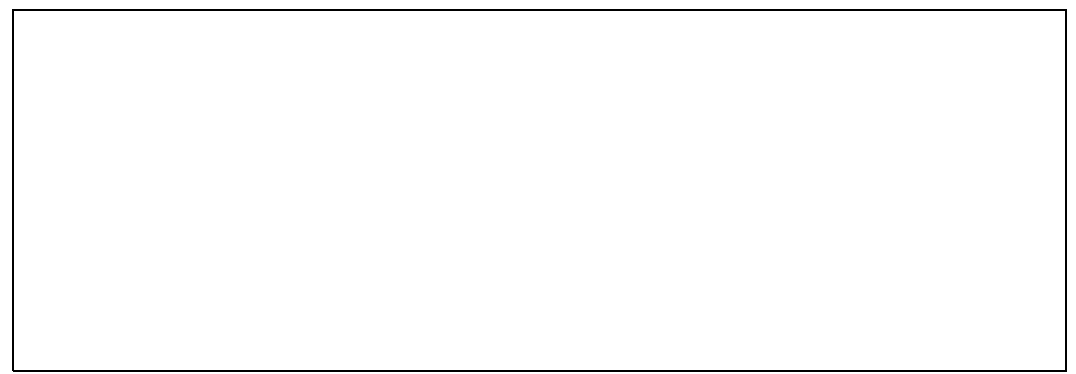

3.11 Welche Nachteile haben Sie bei der Kooperative Home Funktion erkannt?

3.12 Haben Sie Kommentare / Anmerkungen / Feedback / Kritik I Verbesserungsvorschläge ... zu der Kooperativen Home Funktion?

\section{Bitte um Rücksprache mit Versuchsleiter}




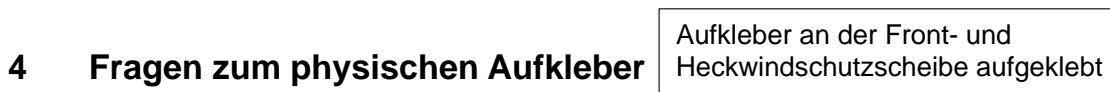

4.1 Wie bewerten Sie die Eignung des physischen Aufklebers die Angst des Besitzers vor Fahrzeugdiebstahl zu reduzieren?

\begin{tabular}{|c|c|c|c|c|c|c|c|c|c|c|c|c|c|c|}
\hline \multicolumn{3}{|c|}{$\begin{array}{c}\text { Überhaupt } \\
\text { nicht geeignet }\end{array}$} & \multicolumn{3}{|c|}{$\begin{array}{l}\text { Eher nicht } \\
\text { geeignet }\end{array}$} & \multicolumn{3}{|c|}{ Neutral } & \multicolumn{3}{|c|}{ Eher geeignet } & \multicolumn{3}{|c|}{ Sehr geeignet } \\
\hline 1 & 2 & 3 & 4 & 5 & 6 & 7 & 8 & 9 & 10 & 11 & 12 & 13 & 14 & 15 \\
\hline
\end{tabular}

4.2 Wie bewerten Sie die Eignung des physischen Aufklebers Fahrzeugdiebe abzuschrecken?

\begin{tabular}{|c|c|c|c|c|c|c|c|c|c|c|c|c|c|c|}
\hline \multicolumn{2}{|c|}{$\begin{array}{c}\text { Überhaupt } \\
\text { nicht geeignet }\end{array}$} & \multicolumn{2}{|c|}{$\begin{array}{c}\text { Eher nicht } \\
\text { geeignet }\end{array}$} & \multicolumn{3}{|c|}{ Neutral } & \multicolumn{3}{c|}{ Eher geeignet } & \multicolumn{3}{|c|}{ Sehr geeignet } \\
\hline 1 & 2 & 3 & 4 & 5 & 6 & 7 & 8 & 9 & 10 & 11 & 12 & 13 & 14 & 15 \\
\hline
\end{tabular}

4.3 Wie bewerten Sie die Eignung des physischen Aufklebers Ihr Sicherheitsgefühl vor Fahrzeugdiebstahl zu erhöhen?

\begin{tabular}{|c|c|c|c|c|c|c|c|c|c|c|c|c|c|c|}
\hline \multicolumn{3}{|c|}{$\begin{array}{c}\text { Überhaupt } \\
\text { nicht geeignet }\end{array}$} & \multicolumn{3}{|c|}{$\begin{array}{l}\text { Eher nicht } \\
\text { geeignet }\end{array}$} & \multicolumn{3}{|c|}{ Neutral } & \multicolumn{3}{|c|}{ Eher geeignet } & \multicolumn{3}{|c|}{ Sehr geeignet } \\
\hline 1 & 2 & 3 & 4 & 5 & 6 & 7 & 8 & 9 & 10 & 11 & 12 & 13 & 14 & 15 \\
\hline
\end{tabular}

4.4 Wie bewerten Sie die Eignung des physischen Aufklebers Fahrzeugdiebstahl zu reduzieren?

\begin{tabular}{|c|c|c|c|c|c|c|c|c|c|c|c|c|c|c|}
\hline \multicolumn{2}{|c|}{$\begin{array}{c}\text { Überhaupt } \\
\text { nicht geeignet }\end{array}$} & \multicolumn{3}{|c|}{$\begin{array}{c}\text { Eher nicht } \\
\text { geeignet }\end{array}$} & \multicolumn{3}{|c|}{ Neutral } & \multicolumn{3}{|c|}{ Eher geeignet } & \multicolumn{3}{|c|}{ Sehr geeignet } \\
\hline 1 & 2 & 3 & 4 & 5 & 6 & 7 & 8 & 9 & 10 & 11 & 12 & 13 & 14 & 15 \\
\hline
\end{tabular}

4.5 Wie bewerten Sie die Wahrscheinlichkeit eines gestohlenen Fahrzeugs mit Hilfe des physischen Aufklebers während der Fahrt von der Polizei entdeckt zu werden?

\begin{tabular}{|c|c|c|c|c|c|c|c|c|c|c|c|c|c|c|}
\hline $\begin{array}{c}\text { Völlig } \\
\text { unwahr- } \\
\text { scheinlich }\end{array}$ & \multicolumn{2}{|c|}{$\begin{array}{c}\text { Eher unwahr- } \\
\text { scheinlich }\end{array}$} & \multicolumn{4}{|c|}{ Neutral } & \multicolumn{3}{|c|}{$\begin{array}{c}\text { Eher } \\
\text { wahrscheinlich }\end{array}$} & \multicolumn{3}{|c|}{$\begin{array}{c}\text { Sehr } \\
\text { wahrscheinlich }\end{array}$} \\
\hline 1 & 2 & 3 & 4 & 5 & 6 & 7 & 8 & 9 & 10 & 11 & 12 & 13 & 14 & 15 \\
\hline
\end{tabular}


B. Questionnaires

4.6 Haben Sie Kommentare / Anmerkungen / Feedback / Kritik I Verbesserungsvorschläge ... zum physischen Aufkleber?

Bitte um Rücksprache mit Versuchsleiter 


\section{Versenden einer Nachricht „Ich bin ein gestohlenes Fahrzeug" per \\ 5 Fragen zum elektronischen Aufkleber \\ Fahrzeug zu Fahrzeug \\ Kommunikation an Polizeifahrzeuge \\ im näheren Umfeld}

5.1 Wie bewerten Sie die Eignung des elektronischen Aufklebers die Angst des Besitzers vor Fahrzeugdiebstahl zu reduzieren?

\begin{tabular}{|c|c|c|c|c|c|c|c|c|c|c|c|c|c|c|}
\hline \multicolumn{2}{|c|}{$\begin{array}{c}\text { Überhaupt } \\
\text { nicht geeignet }\end{array}$} & \multicolumn{3}{|c|}{$\begin{array}{c}\text { Eher nicht } \\
\text { geeignet }\end{array}$} & \multicolumn{3}{|c|}{ Neutral } & \multicolumn{3}{|c|}{ Eher geeignet } & \multicolumn{3}{|c|}{ Sehr geeignet } \\
\hline 1 & 2 & 3 & 4 & 5 & 6 & 7 & 8 & 9 & 10 & 11 & 12 & 13 & 14 & 15 \\
\hline
\end{tabular}

5.2 Wie bewerten Sie die Eignung des elektronischen Aufklebers Fahrzeugdiebe abzuschrecken?

\begin{tabular}{|c|c|c|c|c|c|c|c|c|c|c|c|c|c|c|}
\hline \multicolumn{2}{|c|}{$\begin{array}{c}\text { Überhaupt } \\
\text { nicht geeignet }\end{array}$} & \multicolumn{2}{|c|}{$\begin{array}{c}\text { Eher nicht } \\
\text { geeignet }\end{array}$} & \multicolumn{3}{|c|}{ Neutral } & \multicolumn{3}{|c|}{ Eher geeignet } & \multicolumn{3}{|c|}{ Sehr geeignet } \\
\hline 1 & 2 & 3 & 4 & 5 & 6 & 7 & 8 & 9 & 10 & 11 & 12 & 13 & 14 & 15 \\
\hline
\end{tabular}

5.3 Wie bewerten Sie die Eignung des elektronischen Aufklebers Ihr Sicherheitsgefühl vor Fahrzeugdiebstahl zu erhöhen?

\begin{tabular}{|c|c|c|c|c|c|c|c|c|c|c|c|c|c|c|}
\hline \multicolumn{2}{|c|}{$\begin{array}{c}\text { Überhaupt } \\
\text { nicht geeignet }\end{array}$} & \multicolumn{2}{|c|}{$\begin{array}{c}\text { Eher nicht } \\
\text { geeignet }\end{array}$} & \multicolumn{3}{|c|}{ Neutral } & \multicolumn{3}{|c|}{ Eher geeignet } & \multicolumn{3}{|c|}{ Sehr geeignet } \\
\hline 1 & 2 & 3 & 4 & 5 & 6 & 7 & 8 & 9 & 10 & 11 & 12 & 13 & 14 & 15 \\
\hline
\end{tabular}

5.4 Wie bewerten Sie die Eignung des elektronischen Aufklebers Fahrzeugdiebstahl zu reduzieren?

\begin{tabular}{|c|c|c|c|c|c|c|c|c|c|c|c|c|c|c|}
\hline \multicolumn{2}{|c|}{$\begin{array}{c}\text { Überhaupt } \\
\text { nicht geeignet }\end{array}$} & \multicolumn{2}{|c|}{$\begin{array}{c}\text { Eher nicht } \\
\text { geeignet }\end{array}$} & \multicolumn{3}{|c|}{ Neutral } & \multicolumn{3}{|c|}{ Eher geeignet } & \multicolumn{3}{|c|}{ Sehr geeignet } \\
\hline 1 & 2 & 3 & 4 & 5 & 6 & 7 & 8 & 9 & 10 & 11 & 12 & 13 & 14 & 15 \\
\hline
\end{tabular}

5.5 Wie bewerten Sie Ihre Akzeptanz bei Nutzung des elektronischen Aufklebers fälschlicherweise von der Polizei angehalten und kontrolliert zu werden?

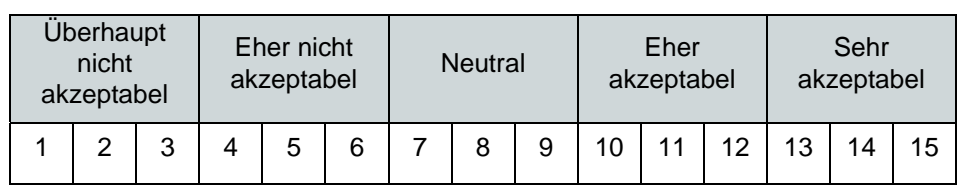


5.6 Wie bewerten Sie die Rückfallvariante per PIN-Eingabe an der HeadUnit, falls z.B. das Smartphone nicht zur Hand ist, der Akku leer ist oder das Fahrzeug verliehen wurde?

\begin{tabular}{|c|c|c|c|c|c|c|c|c|c|c|c|c|c|c|}
\hline $\begin{array}{c}\text { Überhaupt } \\
\text { nicht } \\
\text { akzeptabel }\end{array}$ & \multicolumn{2}{|c|}{$\begin{array}{c}\text { Eher nicht } \\
\text { akzeptabel }\end{array}$} & \multicolumn{3}{|c|}{ Neutral } & \multicolumn{3}{|c|}{$\begin{array}{c}\text { Eher } \\
\text { akzeptabel }\end{array}$} & \multicolumn{3}{|c|}{$\begin{array}{c}\text { Sehr } \\
\text { akzeptabel }\end{array}$} \\
\hline 1 & 2 & 3 & 4 & 5 & 6 & 7 & 8 & 9 & 10 & 11 & 12 & 13 & 14 & 15 \\
\hline
\end{tabular}

5.7 Würden Sie wollen, dass Ihr Fahrzeug bei einem Diebstahl kontinuierlich eine Nachricht an Polizeifahrzeuge versendet?

\begin{tabular}{|c|c|c|c|c|c|c|c|c|c|c|c|c|c|c|}
\hline \multicolumn{2}{|c|}{$\begin{array}{c}\text { Triff } \\
\begin{array}{c}\text { überhaupt } \\
\text { nicht zu }\end{array}\end{array}$} & \multicolumn{2}{|c|}{$\begin{array}{c}\text { Trifft eher } \\
\text { nicht zu }\end{array}$} & \multicolumn{3}{|c|}{ Neutral } & \multicolumn{4}{|c|}{ Trifft eher zu } & \multicolumn{3}{|c|}{ Trifft voll zu } \\
\hline 1 & 2 & 3 & 4 & 5 & 6 & 7 & 8 & 9 & 10 & 11 & 12 & 13 & 14 & 15 \\
\hline
\end{tabular}

5.8 Zur Erhöhung der Sendereichweite, würden Sie wollen, dass die Nachricht von anderen Fahrzeugen anonym empfangen und weitergesendet wird?

\begin{tabular}{|c|c|c|c|c|c|c|c|c|c|c|c|c|c|c|}
\hline $\begin{array}{c}\text { Triff } \\
\text { überhaupt } \\
\text { nicht zu }\end{array}$ & \multicolumn{2}{|c|}{$\begin{array}{c}\text { Trifft eher } \\
\text { nicht zu }\end{array}$} & \multicolumn{3}{|c|}{ Neutral } & \multicolumn{3}{|c|}{ Trifft eher zu } & \multicolumn{3}{|c|}{ Trifft voll zu } \\
\hline 1 & 2 & 3 & 4 & 5 & 6 & 7 & 8 & 9 & 10 & 11 & 12 & 13 & 14 & 15 \\
\hline
\end{tabular}


5.9 Wie bewerten Sie die Einschränkung im alltäglichen Gebrauch durch eine (De)Aktivierung des elektronischen Aufklebers per Zeitplan?

\begin{tabular}{|c|c|c|c|c|c|c|c|c|c|c|c|c|c|c|}
\hline \multicolumn{3}{|c|}{$\begin{array}{c}\text { Überhaupt } \\
\text { nicht } \\
\text { einschränkend }\end{array}$} & \multicolumn{3}{|c|}{$\begin{array}{c}\text { Eher nicht } \\
\text { einschränkend }\end{array}$} & \multicolumn{3}{|c|}{ Neutral } & \multicolumn{3}{|c|}{$\begin{array}{c}\text { Eher } \\
\text { einschränkend }\end{array}$} & \multicolumn{3}{|c|}{$\begin{array}{c}\text { Sehr } \\
\text { einschränkend }\end{array}$} \\
\hline 1 & 2 & 3 & 4 & 5 & 6 & 7 & 8 & 9 & 10 & 11 & 12 & 13 & 14 & 15 \\
\hline
\end{tabular}

5.10 Welchen Aufpreis würden Sie maximal für den elektronischen Aufkleber bei (De)Aktivierung per Zeitplan bezahlen?

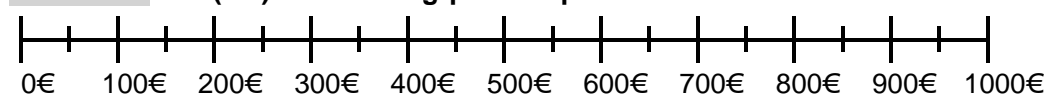

5.11 Welche Vorteile I Vorzüge haben Sie bei der (De)Aktivierung des elektronischen Aufklebers per Zeitplan erkannt?

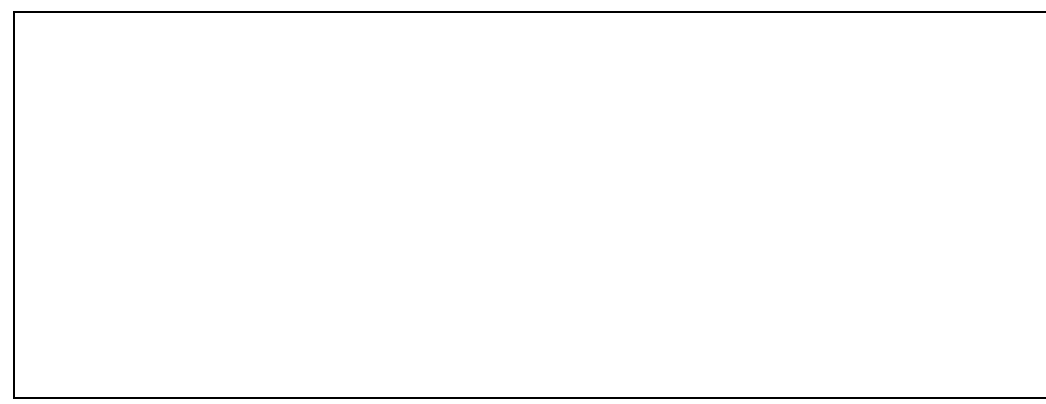

5.12 Welche Nachteile haben Sie bei der (De)Aktivierung des elektronischen Aufklebers per Zeitplan erkannt? 
5.13 Wie bewerten Sie die Einschränkung im alläglichen Gebrauch durch eine (De)Aktivierung des elektronischen Aufklebers per Schlüssel?

\begin{tabular}{|c|c|c|c|c|c|c|c|c|c|c|c|c|c|c|}
\hline \multicolumn{2}{|c|}{$\begin{array}{c}\text { Überhaupt } \\
\text { nicht } \\
\text { einschränkend }\end{array}$} & \multicolumn{3}{|c|}{$\begin{array}{c}\text { Eher nicht } \\
\text { einschränkend }\end{array}$} & \multicolumn{4}{|c|}{ Neutral } & \multicolumn{3}{|c|}{$\begin{array}{c}\text { Eher } \\
\text { einschränkend }\end{array}$} & \multicolumn{3}{|c|}{$\begin{array}{c}\text { Sehr } \\
\text { einschränkend }\end{array}$} \\
\hline 1 & 2 & 3 & 4 & 5 & 6 & 7 & 8 & 9 & 10 & 11 & 12 & 13 & 14 & 15 \\
\hline
\end{tabular}

5.14 Welchen Aufpreis würden Sie maximal für den elektronischen Aufkleber bei (De)Aktivierung per Schlüssel bezahlen?

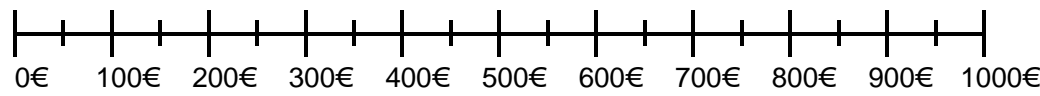

5.15 Welche Vorteile I Vorzüge haben Sie bei der (De)Aktivierung des elektronischen Aufklebers per Schlüssel erkannt?

5.16 Welche Nachteile haben Sie bei der (De)Aktivierung des elektronischen Aufklebers per Schlüssel erkannt? 
5.17 Wie bewerten Sie die Einschränkung im alltäglichen Gebrauch durch eine (De)Aktivierung des elektronischen Aufklebers per Smartphone?

\begin{tabular}{|c|c|c|c|c|c|c|c|c|c|c|c|c|c|c|}
\hline \multicolumn{2}{|c|}{$\begin{array}{c}\text { Überhaupt } \\
\text { nicht } \\
\text { einschränkend }\end{array}$} & \multicolumn{3}{|c|}{$\begin{array}{c}\text { Eher nicht } \\
\text { einschränkend }\end{array}$} & \multicolumn{4}{|c|}{ Neutral } & \multicolumn{3}{|c|}{$\begin{array}{c}\text { Eher } \\
\text { einschränkend }\end{array}$} & \multicolumn{3}{c|}{$\begin{array}{c}\text { Sehr } \\
\text { einschränkend }\end{array}$} \\
\hline 1 & 2 & 3 & 4 & 5 & 6 & 7 & 8 & 9 & 10 & 11 & 12 & 13 & 14 & 15 \\
\hline
\end{tabular}

5.18 Welchen Aufpreis würden Sie maximal für den elektronischen Aufkleber bei (De)Aktivierung per Smartphone bezahlen?

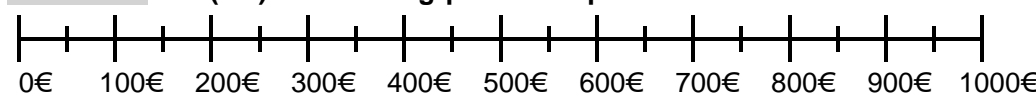

5.19 Welche Vorteile I Vorzüge haben Sie bei der (De)Aktivierung des elektronischen Aufklebers per Smartphone erkannt?

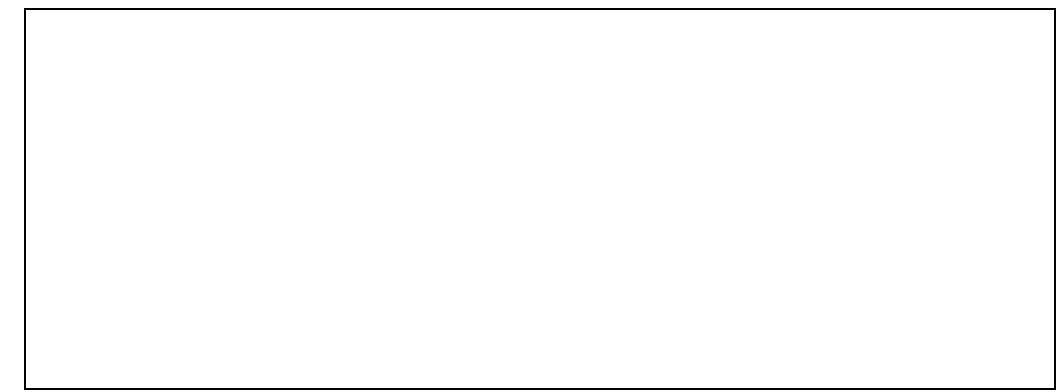

5.20 Welche Nachteile haben Sie bei der (De)Aktivierung des elektronischen Aufklebers per Smartphone erkannt? 
5.21 Vergeben Sie bitte für die (De)Aktivierungs-Methoden eine Rangfolge von 1 bis 3, wie Sie den elektronischen Aufkleber (de)aktivieren würden, wobei 1 für Ihren Favoriten steht.

\begin{tabular}{|l|l|}
\hline (De)Aktivierung per Zeitplan & \\
\hline (De)Aktivierung per Fahrzeugschlüssel & \\
\hline (De)Aktivierung per Smartphone & \\
\hline
\end{tabular}

5.22 Haben Sie Kommentare / Anmerkungen / Feedback / Kritik I Verbesserungsvorschläge ... zum elektronischen Aufkleber?

Bitte um Rücksprache mit Versuchsleiter 


\section{Fragen zu Security-Funktionen}

6.1 Wie bewerten Sie den Einsatz neuer Technologien im Fahrzeug zur Bekämpfung / Verhinderung / Aufklärung von fahrzeugbezogener Kriminalität?

\begin{tabular}{|c|c|c|c|c|c|c|c|c|c|c|c|c|c|c|}
\hline \multicolumn{2}{|c|}{$\begin{array}{c}\text { Überhaupt } \\
\text { nicht sinnvoll }\end{array}$} & \multicolumn{3}{|c|}{$\begin{array}{c}\text { Eher nicht } \\
\text { sinnvoll }\end{array}$} & \multicolumn{3}{|c|}{ Neutral } & \multicolumn{3}{c|}{ Eher sinnvoll } & \multicolumn{3}{|c|}{ Sehr sinnvoll } \\
\hline 1 & 2 & 3 & 4 & 5 & 6 & 7 & 8 & 9 & 10 & 11 & 12 & 13 & 14 & 15 \\
\hline
\end{tabular}

6.2 Wie bewerten Sie den Einsatz neuer Technologien im Fahrzeug zur Bekämpfung / Verhinderung / Aufklärung von folgenden Straftaten?

\begin{tabular}{|l|c|c|c|c|c|c|c|c|c|c|c|c|c|c|c|}
\hline & \multicolumn{2}{|c|}{$\begin{array}{c}\text { Überhaupt } \\
\text { nicht } \\
\text { sinnvoll }\end{array}$} & \multicolumn{2}{c|}{$\begin{array}{c}\text { Eher } \\
\text { nicht } \\
\text { sinnvoll }\end{array}$} & \multicolumn{3}{c|}{ Neutral } & \multicolumn{3}{|c|}{$\begin{array}{c}\text { Eher } \\
\text { sinnvoll }\end{array}$} & \multicolumn{3}{|c|}{$\begin{array}{c}\text { Sehr } \\
\text { sinnvoll }\end{array}$} \\
\hline Fahrzeugdiebstahl & 1 & 2 & 3 & 4 & 5 & 6 & 7 & 8 & 9 & 10 & 11 & 12 & 13 & 14 & 15 \\
\hline $\begin{array}{l}\text { Diebstahl von } \\
\text { Wertgegenständen } \\
\text { aus dem Fahrzeug }\end{array}$ & 1 & 2 & 3 & 4 & 5 & 6 & 7 & 8 & 9 & 10 & 11 & 12 & 13 & 14 & 15 \\
\hline $\begin{array}{l}\text { Diebstahl von } \\
\text { Fahrzeugteilen }\end{array}$ & 1 & 2 & 3 & 4 & 5 & 6 & 7 & 8 & 9 & 10 & 11 & 12 & 13 & 14 & 15 \\
\hline $\begin{array}{l}\text { Diebstahl des } \\
\text { Fahrzeug- } \\
\text { schlüssels }\end{array}$ & 1 & 2 & 3 & 4 & 5 & 6 & 7 & 8 & 9 & 10 & 11 & 12 & 13 & 14 & 15 \\
\hline $\begin{array}{l}\text { Kratzer am } \\
\text { Fahrzeug }\end{array}$ & 1 & 2 & 3 & 4 & 5 & 6 & 7 & 8 & 9 & 10 & 11 & 12 & 13 & 14 & 15 \\
\hline $\begin{array}{l}\text { Zerstörung von } \\
\text { Autoteilen }\end{array}$ & 1 & 2 & 3 & 4 & 5 & 6 & 7 & 8 & 9 & 10 & 11 & 12 & 13 & 14 & 15 \\
\hline $\begin{array}{l}\text { In Brand setzen } \\
\text { des Fahrzeugs }\end{array}$ & 1 & 2 & 3 & 4 & 5 & 6 & 7 & 8 & 9 & 10 & 11 & 12 & 13 & 14 & 15 \\
\hline $\begin{array}{l}\text { Überfall beim Ein- } \\
\text { IAussteigen }\end{array}$ & 1 & 2 & 3 & 4 & 5 & 6 & 7 & 8 & 9 & 10 & 11 & 12 & 13 & 14 & 15 \\
\hline
\end{tabular}


B. Questionnaires

6.3 Haben Sie abschließende Kommentare / Anmerkungen / Anregungen I Feedback?

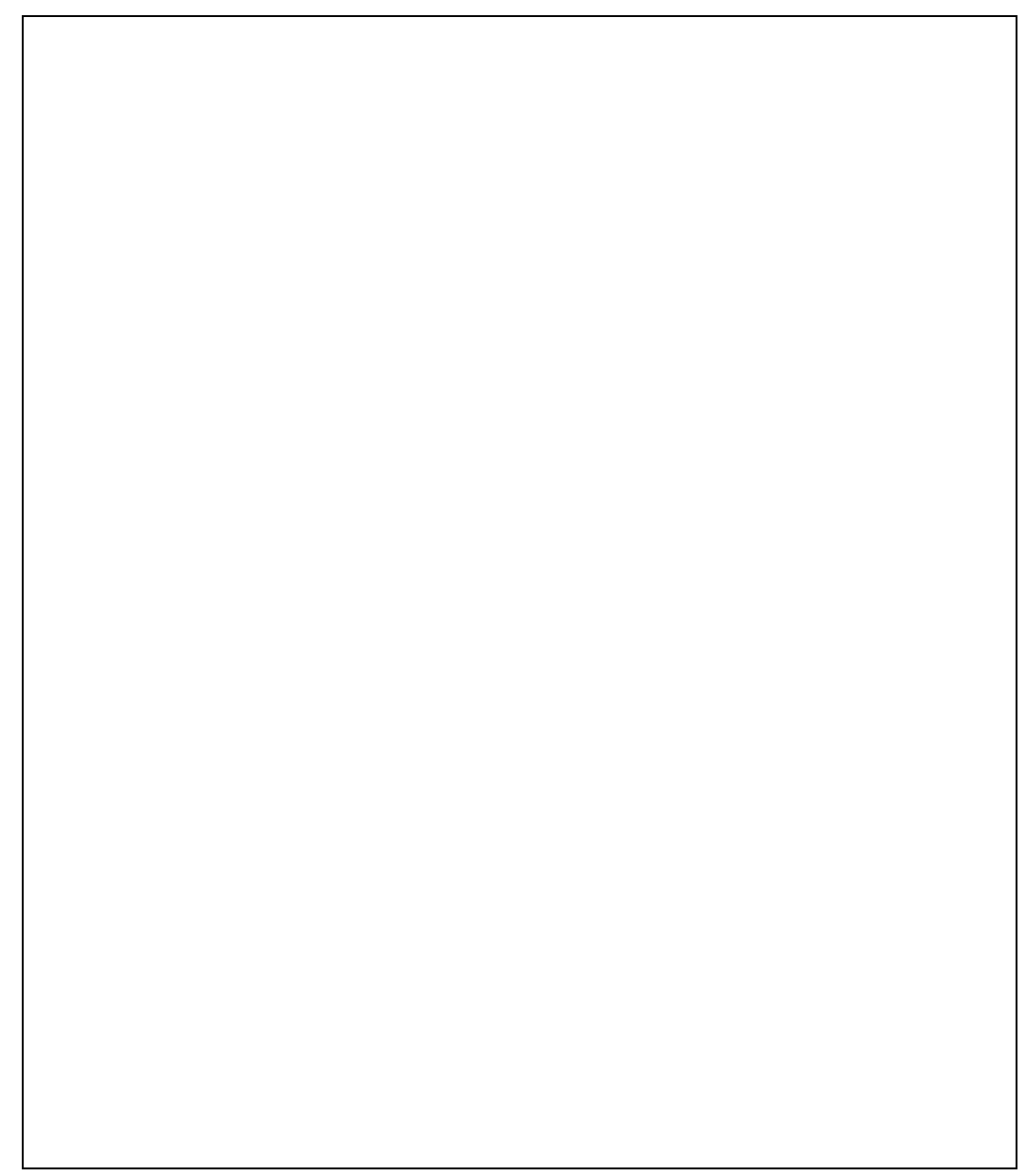

Vielen Dank! 


\section{Appendix}

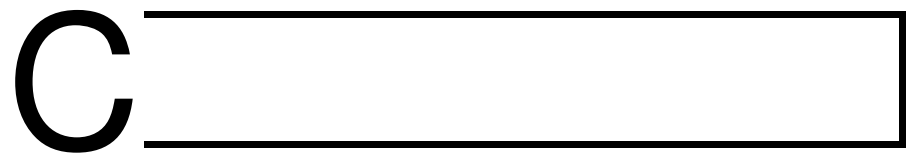

\section{Bibliography}

\section{C.1. Author's publications}

[1] Peter Knapik et al. „Understanding Vehicle Related Crime to Elaborate on Countermeasures Based on ADAS and V2X Communication." In: Vehicular Networking Conference (VNC). IEEE, Nov. 2012, pp. 86-93. DOI: 10.1109/VNC.2012.6407449.

[2] Peter Knapik. The Use of Vehicle-to-X Communication to Combat Vehicle Related Crime. Tech. rep. Proceedings of the 1st GI/ITG KuVS Fachgespräch Inter-Vehicle Communication (FG-IVC 2013), Feb. 2013. URL: http:/ / www.ccs-labs.org/bib / knapik2013cri me/knapik2013crime.pdf.

[3] Peter Knapik, Elmar Schoch, and Frank Kargl. Security-Funktionen zur Bekämpfung fahrzeugbezogener Kriminalität. Tech. rep. 29. VDI/VW-Gemeinschaftstagung Automotive Security, Sept. 2013.

[4] Peter Knapik, Elmar Schoch, and Frank Kargl. „Simulation of a Security Function Based on Vehicle-to-X Communication and Automotive Lighting. "In: VEHICULAR 2013. IARIA, July 2013, pp. 8-11. URL: http: / / www . thinkmind.org / download . php ? articleid = vehicular_2013_1_30_60027.

[5] Peter Knapik, Elmar Schoch, and Frank Kargl. „Electronic Decal: A Security Function Based on V2X Communication." In: Vehicular Technology Conference (VTC Spring). IEEE, June 2013, pp. 1-5. DOI: 10.1109/VTCSpring.2013.6692534.

[6] Peter Knapik et al. „Cooperative Home Light: Assessment of a Security Funtion for the Automotive Field." In: IARIA, International Journal on Advances in Security 7.1\&2 (June 2014), pp. 1-14. URL: http: / / www .iariajournals.org / security / sec_v7_n12_2014_ paged.pdf.

\section{C.2. Bibliography}

[7] Gary Cordner. Reducing Fear of Crime. Tech. rep. U.S. Department of Justice, 2010.

[8] Karin Wittebrood and Marianne Junger. „Trends in violent crime: a comparison between police statistics and victimization surveys." In: Social Indicators Research 59.2 (Aug. 2002), pp. 153-173.

[9] Helmut Kury and Joachim Obergfell-Fuchs. „Kriminalitätsfurcht und ihre Ursachen.“ In: Der Bürger im Staat - Sicherheit und Kriminalität 53.1 (2003), pp. 9-18. 
[10] Oliver Wendell Holmes, Jr. The Common Law. Ed. by Sheldon M. Novick. Mineola, NY: Dover Publications, 1991.

[11] Barry Webb and Gloria Laycock. Tackling Car Crime: The Nature and Extent of the Problem. Crime Prevention Unit Series 32. Home Office, 1992.

[12] Michael Cherbonneau and Richard Wright. „Auto Theft." In: The Oxford Handbook of Crime and Public Policy. Ed. by Michael Tonry. Oxford Handbooks. Oxford: Oxford University Press, 2011, pp. 191-222.

[13] Mikel Longman. „The problem of auto theft.“ In: Forensic Investigation of Stolen-Recovered and Other Crime-Related Vehicles. Ed. by Eric Stauffer and Monica S. Bonfanti. 1st ed. Burlington, MA: Elsevier Academic Press, 2006, pp. 1-21.

[14] Barry Webb. „Steering Column Locks and Motor Vehicle Theft: Evaluations from Three Countries." In: Crime Prevention Studies. Ed. by Ronald V. Clarke. Vol. 2. Crime Prevention Studies. Monsey, NY: Criminal Justice Press, 1994, pp. 71-89.

[15] B. N. W. Lee, G. P. Rikoski, and D. Whitcomb. Vehicle theft prevention strategies. Washington, DC: U.S. Dept. of Justice, National Institute of Justice, Office of Development, Testing, and Dissemination, 1984.

[16] Tim Dawkins. Global car theft hot-spots and trends revealed. Tech. rep. SBD, 2013.

[17] Pat Mayhew, Ronald V. Clarke, and David Elliott. „Motorcycle Theft, Helmet Legislation and Displacement." In: The Howard Journal of Criminal Justice 28.1 (Feb. 1989), pp. 18.

[18] Ronald V. Clarke and Patricia M. Harris. „Auto Theft and Its Prevention." In: Crime and Justice: An Annual Review of Research. Ed. by Michael Tonry. Vol. 16. Chicago, IL: University of Chicago Press, 1992, pp. 1-54.

[19] U.S. Congress. Motor Vehicle Theft Law Enforcement Act of 1984. Public Law 98-547. 98th Congress, 1984.

[20] U.S. Congress. Anti Car Theft Act of 1992. Public Law 102-519. 102nd Congress, 1992.

[21] Gloria Laycock. „The UK Car Theft Index: An Example of Government Leverage.“ In: Understanding and Preventing Car Theft. Ed. by Michael G. Maxfield and Ronald V. Clarke. Vol. 17. Crime Prevention Studies. Monsey, NY: Criminal Justice Press, 2004, pp. 25-44.

[22] Rick Brown. „Effectiveness of Electronic Immobilization: Changing Patterns of Temporary and Permanent Vehicle Theft." In: Understanding and Preventing Car Theft. Ed. by Michael G. Maxfield and Ronald V. Clarke. Vol. 17. Crime Prevention Studies. Monsey, NY: Criminal Justice Press, 2004, pp. 101-119.

[23] Rick Brown. „Reviewing the effectiveness of electronic vehicle immobilisation: Evidence from four countries." In: Security Journal 28.4 (Oct. 2013), pp. 329-351.

[24] Graham Farrell, Andromachi Tseloni, and Nick Tilley. "The effectiveness of vehicle security devices and their role in the crime drop." In: Criminology and Criminal Justice 11.1 (Feb. 2011), pp. 21-35.

[25] Jan van Dijk et al. The Burden of Crime in the EU - A Comparative Analysis of the European Survey of Crime and Safety (EU ICS) 2005. Tech. rep. European Commission, 2005.

[26] Pat Mayhew, David Elliott, and Lizanne Dowds. The 1988 British Crime Survey. Home Office Research Studies 111. Her Majesty's Stationery Office, 1989.

[27] James Q. Wilson and George L. Kelling. „Broken Windows - The police and neighborhood safety." In: The Atlantic (Mar. 1982). 
[28] Pat Mayhew, Natalie Aye Maung, and Catriona Mirrlees-Black. The 1992 British Crime Survey. Home Office Research Studies 132. Her Majesty's Stationery Office, 1993.

[29] Sven Tuchscheerer. „Human Factors in Automotive Crime and Security.“ PhD thesis. University of Technology Chemnitz, 2011.

[30] ONS. The 2011/12 Crime Survey for England and Wales. Tech. rep. JN 223826. Office for National Statistics, 2012.

[31] Jan van Dijk, John van Kesteren, and Paul Smit. Criminal Victimisation in International Perspective - Key findings from the 2004-2005 ICVS and EU ICS. Tech. rep. United Nations Interregional Crime and Justice Research Institute (UNICRI), United Nations Office on Drugs and Crime (UNODC), 2007.

[32] Diederik Cops and Stefaan Pleysier. „Doing Gender in Fear of Crime: The Impact of Gender Identity on Reported Levels of Fear of Crime in Adolescents and Young Adults." In: The British Journal of Criminology 51.1 (Jan. 2011), pp. 58-74.

[33] Catriona Mirrlees-Black and Jonathan Allen. Concern About Crime: Findings From the 1998 British Crime Survey. Tech. rep. Home Office, 1998.

[34] Thomas Naplava. Individuelle und sozialräumliche Determinanten der Kriminalitätsfurcht - Sekundäranalyse der Allgemeinen Bürgerbefragungen der Polizei in Nordrhein-Westfalen. Tech. rep. Landeskriminalamt Nordrhein-Westfalen, 2006.

[35] Rachel Pain. „Gender, Race, Age and Fear in the City.“ In: Urban Studies 38.5-6 (May 2001), pp. 899-913.

[36] Kenneth F. Ferraro. Fear of Crime: Interpreting Victimization Risk. Ed. by Austin T. Turk. Albany, NY: Stanford University of New York Press, 1995.

[37] Natalia Chivite-Matthews and Penelope Maggs. Crime, Policing and Justice: The Experience of Older People. Tech. rep. Home Office, Aug. 2002.

[38] Dieter Hermann and Christine Simsa. „Lebensstile, Opferwerdung und Kriminalitätsfurcht." In: Kommunale Kriminalprävention - Analysen und Perspektiven: Ergebnisse der Begleitforschung zu den Pilotprojekten in Baden-Würtemberg. Ed. by Dieter Dölling et al. Vol. 15. Holzkirchen/Obb: Felix-Verlag GbR, 2003, pp. 222-232.

[39] Ulf-Dietrich Reips. „The methodology of Internet-based experiments.“ In: The Oxford Handbook of Internet Psychology. Ed. by Adam N. Joinson et al. Oxford Handbooks. Oxford: Oxford University Press, 2007, pp. 373-390.

[40] Arlene Fink. The Survey Handbook. Ed. by Diane S. Forster, Joyce Kuhn, and Janelle LeMaster. 1st ed. Vol. 1. The Survey Kit. Thousand Oaks, CA: SAGE Publications, 1995.

[41] Linda B. Bourque and Eve P. Fiedler. How to Conduct Self-Administered and Mail Survey. Ed. by Diane S. Forster, Joyce Kuhn, and Janelle LeMaster. 1st ed. Vol. 3. The Survey Kit. Thousand Oaks, CA: SAGE Publications, 1995.

[42] Arlene Fink. How to Ask Survey Questions. Ed. by Diane S. Forster, Joyce Kuhn, and Janelle LeMaster. 1st ed. Vol. 2. The Survey Kit. Thousand Oaks, CA: SAGE Publications, 1995.

[43] Mark S. Litwin. How to Measure Survey Reliability and Validity. Ed. by Diane S. Forster, Joyce Kuhn, and Janelle LeMaster. 1st ed. Vol. 7. The Survey Kit. Thousand Oaks, CA: SAGE Publications, 1995.

[44] Arlene Fink. How to Sample in Surveys. Ed. by Diane S. Forster, Joyce Kuhn, and Janelle LeMaster. 1st ed. Vol. 6. The Survey Kit. Thousand Oaks, CA: SAGE Publications, 1995. 
[45] Jürgen Bortz and Gustav A. Lienert. Kurzgefasste Statistik für die klinische Forschung. Ed. by Svenja Wahl, Meike Seeker, and Christine Bier. 3rd ed. Vol. 3. Heidelberg: Springer, 2008.

[46] Harald Heinzl. Statistische Tests bei medizinischen Fragestellungen. Medizinische Universität Wien, 2006.

[47] Peter Zöfel. Statistik für Psychologen im Klartext. Ed. by Irmgard Wagner and Petra Kienle. München: Pearson Studium, 2003.

[48] Markus Bühner and Matthias Ziegler. Statistik für Psychologen und Sozialwissenschaftler. Ed. by Christian Schneider and Brigitta Keul. München: Pearson Studium, 2009.

[49] Ulrike Pott. „Einbruch-Bilanz 2012: Wohnungseinbrüche steigen weiter und kosten Versicherer knapp eine halbe Milliarde Euro." In: Pressemitteilung des Gesamtverbands der Deutschen Versicherungswirtschaft e. V. (May 2013), pp. 1-2.

[50] Ronald V. Clarke. The Theory and Practice of Situational Crime Prevention. Tech. rep. Rutgers University, 1998.

[51] Ronald V. Clarke. Situational Crime Prevention: Successful Case Studies. Ed. by Ronald V. Clarke. Albany, NY: Harrow and Heston, 1992.

[52] Ronald V. Clarke. Situational Crime Prevention: Successful Case Studies. Ed. by Ronald V. Clarke. 2nd ed. Albany, NY: Harrow and Heston, 1997.

[53] Derek B. Cornish and Ronald V. Clarke. „Situational prevention, displacement of crime and rational choice theory." In: Situational crime prevention: From theory into practice. Ed. by Kevin Heal and Gloria Laycock. London: Her Majesty's Stationery Office, 1986, pp. 1-16.

[54] Ronald V. Clarke and Derek B. Cornish. „Modeling Offenders' Decisions: A Framework for Research and Policy." In: Crime and Justice: A Review of Research. Ed. by Michael Tonry and Norval Morris. Vol. 6. Chicago, IL: University of Chicago Press, 1985, pp. 147-185.

[55] Ronald V. Clarke and Derek B. Cornish. „Rational Choice.“ In: Explaining Criminals and Crime: Essays in Contemporary Criminological Theory. Ed. by R. Paternoster and R.Bachman. Los Angeles, CA: Roxbury Publishing Company, 2000, pp. 27-41.

[56] Barry Poyner and Barry Webb. Crime Free Housing. Oxford: Butterworth Architecture, 1991, p. 126.

[57] Robert P. Abelson. "Script processing in attitude formation and decision making." In: Cognition and Social Behaviour. Ed. by John S. Carroll and John W. Payne. Hillsdale, NJ: Lawrence Erlbaum Associates, 1976, pp. 33-46.

[58] Roger C. Schank and Robert P. Abelson. Scripts, Plans, Goals and Understanding: An Inquiry into Human Knowledge. Hillsdale, NJ: Lawrence Erlbaum Associates, 1977.

[59] Robert P. Abelson. „Psychological status of the script concept.“ In: American Psychologist 36.7 (July 1981), pp. 715-729.

[60] James A. Galambos, Robert P. Abelson, and John B. Black. „Scripts.“ In: Knowledge Structures. Ed. by James A. Galambos, Robert P. Abelson, and John B. Black. Hillsdale, NJ: Lawrence Erlbaum Associates, 1986, p. 19.

[61] Derek B. Cornish. „Crimes as Scripts.“ In: Proceedings of the International Seminar on Environmental Criminology and Crime Analysis. Ed. by Diane Zahm and Paul Cromwell. Florida Statistical Analysis Center, Florida Criminal Justice Executive Institute, 1994, pp. 30-45. 
[62] Derek Cornish. „The Procedural Analysis of Offending and Its Relevance for Situational Prevention." In: Crime Prevention Studies. Ed. by Ronald V. Clarke. Vol. 3. Crime Prevention Studies. Monsey, NY: Criminal Justice Press, 1994, pp. 151-196.

[63] John Leddo and Robert P. Abelson. „The Nature of Explanations.“ In: Knowledge Structures. Ed. by James A. Galambos, Robert P. Abelson, and John B. Black. Hillsdale, NJ: Lawrence Erlbaum Associates, 1986, pp. 103-122.

[64] Roger C. Schank. Dynamic memory: A theory of reminding and learning in computers and people. Ed. by Robert J. Sternberg. New York, NY: Cambridge University Press, 1982, p. 186.

[65] Roy Light, Claire Nee, and Helen Ingham. Car Theft: The Offender's Perspective. Home Office Research Studies 130. Her Majesty's Stationery Office, 1993.

[66] Martha J. Smith. „Regulating Opportunities: Multiple Roles for Civil Remedies in Situational Crime Prevention." In: Civil Remedies and Crime Prevention. Ed. by Lorraine Green Mazerolle and Jan Roehl. Vol. 9. Crime Prevention Studies. Monsey, NY: Criminal Justice Press, 1998, pp. 67-88.

[67] Oscar Newman. Defensible Space, Crime Prevention Through Urban Design. New York, NY: The Macmillan Company, 1972.

[68] Clarence R. Jeffery. Crime prevention through environmental design. Beverly Hills, CA: SAGE Publications, 1971.

[69] Derek B. Cornish and Ronald V. Clarke. „Opportunities, Precipitators and Criminal Decisions: A Reply to Wortley's Critique of Situational Crime Prevention." In: Theory for Practice in Situational Crime Prevention. Ed. by Martha J. Smith and Derek B. Cornish. Vol. 16. Crime Prevention Studies. Monsey, NY: Criminal Justice Press, 2003, pp. 41-96.

[70] Ronald V. Clarke. „Crime Science.“ In: The SAGE Handbook of Criminological Theory. Ed. by Eugene McLaughlin and Tim Newburn. Thousand Oaks, CA: SAGE Publications, 2010, pp. 271-283.

[71] Mike Hough, Ronald V. Clarke, and Patricia Mayhew. „Introduction.“ In: Designing Out Crime. Ed. by John Croft. London: Her Majesty's Stationery Office, 1980, pp. 1-18.

[72] Ronald V. Clarke and Ross Homel. „A Revised Classification of Situational Crime Prevention Techniques." In: Crime Prevention at a Crossroads. Ed. by Steven P. Lab. Highland Heights, KY: Academy of Criminal Justice Sciences and Anderson Publishing Co., 1997, pp. 17-30.

[73] Gordon Trasler. „Situational crime control and rational choice: a critique.“ In: Situational Crime Prevention: From Theory Into Practice. Ed. by Kevin Heal and Gloria Laycock. London: Her Majesty's Stationery Office, 1986, pp. 17-24.

[74] Rene B.P. Hesseling. „Displacement: A Review of the Empirical Literature.“ In: Crime Prevention Studies. Ed. by Ronald V. Clarke. Vol. 3. Crime Prevention Studies. Monsey, NY: Criminal Justice Press, 1994, pp. 197-230.

[75] Rob T. Guerette. Analyzing Crime Displacement and Diffusion. Problem-Oriented Guides for Police Series - Problem-Solving Tools Series 10. U.S. Department of Justice, 2009.

[76] Rob T. Guerette and Kate T. Bowers. „Assessing the Extent of Crime Displacement and Diffusion of Benefits: A Review of Situational Crime Prevention Evaluations." In: Criminology 47.4 (Nov. 2009), pp. 1331-1368.

[77] A.N. Mancini and R. Jain. „Commuter Parking Lots: Vandalism and Deterrence.“ In: Transportation Quarterly 41.4 (Oct. 1987), pp. 539-554. 
[78] Jan Pelzl. „IT-Sicherheit im Automobil.“ In: Sicherheit und Vertrauen in der mobilen Informations- und Kommunikationstechnologie. Ed. by Udo Bub and Klaus-Dieter Wolfenstetter. Wiesbaden: Vieweg und Teubner, 2009, pp. 137-156.

[79] Kerstin Lemke, Ahmad-Reza Sadeghi, and Christian Stüble. „Anti-theft Protection: Electronic Immobilizers." In: Embedded Security in Cars. Ed. by Kerstin Lemke, Christof Paar, and Marko Wolf. Berlin, Heidelberg: Springer, 2006, pp. 51-68.

[80] Rick Brown and Nerys Thomas. „Aging Vehicles: Evidence of the Effectiveness of New Car Security from the Home Office Car Theft Index." In: Security Journal 16.3 (July 2003), pp. 45-53.

[81] Jörg Bässmann. „Vehicle Theft Reduction in Germany: The Long-Term Effectiveness of Electronic Immobilisation." In: European Journal on Criminal Policy and Research 17.3 (Sept. 2011), pp. 221-246.

[82] Karsten Nohl. "Car immobilizer hacking.“ In: Conference on the Social and Technical Aspects of Digital Society (SIGINT). Chaos Computer Club, 2013.

[83] Chris D. Aldridge. Bait Vehicle Technologies and Motor Vehicle Theft Along the Southwest Border. Tech. rep. Sandia National Laboratories, 2007.

[84] Ralph Ogden et al. Arizona Auto Theft Study. Tech. rep. Arizona Criminal Justice Commission, 2004.

[85] D. E. Cochran. „Affordable Auto Theft Reduction.“ In: Law and Order 36.5 (May 1988), pp. 51-53.

[86] BACSA. Microdot Technology. Tech. rep. Business Against Crime South Africa, 2012.

[87] Todd Keister. Thefts of and from Cars on Residential Streets and Driveways. Problem-Oriented Guides for Police Series - Problem-Specific Guide Series 46. U.S. Department of Justice, 2007.

[88] Christian Weiss and Benjamin Oberkersch. „Field operational test carried out within research project simTD proves: Car-to-x communication is ready for everyday use." In: Press release simTD (June 2013), pp. 1-3.

[89] Ronald V. Clarke and John E. Eck. Crime Analysis for Problem Solvers in 60 Small Steps. Tech. rep. U.S. Department of Justice, 2005.

[90] Pascal Belin, Shirley Fecteau, and Catherine Bédard. „Thinking the voice: neural correlates of voice perception.“ In: Trends in Cognitive Sciences 8.3 (Mar. 2004), pp. 129-135.

[91] ETSI. Intelligent Transport Systems (ITS); Communication Architecture. European Telecommunications Standards Institute, Sept. 2010.

[92] ETSI. Intelligent Transport Systems (ITS); Classification and management of ITS application objects. European Telecommunications Standards Institute, May 2011.

[93] ETSI. Intelligent Transport Systems (ITS); Application Object Identifier (ITS-AID); Registration list. European Telecommunications Standards Institute, Mar. 2013.

[94] ETSI. Intelligent Transport systems (ITS); Vehicular Communications; Basic Set of Applications; Part 3: Specification of Decentralized Environmental Notification Basic Service. European Telecommunications Standards Institute, Sept. 2010.

[95] ETSI. Intelligent Transport systems (ITS); Vehicular Communications; Basic Set of Applications; Part 2: Specification of Cooperative Awareness Basic Service. European Telecommunications Standards Institute, Mar. 2011.

[96] ETSI. Intelligent Transport Systems (ITS); Security; Security header and certificate formats. European Telecommunications Standards Institute, June 2015. 
[97] ETSI. Intelligent Transport Systems (ITS); Security; ITS communications security architecture and security management. European Telecommunications Standards Institute, June 2012.

[98] ETSI. Intelligent Transport Systems (ITS); Security; Security Services and Architecture. European Telecommunications Standards Institute, Sept. 2010.

[99] David Salomon. The Computer Graphics Manual. Ed. by David Gries and Fred B. Schneider. Springer, 2011.

[100] Paramvir Bahl and Venkata N. Padmanabhan. „RADAR: An In-Building RF-based User Location and Tracking System." In: INFOCOM 2000, 19th Annual Joint Conference of the IEEE Computer and Communications Societies. Vol. 2. IEEE, 2000, pp. 775-784.

[101] Paramvir Bahl, Venkata N. Padmanabhan, and Anand Balachandran. Enhancements to the RADAR User Location and Tracking System. Tech. rep. MSR-TR-2000-12. Microsoft Research, 2000.

[102] Moustafa A. Youssef, Ashok Agrawala, and A. Udaya Shankar. „WLAN Location Determination via Clustering and Probability Distributions." In: Proceedings of the 1st International Conference on Pervasive Computing and Communications (PerCom). IEEE, 2003, pp. 143-150.

[103] Moustafa A. Youssef and Ashok Agrawala. „Handling Samples Correlation in the Horus System." In: 23rd Annual Joint Conference of the IEEE Computer and Communications Societies (INFOCOM). Vol. 2. IEEE, 2004, pp. 1023 -1031.

[104] Petri Kontkanen et al. „Topics in probabilistic location estimation inwireless networks.“ In: International Symposium on Personal, Indoor and Mobile Radio Communications (PIMRC). Vol. 2. IEEE, 2004, pp. $1052-1056$.

[105] Kinh Tran, Tu Le, and Tien Dinh. „A high-accuracy step counting algorithm for iPhones using Accelerometer." In: International Symposium on Signal Processing and Information Technology (ISSPIT). IEEE, 2012, pp. 213-217.

[106] Christopher Barthold, Kalyan P. Subbu, and Ram Dantu. „Evaluation of Gyroscopeembedded Mobile Phones." In: International Conference on Systems, Man, and Cybernetics (SMC). IEEE, 2011, pp. 1632-1638.

[107] Shyi-Shiou Wu and Hsin-Yi Wu. „The Design of an Intelligent Pedometer using Android." In: 2nd International Conference on Innovations in Bio-inspired Computing and Applications (IBICA). IEEE, 2011, pp. 313-315.

[108] Andre Ibisch et al. „Towards Autonomous Driving in a Parking Garage: Vehicle Localization and Tracking Using environment-embedded LIDAR Sensors." In: Intelligent Vehicles Symposium. IEEE, 2013, pp. 829-834.

[109] NIMA. Department of Defense World Geodetic System 1984. Tech. rep. TR8350.2. National Imagery and Mapping Agency, 2000.

[110] Marko H. Hörter, Christoph Stiller, and Christian Koelen. „A Hardware and Software Framework for Automotive Intelligent Lighting. “ In: Intelligent Vehicles Symposium. IEEE, 2009, pp. 299-304.

[111] AGVSIUPSA. Beleuchtungsanlage/Scheinwerfer. Tech. rep. Auto Gewerbe Verband Schweiz, union professionelle suisse de l'automobile, Jan. 2009.

[112] Kunden-Service-Center. Licht ist Technologie - Know-How für den Werkstatt-Profi. Tech. rep. HELLA KGaA Hueck \& Co., 2013.

[113] James M. Tien et al. Street Lighting Projects. Tech. rep. 21. U.S. Department of Justice, 1979. 
[114] Malcolm Ramsay and Rosemary Newton. The Effect of Better Street Lighting on Crime and Fear: A Review. Crime Prevention Unit Series 29. Home Office, 1991.

[115] Stephen Atkins, Sohail Husain, and Angele Storey. The Influence of Street Lighting on Crime and Fear of Crime. Crime Prevention Unit Series 28. Home Office, 1991.

[116] Ken Pease. "A Review of Street Lighting Evaluations: Crime Reduction Effects." In: Surveillance of Public Space: CCTV, Street Lighting and Crime Prevention. Ed. by Kate Painter and Nick Tilley. Vol. 10. Crime Prevention Studies. Monsey, NY: Criminal Justice Press, 1999, pp. 47-76.

[117] Kate Painter and David P. Farrington. „Street Lighting and Crime: Diffusion of Benefits in the Stoke-on-Trent Project." In: Surveillance of Public Space: CCTV, Street Lighting and Crime Prevention. Ed. by Kate Painter and Nick Tilley. Vol. 10. Crime Prevention Studies. Monsey, NY: Criminal Justice Press, 1999, pp. 77-122.

[118] David P. Farrington and Brandon C. Welsh. Effects of improved street lighting on crime: a systematic review. Home Office Research Studies 251. Home Office, 2002.

[119] Brandon C. Welsh and David P. Farrington. Improved Street Lighting and Crime Prevention: A Systematic Review. Tech. rep. The Swedish National Council for Crime Prevention, 2007.

[120] Rebecca Steinbach et al. „The effect of reduced street lighting on road casualties and crime in England and Wales: controlled interrupted time series analysis." In: Journal of Epidemiology \& Community Health 69.11 (Nov. 2015), pp. 1091-1101.

[121] Judith Green et al. „Reduced street lighting at night and health: A rapid appraisal of public views in England and Wales." In: Health E Place 34 (July 2015), pp. 171-180.

[122] Jonathan Brown. Vehicle Watch: A Multi-agency Approach. Home Office, Police Research Group, 1992, p. 164.

[123] Terry Honess and Michael Maguire. Vehicle Watch and Car Theft: An Evaluation. Crime Prevention Unit Series 50. Home Office, 1993.

[124] Philip A. Ethridge and Jonathan R. Sorensen. „An Evaluation of Citizens Against Auto Theft.“ In: Security Journal 4.1 (1993), pp. 13-19.

[125] Chet Merta. Motor Vehicle Theft - A Study of Contributions by Society. Tech. rep. Dearborn Police Department and Eastern Michigan University, 2004.

[126] Hartmut Gieselmann and Jan-Keno Janssen. „Endlich mittendrin! - Erster Test der VRBrille Oculus Rift." In: ct mag 10 (2013), pp. 102-109.

[127] Ulrike Kuhlmann and Jan-Keno Janssen. „Aufgesetzt.“ In: ct mag 24 (2012), pp. 102-109.

[128] Ulrike Kuhlmann. „Realitätsnähe.“ In: ct mag 24 (2012), pp. 96-101.

[129] Franz Faul et al. „G*Power 3: A flexible statistical power analysis program for the social, behavioral, and biomedical sciences." In: Behavior Research Methods 39.2 (May 2007), pp. 175-191.

[130] Jacob Cohen. Statistical Power Analysis for the Behavioral Sciences. 2nd ed. Hillsdale, NJ: Lawrence Erlbaum Associates, 1988.

[131] Jum N. Nunnally. Psychometric Theory. 2nd ed. New Yory, NY: McGraw-Hill, 1978.

[132] Jum N. Nunnally and Ira H. Bernstein. Psychometric Theory. Ed. by Jane Vaicunas and James R. Belser. 3rd ed. New York, NY: McGraw-Hill, 1994.

[133] Henrica C. W. de Vet et al. Measurement in Medicine: A Practical Guide. Ed. by Susan Ellenberg et al. Cambridge: Cambridge University Press, 2011. 
[134] Dores Ferreira and Pedro Palhares. „Chess and problem solving involving patterns.“ In: The Montana Mathematics Enthusiast. Ed. by Bharath Sriraman. Vol. 5. 2 and 3. Charlotte, NC: Information Age Publishing, July 2008, pp. 249-256.

[135] Waldemar Zimmermann. „Implementierung einer Simulationsumgebung für SecurityFunktionen im Automobilbereich." MA thesis. Hochschule Hannover - University of Applied Sciences and Arts, Aug. 2013.

[136] Andreas Kwoczek et al. „Influence of car panorama glass roofs on Car2Car communication (poster)." In: Vehicular Networking Conference (VNC). IEEE, Nov. 2011, pp. 246251.

[137] IEEE. IEEE 802.11p - Amendment 6: Wireless Access in Vehicular Environments. IEEE Computer Society, 2010.

[138] Daniel Birks and Henk Elffers. "Agent-Based Assessments of Criminological Theory.“ In: Encyclopedia of Criminology and Criminal Justice. New York: Springer, 2014, pp. 19-32.

\section{C.3. Web references}

[139] BKA. Polizeiliche Kriminalstatistik. [Last accessed: Sep. 20, 2015]. Bundeskriminalamt. URL: http:/ / www.bka.de.

[140] KBA. Fahrzeugbestand. [Last accessed: Sep. 20, 2015]. Kraftfahrt-Bundesamt. URL: http: //www.kba.de.

[141] DESTATIS. Bevölkerungsentwicklung in Deutschland. [Last accessed: Sep. 20, 2015]. Statistisches Bundesamt. URL: http://www.destatis.de/.

[142] FBI. Uniform Crime Reports. [Last accessed: Sep. 20, 2015]. Federal Bureau of Investigation. URL: http://www.fbi.gov/stats-services/crimestats.

[143] USCB. Population Overview. [Last accessed: Sep. 20, 2015]. United States Census Bureau. URL: http://www.census.gov.

[144] DOT. Number of U.S. Aircraft, Vehicles, Vessels, and Other Conveyances. [Last accessed: Sep. 20, 2015]. Department of Transportation - Bureau of Transportation Statistics. URL: http://www.rita.dot.gov/bts/.

[145] HO. Crime Statistics at Home Office. [Last accessed: Sep. 20, 2015]. Home Office. URL: https://www.gov.uk/government/organisations/home-office/about/statistics.

[146] ONS. Population Estimates for England and Wales. [Last accessed: Sep. 20, 2015]. Office for National Statistics. URL: http:/ /www.ons.gov.uk.

[147] DFT. Vehicles Statistics. [Last accessed: Sep. 20, 2015]. Department for Transport. URL: http:/ / www.gov.uk/government/collections/vehicles-statistics.

[148] SESNSP. Incidencia Delictiva. [Last accessed: Sep. 20, 2015]. Secretariado Ejecutivo del Sistema Nacional de Seguridad Publica. URL: http:/ / www.estadisticadelictiva.secreta riadoejecutivo.gob.mx/mondrian/.

[149] INEGI. Poblacion total. [Last accessed: Sep. 20, 2015]. Instituto Nacional de Estadistica y Geografia. URL: http://www.inegi.org.mx/.

[150] INEGI. Vehiculos de Motor Registrados en Circulacion. [Last accessed: Sep. 20, 2015]. Instituto Nacional de Estadistica y Geografia. URL: http:/ / www.inegi.org.mx/. 
[151] NCRB. Crime in India. [Last accessed: Sep. 20, 2015]. National Crime Records Bureau. URL: http://ncrb.nic.in/.

[152] MOHA. Census Data Summary. [Last accessed: Sep. 20, 2015]. Ministry of Home Affairs. URL: http:// www.censusindia.gov.in.

[153] MORTH. Road Transport Year Book India. [Last accessed: Sep. 20, 2015]. Ministry of Road Transport and Highways. URL: http:/ / morth.nic.in.

[154] SAPS. Crime Reports. [Last accessed: Sep. 20, 2015]. South African Police Service. URL: http://www.saps.gov.za/.

[155] TE. South Africa Population. [Last accessed: Sep. 20, 2015]. Trading Economics. URL: http: //www.tradingeconomics.com/south-africa/population.

[156] eNaTIS. Live Vehicle Population. [Last accessed: Sep. 20, 2015]. Electronic National Administration Traffic Information System. URL: http:/ / www.enatis.com.

[157] Protests grow over gang rape of Indian woman. [Last accessed: Sep. 20, 2015]. The Telegraph. Dec. 2012. URL: http://www.telegraph.co.uk/news/worldnews / asia /india / 9756318/Protests-grow-over-gang-rape-of-Indian-woman.html.

[158] Thatcham Research. The Motor Insurance Repair Research Centre for Safety, Security and Crash Repair. [Last accessed: Sep. 20, 2015]. URL: http:/ / www.thatcham.org.

[159] Brian Wheeler. Why are vandalism rates falling? [Last accessed: Sep. 20, 2015]. BBC News Magazine. Jan. 2013. URL: http:/ / www.bbc.com/news/magazine-21041160.

[160] NJSP. Carjacking Offense Reports. [Last accessed: Sep. 20, 2015]. New Jersey State Police. URL: http:/ / www.njsp.org/info/stats.html\#ucr.

[161] ONS. Office for National Statistics. [Last accessed: Sep. 20, 2015]. URL: http:/ /www.ons. gov.uk/ons/index.html.

[162] UNICRI. United Nations Interregional Crime and Justice Research Institute. [Last accessed: Sep. 20, 2015]. URL: http:/ / www.unicri.it.

[163] USCB. United States Census Bureau. [Last accessed: Sep. 20, 2015]. URL: http: / / www. census.gov.

[164] BJS. Bureau of Justice Statistics. [Accessed: Aug 29, 2015]. URL: http://www.bjs.gov.

[165] Deutsche Presse-Agentur GmbH / Agence France-Presse. Zahl der Einbrüche in Deutschland steigt. [Last accessed: Sep. 20, 2015]. May 2013. URL: http: / / www.handelsblatt. com / panorama / aus - aller - welt / statistik - zahl - der - einbrueche - in - deutschland steigt/8190860.html.

[166] Karin Truscheit. Gelegenheit und Drogensucht machen Diebe. [Last accessed: Sep. 20, 2015]. Frankfurter Allgemeine. Apr. 2015. URL: http: / / www.faz.net/aktuell / gesellschaft / kriminalitaet/zahl-der-einbrueche-in-deutschland-steigt-auch-2014-13535578.html.

[167] GPS Business News. Honda partners with Japanese police for location-based crime info in nav system. [Last accessed: Sep. 20, 2015]. Apr. 2008. URL: http: / / www.gpsbusinessnews. com.

[168] GDV. Union of German Insurers. [Last accessed: Sep. 20, 2015]. URL: http:/ / www.en. gdv.de/.

[169] Watch Your Car Program (Maryland). [Last accessed: Sep. 20, 2015]. Maryland Vehicle Theft Prevention Council. URL: http: / / mdsp.maryland gov / Organization / Pages / OfficeoftheSuperintendent/WatchYourCarProgram.aspx. 
[170] Combat Auto Theft Program. [Accessed: May 31, 2014]. East Point Police Department. URL: http://www.eastpointpolice.org/cat.htm.

[171] Watch Your Car Program (Arizona). [Last accessed: Sep. 20, 2015]. Arizona Automobile Theft Authority. URL: http:/ / aata.az.gov/content/watch-your-car-program.

[172] Watch Your Car Program (Utah). [Last accessed: Sep. 20, 2015]. State of Utah. URL: https: //secure.utah.gov/wyc/wyc.

[173] Door lock remote control system Double Locking System. [Last accessed: Sep. 20, 2015]. Your Online Mechanic.com. Aug. 2011. URL: http:/ / youronlinemechanic.com/door-lockremote-control-system-double-locking-system/.

[174] DAT. DAT-Reports. [Last accessed: Sep. 20, 2015]. Deutsche Automobil Treuhand GmbH. URL: http://www.dat.de/report.

[175] IMPACT. Baitcar - Steal one go to jail. [Last accessed: Sep. 20, 2015]. Integrated Municipal Provincial Auto Crime Team. URL: http:/ / www.baitcar.com.

[176] BFStrMG. Bundesfernstraßenmautgesetz. [Last accessed: Sep. 20, 2015]. Bundesministerium der Justiz und für Verbraucherschutz. URL: http: / / www .gesetze-im-internet.de / bfstrmg/index.html.

[177] DataDot. Microdot Technology. [Last accessed: Sep. 20, 2015]. URL: http://www.datadot. co.za/vehicles.html.

[178] CobraTrak. Stolen vehicle tracking. [Last accessed: Sep. 20, 2015]. URL: http:/ / automotiv e.vodafone.co.uk/stolen-vehicle-tracking.aspx.

[179] OnStar. Security services. [Last accessed: Sep. 20, 2015]. URL: https:/ /www.onstar.com/ us/en/services/security.html.

[180] DENATRAN. Departamento Nacional de Trânsito. [Last accessed: Sep. 20, 2015]. URL: http: //www.denatran.gov.br.

[181] SINIAV. Sistema Nacional de Identificacão Automática de Veículos. [Last accessed: Sep. 20, 2015]. DENATRAN - Brazilian Department of Transportation. URL: http:/ / www.dena tran.gov.br/siniav.htm.

[182] albabawa Business. Fines for engines left running, to combat car theft. [Last accessed: Sep. 20, 2015]. May 2012. URL: http: / / www. albawaba.com/business / uae-drivers-fine424650 .

[183] Center for Problem-Oriented Policing. 25 techniques of situational prevention. [Last accessed: Sep. 20, 2015]. URL: http://www.popcenter.org/25techniques/.

[184] simTD. Safe and Intelligent Mobility Test Field Germany. [Last accessed: Sep. 20, 2015]. URL: http:/ / www.simtd.de.

[185] Damon Lavrinc. NHTSA Testing V2V Communication Systems, Considering Requiring Technology on New Cars. [Last accessed: Sep. 20, 2015]. WIRED. Apr. 2012. URL: http: / / www . wired . com / autopia / 2012 / 04 / nhtsa- testing-v2v- communication- systems considering-requiring-technology-on-new-cars /.

[186] Alfred Vollmer. Der Weg zum pilotierten Fahren. [Last accessed: Sep. 20, 2015]. Aug. 2012. URL: http:/ / www.all-electronics.de/texte/anzeigen/47258/Der-Weg-zum-pilotierte n-Fahren.

[187] David Goldman. Your new smartphone is already a dinosaur. [Last accessed: Sep. 20, 2015]. CNN Money. Feb. 2011. URL: http://money.cnn.com/2011/01/31/technology/new_ smartphone/index.htm. 
[188] Google. Our Mobile Planet. [Last accessed: Sep. 20, 2015]. URL: http: / / www .thinkwithgoogle.com/mobileplanet.

[189] CCC. MirrorLink. [Last accessed: Sep. 20, 2015]. Car Connectivity Consortium. URL: htt p://www.mirrorlink.com.

[190] ADAC. Allgemeiner Deutscher Automobil-Club e.V. [Last accessed: Sep. 20, 2015]. URL: http://www.adac.de.

[191] NHTSA. U.S. Department of Transportation Announces Decision to Move Forward with Vehicleto-Vehicle Communication Technology for Light Vehicles. [Last accessed: Sep. 20, 2015]. National Highway Traffic Safety Administration. Feb. 2014. URL: http:/ / www.nhtsa.gov/ About+NHTSA / Press+Releases / 2014 / USDOT + to+Move+Forward + with + Vehicleto-Vehicle+Communication+Technology+for+Light+Vehicles.

[192] AUDI. Audi connect Dienste. [Last accessed: Sep. 20, 2015]. URL: http://www.audi.de/ de / brand / de / service / infotainment_und_kommunikation / audi_connect_dienste. html.

[193] BMW. BMW Connected Drive. [Last accessed: Sep. 20, 2015]. URL: http: / / www.bmw. $\mathrm{de} / \mathrm{de} /$ topics/faszination-bmw/connecteddrive-2013/ubersicht.html.

[194] Mercedes-Benz. Mercedes-Benz COMAND Online. [Last accessed: Sep. 20, 2015]. URL: http://m.mercedes-benz.de/de_DE/comand_online/detail.html.

[195] Natasha Waddington et al. Hyundai reveals higher levels of smartphone-car connectivity. [Last accessed: Sep. 20, 2015]. Hyundai. Jan. 2013. URL: http:/ / www.hyundaipressoffi ce.co.uk/release/362/.

[196] ETSI. European Telecommunications Standards Institute. [Last accessed: Sep. 20, 2015]. URL: http://www.etsi.org.

[197] ZEBRA Technologies. Dart Ultra Wideband (UWB) Solutions. [Last accessed: Sep. 20, 2015]. URL: http://www.zebra.com.

[198] Ubisense. RTLS Solutions. [Last accessed: Sep. 20, 2015]. URL: http://www.ubisense.net.

[199] Ekahau. Business Intelligence Through Location. [Last accessed: Sep. 20, 2015]. URL: http: //www.ekahau.com.

[200] German Aerospace Center, Institute of Transportation System. Application Platform for Intelligent Mobility (AIM). [Last accessed: Sep. 20, 2015]. URL: http:/ / www.dlr.de/ts / aim.

[201] V-Charge. Automated Valet Parking and Charging for e-Mobility. [Last accessed: Sep. 20, 2015]. URL: http://www.v-charge.eu/.

[202] IEEE. Institute of Electrical and Electronics Engineers. [Last accessed: Sep. 20, 2015]. URL: http://www.ieee.org.

[203] UNECE. Vehicle Regulations. [Last accessed: Sep. 20, 2015]. United Nations Economic Commission for Europe. URL: http://www.unece.org.

[204] Technik-Lexikon. Kurvenfahrlicht. [Last accessed: Sep. 20, 2015]. Volkswagen. URL: http: //www.volkswagen.de/de/technologie/technik-lexikon/kurvenfahrlicht.html.

[205] GOV.UK. British Home Office. [Last accessed: Sep. 20, 2015]. URL: https: / / www.gov. uk/government/organisations/home-office.

[206] bra. Swedish National Council for Crime Prevention. [Last accessed: Sep. 20, 2015]. URL: http://www.bra.se/bra/bra-in-english/home.html. 
[207] NHTSA. National Highway Traffic Safety Administration. [Last accessed: Sep. 20, 2015]. URL: http://www.nhtsa.gov.

[208] Hong Kong University of Science and Technology. Cybersickness. [Last accessed: Sep. 20, 2015]. URL: http:/ /www.cybersickness.org.

[209] Google. Maps. [Last accessed: Sep. 20, 2015]. URL: https://maps.google.de/maps.

[210] Bing. Maps. [Last accessed: Sep. 20, 2015]. URL: http://www.bing.com/maps.

[211] VSimRTI - Smart Mobility Simulation. The V2X Simulation Runtime Infrastructure. [Last accessed: Sep. 20, 2015]. Daimler Center for Automotive Information Technology Innovations. URL: http://www.dcaiti.tu-berlin.de/research/simulation/.

[212] SUMO. Simulation of Urban MObility. [Last accessed: Sep. 20, 2015]. Deutsches Zentrum für Luft- und Raumfahrt e.V. (DLR). URL: http:/ /sumo-sim.org/.

[213] ns3. Network Simulator 3. [Last accessed: Sep. 20, 2015]. URL: http:/ / www.nsnam.org. 